Classificação e detecção de variações de comportamento: uma abordagem aplicada à identificação de perfis de usuários Matheus Lorenzo dos Santos 



\title{
Classificação e detecção de variações de comportamento: uma abordagem aplicada à identificação de perfis de usuários
}

\author{
Matheus Lorenzo dos Santos
}

Orientador: Prof. Dr. Rodrigo Fernandes de Mello

Dissertação apresentada ao Instituto de Ciências Matemáticas e de Computação - ICMC-USP, como parte dos requisitos para obtenção do título de Mestre em Ciências de Computação e Matemática Computacional.

USP - São Carlos

Novembro/2008 

Agradeço primeiramente a Deus, em seguida a meus pais pela oportunidade de realizar meus estudos. Em especial à Alessandra Kelli Barbato pelo carinho, incentivo e compreenssão.

Aos meus amigos que diretamente auxiliaram no desenvolvimento das pesquisas apresentadas nesta dissertação: Evgueni Dodonov, José Augusto Andrade Filho e Marcelo Keese Albertini.

A paciência, confiança e dedicação de meu amigo e orientador Rodrigo Fernandes de Mello.

À CAPES e FAPESP pelo apoio dado a este trabalho.

Aos amigos de faculdade e demais pessoas que auxiliaram direta ou indiretamente nesta dissertação. 



\section{Resumo}

Estudos comportamentais têm sido conduzidos, há séculos, por cientistas e filósofos, abordando assuntos tais como trajetórias de estrelas e planetas, organizações da sociedade, evolução dos seres vivos, comportamento e linguagem humana. Com o advento da computação, grandes quantidades de informação tornaram-se disponíveis, as quais geram novos desafios a fim de explorar e compreender variações comportamentais de interação com esses sistemas. Motivado por esses desafios e pela disponibilidade de informações, esta dissertação de mestrado propõe uma metodologia com objetivo de classificar, detectar e identificar padrões de comportamento. A fim de validar essa metodologia, modelou-se conhecimentos embutidos em informações relativas a interações de usuários durante a grafia digital de assinaturas (tais informações foram obtidas de uma base de dados do campeonato SVC2004 - First International Signature Verification Competition). Os modelos de conhecimento gerados foram, posteriormente, empregados em experimentos visando o reconhecimento de assinaturas. Resultados obtidos foram comparados a outras abordagens propostas na literatura. 



\section{Abstract}

Throughout the centuries, behavioral studies have been conducted by scientists and philosophers, approaching subjects such as stars and planet trajectories, social organizations, living beings, human behavior and language. With the advent of computer science, large amounts of information have been made available, which brings out new challenges in the interactive behavior context. Such challenges have motivated this master thesis which proposes a methodology to classify, detect and identify behavioral patterns. A digital signature verification database, obtained from the First International Signature Verification Competition (SVC2004), was used to validate the proposed methodology. Knowledge models were obtained and, afterwards, employed in signature verification experiments. Results were compared to other approaches from the literature. 

Lista de Figuras . . . . . . . . . . . . . . . . . . . . . . . . xii

Lista de Tabelas . . . . . . . . . . . . . . . . . . . . . xiii

Lista de Abreviaturas e Siglas . . . . . . . . . . . . . . . . . . . xvi

1 Introdução 1

1.1 Contextualização . . . . . . . . . . . . . . . . . . . . . . 1

1.2 Motivação . . . . . . . . . . . . . . . . . . . . 5

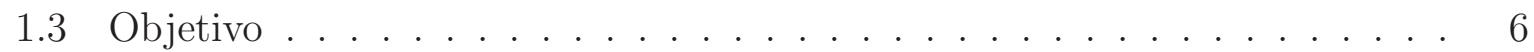

1.4 Organização do Texto . . . . . . . . . . . . . . . . 6

2 Trabalhos Relacionados $\quad 7$

2.1 Considerações Iniciais . . . . . . . . . . . . . . . . . . . . . . . 7

2.2 Comportamentos de Usuários . . . . . . . . . . . . . . . . . . . . . . 7

2.3 Reconhecimento de Assinaturas . . . . . . . . . . . . . . . . . . . 14

2.4 Considerações Finais . . . . . . . . . . . . . . . . . . . . . . . . . . . 18

3 Técnicas Adotadas na Classificação e Detecção de Comportamento de Usuários $\quad 19$

3.1 Considerações Iniciais . . . . . . . . . . . . . . . . . . . . . . . . . 19

3.2 Padrão de Comportamento de Usuário . . . . . . . . . . . . . . . . . . . 19

3.2.1 Modelo de Markov . . . . . . . . . . . . . . . . . . . . . . . . . . . 19

3.2 .2 Teoria da Informação . . . . . . . . . . . . . . . . . . . . . . 22

3.3 Técnicas de Classificação . . . . . . . . . . . . . . . . . . . . . . 23

3.3.1 Redes Neurais Artificiais . . . . . . . . . . . . . . . 23

3.3.2 SONDE - Self-Organizing Novelty Detection . . . . . . . . . . . . 26

3.4 Medidas de Similaridade . . . . . . . . . . . . . . . . . . . . . 29

3.4.1 DTW - Dynamic Time Warping . . . . . . . . . . . . . . . 29

3.4.2 CDM - Compression-based Dissimilarity Measure . . . . . . . . . . 31

3.4.3 SAX - Symbolic Aggregate approXimation . . . . . . . . . . . . 32

3.5 Considerações Finais . . . . . . . . . . . . . . . . . . 36

4 Classificação e Detecção de Variações de Comportamento de Usuários 37

4.1 Considerações Iniciais . . . . . . . . . . . . . . . . . . . 37

4.2 Objetivo . . . . . . . . . . . . . . . . . . . . . . 37

4.3 Metodologia . . . . . . . . . . . . . . . . . 37

4.3.1 Etapa 1 - Distribuição dos dados . . . . . . . . . . . . . . . 39

4.3.2 Etapa 2 - Classificação e representação com cadeias de Markov . . 39

4.3.3 Etapa 3 - Medida de energia . . . . . . . . . . . . . . . . 42 
4.3.4 Etapa 4 - Medida de similaridade . . . . . . . . . . . . . . . . . 42

4.4 Considerações Finais . . . . . . . . . . . . . . . . . . . . . 45

$\begin{array}{llr}5 & \text { Resultados } & 47\end{array}$

5.1 Considerações Iniciais . . . . . . . . . . . . . . . . . . . . . . 47

5.2 Resultados de Experimentos sobre Assinaturas de Usuários . . . . . . . . . 47

5.3 Avaliação dos resultados dos experimentos realizados . . . . . . . . . . . . 55

5.4 Resultados Complementares sobre Comportamentos de Usuários . . . . . . 59

5.5 Considerações Finais . . . . . . . . . . . . . . . . . . . . 63

6 Conclusões e Trabalhos Futuros $\quad 67$

$\begin{array}{ll}\text { Referências Bibliográficas } & 68\end{array}$

Apêndice

A $\quad$ - Resultados de experimentos (DTW) . . . . . . . . . . . . 75

B - Resultados de experimentos $(\mathrm{CDM}) \ldots \ldots \ldots \ldots \ldots$ 
2.1 Grafo de dependência no PRORD (Lee et al., 2006). . . . . . . . . . . . . 12

2.2 Extração de características: (a) Exemplo de assinatura e, (b) corresponde a matriz 1024 dimensional GSC de características (Kalera et al., 2004). . . 17

3.1 Diagrama de transição de estados. . . . . . . . . . . . . . . . . . . 21

3.2 Representação de um neurônio biológico (Freeman \& Skapura, 1991). .. . 24

3.3 Representação de um neurônio artificial. . . . . . . . . . . . . . . . . . . 24

3.4 Estrutura de uma RNA do tipo feed-forward. . . . . . . . . . . . . . . 25

3.5 Arquitetura da rede neural SONDE (Albertini \& de Mello, 2007). . . . . . 26

3.6 Experimento de detecção de novidade em uma seqüência periódica com três valores (Albertini \& de Mello, 2007). . . . . . . . . . . . . . . . 28

3.7 Exemplo de comparação entre séries temporais utilizando a medida de similaridade Euclidiana (alinhamento linear) e a DTW (alinhamento não-linear) (Keogh \& Ratanamahatana, 2005). . . . . . . . . . . . . . . . . . 29

(a) Euclidiana . . . . . . . . . . . . . . . . . . . 29

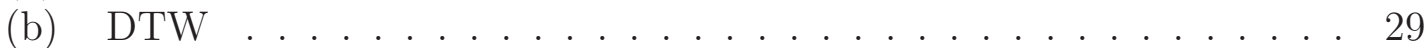

3.8 Exemplo de uma matriz de alinhamento entre duas séries temporais $Q$ e C. A) Mostra duas séries similares, porém fora de fase. B) O resultado da procura do melhor alinhamento entre as séries é apresentado pelos quadrados preenchidos. C) Apresenta o resultado do alinhamento entre as séries. (Keogh \& Ratanamahatana, 2005). . . . . . . . . . . . . . . . . . 30

3.9 Exemplo de representação $P A A$ de uma série temporal. Neste caso, a série de tamanho 128 foi reduzida para 8 dimensões (Lin et al., 2003). . . . . . .

3.10 Exemplo de uma série temporal normalizada e discretizada por meio da representação PAA. Além disso são apresentados os coeficientes PAA em símbolos SAX, usando a tabela de breakpoints. Nesse exemplo, adota-se os valores $n=128, w=8$ e $a=3$. Observa-se que série temporal é mapeada na palavra baabccbc. (Lin et al., 2003). . . . . . . . . . . . . 35

3.11 Dez primeiros pontos de três Eletrocardiogramas (Keogh et al., 2007). . . . 35

4.1 Exemplo de distribuições de dados geradas a partir dos dados sobre assinaturas de usuários armazenados na base de dados do SVC2004. . . . . . 40

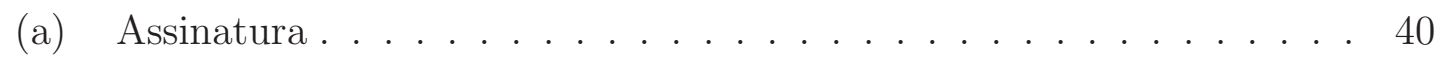

(b) DD1 - diferença entre as coordenadas da amostragem . . . . . . . . . 40

(c) DD2 - tempo por ponto . . . . . . . . . . . . . . 40

(d) DD3-freqüência dos pontos . . . . . . . . . . . . . . . . 40

(e) DD4 - derivada entre as coordenadas da amostragem . . . . . . . . . 40

(f) DD5 - derivada entre os pontos por tempo . . . . . . . . . . . 40 
(g) DD6 - distância entre os pontos . . . . . . . . . . . . . . . . 40

(h) DD7 - distância por tempo (velocidade) . . . . . . . . . . . . . 40

4.2 Exemplo de classificação de uma série temporal. . . . . . . . . . . . . . . . 41

4.3 Exemplos de matriz de transições e cadeias de Markov representando o comportamento do usuário em cada instante de tempo. . . . . . . . . . . . 42

4.4 Curvas que representam o perfil de comportamento de uma assinatura de usuário representados por sete diferentes distribuições. . . . . . . . . . . 43

(a) Assinatura . . . . . . . . . . . . . . . . . . . . 43

(b) DD1 - diferença entre as coordenadas da amostragem . . . . . . . . 43

(c) DD2 - tempo por ponto . . . . . . . . . . . . . . 43

(d) DD3 - freqüência dos pontos . . . . . . . . . . . . . . . . . 43

(e) DD4 - derivada entre as coordenadas da amostragem . . . . . . . . . 43

(f) DD5 - derivada entre os pontos por tempo . . . . . . . . . . . . 43

(g) DD6 - distância entre os pontos . . . . . . . . . . . . . 43

(h) DD7 - distância por tempo (velocidade) . . . . . . . . . . . 43

4.5 Comparação de comportamento entre as assinaturas verdadeiras (1 e 2) e as assinaturas falsas (21 e 22) de um mesmo usuário. . . . . . . . . . . . 44

(a) Assinatura 1 - Verdadeira . . . . . . . . . . . . . . . . . 44

(b) Assinatura 2 - Verdadeira . . . . . . . . . . . . . . . . . . . 44

(c) Assinatura 21 - Falsa . . . . . . . . . . . . . . . . . . . . 44

(d) Assinatura 22 - Falsa . . . . . . . . . . . . . . . . 44

5.1 São apresentados a média do somatório de erro e o intervalo de confiança obtidos pela comparação do treinamento das primeiras 10 assinaturas verdadeiras com as demais 40 (20 falsas treinadas e 20 de outros usuários) utilizando a medida de similaridade DTW. . . . . . . . . . . . . . . . . 49

(a) Assinatura . . . . . . . . . . . . . . . . . . . . . 49

(b) DD1 - diferença entre as coordenadas da amostragem . . . . . . . . . 49

(c) DD2 - tempo por ponto . . . . . . . . . . . . . . . . . 49

(d) DD3 - freqüência dos pontos . . . . . . . . . . . . . . . . . . 49

(e) DD4 - derivada entre as coordenadas da amostragem . . . . . . . . . . 49

(f) DD5 - derivada entre os pontos por tempo . . . . . . . . . . . . 49

(g) DD6 - distância entre os pontos . . . . . . . . . . . . . . . . 49

(h) DD7 - distância por tempo (velocidade) . . . . . . . . . . . . . 49

5.2 São apresentados a média do somatório de erro e o intervalo de confiança obtidos pela comparação do treinamento das primeiras 10 assinaturas verdadeiras com as demais 40 (20 falsas treinadas e 20 de outros usuários) utilizando a medida de similaridade CDM. . . . . . . . . . . . . . . 50

(a) Assinatura . . . . . . . . . . . . . . . . . 50 50

(b) DD1 - diferença entre as coordenadas da amostragem . . . . . . . . 50

(c) DD2 - tempo por ponto . . . . . . . . . . . . . 50

(d) DD3 - freqüência dos pontos . . . . . . . . . . . . 50

(e) DD4 - derivada entre as coordenadas da amostragem . . . . . . . 50

(f) DD5 - derivada entre os pontos por tempo . . . . . . . . . . 50

(g) DD6 - distância entre os pontos . . . . . . . . . . . 50

(h) DD7 - distância por tempo (velocidade) . . . . . . . . . . 50

5.3 Média das curvas ROC para cada distribuição dos 40 usuários utilizando a DTW como medida de similaridade, considerando a comparação de assinaturas verdadeiras às falsas treinadas. . . . . . . . . . . . . . . . . 52

(a) DD1 - diferença entre as coordenadas da amostragem . . . . . . . 52 


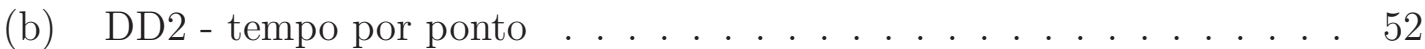

(c) DD3-freqüência dos pontos . . . . . . . . . . . . . 52

(d) DD4 - derivada entre as coordenadas da amostragem . . . . . . . . . . 52

(e) DD5 - derivada entre os pontos por tempo . . . . . . . . . . . . 52

(f) DD6 - distância entre os pontos . . . . . . . . . . . . 52

(g) DD7 - distância por tempo (velocidade) . . . . . . . . . . 52

5.4 Média das curvas ROC de cada distribuição dos 40 usuários utilizando a DTW como medida de similaridade, considerando a comparação de assinaturas verdadeiras às de outros usuários. . . . . . . . . . . . . . . . 53

(a) DD1 - diferença entre as coordenadas da amostragem . . . . . . . . 53

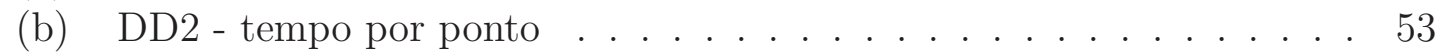

(c) DD3-freqüência dos pontos . . . . . . . . . . . . 53

(d) DD4 - derivada entre as coordenadas da amostragem . . . . . . . . 53

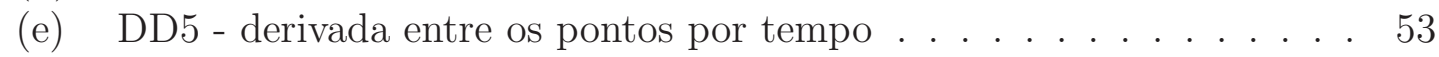

(f) DD6 - distância entre os pontos . . . . . . . . . . . . . 53

(g) DD7 - distância por tempo (velocidade) . . . . . . . . . . 53

5.5 Média das curvas ROC de cada distribuição dos 40 usuários utilizando a CDM como medida de similaridade, considerando a comparação de assinaturas verdadeiras às falsas treinadas. . . . . . . . . . . . . . . . . 54

(a) DD1 - diferença entre as coordenadas da amostragem . . . . . . . . 54

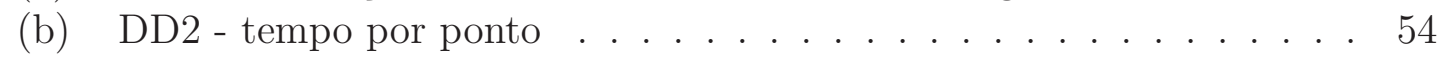

(c) DD3-freqüência dos pontos . . . . . . . . . . . . . 54

(d) DD4 - derivada entre as coordenadas da amostragem . . . . . . . . 54

(e) DD5 - derivada entre os pontos por tempo . . . . . . . . . 54

(f) DD6 - distância entre os pontos . . . . . . . . . . . . 54

(g) DD7 - distância por tempo (velocidade) . . . . . . . . . . 54

5.6 Média das curvas ROC de cada distribuição dos 40 usuários utilizando a CDM como medida de similaridade, considerando a comparação de assinaturas verdadeiras às de outros usuários. . . . . . . . . . . . . . . . . 55

(a) DD1 - diferença entre as coordenadas da amostragem . . . . . . . . . 55

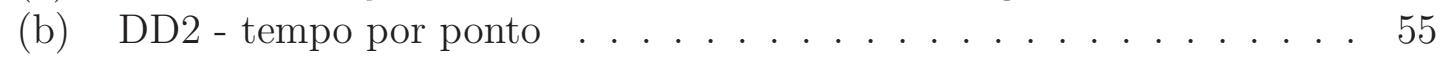

(c) DD3-freqüência dos pontos . . . . . . . . . . . . 55

(d) DD4 - derivada entre as coordenadas da amostragem . . . . . . 55

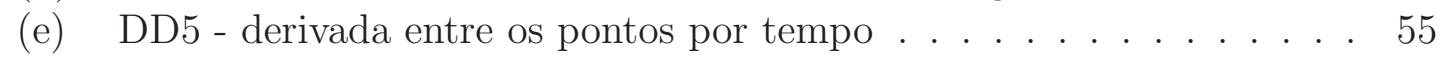

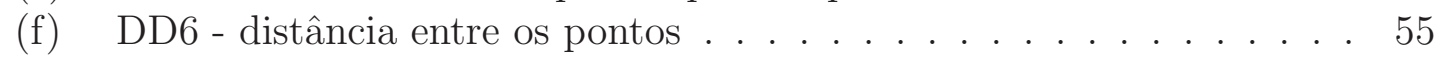

(g) DD7 - distância por tempo (velocidade) . . . . . . . . . . 55

5.7 Média das curvas ROC, contendo comparações das assinaturas verdadeiras às falsas treinadas e às de outros usuários, utilizando DTW e CDM. As distribuições que melhor representam o comportamento de cada usuário foram adotadas. . . . . . . . . . . . . . . . 56

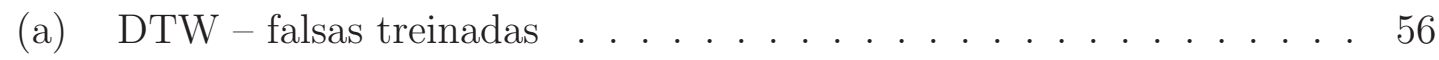

(b) CDM - falsas treinadas . . . . . . . . . . . . . 56 56

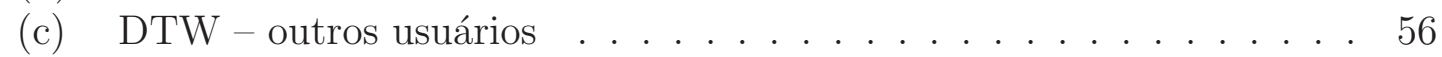

(d) CDM - outros usuários . . . . . . . . . . . . . . 56

5.8 Exemplo de distribuição das taxas de falso positivo e negativo. O ponto de cruzamento entre as distribuições representa o Equal Error Rate (EER). . . 57

5.9 Imagem da interação de um usuário jogando Sudoku sobre o sistema iClass. 61

5.10 Exemplos de distribuições de dados sobre a interação de um usuário com o jogo Sudoku. . . . . . . . . . . . . . . . . . . . 62

(a) Quantidade de pontos no intervalo de tempo. . . . . . . . . . 62 
(b) Freqüência do número de pontos. . . . . . . . . . . . . . . . . . 62

(c) Freqüência do número de pontos por segundo. . . . . . . . . . . . . . 62

(d) Freqüência do tempo gasto por ponto. . . . . . . . . . . . . . 62

(e) Frequiência do tempo consumido por ponto, discretizada em milissegundos. . . . . . . . . . . . . . . . . . . 62

5.11 Exemplo de dois usuários interagindo no sistema iClass. . . . . . . . . . . 63

(a) Usuário 1 - Sudoku. . . . . . . . . . . . . . . . 63

(b) Usuário 2 - Sudoku. . . . . . . . . . . . . . . . . . . . 63

(c) Usuário 1 - Labirinto. . . . . . . . . . . . . . . . . . . . 63

(d) Usuário 2 - Labirinto. . . . . . . . . . . . . . . . . . . 63

5.12 Distribuição de dados das informações de interação de cada usuário. . . . . 64

(a) Usuário 1 - Sudoku. . . . . . . . . . . . . . . . . . 64

(b) Usuário 2 - Sudoku. . . . . . . . . . . . . . . . . . . . . . . 64

(c) Usuário 1 - Labirinto. . . . . . . . . . . . . . . . . . . . . . . 64

(d) Usuário 2 - Labirinto. . . . . . . . . . . . . . . . . . . 64

5.13 Cadeias de Markov representando o último instante de interação de cada usuário. . . . . . . . . . . . . . . . . . . . 65

(a) Usuário 1 - Sudoku. . . . . . . . . . . . . . . . 65

(b) Usuário 2 - Sudoku. . . . . . . . . . . . . . . . . . . . . . 65

(c) Usuário 1 - Labirinto. . . . . . . . . . . . . . . . . . 65

(d) Usuário 2 - Labirinto. . . . . . . . . . . . . . . 65

5.14 Variação no padrão de comportamento de cada usuário. . . . . . . . . . . 65

(a) Usuário 1 - Sudoku. . . . . . . . . . . . . . . . . . . . 65

(b) Usuário 2 - Sudoku. . . . . . . . . . . . . . . . . . 65

(c) Usuário 1 - Labirinto. . . . . . . . . . . . . . . . . . . 65

(d) Usuário 2 - Labirinto. . . . . . . . . . . . . . . . 65 


\section{Lista de Tabelas}

2.1 Regras geradas pela árvore de decisão (Schuler \& Perez, 2006). . . . . . . . 9

3.1 Estado do uso da terra em 1993 (Hillier \& Lieberman, 2001). . . . . . . . . 20

3.2 Probabilidade de transição (Hillier \& Lieberman, 2001) . . . . . . . . . . . . 21

3.3 Algoritmo da CDM em MatLab (Keogh et al., 2007). . . . . . . . . . . . 32

3.4 Tabela de breakpoints contendo valores que divide a distribuição Gaussiana por um número arbitrário de regiões (de 3 a 10) (Lin et al., 2003). . . . . . 34

5.1 Tabela contendo a porcentagem das melhores distribuições para os experimentos realizados. . . . . . . . . . . . . . . . 56

5.2 EERs dos experimentos utilizando a medida de similaridade DTW. . . . . 57

5.3 EER dos experimentos utilizando a medida de similaridade CDM. . . . . . 58

5.4 Resultados dos trabalhos submetidos ao campeonato de reconhecimento de assinaturas SVC2004 (Yeung et al., 2004). . . . . . . . . . . . . . 59 

API Application Programming Interface

ART Adaptive Resonance Theory

BMU Best-Matching Unit

CDM Compression-based Dissimilarity Measure

CPU Central Processing Unit

DDD Discagem Direta a Distância

DDI Discagem Direta Internacional

DD1 Distribuição de Dados da diferença entre as coordenadas X e Y

DD2 Distribuição de Dados do tempo gasto por ponto

DD3 Distribuição de Dados da frequência de ocorrência dos pontos

DD4 Distribuição de Dados da derivada entre os pontos

DD5 Distribuição de Dados da derivada entre pontos por tempo

DD6 Distribuição de Dados da distância entre pontos

DD7 Distribuição de Dados da distância entre pontos por tempo

DDI Dots Per Inch

DTW Dynamic Time Warping

EER Equal Error Rate

GSC Gradient, Structure and Concavity

GWR Grow When Required

HTTP Hypertext Transfer Protocol

ID Identification

IFIP International Federation for Information Processing

IP Internet Protocol

KUCAS Known User Continuous Authentication System

LCD Liquid Crystal Display

LSI Latent Semantic Indexing

MLP Multi Layer Perceptron

PAA Piecewise Aggregate Approximation

PC Personal Computer

PDA Personal Digital Assistant

PRORD Proactive Request Distribution

ROC Receiver Operating Characteristic

RNA Rede Neural Artificial

RNB Rede Neural Biológica

SAX Symbolic Aggregate approXimation

SOM Self Organizing Maps

SONDE Self-Organizing Novelty Detection 
SVC2004 Signature Verification Competition in 2004 TPS Trusted Pocket Singer

UP Unidade de Processamento

URL Uniform Resource Locator

XML Extensible Markup Language 


\section{Introdução}

"Os principais problemas enfrentados hoje pelo mundo só poderão ser resolvidos se melhorarmos nossa compreensão do comportamento humano" (Skinner, 1974).

\subsection{Contextualização}

Estudos comportamentais vêm sendo realizados, durante séculos, por diferentes pensadores e cientistas. Grandes filósofos antigos analisavam as interações entre objetos (tais como: animais, natureza, estrelas, comportamento humano, entre outros) a fim de compreender o mundo ao seu redor. No século $I V$ a.C., Platão (Platão, 2006), por exemplo, em uma de suas principais obras, A República, baseia-se no estudo do comportamento humano e da sociedade para descrever o funcionamento das cidades, da política grega, da ética, da cidadania e de questões sobre a imortalidade da alma.

No mesmo século (IV a.C.), Aristóteles (Aristóteles, 2006) em uma de suas áreas de estudo, denominada Alma, realiza investigações sobre o comportamento humano. Por meio desses trabalhos, o filósofo conclui que todo ser humano tem por objetivo a busca do prazer e, nesse contexto, divide o comportamento humano em dois grupos: o comportamento objetivo - que se refere às sensações humanas, e o transacional - que envolve sentimentos entre pessoas. Por sua vez, quaisquer um dos grupos citados ainda podem ser classificados como ativos - quando o indivíduo busca o objeto de seu desejo, e passivos quando o indivíduo recebe ou é presenteado com o objeto conquistado.

Entre os séculos XVI e XVII, no campo da astronomia, destacam-se Tycho Brahe (Brahe, 1925), Johannes Kepler (Kepler \& Donahue, 1993) e Galileo Galilei (Galilei, 1870). Tycho foi o último grande astrônomo observacional (antes da invenção do telescópio). Ele desenvolveu instrumentos para observar o comportamento dos astros (em especial o 
planeta Marte), prever a posição precisa dos planetas e provar que a Terra movimenta-se. Seus estudos reforçaram a teoria heliocentrista, iniciada por Copérnico (Copernicus, 1978) no século $X V I$.

Baseado nos estudos de Tycho, Kepler conseguiu determinar as diferentes posições da Terra após cada período sideral de Marte e, assim, conseguiu traçar a órbita terrestre. Prosseguindo nesses estudos, ele ainda observou a órbita de outros planetas e concluiu que essas são elípticas e desenvolvem-se ao redor do Sol.

Na astronomia, com o auxílio de telescópios, Galileu observou o comportamento de diversos planetas e reafirmou a idéia de Copérnico, onde a Terra não é o centro do universo. Galileu é considerado o pai da Física, pois estabeleceu a base do pensamento científico moderno, resgatando o método experimental muito utilizado, no século III a.C., por Arquimedes (Archimedes \& Health, 1897).

No século $X I X$, outro exemplo da importância da análise comportamental ao longo de nossa história foi a teoria da Seleção Natural das espécies proposta por Charles Darwin (Darwin, 2004) em seu livro A Origem das Espécies. Segundo essa teoria, Darwin introduz a idéia de evolução a partir de um ancestral comum, por meio da seleção natural. Após experimentos com plantas e pesquisas sobre a vida de alguns animais, Darwin concluiu que alguns indivíduos de uma mesma espécie são mais fortes, podem correr mais rapidamente ou são imunes a determinadas doenças. Essas características fazem com que esses indivíduos sobrevivam por mais tempo e consigam reproduzir, reforçando novas características em seus descendentes. Indivíduos menos aptos tendem a desaparecer.

Posteriormente, em meados do século $X X$, uma das áreas de grande destaque na ciência foi o estudo do comportamento humano, o qual é amplamente investigado no ramo da psicologia. Trabalhos como os de Frederic Skinner (Skinner, 1999) e, posteriormente, de Noam Chomsky (Chomsky, 1959), destacam a importância do estudo do comportamento humano. Skinner se opõe à idéia do homem composto de corpo e mente, acreditando no homem como entidade única e uniforme. Em seu trabalho, propôs uma filosofia sobre o comportamento humano, chamado de Behaviorismo Radical. Para explicar essa filosofia, Skinner desenvolveu os princípios do condicionamento operante e do condicionamento respondente.

O condicionamento operante é definido pela probabilidade de um estímulo gerar uma resposta que pode ser amplificada por meio de reforço. Um estímulo de reforço é aquele que ocorre logo após uma resposta. O reforço é empregado a fim de favorecer comportamentos por meio de estímulos positivos, quando há recompensa, ou negativo, quando retira-se o desprazer. Diferente da punição, o reforço negativo se caracteriza pela ausência (retirada) de um desprazer após a ocorrência de um comportamento pretendido, enquanto a punição é um estimulo de desprazer aplicado após a ocorrência de um comportamento não pretendido. 
O condicionamento respondente refere-se aos reflexos ou ações involuntárias do ser humano, tais como a dilatação e contração da pupila em contato com a variação de luminosidade, arrepios por causa de uma friagem ou um susto causado por um evento inesperado. Ao contrário do comportamento operante, o respondente é gerado por um estímulo anterior, e o operante em resposta a um estímulo posterior.

Skinner focou seus estudos e experimentos no comportamento operante. Para realizar estudos científicos estritos, Skinner utilizou-se de pequenos animais, tais como ratos e pombos, ao invés de seres humanos. Para isso, desenvolveu um equipamento que recebeu o nome de Caixa de Skinner. Esse equipamento é constituído por uma caixa acusticamente isolada, contendo algumas chaves e alavancas, além de um fornecedor de alimentos.

Nessa caixa foram realizados diversos experimentos com ratos e pombos, a fim de comprovar o comportamento operante, para o qual se aplica um reforço em resposta a um comportamento pretendido. Em um desses experimentos, Skinner condicionou um rato a apertar a alavanca para receber alimento. Para isso, toda vez que o rato se aproximava da alavanca, recebia recompensa na forma de alimento e, assim, ele reforçava seu comportamento. Após certo tempo, o rato aprende a pressionar a alavanca, condicionando-se (comportamento operante).

Um fato curioso ocorreu quando Skinner resolveu mudar seu método tradicional de experimentos. Ao invés de recompensar o animal após a ocorrência de um comportamento pretendido, preparou o equipamento para dar alimento em intervalos fixos de tempo, sem levar em consideração o comportamento (estudo realizado com pombos). Nesse experimento observou-se que, depois de um tempo, alguns pombos apresentaram comportamentos peculiares. Alguns deles, antes de receber o alimento, giravam em círculos, outros esticavam o pescoço em um canto da caixa, outras ainda tombavam o corpo de um lado para outro. Após analisar esses comportamentos, Skinner concluiu que se travava de um comportamento supersticioso, pois para o entendimento do pombo, o alimento só era recebido quando ela realizava algum movimento. Ao final, mesmo sem querer, o alimento funcionou como reforço para o comportamento supersticioso, o qual iniciou de maneira sutil e, com o passar do tempo, intensificou-se. O mesmo é observado nos seres humanos em, por exemplo, jogos de azar, onde se sopra as mãos antes de jogar um dado, ou quando índios realizam a dança da chuva ou, até mesmo, quando um indivíduo veste sua camisa da sorte para que seu time de futebol seja vencedor.

Em seu último livro (Skinner, 1957), Skinner define comportamento verbal como aquele estabelecido e mantido por reforço, mediado por outra pessoa, isto é, a relação entre o mediador (ouvinte) e o falante é representada por uma função de variáveis ambientais, a qual pode ser descrita em termos de contingências de reforçamento. Dessa forma, a contingência seria responsável pelo estabelecimento e manutenção do compor- 
tamento operante, conforme conseqüências produzidas pelo comportamento no ambiente. Se um evento ambiental está presente quando um determinado comportamento gera uma conseqüência, esse evento, em situações similares no futuro, tende a ter uma maior probabilidade de evocar tal operante, isto é, gerar uma mesma conseqüência em função desse comportamento e, dessa forma, estabelecer o controle do estímulo. Para Skinner, as linguagens são aprendidas pelos seres por meio de estímulos e reforços, desde que o mediador (ouvinte) e o falante estejam inseridos no mesmo ambiente e ambos possam responder, adequadamente, aos diferentes operantes emitidos pelo falante. Em resumo, a linguagem é definida, meramente, como um comportamento aprendido como qualquer outro, podendo ser atribuída a um treinamento com base em recompensas e penalidades.

Logo após o último livro de Skinner, Noam Chomsky escreveu uma resenha criticando essas idéias e o Behaviorismo Radical (Chomsky, 1959). Chomsky, ao contrário de Skinner, defende a idéia de que a mente é cognitiva, isto é, possui estados como, por exemplo, crenças, medos, dúvidas e certezas. Além disso, Chomsky defende a tese de que a mente humana contém informações que são natas, contrariando as teorias de Skinner que defendem que ela é condicionada a aprender. Para Chomsky, o fato de uma criança conseguir assimilar uma linguagem nos primeiros anos de vida é fruto de informações prévias, refutando a idéia de que a mente é um "papel em branco" quando se nasce.

As críticas de Chomsky são extensas, e repudiam, duramente, as teorias de Skinner. Skinner não escreveu nenhuma réplica, pois considerou tais críticas como inválidas e que as teorias de Chomsky apenas propunham uma abordagem distinta (dos Reis Justi \& de Freitas Araujo, 2004). Na comunidade científica não existe um consenso a respeito das teorias de Skinner e Chomsky. Sabe-se, contudo, que ambas são de grande importância e bastante empregadas em diversos trabalhos.

O que fica evidente nesta discussão é a preocupação com o estudo do comportamento. Seguindo esse enfoque, observa-se que o estudo comportamental esteve presente, ao longo dos tempos, em diferentes linhas de pesquisa. Foram mencionados estudos sobre trajetórias de estrelas e planetas, organizações da sociedade, a alma, a evolução dos seres vivos, o comportamento e a linguagem humana, entre outros. Atualmente, com o advento do computador digital, observa-se uma ampla gama de novos recursos e desafios a serem explorados, os quais envolvem diferentes formas de comportamento. Desafios esses que podem ser desde a otimização de sistemas computacionais até a identificação de usuários.

O estudo comportamental, por meio da informática, motiva o trabalho proposto nesta dissertação de mestrado, conforme apresentado a seguir. 


\subsection{Motivação}

Como apresentado anteriormente, a preocupação e o interesse pelo comportamento de objetos e pessoas têm sido de grande importância ao longo da história. No século passado, focou-se no estudo do comportamento humano. Atualmente, com o advento da informática, uma série de novas possibilidades de estudo comportamental têm surgido, sendo proporcionadas por novas formas de interação, tais como: utilização de teclado e mouse, comunicação entre computadores, interação com softwares e acesso a dispositivos. Conseqüentemente, a informática motivou diversos trabalhos, tais como Eleftheriadis \& Theologou (1994); Godoy \& Amandi (2005); Brosso (2006); Schuler \& Perez (2006); Bohmerwald (2005).

Eleftheriadis \& Theologou (1994) propõem identificar perfis de usuários de telefones móveis a fim de determinar serviços a serem disponibilizados. Godoy \& Amandi (2005) e Zhou et al. (2006) propõem gerar perfis de preferência de usuários, analisando seus comportamentos de acesso a páginas Web. Conhecendo as preferências de usuários, pode-se optimizar e tornar recursos, tais como mecanismos de busca de páginas e informações na Web, tornam-se mais eficientes. Brosso (2006) propõe um método de autenticação contínua de usuários, analisando seus comportamentos durante a utilização do sistema. Dessa maneira, o usuário pode perder ou ganhar privilégios de acordo com seu comportamento. Schuler \& Perez (2006) identificam perfis de usuários inadimplentes de uma companhia telefônica, analisando históricos de cobranças. Com o perfil dos usuários em mãos, a companhia consegue antecipar um potencial inadimplente. Bohmerwald (2005) estuda o comportamento de usuários acessando um acervo digital de uma faculdade. Nesse trabalho, o autor apresenta um método de avaliação de bibliotecas digitais, auxiliando nos sistemas de buscas e na organização de acervos.

Um outro exemplo relacionado à análise comportamental decorre dos trabalhos apresentados no First International Signature Verification Competition (SVC2004) (Yeung et al., 2004). O objetivo desse campeonato foi de promover uma competição entre técnicas de reconhecimento de assinaturas digitalmente manuscritas, por meio da análise de comportamento durante a grafia, ao invés do desenho da assinatura. Datasets são disponibilizados para avaliar diferentes abordagens.

Os diversos trabalhos em análise comportamental de informações, oriundas de sistemas computacionais, motivaram esta dissertação de mestrado, cujo objetivo é destacado a seguir. 


\subsection{Objetivo}

Motivado pelos trabalhos de análise comportamental e pela possibilidade de obtenção de informações com o auxílio de sistemas computacionais, esta dissertação de mestrado estudou a classificação de padrões comportamentais e, por conseguinte, propôs uma metodologia para detectar e classificar tais padrões. Com a metodologia proposta, perfis de comportamento são obtidos, os quais auxiliam na compreensão de objetos de estudo tais como interações de usuários, operações de aplicações, intrusos em sistemas, autenticação de usuários, etc.

A metodologia proposta pode ser aplicada para diferentes fins, contudo, para sua validação, realizou-se um estudo comportamental visando o reconhecimento de assinaturas digitalmente grafadas, empregando os conjuntos de dados do First International Signature Verification Competition (SVC2004), os quais permitem comparar essa abordagem com as demais da literatura.

\subsection{Organização do Texto}

Este trabalho de mestrado é composto pelos seguintes capítulos:

- Trabalhos Relacionados (Capítulo 2) - apresenta trabalhos que utilizam diferentes técnicas de classificação e identificação de perfis de comportamento de usuários a fim de solucionar problemas encontrados na área de computação;

- Técnicas Adotadas na Classificação e Detecção de Comportamento de Usuários (Capítulo 3) - descreve técnicas utilizadas na metodologia proposta neste trabalho de mestrado, tais como redes neurais artificiais, cadeias de Markov, teoria da informação e medidas de similaridade;

- Classificação e Detecção de Variações de Comportamento de Usuários (Capítulo 4) - apresenta, em detalhes, o funcionamento da metodologia de classificação de perfis de usuário proposta e aplicada no reconhecimento de assinaturas;

- Resultados (Capítulo 5) - apresenta resultados sobre experimentos iniciais e reconhecimento de assinaturas e os compara a outras abordagens da literatura;

- Conclusões e Trabalhos Futuros (Capítulo 6) - apresenta conclusões e sugere trabalhos futuros. 


\section{Trabalhos Relacionados}

\subsection{Considerações Iniciais}

Neste capítulo são apresentados trabalhos que utilizam diferentes técnicas de classificação e identificação de perfis de comportamento de usuários, aplicados a diferentes finalidades. Esses trabalhos motivaram o desenvolvimento desta dissertação de mestrado.

\subsection{Comportamentos de Usuários}

Brosso (2006), em sua tese de doutorado, propõe um sistema para autenticação de usuários em redes de computadores, onde utiliza análise comportamental e reconhecimento facial para identificar a confiabilidade de usuários do sistema. Para isso, Brosso (2006) desenvolveu um sistema chamado KUCAS (Known User Continuous Authentication System), que é baseado na análise comportamental e biométrica de usuários, definindo seus graus de confiança para o sistema. A confiança em uma pessoa pode variar ao longo do tempo de acordo com seu comportamento.

O Sistema KUCAS é dividido em três partes:

- F-KUCAS - ambiente com uma infra-estrutura formada por várias API's que recebem informações do ambiente, podendo acionar o algoritmo A-KUCAS e o módulo S-KUCAS;

- A-KUCAS - algoritmo de autenticação de usuários, responsável por gerar logs do Sistema KUCAS, acessar bases de dados de comportamentos e de imagens de faces, enviar mensagens de alertas e acionar o Módulo de Segurança S-KUCAS em caso de alteração de comportamento; 
- S-KUCAS - módulo de segurança que, quando acionado, ativa sensores, câmeras de vídeo e aciona uma Tecnologia de Reconhecimento Facial.

Para a análise de comportamento de usuários, Brosso (2006) utiliza do conceito de Computação Ciente de Contexto que consiste no estudo de aplicações que se adaptam de acordo com a sua localidade, e nas mudanças que ocorrem com as pessoas e objetos ao longo do tempo (Schilit \& Theimer, 1994). Além da computação ciente de contexto, é utilizada a proposta das cinco semânticas (dimensões semânticas), definida por Abowd et al. (1999) e Abowd \& Mynatt (2000), as quais auxiliam a qualificar a relevância da informação (Who, Where, What, When e Why). Dessa maneira, para a análise de comportamento do usuário, é definida uma matriz comportamental que contém informações baseadas em computação ciente de contexto. Tais informações compreendem o usuário, o lugar, o período de tempo da interação com o sistema, se algum comportamento virou hábito (why) e as restrições de confiança em relação ao usuário.

Por meio da matriz comportamental de usuários, Brosso (2006) realiza, periodicamente, análises por meio de extrações e manipulações de dados da matriz, associados às restrições comportamentais. Portanto, dependendo das variações dos valores da matriz comportamental, o sistema KUCAS aumenta ou reduz o grau de confiança do usuário, podendo manter ou restringir privilégios de acesso ao sistema.

Diferentemente do trabalho de Brosso (2006), o trabalho apresentado nesta dissertação propõe uma metodologia para classificar e identificar perfis de comportamento de usuário em quaisquer situações e sistemas. Em seu trabalho Brosso (2006) analisa a semântica de dados comparando seu conteúdo com o histórico do usuário a fim de identificar comportamentos. Este trabalho de mestrado não é restrito ao conteúdo propriamente dito dos dados, e sim voltado para a extração e classificação de eventos de interação a fim de identificar padrões de comportamento (perfis).

Schuler \& Perez (2006) propõem a utilização de técnicas de mineração de dados para a descoberta de perfis de usuários inadimplentes no setor de telecomunicações. Para isso, dispõe de 63.534 registros de dados com informações sobre 350 usuários inadimplentes. Cada registro contém cinco atributos: dia da semana que a chamada foi efetuada, sua hora inicial, sua origem, seu destino (local, DDD, celular, DDI) e duração.

Antes de realizar experimentos, Schuler \& Perez (2006) pré-processaram os dados, eliminando o atributo origem, pois, segundo os autores, não contribui consideravelmente no perfil geral de inadimplentes. Também foi necessária uma codificação dos dados para que os valores dos atributos contivessem o mesmo tipo de representação numérica, permitindo inferências de maior qualidade. Tendo transformado os dados, Schuler \& Perez (2006) realizaram experimentos utilizando duas diferentes técnicas de mineração de dados: árvore de decisão e redes neurais. 
Tabela 2.1: Regras geradas pela árvore de decisão (Schuler \& Perez, 2006).

\begin{tabular}{cl}
\hline Regra & Descrição \\
\hline 01 & Os dias da semana com maior número de chamadas são quarta e quinta-feira \\
& no horário entre 06:00h e 12:00h: \\
& - Quarta-feira: $22 \%$ \\
& - Quinta-feira: $31 \%$ \\
& - Na sexta-feira o horário de maior tráfego é entre 18:00h e 24:00h: $21 \%$ \\
\hline 02 & Nas segundas-feiras o horário entre 12:00h e 18:00h concentra chamadas \\
& para serviços especiais: $33 \%$ \\
\hline 03 & Nas quartas-feiras o horário entre 12:00h e 18:00h concentra chamadas: \\
& - para telefone fixo (Local): $23 \%$ \\
& - para telefone celular (DDD): $22 \%$ \\
\hline 04 & Nas quintas-feiras o horário entre 12:00h e 18:00h concentram-se chamadas \\
& para telefone fixo (DDI): $30 \%$ \\
\hline 05 & Nas sextas-feiras o horário entre 12:00h e 18:00h concentram-se chamadas: \\
& - para telefone celular (Local): $22 \%$ \\
& - para telefone fixo (DDD): $24 \%$
\end{tabular}

No primeiro experimento, utilizando a técnica de árvores de decisão, Schuler \& Perez (2006) utilizaram o software Sipina (Rakotomalala, 2005), com licença educacional, que implementa o método de árvores de decisão para classificar e representar o conhecimento obtido. Para geração da árvore, o nó principal foi criado com o atributo "dia da semana", com o objetivo de descobrir quais os momentos de acesso preferidos dos usuários e, os nós filhos foram determinados com atributos "hora" e "destino" para verificar em quais horários e dias da semana prefere-se gerar chamadas e qual é a duração. Como resultado, as regras geradas pela árvore de decisão (Tabela 2.1) representam o perfil geral de inadimplentes. Com a árvore definida, pode-se avaliar a pertinência de um usuário a determinada classe.

No segundo experimento, Schuler \& Perez (2006) utilizam a técnica de redes neurais para realizar a mineração de dados de usuários inadimplentes. Para isso foi utilizada uma versão de demonstração do software QwikNet (Qwiknet, 2005) que consiste em um simulador de redes neurais. A rede neural implementada no QwikNet é a MLP - MultiLayer Perceptron. Para o experimento, a rede neural foi configurada com quatro neurônios de entrada mais um neurônio de saída, a taxa de aprendizado de 0,1 com 25.000 épocas de treinamento. Dadas as limitações da versão de demonstração do QwikNet, utilizada nesse trabalho, o treinamento da rede neural foi realizado utilizando apenas 499 linhas de dados (de um total de 63.534 linhas). Cada linha de entrada é composta pelos atributos "dia da semana", "horário", "destino da chamada" e "duração".

Após o treinamento da rede neural, Schuler \& Perez (2006) realizaram um experimento utilizando um arquivo de 240 linhas contendo informações de um único usuário. Do total de registros submetidos, apenas 3 encaixaram-se ao perfil aprendido pela rede.

Comparando os resultados dos dois experimentos (utilizando árvore de decisão e re- 
des neurais), os autores concluíram que a técnica de árvore de decisão permite representar um padrão de comportamento / perfil do usuário, contudo apresenta um grande número de subdivisões tornando a leitura dos dados pouco eficiente, porém de fácil compreensão. Os experimentos com redes neurais são mal projetados e com pouco fundamento para avaliações, além de utilizarem uma versão, com funcionalidades limitadas, de demonstração do software QwikNet.

Godoy \& Amandi (2005) propõem uma técnica para gerar perfis de interesse de usuários por meio de observações de seus comportamentos na Web. Essa técnica está inserida no algoritmo Web Document Conceptual Clustering (Godoy \& Amandi, 2006), que permite caracterizar um perfil sem que haja um prévio conhecimento dos interesses do usuário.

O perfil de um usuário é organizado em uma árvore hierárquica, onde no nível mais alto são representados seus interesses mais amplos e, no nível mais baixo, os particulares. Tais interesses podem ser provenientes de quaisquer informações acessadas pelo usuário, tais como: esportes, trabalho, notícia (informação), jogos, entre outros. O grau de relevância dos interesses dos usuários é mensurado por meio de observações da freqüência dos termos acessados, uma vez que esses tendem a persistir no acesso a termos de maior interesse (Godoy \& Amandi, 2005).

Os termos de interesse do usuário são representados por um vetor de $n$ dimensões $d_{j}=<\left(t_{1}, w_{1}\right), \ldots,\left(t_{n}, w_{n}\right)>$, onde cada $w_{i}$ representa o peso do termo $t_{i}$ em um documento Web $d_{j}$. Antes de extrair os termos contidos no documento, o algoritmo remove todos os termos não relevantes, utilizando uma lista de stop-words. Os termos sobressalentes são processados pelo algoritmo Porter stemming (Porter, 1980), que os normaliza para uma forma comum, eliminando variações de um mesmo termo (exemplo: casas, casa, casarão $=$ casa $)($ Godoy \& Amandi, 2005).

A árvore hierárquica do perfil de interesses do usuário é constituída por um número arbitrário de conceitos, denotado por $C=c_{1}, c_{2}, \ldots, c_{m}$, onde cada elemento é representado por uma série de termos, $c_{i}=<\left(t_{1}, w_{1}\right), \ldots,\left(t_{p}, w_{p}\right)>$. Essas informações representam um histórico de interesses do usuário que é atualizado à medida que esse acessa documentos Web. A classificação de novas informações é feita calculando a distância vetorial entre as informações contidas na árvore de interesses e as relativas aos novos documentos acessados. Conforme o usuário interage com o sistema Web, o algoritmo adapta-se e refina a árvore de interesses de um dado usuário, definindo seu perfil.

Nesse trabalho, Godoy \& Amandi (2005) utilizam a freqüência dos termos mais comuns entre os assuntos de interesse do usuário para determinar o seu perfil. De maneira diferente, o método proposto nesta dissertação classifica perfis de usuários reconhecendo padrões de comportamento durante interações com sistemas, e não construir o seu perfil sobre o conteúdo acessado pelo usuário. Dessa maneira, ao utilizar esse novo método 
proposto sobre o problema abordado no trabalho de Godoy \& Amandi (2005), usuários teriam seu comportamento classificado apenas utilizando dados de interação com o sistema (cliques do mouse, tempo por página, quantidade de bytes da página, entre outros). Esses perfis poderiam ser confrontados com perfis de outros usuários para determinar características em comum, permitindo identificar interesses de cada usuário.

Macedo et al. (2003) propõem um sistema chamado WebMemex, o qual recomenda informações ao usuário por meio da análise do histórico de navegação de uma lista de usuários conhecidos. O WebMemex captura e recomenda páginas Web para usuários ou grupos. Os usuários são identificados quando estabelecida conexão com servidor proxy Web, onde toda requisição HTTP realizada pelo usuário é interceptada. Com isso, o WebMemex obtém informações como endereço IP e o ID dos usuários, o tempo que os usuários estão ativos no sistema e o endereço Web acessado. Essas informações são armazenadas em um banco de dados contendo links relacionados aos documentos acessados pelos usuários. Os links de hypertexto entre páginas Web, acessadas pelos usuários, são gerados automaticamente. Após obter os dados sobre as URLs de cada página visitada pelos usuários, os links relacionados são gerados, automaticamente, seguindo dois passos: indexar todas as páginas Web e estabelecer os links entre as páginas, seguindo as similaridades definidas pela técnica $\mathrm{LSI}^{1}$ (Latent Semantic Indexing).

Para utilizar o sistema, o usuário precisa configurar seu browser para se conectar ao servidor proxy, no qual o WebMemex está instalado. Quando o usuário começa a navegar pelas páginas Web, o browser, automaticamente, abre uma janela de autenticação do sistema. Uma vez autenticado, o Web browser sugere URLs para os usuários a partir do histórico de navegação. A relação de URLs é apresentada em uma pequena janela do browser.

A principal contribuição do trabalho está na criação automática de links relacionados por meio da análise de páginas Web acessadas por um grupo de usuários. No entanto, esses links de relacionamentos são disponibilizados sem levar em consideração o perfil de preferência de cada usuário. Cada usuário, ou grupo, possui preferências que os diferencia dos demais. Esse tipo de perfil não é identificado no trabalho de Macedo et al. (2003). Utilizando a técnica de classificação de perfis de usuário proposta neste trabalho de mestrado, o perfil de cada usuário pode ser identificado, e assim eles receberiam uma lista de links relacionados conforme seu perfil de preferência. Os dados de perfis de preferências de usuários ainda poderiam ser confrontados a fim de identificar grupos com perfis semelhantes, e dessa forma, além de fornecer uma lista de links relacionados, o WebMemex auxiliaria o servidor proxy Web a dar prioridade às paginas acessadas, conforme preferências de usuários.

Lee et al. (2006) propõem em seu trabalho uma nova política de balanceamento de

\footnotetext{
${ }^{1}$ Baseado na proximidade de termos em um espaço semântico, o LSI é usado na identificação de similaridades entre dois elementos gerando links de hypertexto.
} 
carga de servidores Web distribuidos chamada PRORD (Proactive Request Distribution). Os servidores Web distribuídos têm normalmente um front-end, que é responsável por receber as requisições de páginas Web de usuários, e o back-end, que é formado por um conjunto de servidores onde são armazenados conteúdos de páginas Web (esse conteúdo pode ser distribuído ou replicado). O front-end recebe uma requisição de uma página Web e escolhe a melhor ou a única máquina back-end com o conteúdo necessário para atender tal requisição de usuário (Pai et al., 1998).

O PRORD é responsável por realizar o pré-carregamento de páginas Web com maior probabilidade de serem requisitadas no futuro, para isso, o sistema analisa as informações contidas nos caches dos servidores Web e estima, por meio do comportamento de acesso, as páginas Web mais acessadas pelos usuários. Com essa pré-carga, o servidor Web antecipa as páginas Web com alta probabilidade de acesso, diminuindo o tempo de resposta do servidor e aumentando sua eficiência (Lee et al., 2006).

A dependência entre as páginas Web é representada na forma de um grafo (exemplo na Figura 2.1). Cada nó representa uma página Web e cada aresta contém um valor de confiança que representa o padrão de navegação do usuário entre páginas. O sistema analisa e categoriza as requisições de usuários em grupos específicos. Por exemplo, na Figura 2.1 existem dois grupos de seqüências que contêm a página $D$, onde $70 \%$ das seqüências do primeiro grupo, que visita a página $A$, visitam a página $C$, enquanto $60 \%$ das seqüências do segundo grupo, que visita a página $B$, acessam a página $E$ (Lee et al., 2006).

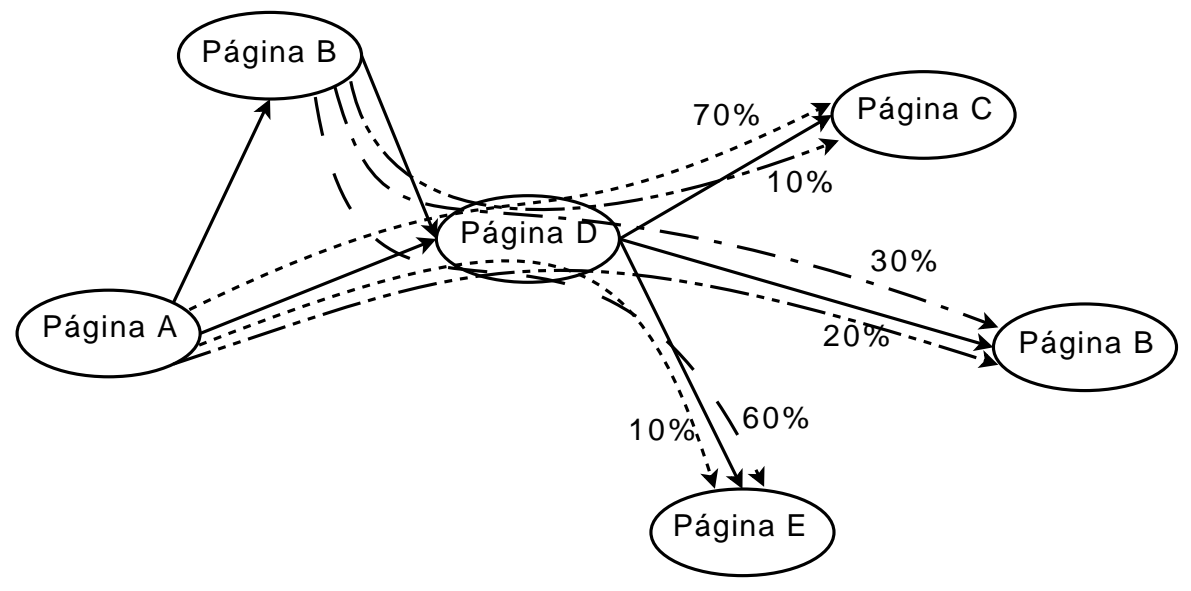

Figura 2.1: Grafo de dependência no PRORD (Lee et al., 2006).

Dessa maneira, o PRORD compara as requisições do usuário atual com informações contidas nos logs dos servidores back-end, relacionando aos grupos de padrões de sequiências de páginas Web a fim de pré-carregar, em cache, as páginas com maior probabilidade de acesso.

Nesse trabalho, o padrão de acesso a páginas Web é representado em um grafo de 
dependência. Idéia semelhante é proposta neste trabalho de mestrado, onde cada instante de tempo de interação de usuário em um sistema (como no reconhecimento de assinaturas) é representado por um grafo de transições (cadeia de Markov). Nesse caso, o comportamento do usuário é representado por uma seqüência de cadeias de Markov definidas em intervalos de tempo. Com isso, é possível visualizar o perfil de comportamento do usuário por meio da variação de energia (entropia) entre cadeias.

Pepyne et al. (2004) propõem um método de classificação de perfis de usuários com base no comportamento de aplicações, utilizando teoria de filas e regressão logística. O objetivo é identificar perfis de um grupo especializado de usuários, que devido à natureza de seu trabalho, executam tarefas de maneira repetitiva, por exemplo, caixas de banco, vendedores de seguros, etc.

Segundo os autores, o comportamento desses grupos de usuários é caracterizado pelo seqüenciamento na execução de tarefas, havendo períodos de atividade e inatividade. As seqüências de interação de cada usuário compõem sua sessão, representada por um vetor de 6 dimensões na forma,

$$
X=(\text { intervalo, tamanho, saída, densidade, dia, hora })
$$

onde,

- intervalo = tempo gasto desde o final da ultima sessão;

- $\operatorname{tamanho}=$ duração da sessão atual;

- saída = número de comandos de sistema gerados na sessão;

- densidade = taxa de comandos (comandos/minuto);

- dia = número indicando o dia da semana que iniciou a sessão;

- hor $a=$ número indicando a hora do dia que a sessão iniciou.

Os vetores de uma sessão representam o perfil de determinado usuário. Vetores de sessões distintas são, posteriormente, comparados a fim de determinar similaridades entre perfis.

Nos experimentos os autores utilizaram um histórico de 15 semanas de comandos em Linux (comandos em shell csh/tcsh), extraídos de alunos de graduação e professores da Universidade de Massachusetts. Foram utilizados vetores de características contendo informações das 5 primeiras semanas para o treinamento do modelo, as demais 10 semanas foram utilizadas para testes de validação. Resultados obtidos, na forma de curvas ROC, comparam o comportamento de 2 usuários aos demais. Segundo os autores os resultados são satisfatórios, contudo não há uma análise estatística extensiva que os comprove. 
Este trabalho de mestrado segue a mesma linha do trabalho apresentado de Pepyne et al. (2004), no entanto, o objetivo não se restringe a classificar o comportamento de uma classe específica de usuários e, sim, o perfil de quaisquer usuários interagindo em um ambiente computacional.

\subsection{Reconhecimento de Assinaturas}

Além dos trabalhos anteriormente apresentados, outra área que emprega perfis de usuários é a reconhecimento de assinaturas. O fato dessa área ter conjuntos de dados disponíveis para experimentos, motivou sua adoção como forma de comprovar a abordagem proposta nesta dissertação. Alguns dos trabalhos de classificação de comportamento de usuários, voltados para a área de reconhecimento de assinaturas, são descritos nesta seção.

Kholmatov \& Yanikoglu (2005) propõem um método para classificação de assinaturas dinamicamente manuscritas, isto é, reconhecimento de assinaturas por meio de características dinâmicas, tais como, pressão, ângulo, velocidade, ao invés do desenho da assinatura (estático). Para realizar comparações entre assinaturas, os autores selecionam três características extraídas da interação de usuários durante a grafia das assinaturas: a diferença entre a coordenada $x$ e $y$ em cada ponto, a diferença entre os pontos da assinatura e a os ângulos entre pontos.

Os autores concluem que, das características avaliadas, a diferença entre pontos é a que apresenta melhores resultados. Utilizando-se de tal característica, esse trabalho emprega a medida de similaridade DTW (Dynamic Time Warping), a qual calcula o melhor alinhamento não-linear entre dois vetores (assinaturas) retornando a distância mínima entre eles, a qual auxilia a determinar a veracidade das assinaturas.

Inicialmente esse trabalho coleta amostras de assinaturas de usuários $\left(R_{I D}\right)$, as quais são utilizadas para mensurar variações. Esses dados são usados mais tarde no processo de treinamento e de verificação. Para avaliar variações, primeiramente são realizadas comparações par a par entre as assinaturas da amostra, as quais permitem determinar a assinatura que possui, na média, a menor diferença entre as demais (essa assinatura é chamada de template). Depois são calculadas a distância da assinatura que possui o vizinho mais próximo $\left(\overline{d_{\min }}\left(R_{I D}\right)\right)$, a distância da assinatura que possui vizinho mais distante $\left(\overline{d_{\max }}\left(R_{I D}\right)\right)$ e a distância média entre todas as assinaturas da amostra $R_{I D}$ em relação à assinatura template $\left(\overline{d_{\text {template }}}\left(R_{I D}\right)\right)$.

Em seguida, é realizado o treinamento do classificador. Para isso, foi utilizado um conjunto de dados constituído por 76 assinaturas verdadeiras e 54 assinaturas falsas. Cada assinatura de treino $Y$ é comparada com as de referência $R_{I D}$ e, assim, obtémse três valores de distâncias $\left(d_{\min }\left(Y, R_{I D}\right), d_{\max }\left(Y, R_{I D}\right)\right.$ e $\left.d_{\text {template }}\left(Y, R_{I D}\right)\right)$. Os valores 
dessas distâncias são normalizados utilizando a amostra $R_{I D}$, em seguida gera-se um vetor tridimensional $F_{Y}$ de características, conforme exemplificado na Equação 2.2, o qual corresponde aos dados de treinamento.

$$
F_{Y}=\left[\begin{array}{c}
d_{\min }\left(Y, R_{I D}\right) / \overline{d_{\text {min }}}\left(R_{I D}\right) \\
d_{\text {max }}\left(Y, R_{I D}\right) / \overline{d_{\text {max }}}\left(R_{I D}\right) \\
d_{\text {template }}\left(Y, R_{I D}\right) / d_{\text {template }}\left(R_{I D}\right)
\end{array}\right]
$$

Esses dados são submetidos a um classificador, o qual realiza o treinamento a fim de adquirir conhecimento sobre as duas classes de assinaturas (falsas e verdadeiras). Após o treinamento do classificador, o mesmo é submetido a experimentos a fim de avaliar o desempenho da metodologia proposta no trabalho.

Experimentos consideraram 306 assinaturas verdadeiras e 313 falsas. Aplicando o classificador treinado a essas assinaturas, o resultado obtido foi uma Taxa de Falso Negativo de 1,64\%, de Falso Positivo de 1,28\% e Equal Error Rate (EER - medida detalhada na Seção 5.3) igual a 1,4\%.

Da mesma forma apresentada no trabalho de Kholmatov \& Yanikoglu (2005), a metodologia proposta nesta dissertação, também emprega técnicas tais como a DTW (maiores detalhes na Seção 3.4.1) e extração de características de interação, gerando diversas distribuições de dados (detalhes Seção 4.3.1). Porém, este trabalho de mestrado não valida assinaturas e sim obtém uma representação de comportamento de usuários que pode ser utilizada para identificação, previsão do mercado de ações e, inclusive, reconhecimento de assinaturas.

Skrbek (2003) propõe integrar um algoritmo de reconhecimento de assinaturas manuscritas ao sistema Trusted Pocket Singer $\left(\mathrm{TPS}^{2}\right.$ ). O TPS consiste de um PDA (Personal Digital Assistant) do tamanho de um handheld, que conta com monitor LCD colorido touch screen e executa sistema operacional Linux. Nesse PDA, documentos são recebidos por meio de rede Wireless ou Bluetooth, onde o usuário pode se autenticar e visualizar, com segurança, documentos utilizando um SmartCard inserido no PDA.

Tendo recebido tal documento no PDA, o usuário deve assinar uma autorização de acesso pela tela LCD do PDA. Posteriormente, o documento assinado é retornado ao PC para realizar a validação da assinatura. Nessa fase, o algoritmo de reconhecimento de assinaturas é executado para autenticar a veracidade da assinatura do usuário. O algoritmo de reconhecimento de assinaturas foi baseado no trabalho de Wirtz (1995).

A validação é feita comparando seqüências de segmentos da assinatura com a de referência, previamente armazenada na base de dados. Os segmentos representam traços grafados durante a escrita da assinatura, isto é, esses correspondem aos momentos em que a caneta é pressionada até sua elevação (também conhecidos como strokes). A

\footnotetext{
${ }^{2}$ Site do projeto (último acesso em outubro de 2008): http://truposign.sit.fraunhofer.de
} 
comparação entre os segmentos é feita calculando suas distâncias por meio de técnicas de programação dinâmica, tais como a DTW. Com isso, ao se calcular todas as distâncias entre segmentos, tem-se um somatório de erros de segmentos que representa a distância total entre assinaturas. Esse somatório é comparado a um valor limiar (threshold), calculado durante o treinamento, o qual também foi gerado para a assinatura de referência adotada na comparação e, assim, validando a assinatura.

Skrbek realizou alguns experimentos considerando 5500 assinaturas coletadas de 36 usuários. O resultado dos experimentos apresentou um EER (Equal Error Rate) abaixo de $5 \%$.

Conforme descrito, Skrbek apresenta um sistema completo de certificação eletrônica por meio de assinaturas digitalmente manuscritas. O algoritmo de reconhecimento de assinaturas considerado baseia-se na medida de similaride DTW para realizar comparações entre as assinaturas, mas nesse caso, o autor aplicou a técnica em segmentos de assinatura. Nesta dissertação, as informações de assinaturas utilizadas nos experimentos não levam em consideração segmentos de assinaturas, portanto, toda interação do usuário durante sua assinatura é representada de maneira única. Os dados de interação de usuários são representados pela ação do usuário no início da grafia de sua assinatura até o término da mesma e, dessa forma, o perfil de comportamento é representado por uma única curva de variação de energia (entropia).

Kalera et al. (2004) propõem um método de reconhecimento off-line de assinaturas manuscritas, isto é, o reconhecimento é feito a partir da digitalização de assinaturas feitas em papel comum. Informações são, portanto, extraídas a partir da imagem resultante. Diferente das assinaturas on-line, onde as assinaturas são, dinamicamente, capturadas por meio eletrônico (Tablet-PC, Mesa Digitalizadora, por exemplo).

Nesse trabalho, a tarefa de reconhecimento de assinaturas foi dividida em quatro etapas: aquisição dos dados, pré-processamento, extração de características e comparação. $\mathrm{Na}$ primeira etapa, imagens das assinaturas são digitalizadas para o computador, em seguida, ocorre o pré-processamento das imagens. No pré-processamento, as imagens das assinaturas são rotacionadas, normalizando-as em um mesmo ângulo em relação ao eixo horizontal. Após o pré-processamento, são extraídas as características das assinaturas. Os autores utilizaram a combinação de três fatores para representar as características das assinaturas: o gradiente, a estrutura e a concavidade (GSC - Gradient, Structure and Concavity). O gradiente representa características locais das imagens e provê uma grande quantidade de informações sobre as formas dos traços (strokes) das assinaturas. A característica estrutural estende o gradiente e fornece informações sobre as trajetórias dos traços. A concavidade representa as relações entre traços das assinaturas.

A técnica de extração de características descrita no trabalho de Kalera et al., representa os três fatores (GSC) em uma matriz binária. A matriz de características GSC 
é gerada seguindo algumas etapas. Inicialmente a imagem da assinatura é divida em 4 partes, seguindo a direção vertical, contendo em cada parte o mesmo número de pontos da imagem. Em seguida, cada uma dessas partes é subdividida em 8 trechos iguais na direção horizontal, formando, assim, $4 \times 8$ subregiões na imagem da assinatura. Então, para cada subregião, são extraídas as características GSC, as quais fornecem 12 bits de informações para a característica de gradiente, 12 bits para a estrutural e 8 relativos à concavidade, formando, com isso, um total de 1024 bits na matriz de características GSC. A Figura 2.2 apresenta o exemplo de uma assinatura e sua matriz GSC correspondente.

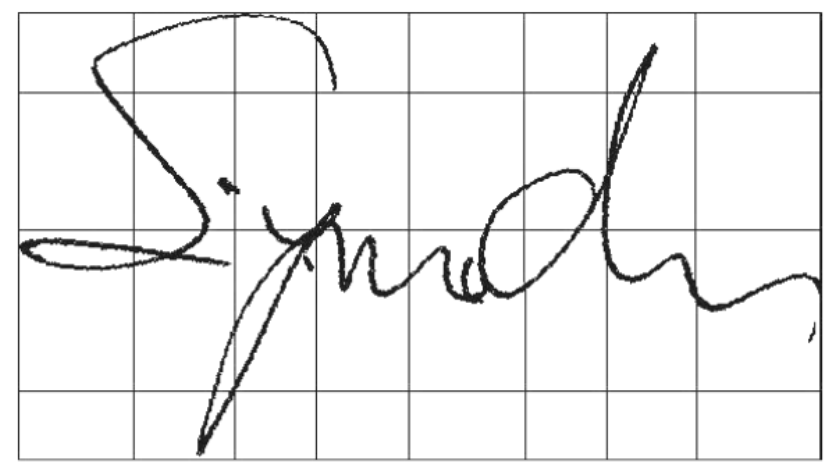

(a)

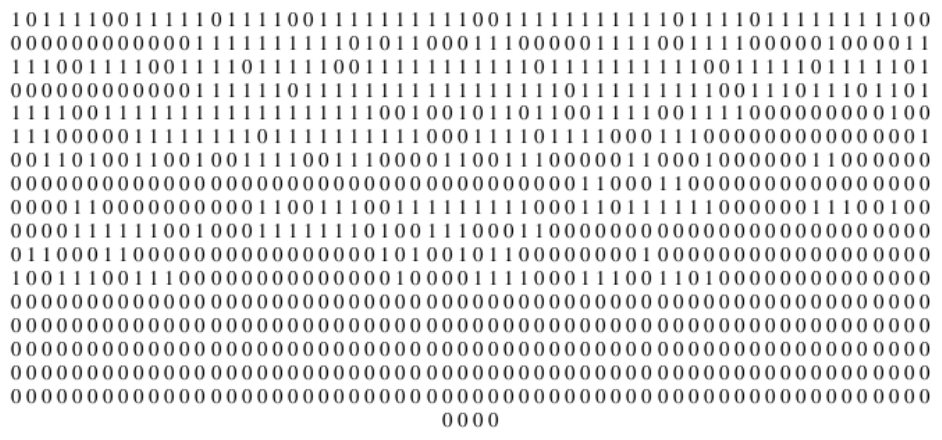

(b)

Figura 2.2: Extração de características: (a) Exemplo de assinatura e, (b) corresponde a matriz 1024 dimensional GSC de características (Kalera et al., 2004).

Após a etapa de extração de características, segue a última etapa, que consiste em realizar comparações entre as matrizes de características GSC, que representam as assinaturas. Para realização das comparações entre matrizes, os autores adotam o Coeficiente de Correlação linear como medida de similaridade. Nos experimentos foram utilizadas duas bases de dados $(A$ e $B)$. A primeira base, $A$, foi obtida pelos próprios autores, onde 55 usuários grafaram suas assinaturas em papel comum em um espaço de $2 \times 2$ polegadas. Para cada usuário foram obtidas 24 assinaturas verdadeiras e 20 assinaturas falsas treinadas. As imagens dessas assinaturas foram digitalizadas por meio de um scanner utilizando resolução de 300 dpi e 8 bits de escala de cinza. A base de dados $B^{3}$, consiste de duas

\footnotetext{
${ }^{3}$ Disponível no endereço eletrônico (último acesso em outubro de 2008):
} 
séries de dados, totalizando 3960 amostras de assinaturas de 106 usuários. Nessa base de dados, as informações sobre assinaturas foram obtidas por meio de uma câmera digital, onde foram capturados momentos de interação da grafia. As assinaturas foram coletadas em dias diferentes, fazendo com que a base de dados $B$ apresente maior variação entre assinaturas do que a base $A$. Portanto a base de dados $A$ é puramente off-line, enquanto a base $B$ não, pois utiliza momentos de interação da assinatura capturado por câmeras.

Utilizando-se o Coeficiente de Correlação linear como medida de similaridade, foram calculadas as taxas de Falso e Verdadeiro Positivo das bases de dados $A$ e $B$. Para a base de dados $A$, obteve-se um Equal Error Rate (EER) igual a 21,9\% e, para a base $B$, um EER igual a 31,62\%, considerando a primeira série e 32,67\% para a segunda.

Conforme visto no trabalho de Kalera et al., adotou-se uma técnica de reconhecimento de assinaturas off-line, diferente da metodologia proposta neste trabalho, que se baseia em dados de interação de usuários a fim de definir e identificar perfis de comportamento de assinaturas.

\subsection{Considerações Finais}

Este capítulo apresentou trabalhos relacionados à classificação de comportamento de usuários. Dentro do contexto desta dissertação, o comportamento de usuários é utilizado para o reconhecimento e identificação de assinaturas como meio de validação da metodologia proposta. No próximo capítulo são descritas as técnicas utilizadas na classificação de padrões de comportamento de usuários.

http://www.vision.caltech.edu/mariomu/research/data/ 


\section{Técnicas Adotadas na Classificação e Deteç̧ão de Comportamento de Usuários}

\subsection{Considerações Iniciais}

Neste capítulo são apresentadas as técnicas adotadas na metodologia de classificação de perfis de usuário proposta neste trabalho de mestrado. Inicialmente são apresentadas duas técnicas que auxiliam na classificação e na identificação de padrões de comportamento de usuários. A primeira é o Modelo de Markov, utilizado para representar o comportamento de usuários em determinado instante de tempo. Logo após são apresentados conceitos sobre Teoria da Informação, os quais são utilizados para identificar variações de comportamento.

Em seguida, apresenta-se conceitos sobre redes neurais artificiais e detalhes da rede neural SONDE, adotada no contexto deste trabalho devido ao fato de gerar cadeias de Markov e medir entropia de padrões de entrada. Finalmente são apresentadas duas medidas de similaridade comumente utilizadas para comparar perfis de usuários: Dynamic Time Warping (DTW) - similaridade por distância, e a Compression-based Dissimilarity Measure - similaridade estrutural. Essas técnicas são utilizadas neste trabalho para comparação de dados sobre comportamento das assinaturas de usuários.

\subsection{Padrão de Comportamento de Usuário}

\subsubsection{Modelo de Markov}

Em 1907, Andrei Andreyevich Markov iniciou o estudo de um importante e novo processo probabilístico, no qual o resultado de certo experimento pode interferir em um 
próximo. Esse tipo de processo foi então denominado Markoviano (Grinstead \& Snell, 1997). Tais processos deram origem às cadeias de Markov, que representam a probabilidade de ocorrência de uma série de estados $X=\left\{x_{1}, x_{2}, \ldots, x_{k}\right\}$. Dado um estado inicial $x_{i}$, pode-se mover para um próximo $x_{j}$ considerando a probabilidade de transição pij associada, a qual não depende dos estados anteriores da cadeia (Grinstead \& Snell, 1997).

A probabilidade de transição, na verdade, é uma probabilidade condicional da forma $P\left\{X\left(t_{k+1}\right)=x_{k+1} \mid X\left(t_{k}\right)=x_{k}\right\}$, onde $P$ representa a probabilidade do estado $X\left(t_{k+1}\right)$ ser $x_{k+1}$ no instante $t_{k+1}$ dado que o estado $X\left(t_{k}\right)$ é $x_{k}$ em $t_{k}$ (Hillier \& Lieberman, 2001).

Para exemplificar, considere uma cidade de 50 quilômetros quadrados de área. Nessa cidade as terras podem ter finalidade para uso residencial (R), comercial (C) e industrial (I). Na Tabela 3.1 é representado o percentual de uso das terras no ano de 1993 (Hillier \& Lieberman, 2001).

Tabela 3.1: Estado do uso da terra em 1993 (Hillier \& Lieberman, 2001).

\begin{tabular}{|c|c|c|}
\hline Estado & Tipo de uso & Percentual \\
\hline \hline$R$ & uso residencial & $30 \%$ \\
\hline$C$ & uso comercial & $20 \%$ \\
\hline$I$ & uso industrial & $50 \%$ \\
\hline
\end{tabular}

Os valores da Tabela 3.1 podem ser dispostos em um vetor $x$, denominado vetor de estados conforme a Equação 3.1.

$$
x=[R C I]
$$

As probabilidades de cada estado (probabilidade não-condicional), também podem ser dispostas em um vetor $\pi$ denominado vetor de probabilidade de estado, segundo a Equação 3.2.

$$
\pi=\left[\begin{array}{lll}
0.3 & 0.2 & 0.5
\end{array}\right]
$$

Na Tabela 3.2 são representadas as probabilidades de transição (probabilidade condicional) entre os estados de uso da terra depois de 5 anos.

De uma maneira informal, as probabilidades condicionais apresentadas na Tabela 3.2 podem ser entendidas da seguinte maneira:

- de $R$ para $R$ - a probabilidade do estado $R$ ir para o estado $R$ após 5 anos é 0.8 , isto é, $P\{X(t+5)=R \mid X(t)=R\}=0.8$ ou $P\{X(1998)=R \mid X(1993)=R\}=0.8$; 
Tabela 3.2: Probabilidade de transição (Hillier \& Lieberman, 2001).

\begin{tabular}{|c||c|c|c|}
\hline de/para & R & C & I \\
\hline \hline $\mathbf{R}$ & 0.8 & 0.1 & 0.1 \\
\hline $\mathbf{C}$ & 0.1 & 0.7 & 0.2 \\
\hline $\mathbf{I}$ & 0 & 0.1 & 0.9 \\
\hline
\end{tabular}

- de $R$ para $C$ - a probabilidade do estado $R$ ir para o estado $C$ após 5 anos é 0.1, isto é, $P\{X(t+5)=C \mid X(t)=R\}=0.1$ ou $P\{X(1998)=C \mid X(1993)=R\}=0.1$;

- e assim segue o raciocínio para as demais transições.

Os dados da Tabela 3.2 podem ser representados por uma matriz $P$ denominada matriz de transições da forma:

$$
P=\left[\begin{array}{ccc}
0.8 & 0.1 & 0.1 \\
0.1 & 0.7 & 0.2 \\
0 & 0.1 & 0.9
\end{array}\right]
$$

Então, a partir da matriz $P$ e do vetor de probabilidade de estado $\pi^{(0)}$ do ano 1993, é possível calcular o vetor de probabilidade de estado $\pi^{(1)}$ para o ano 1998 conforme:

$$
\pi^{(1)}=\pi^{(0)} P=\left[\begin{array}{lll}
30 & 20 & 50
\end{array}\right]\left[\begin{array}{ccc}
0.8 & 0.1 & 0.1 \\
0.1 & 0.7 & 0.2 \\
0 & 0.1 & 0.9
\end{array}\right]=\left[\begin{array}{lll}
26 & 22 & 52
\end{array}\right]
$$

Uma maneira alternativa de representar as probabilidades de transição é utilizar o diagrama de transição de estados. Para exemplificar, na Figura 3.1 é representado um diagrama de transição de estados construído a partir dos valores de probabilidade de transição da matriz $P$ (Equação 3.4). Nesse diagrama, os estados são representados por círculos e os arcos direcionais indicam a probabilidade de transição do estado $i$ para $j$.

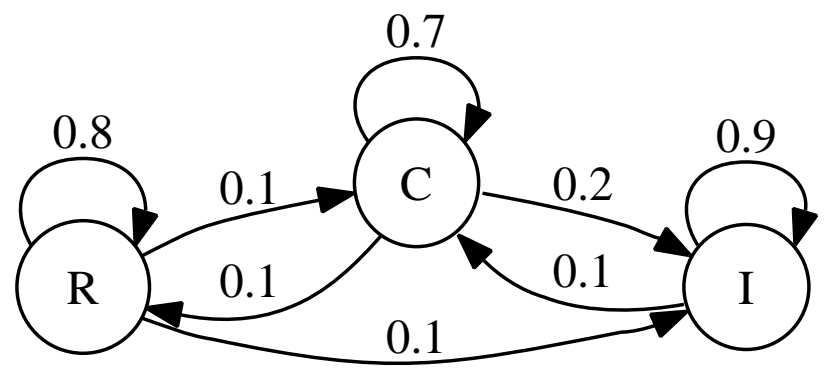

Figura 3.1: Diagrama de transição de estados.

No contexto desta dissertação de mestrado, cadeias de Markov são utilizadas para representar o comportamento de usuários em determinado instante de tempo. Os estados 
dessas cadeias são criados por redes neurais artificiais (maiores detalhes na Seção 3.3), os quais agrupam ações similares (recorrentes) de interação de usuários. As probabilidades de transição representam as prováveis mudanças entre as ações de interação de usuários. Portanto, o perfil de cada usuário é descrito por um conjunto de cadeias de Markov, onde cada cadeia representa detalhes comportamentais desse usuário em certo instante de tempo.

Na próxima seção, é apresentado um modelo matemático de medição quantitativa de informações, o qual é utilizado neste trabalho de mestrado para representar a variação de comportamento de usuários (perfil).

\subsubsection{Teoria da Informação}

A teoria da informação foi introduzida por Shannon (1948) para estudo de sistemas dinâmicos. Nesse estudo Shannon apresenta o estudo sobre componentes de um sistema de comunicação utilizando elementos probabilísticos. Resultados apresentados comprovam melhorias nos meios de comunicação separando informação desejada (sinal) de dados desprezíveis (ruído).

Shannon foi o primeiro a relacionar entropia e informação, propondo uma forma para medir quantitativamente a informação fornecida por um evento probabilístico, baseada na expressão de entropia de Boltzmann (Boltzmann, 1896). A noção de entropia está ligada ao grau de desorganização existente na fonte de informação. Quanto maior a desordem, maior a entropia (Freeman \& Skapura, 1991; Shannon, 1948).

A quantidade de informação recebida, associada à ocorrência de um evento e, é definida pela Equação 3.5, onde: $P(e)$ é a probabilidade de ocorrência desse evento. A base da função logarítmica determina a unidade de medida de informação, podendo ser qualquer número maior que 1 , sendo comumente adotada a base 2 para sistemas digitais (Freeman \& Skapura, 1991).

$$
I(e)=\log \left(\frac{1}{P(e)}\right)
$$

Supondo uma fonte de informação que tenha uma saída seqüencial de símbolos $S=\left\{s_{1}, s_{2}, \ldots, s_{n}\right\}$, onde cada elemento ocorre com probabilidade $\left\{P\left(s_{1}\right), P\left({ }_{2}\right), \ldots, P(n)\right\}$, e a quantidade de informação de cada símbolo em $S$ é dada pela Equação 3.6 (Freeman \& Skapura, 1991). A quantidade média de informação gerada por símbolo é definida na Equação 3.7. A entropia de uma fonte $S$ considera as entropias de todos os possíveis símbolos por ela gerados, conforme apresentado na Equação 3.8. A máxima desordem de um sistema ocorre quando todos os símbolos de uma fonte apresentam a mesma probabilidade, portanto o sistema produz a máxima quantidade de informação (Freeman \& Skapura, 1991). 


$$
\begin{gathered}
I(e)=\log \left(\frac{1}{P\left(S_{i}\right)}\right) \\
\langle I\rangle=\sum_{i=1}^{n} P\left(s_{i}\right) I\left(s_{i}\right) \quad=-\sum_{i=1}^{n} P\left(s_{i}\right) \log P\left(s_{i}\right) \\
H(S)=-\sum_{i=1}^{n} P\left(s_{i}\right) \log P\left(s_{i}\right)
\end{gathered}
$$

A entropia é uma medida de energia que expressa a quantidade de informação contida em um sistema. Quanto maior for a variabilidade de um sistema, maior será a quantidade de informação e, conseqüentemente, maior será a entropia. Neste trabalho de mestrado, a entropia é utilizada para resumir cadeias de Markov e representar comportamentos de usuários.

\subsection{Técnicas de Classificação}

\subsubsection{Redes Neurais Artificiais}

As redes neurais artificiais (RNAs), idealizadas com base no conhecimento disponível sobre redes neurais biológicas (RNBs), visam auxiliar na resolução de diversos problemas tais como classificação, regressão de funções, etc. As RNAs seguem uma organização semelhante às RNBs onde neurônios (células nervosas) interconectam-se e transmitem sinais (sinapse). A estrutura típica de um neurônio (Figura 3.2) é constituída de (Freeman \& Skapura, 1991; Haykin, 1999):

- dendritos são prolongamentos de neurônios especializados na recepção de estímulos nervosos;

- axônio é um prolongamento responsável por conduzir impulsos elétricos entre o corpo celular e a outra extremidade da célula;

- corpo celular totaliza os sinais recebidos pelos dendritos e envia o resultado para o axônio.

Basicamente, a comunicação entre neurônios funciona da seguinte maneira. Um neurônio recebe sinais elétricos de outras células nervosas através de pontos de contato. Esses sinais são chamados de sinapse. Caso a intensidade desses sinais exceda um certo limiar, a célula propaga essa informação para os próximos neurônios (Haykin, 1999).

Seguindo a mesma idéia das redes neurais biológicas, as RNAs são formadas por meio de ligações entre nós, também chamados de neurônios ou unidades de processamento 


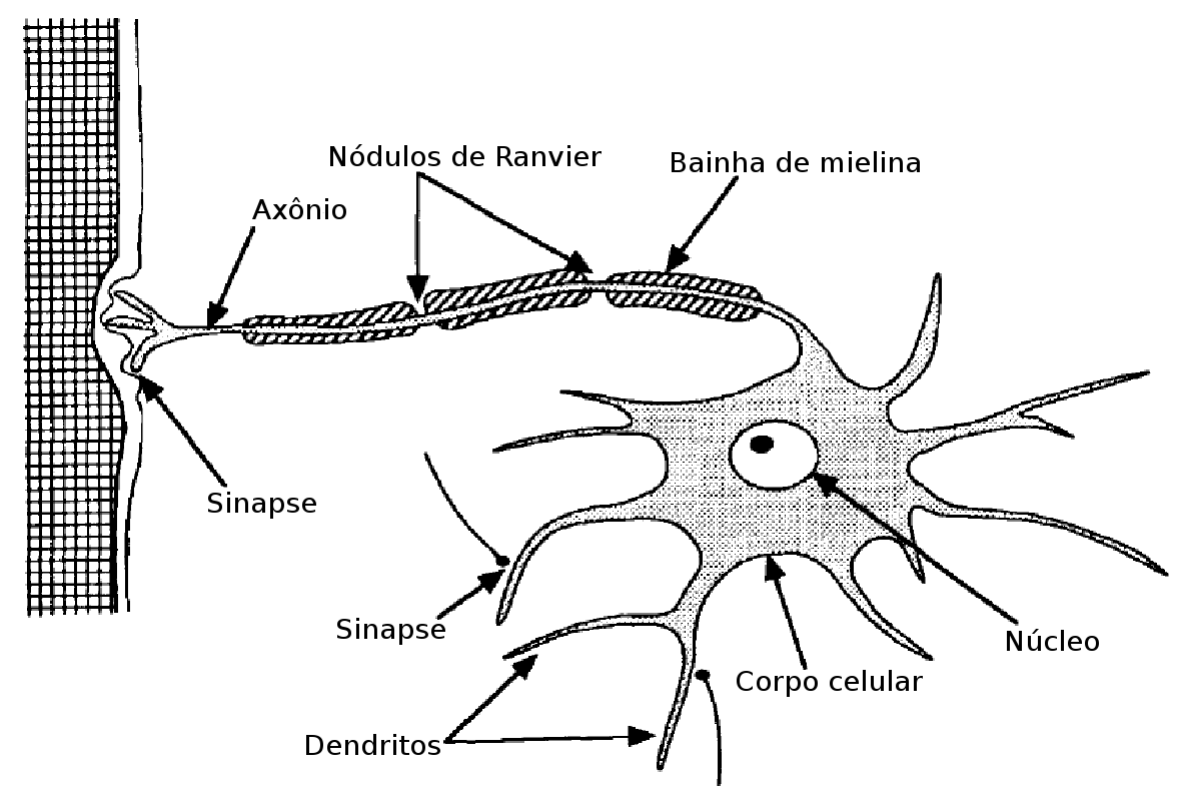

Figura 3.2: Representação de um neurônio biológico (Freeman \& Skapura, 1991).

(UPs). As UPs são dispositivos capazes de totalizar $n$ entradas ponderadas e aplicar uma função de ativação sobre esse resultado. O resultado dessa função é propagado para os neurônios seguintes (Freeman \& Skapura, 1991).

A atuação de um neurônio artificial é similar à de um neurônio biológico. Na Figura 3.3 é apresentado um neurônio artificial que recebe um conjunto $x_{i}$ de sinais de entrada $\left\{x_{1}, x_{2}, \ldots, x_{n}\right\}$. Quando sinais forem provenientes de outros neurônios, esses têm um valor ou um peso $w_{i}$ associado. O sinal de saída y é produzido a partir da função de ativação $F$, aplicada no processamento da soma ponderada dos sinais de entrada $z$ (Freeman \& Skapura, 1991; Haykin, 1999).

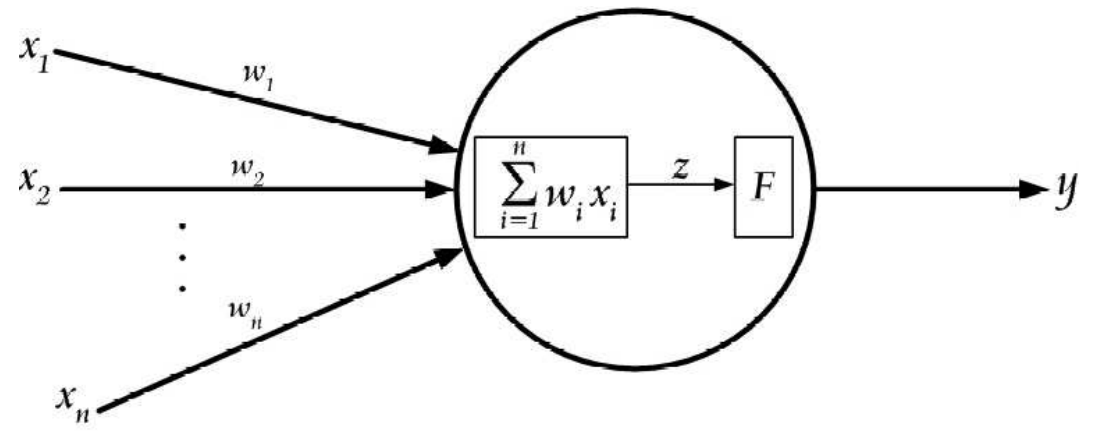

Figura 3.3: Representação de um neurônio artificial.

Na Figura 3.4 é apresentado um exemplo de RNA feed-forward, comumente adotado. Esse tipo de rede apresenta todas as ligações em um único sentido, sem conexões entre neurônios da mesma camada ou de camadas anteriores. Essa RNA tem basicamente 3 tipos de camadas: 1) a primeira, usualmente conhecida como camada de entrada, recebe dados e os propaga, geralmente sem executar qualquer processamento; 2) camadas intermediárias ou ocultas; 3) e uma camada de saída, que gera respostas para padrões de 
entrada (Haykin, 1999).

Uma RNA é processada utilizando os valores de pesos das conexões entre neurônios, os quais correspondem à intensidade das sinapses entre neurônios biológicos. Assim como no cérebro humano, onde as sinapses são estabelecidas por meio de um processo de aprendizagem, as RNAs necessitam de algoritmos para determinar os pesos de conexões entre neurônios. Além da feed-forward, existem outros tipos de RNAs, tais como a SOM (Kohonen et al., 2000; Ypma \& Duin, 1997), ART (de Mello et al., 2005; Senger et al., 2006; Carpenter et al., 1991), etc.

As RNAs podem ser descritas de acordo com sua topologia: número de camadas, UPs e conexões; características das UPs; e algoritmos de aprendizagem aplicados (Freeman \& Skapura, 1991). O aprendizado de uma RNA pode ser classificado como supervisionado ou não supervisionado. No aprendizado supervisionado, a rede recebe conjuntos sucessivos de padrões de entrada e produz saídas correspondentes que são comparadas às esperadas. Durante esse processo são realizados ajustes nos pesos de conexões entre UPs, seguindo uma lei de aprendizado, até que o erro gerado pelas saídas seja minimizado em função dos valores esperados (Haykin, 1999). No aprendizado não supervisionado, a rede extrai propriedades de conjuntos de dados, usualmente aplicados em classificação. Nesse processo a rede extrai conhecimento a fim de representar propriedades das entradas por meio de agrupamentos na camada de saída (Haykin, 1999).

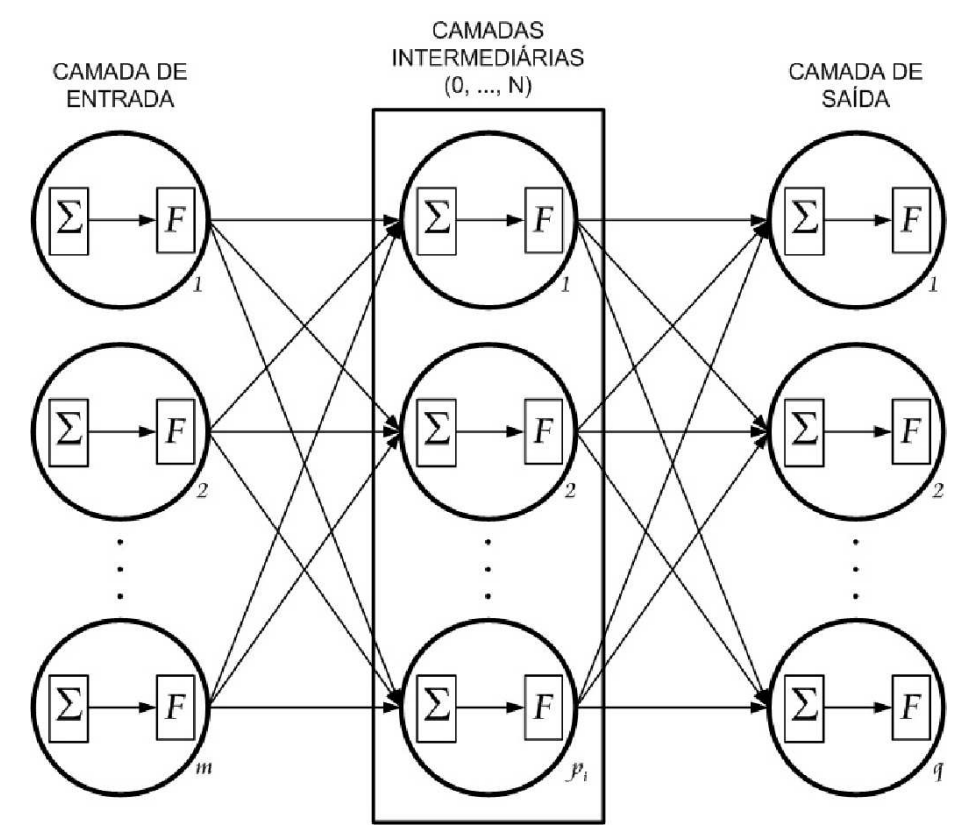

Figura 3.4: Estrutura de uma RNA do tipo feed-forward.

Existem diversas técnicas de aprendizagem para redes neurais. Dentre as principais estão:

- Lei de Hebb - a conexão entre dois neurônios é reforçada sempre que ambos estão ativos, isto é, a intensidade de uma conexão sináptica aumenta quando neurônios são 
simultaneamente estimulados. Essa lei é utilizada como base para outros algoritmos de aprendizagem;

- Backpropagation - a rede opera em uma seqüência de dois passos. Primeiramente apresenta-se um padrão para a camada de entrada da rede. Em seguida, a saída é comparada com o valor esperado. Caso a saída não esteja correta, o erro é calculado e propagado a partir da última camada até a de entrada, atualizando pesos de conexões entre neurônios.

\subsubsection{SONDE - Self-Organizing Novelty Detection}

A rede neural artificial SONDE (Self-Organizing Novelty Detection), proposta por Albertini \& de Mello (2007), consiste em uma arquitetura auto-organizável capaz de detectar novidades de maneira on-line. Esta seção apresenta maiores detalhes sobre essa técnica, pois foi adotada no contexto deste trabalho.

A SONDE integra características de técnicas de detecção de novidades presentes nas redes neurais SOM (Ypma \& Duin, 1997), GWR (Marsland et al., 2002) e ART (de Mello et al., 2005; Senger et al., 2006; Carpenter et al., 1991). A Figura 3.5 apresenta a arquitetura da SONDE que é dividida em 3 camadas: camada de entrada e préprocessamento - onde padrões são, eventualmente, normalizados; camada de neurônios competitivos - onde ocorrem ativações de neurônios para representar padrões de entrada; e a camada final que escolhe a unidade mais representativa para padrões de entrada (BMU - best-matching unit) (Albertini \& de Mello, 2007).

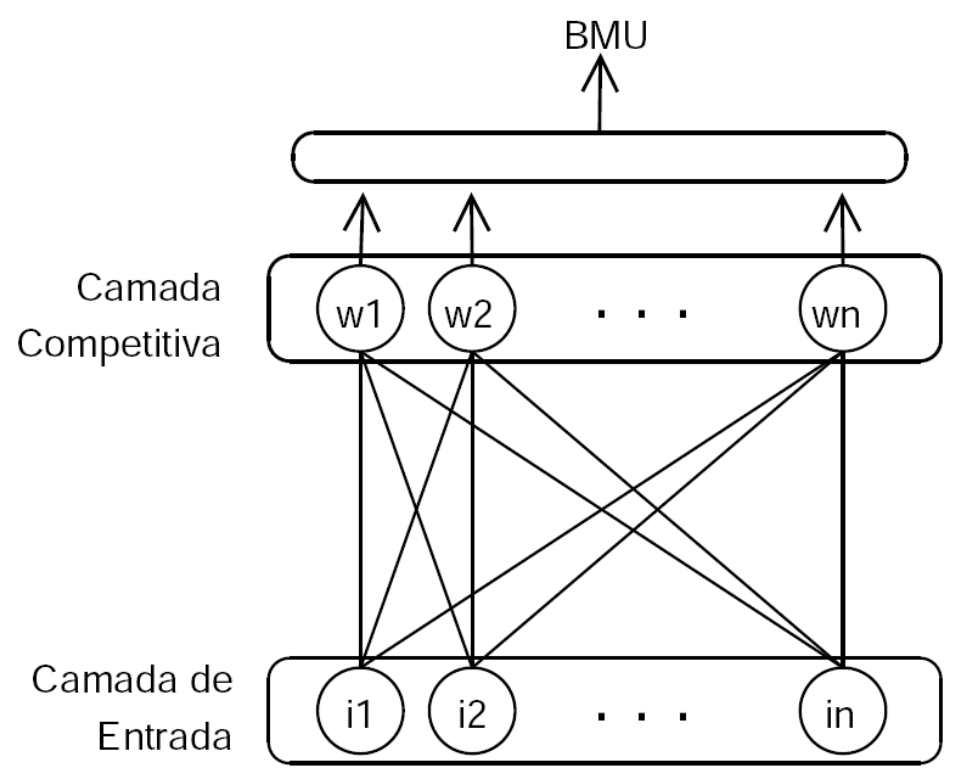

Figura 3.5: Arquitetura da rede neural SONDE (Albertini \& de Mello, 2007).

Na SONDE, neurônios são criados conforme novidades são detectadas nos padrões de entrada. O centróide $w_{c}$ e o raio de ativação $\operatorname{rad}_{c}$ de um neurônio adaptam-se, conforme 
um novo padrão é agrupado.

A classificação é feita de maneira não supervisionada, onde padrões similares de entrada são agrupados no mesmo neurônio. Cada unidade que classifica um padrão é estimulada a fim de manter um histórico de entrada de dados. Entretanto, conforme dados de entrada sofrem modificações, neurônios adaptam-se e, assim, esquecem informações passadas. Essas taxas de esquecimento e adaptação de neurônios são definidas por parâmetros da rede (Albertini \& de Mello, 2007).

Para representar esse mecanismo de adaptação e esquecimento, considere, inicialmente, a Equação 3.9 responsável pela normalização de padrões de entrada multidimensionais. A cada padrão $\vec{I}_{t}$ recebido no instante $t$, o valor de ativação $a_{c}$ de cada neurônio na camada competitiva é calculado utilizando a Equação 3.10 (Albertini \& de Mello, 2007).

$$
\begin{gathered}
\vec{I}_{t}=\frac{\vec{I}_{t}}{\left\|\overrightarrow{I_{t}}\right\|} \\
a_{c}=\exp \left(-\left\|\overrightarrow{I_{t}}-\vec{w}_{c}\right\|\right)
\end{gathered}
$$

Um novo neurônio $w_{\text {new }}^{\overrightarrow{ }}$ é criado quando a Equação 3.11 é satisfeita, ou seja, nenhum neurônio foi capaz de representar o padrão $\vec{I}_{t}$. Esse novo neurônio é configurado com centróide igual aos valores do padrão responsável por sua criação, valor máximo de ativação $\left(a_{\text {new }}=1\right)$ e nível de similaridade mínimo igual a uma constante $\left(\alpha_{\text {new }}=\alpha_{0}\right)$. A cobertura do raio médio inicial $\operatorname{rad}_{n e w}$ é igual a $-\ln \left(\alpha_{0}\right)$ que corresponde ao grau de similaridade inicial (Albertini \& de Mello, 2007).

$$
a_{c}<\alpha_{c}, \forall_{C}
$$

Quando um neurônio vencedor é encontrado, isto é, $B M U=\operatorname{argmax}_{c}\left(\exp \left(-\| \vec{I}_{t}-\right.\right.$ $\left.\vec{w}_{c}||\right)$ ), a Equação 3.12 é satisfeita. O neurônio vencedor é aquele que melhor representa o padrão de entrada (Albertini \& de Mello, 2007).

$$
\left\|\vec{I}_{t}-\vec{w}_{c}\right\|=<-\ln \left(\alpha_{c}\right)
$$

Como mencionado anteriormente, o objetivo da SONDE é detectar novidades em séries temporais. Para isso, a SONDE utiliza cadeias de Markov (Seção 3.2.1) que auxiliam na representação de estados e transições em instantes de tempo consecutivos.

Essas cadeias são utilizadas pela SONDE para detectar novidades. Assim, quando um evento ocorre no passado com baixa freqüência, esse exibe algum grau de novidade. Além disso, novidades podem ser detectadas quando uma transição inesperada ocorre entre dois estados. Como as cadeias de Markov representam as probabilidades de transição 
entre os estados, o grau de novidade pode ser obtido medindo a variação média de energia entre as cadeias em momentos consecutivos.

Na SONDE, a medida utilizada para medir o grau de novidades em uma série temporal é a entropia (Seção 3.2.2). Se a variação de entropia for diferente de zero (um pico negativo ou positivo), há indicação de evento inesperado. Caso o sistema mantenha um padrão de comportamento, mesmo depois de detectar uma novidade, o valor da entropia tenderá a zero.

A Figura 3.6, apresenta os resultados de um experimento realizado com a SONDE, onde foi submetida uma seqüência de três valores na forma 123123...123. A seqüência de entradas é representada pela curva Entradas, a medida de energia (entropia) é descrita pela curva Variação de entropia e a curva Estados representa estados de classificação da SONDE.

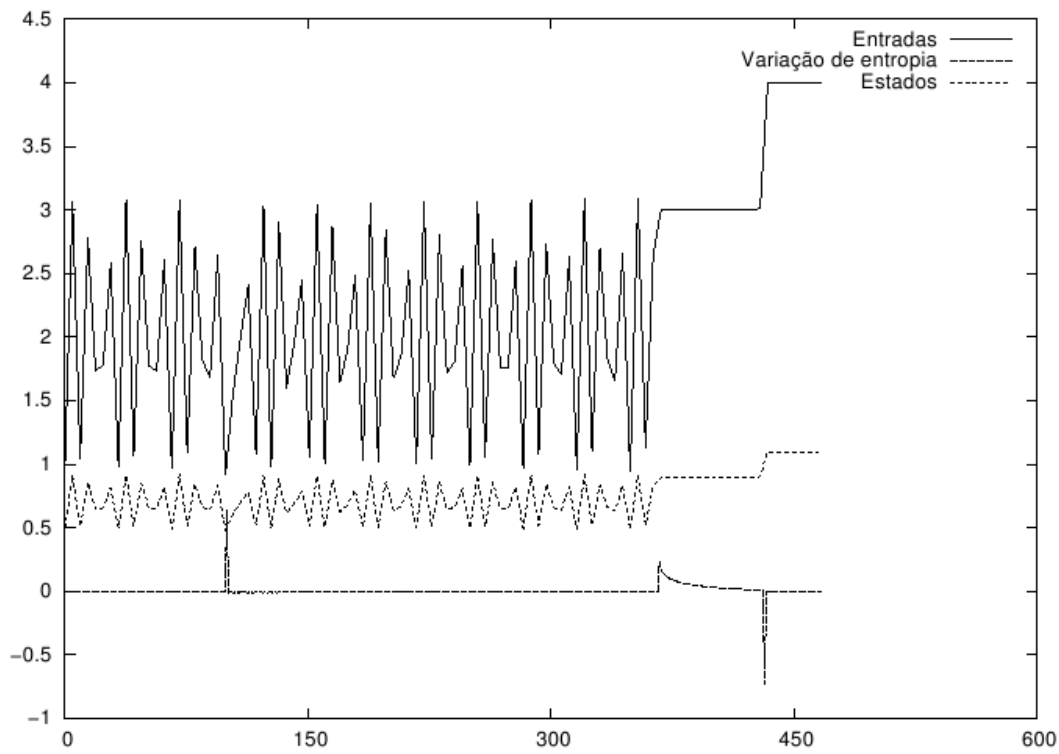

Figura 3.6: Experimento de detecção de novidade em uma seqüência periódica com três valores (Albertini \& de Mello, 2007).

Analisando a Figura 3.6 nota-se a ocorrência de novidades (variação de energia) em três momentos distintos. Quando a seqüência de entrada 123123...123 é interrompida pela ocorrência de dois números 1 consecutivos, a curva Variação de entropia registra uma variação positiva de valor, representando uma novidade (nota-se que nenhum estado novo foi criado). Em outro momento, foi introduzida uma seqüência de números 3 que gerou outro pico de energia. Contudo, conforme a mesma seqüência é repetida, a entropia tende a se estabilizar em zero novamente. Na última situação foram inseridos, após a seqüência de números 3, uma nova seqüência de números 4 (nota-se que nesse caso um novo estado 4 é criado), e, mais uma vez, ocorre uma variação da entropia, indicando novidade na seqüência de entrada. 


\subsection{Medidas de Similaridade}

\subsubsection{DTW - Dynamic Time Warping}

Uma forma simples de se comparar duas séries temporais é por meio do cálculo de distância entre as mesmas. Como exemplo pode-se utilizar a distância Euclidiana para computar as diferenças (distâncias) entre cada ponto de duas séries temporais, isto é, calcula-se a distância entre o primeiro ponto de uma série A com o primeiro ponto de uma série B, e assim sucessivamente (alinhamento linear). Contudo, para obter resultado confiável, faz-se necessário que séries sejam normalizadas em relação ao eixo do tempo e que possuam o mesmo comprimento temporal (Alencar, 2007).

Apesar de simples, a distância Euclidiana apresenta erros para séries temporais com algum tipo de distorção no eixo do tempo (Berndt \& Clifford, 1994). Para superar tais limitações, pode-se adotar técnicas tais como DTW (Dynamic Time Warping), a qual mede a similaridade baseada em técnicas de programação dinâmica (Keogh \& Ratanamahatana, 2005) e realiza alinhamento não-linear entre séries temporais.

Na Figura 3.7 observa-se a comparação entre duas séries temporais de mesmo tamanho e com distorção ao longo do tempo, mostrando a diferença entre o alinhamento linear utilizado pela medida de similaridade Euclidiana (Figura 3.7(a)) e o alinhamento não-linear utilizado na DTW (Figura 3.7(a)). Note que a medida Euclidiana alinha o $i$-ésimo ponto de uma série com o $i$-ésimo da outra, comparando pares, o que produz resultados insatisfatórios de similaridade. O alinhamento não-linear provido pela DTW permite calcular uma medida de similaridade mais intuitiva, pois realiza a comparação entre conjuntos de pontos mais próximos entre séries.

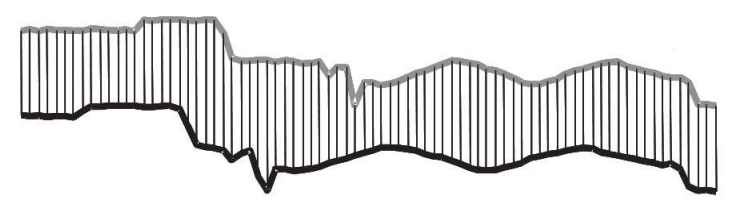

(a) Euclidiana

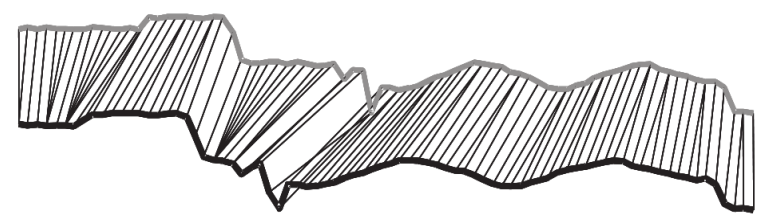

(b) DTW

Figura 3.7: Exemplo de comparação entre séries temporais utilizando a medida de similaridade Euclidiana (alinhamento linear) e a DTW (alinhamento não-linear) (Keogh \& Ratanamahatana, 2005).

Para melhor compreender a DTW, suponha duas séries temporais, $Q=$ $q_{1}, q_{2}, \ldots, q_{i}, \ldots, q_{n}$ e $C=c_{1}, c_{2}, \ldots, c_{j}, \ldots, c_{m}$, com tamanhos $n$ e $m$. A fim de realizar o alinhamento entre essas duas séries, constrói-se uma matriz $n$ por $m$, onde o elemento de índice $(i, j)$ representa a distância entre pares de pontos das séries $Q$ e $C$, isto é $d\left(q_{i}, c_{j}\right)=\left(q_{i}-c_{j}\right)^{2}$ (Keogh \& Ratanamahatana, 2005). Cada elemento $(i, j)$ da matriz corresponde a um alinhamento entre os pontos $q_{i}$ e $c_{j}$, como mostra a Figura 3.8.

Após definir tal matriz, o objetivo é encontrar o melhor caminho de alinhamento 
A)

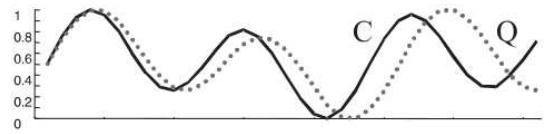

C)

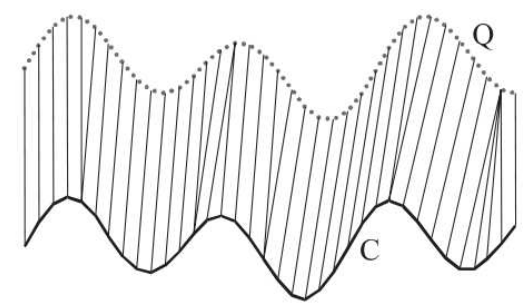

B)
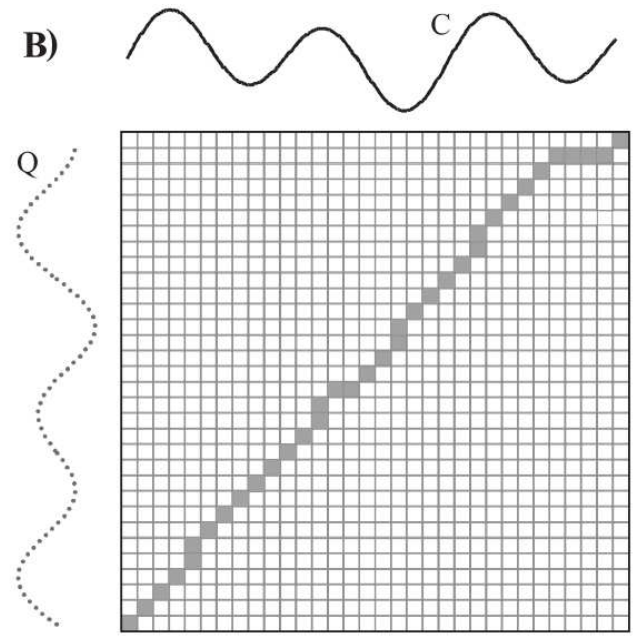

Figura 3.8: Exemplo de uma matriz de alinhamento entre duas séries temporais $Q$ e $C$. A) Mostra duas séries similares, porém fora de fase. B) O resultado da procura do melhor alinhamento entre as séries é apresentado pelos quadrados preenchidos. C) Apresenta o resultado do alinhamento entre as séries. (Keogh \& Ratanamahatana, 2005).

entre duas séries. Um caminho de alinhamento $W$ (Equação 3.13) pode ser definido como uma série de elementos contínuos da matriz de alinhamento que representa o mapeamento entre duas séries temporais $Q$ e $C$, por exemplo. O $k$-ésimo elemento de $W$ é representado por $w_{k}=(i, j)_{k}$ (Keogh \& Ratanamahatana, 2005).

$$
W=w_{1}, w_{2}, \ldots, w_{k}, \ldots, w_{K} \quad \max (m, n) \leq K<m+n-1
$$

O caminho de alinhamento contém algumas restrições, tais como:

- Monotocidade: Dado $w_{k}=(a, b)$, então $w_{k-1}=\left(a^{\prime}, b^{\prime}\right)$, onde $a \geq a^{\prime}$ e $b \geq b^{\prime}$, garantindo que não há volta ao percorrer um caminho de alinhamento.

- Continuidade: Dado $w_{k}=(a, b)$, então $w_{k-1}=\left(a^{\prime}, b^{\prime}\right)$, onde $a-a^{\prime} \leq 1^{\prime}$ e $b-b^{\prime} \leq 1^{\prime}$, garantindo que cada passo no caminho de alinhamento seja adjacente ao anterior, inclusive no sentido diagonal.

- Restrição de Limite: $w_{1}=(1,1)$ e $w_{k}=(m, n)$, garantindo que o início e final do caminho de alinhamento devem ser cantos diagonais opostos da matriz.

Respeitando essas restrições, o alinhamento pode ser realizado por diversos caminhos distintos em uma mesma matriz. No entanto, o objetivo é encontrar o caminho que melhor alinha duas séries temporais, isto é, minimizar o custo do caminho de alinhamento conforme a Equação 3.14.

$$
\operatorname{DTW}(Q, C)=\min \left(\sqrt{\sum_{k=1}^{k} w_{k}}\right)
$$


A programação dinâmica auxilia na busca desse caminho ótimo. Tal técnica deve avaliar a equação de recorrência 3.15, onde a distância acumulativa $\gamma(i, j)$ é definida a partir da distância do elemento atual $d(i, j)$ somada à distância mínima entre elementos adjacentes (Keogh \& Ratanamahatana, 2005).

$$
\gamma(i, j)=d\left(q_{i}, c j\right)+\min (\gamma(i-1, j-1), \gamma(i-1, j), \gamma(i, j-1))
$$

Após encontrado o caminho de alinhamento, o primeiro elemento da matriz conterá o somatório das distâncias Euclidianas do melhor alinhamento entre as séries temporais comparadas. No contexto deste trabalho, utiliza-se a técnica DTW para medir a similaridade entre séries temporais de variação de energia de usuários distintos.

\subsubsection{CDM - Compression-based Dissimilarity Measure}

A DTW e a distância Euclidiana são medidas de similaridade não estruturais que se limitam a detectar diferenças locais entre séries temporais (Alencar, 2007). Essa limitação foi um dos motivos que levou Keogh et al. (2007) a propor uma técnica de medida de similaridade estrutural e livre de parâmetros, denominada CDM. Essa técnica também é adotada neste trabalho para representar similaridade entre séries temporais que representam comportamentos de usuários.

A CDM é baseada na complexidade de Kolmogorov (1965), que visa quantificar a quantidade de informação de strings e objetos de maneira absoluta e direta. Seguindo a notação de Li et al. (2003), a complexidade condicional de Kolmogorov $K(x \mid y)$ de $x$ para $y$, é definida pelo tamanho do menor programa capaz de computar $x$ dado $y$ como entrada. A função $K(x y)$ representa o tamanho do menor programa capaz de gerar uma saída concatenada das entradas $y$ e $x$. Com isso, a distância entre duas strings $x$ e $y$ é definida conforme a Equação 3.16 .

$$
d_{k}(x, y)=\frac{K(x \mid y)+K(y \mid x)}{K(x y)}
$$

Em geral, a complexidade de Kolmogorov não é computável (Keogh et al., 2007). Por esse motivo, Keogh et al., baseado no trabalho de Li et al. (2003), baseia-se no fato de que algoritmos de compressão fornecem um limite superior para tal complexidade. Além da compressão de dados, para a CDM, faz-se necessário que séries comparadas possuam distribuições discretas. Para isso os autores sugerem uma representação conhecida como Symbolic Aggregate approXimation (SAX), a qual converte séries temporais em cadeias de caracteres (maiores detalhes na Seção 3.4.3).

Dessa forma, define-se a medida de similaridade CDM com base na representação discreta de séries temporais (SAX) que são submetidas a um algoritmo de compressão. 
Dado um algoritmo de compressão $C, C(s)$ é definido como o tamanho, em bytes, da string $s$. Assumindo $x$ e $y$ como strings resultantes, respectivamente, das séries temporais $Q$ e $C$ após aplicação da técnica SAX, a distância CDM é definida conforme a Equação 3.17, onde $x y$ é a concatenação de $x \operatorname{com} y$ (Alencar, 2007).

$$
D_{C D M}(Q, C)=\frac{C(x y)}{C(x)+C(y)}
$$

A medida de similaridade CDM retorna resultados próximos a 1 (um) quando $x$ e y não possuem relação (são diferentes), e menor que 1 (um) quando há alguma relação (são similares). Quanto menor for o valor $C D M(x, y)$, maior é a relação entre $x$ e $y$.

Um exemplo de código da CDM é observado na Tabela 3.3 (implementado para MatLab).

Tabela 3.3: Algoritmo da CDM em MatLab (Keogh et al., 2007).

\begin{tabular}{ll}
\hline function Dist = CDM(A,B) & \\
save A.txt A -ASCII & $\%$ Armazena a variável A como A.txt \\
zip('A.zip', 'A.txt'); & $\%$ Comprime A.txt \\
A_file = dir('A.zip'); & $\%$ Extrai informações do arquivo \\
save B.txt B -ASCII & $\%$ Armazena a variável B como B.txt \\
zip('B.zip', 'B.txt'); & $\%$ Comprime B.txt \\
B_file = dir('B.zip'); & $\%$ Extrai informações do arquivo \\
A_n_B = [A; B]; & $\%$ Concatena A e B \\
save A_n_B.txt A_n_B -ASCII & $\%$ Armazena A_n_B.txt \\
zip('A_n_B.zip', 'A_n_B.txt'); & $\%$ Comprime A_n_B.txt \\
A_n_B_file = dir('A_n_B.zip'); & $\%$ Extrai informações do arquivo \\
dist = A_n_B_file.bytes / (A_file.bytes + B_file.bytes) ; $\%$ Retorna a similaridade CDM \\
\hline
\end{tabular}

O algoritmo da CDM é de fácil implementação, de execução relativamente rápida (dependente do tempo de compressão dos dados) e livre de parâmetros (a não ser pelos algoritmos de compressão), contudo requer séries temporais longas (com mais de 1000 pontos de dados) para produzir bons resultados. A aproximação de similaridade dessa técnica é mais precisa para maiores volumes de informação (Keogh et al., 2007).

Na próxima seção é apresentada a técnica de representação discreta de dados, denominada SAX, utilizada neste trabalho para calcular a medida de similaridade CDM.

\subsubsection{SAX - Symbolic Aggregate approXimation}

O SAX consiste em um método de representação simbólica de séries temporais proposto por Lin et al. (2003). Essa representação permite que uma série de comprimento $n$ seja reduzida a uma string de tamanho $w$, com $w<<n$. Dessa forma, o SAX converte uma série temporal, que contém seqüências de números reais, em uma cadeia de caracteres, sem perder suas características originais (Alencar, 2007).

A representação SAX é obtida seguindo três etapas: normalização, PAA (Piecewise Aggregate Approximation) e discretização (Alencar, 2007). Na primeira etapa, a 
série temporal é normalizada com média 0 e desvio padrão 1. Para isso, subtrai-se de cada elemento $Z_{t}$ a média de sua série $(\bar{Z})$ e, posteriormente, divide-se esse resultado pelo desvio padrão de $Z$ (definido por $\hat{\sigma}$ ) (Equação 3.18). Com essa normalização, obtém-se uma distribuição de probabilidade Gaussiana ao longo do eixo das ordenadas.

$$
Z^{\prime}=\frac{Z_{t}-\bar{Z}}{\hat{\sigma}}, \quad t=1, \ldots N
$$

Na próxima etapa, a série temporal de tamanho $n$ é reduzida, utilizando o algoritmo PAA (Keogh et al., 2001), em $w$ segmentos de igual tamanho. A representação PAA é obtida por meio do cálculo da média aritmética do segmento $w$ na série. O $i$-ésimo elemento do vetor de segmentos $\bar{C}$ é dado pela Equação 3.19.

$$
\bar{C}_{i}=\frac{w}{n} \sum_{j=\frac{n}{w}(i-1)+1}^{\frac{n}{w} i} C_{j}, \quad i=1, \ldots, w
$$

Um exemplo de segmentação é mostrado na Figura 3.9, onde $C$ representa a série temporal e $\bar{C}$ o vetor de segmentos. Como $w$ representa a dimensão resultante da redução de uma série de $n$ dimensões, o fator de agregação é dado por $\frac{n}{w}$. Quanto maior o valor de $w$, maior será a agregação e a redução da série temporal.

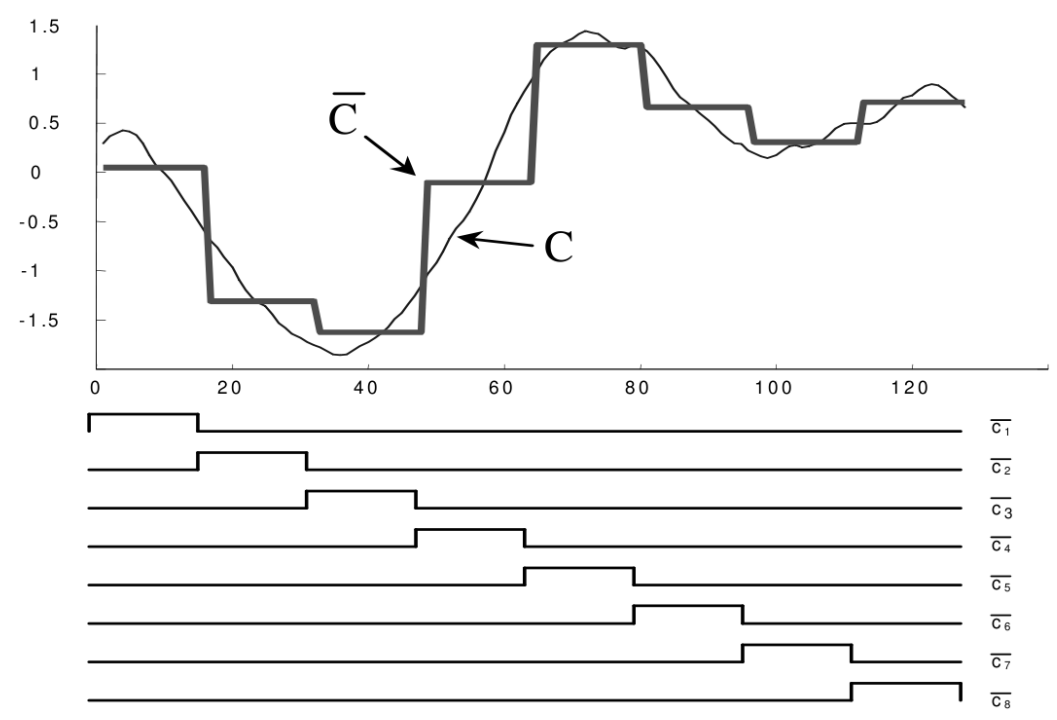

Figura 3.9: Exemplo de representação $P A A$ de uma série temporal. Neste caso, a série de tamanho 128 foi reduzida para 8 dimensões (Lin et al., 2003).

Depois de normalizar e obter a representação PAA da série, ocorre a etapa de discretização. Nessa etapa, cada segmento da representação PAA é transformado em uma letra equiprovável, utilizada para discretização da série temporal. As letras utilizadas compõem um alfabeto. O tamanho $a$ desse alfabeto deve ser maior que $2(a>2)$, para uma melhor discretização dos dados. Para $a=5$, por exemplo, pode-se definir um alfabeto tal 
como $\{$ "a", "b", "c", "d","f" $\}$. O mapeamento entre as letras e os segmentos da representação PAA é realizado seguindo uma lista de breakpoints.

Breakpoints são definidos por uma lista ordenada de números $B=\beta_{1}, \ldots, \beta_{a-1}$, tal que a área de uma curva Gaussiana $N(0,1)$ seja de $\beta_{i}$ até $\beta_{i+1}=\frac{1}{a}\left(\beta_{0}\right.$ e $\beta_{a}$ são definidos como $-\infty$ e $\infty$, respectivamente) (Lin et al., 2003).

Os breakpoints podem ser determinados por meio da Tabela Normal Padrão (Shefler, 1988) (tabela que contém as áreas sob a curva normal e seus respectivos valores de desvio padrão, também conhecida como Tabela $Z$ ). A Tabela 3.4 mostra uma lista de breakpoints contendo intervalos de valores para $a \in[3,10]$.

Tabela 3.4: Tabela de breakpoints contendo valores que divide a distribuição Gaussiana por um número arbitrário de regiões (de 3 a 10) (Lin et al., 2003).

\begin{tabular}{|c||cccccccc|}
\hline \multicolumn{1}{|c||}{} & \multicolumn{7}{c|}{$a$} \\
\cline { 2 - 9 } & $\mathbf{3}$ & $\mathbf{4}$ & $\mathbf{5}$ & $\mathbf{6}$ & $\mathbf{7}$ & $\mathbf{8}$ & $\mathbf{9}$ & $\mathbf{1 0}$ \\
\hline \hline$\beta_{1}$ & -0.43 & -0.67 & -0.84 & -0.97 & -1.07 & -1.15 & -1.22 & -1.28 \\
$\beta_{2}$ & 0.43 & 0 & -0.25 & -0.43 & -0.57 & -0.67 & -0.76 & -0.84 \\
$\beta_{3}$ & - & 0.67 & 0.25 & 0 & -0.18 & -0.32 & -0.43 & -0.52 \\
$\beta_{4}$ & - & - & 0.84 & 0.43 & 0.18 & 0 & -0.14 & -0.25 \\
$\beta_{5}$ & - & - & - & 0.97 & 0.57 & 0.32 & 0.14 & 0 \\
$\beta_{6}$ & - & - & - & - & 1.07 & 0.67 & 0.43 & 0.25 \\
$\beta_{7}$ & - & - & - & - & - & 1.15 & 0.76 & 0.52 \\
$\beta_{8}$ & - & - & - & - & - & - & 1.22 & 0.84 \\
$\beta_{9}$ & - & - & - & - & - & - & - & 1.28 \\
\hline
\end{tabular}

Tendo a tabela de breakpoints é possível discretizar uma série temporal seguindo alguns passos. Primeiro obtém-se a representação PAA da série temporal. Em seguida, é necessário escolher um valor de $a$ para a discretização da série temporal, como exemplo, assume-se o valor de $a=3$. Após isso, todos os coeficientes PAA com valores menores que $\beta_{1}$ são mapeados pela letra " $a$ ", os coeficientes com valores maiores ou iguais a $\beta_{1}$ e menores que $\beta_{2}$ são mapeados pela letra " $b$ ", os demais coeficientes, com valores maiores que $\beta_{3}$, são mapeados pela letra "c". Essa lógica é seguida para diferentes valores de $a$. A Figura 3.10 ilustra esses passos.

Nesta seção foi apresentado um método para discretização de séries temporais que reduz dimensionalidade sem, contudo, eliminar características originais dessas séries. O SAX é usado na medida de similaridade CDM (Seção 3.4.2), pois optimiza o processo de compressão dos dados de séries.

A importância do uso de uma representação de séries temporais, tal como o SAX, é observada no exemplo apresentado na Figura 3.11, que mostra os dez primeiros dados de três Eletrocardiogramas da PhysioNet (Goldberger et al., 2000) em forma de texto.

De acordo com Keogh et al. (2007), os eletrocardiogramas A e C, apresentados na 


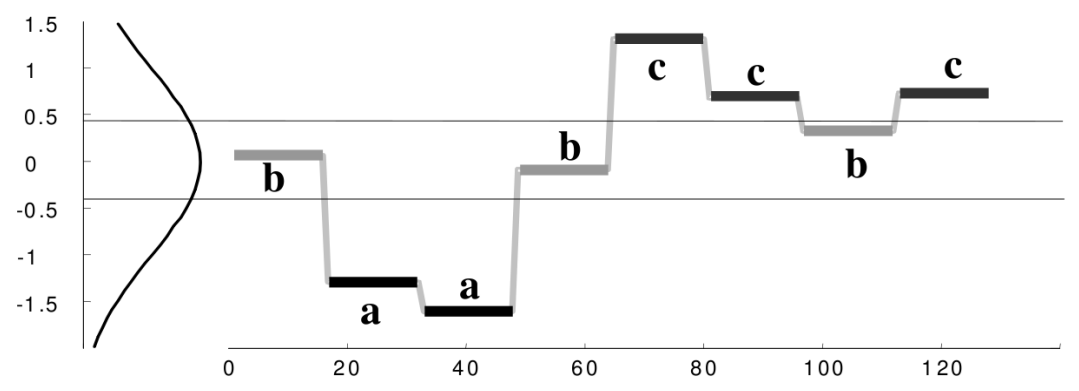

Figura 3.10: Exemplo de uma série temporal normalizada e discretizada por meio da representação PAA. Além disso são apresentados os coeficientes PAA em símbolos SAX, usando a tabela de breakpoints. Nesse exemplo, adota-se os valores $n=128, w=8$ e $a=3$. Observa-se que série temporal é mapeada na palavra baabccbc. (Lin et al., 2003).

$\mathbf{A}$
0.13812500000000
0.04875000000000
0.10375000000000
0.17875000000000
0.24093750000000
0.29875000000000
0.37000000000000
0.48375000000000
0.55593750000000
0.64625000000000
0.70125000000000

\section{B}

0.51250000000000

0.50000000000000

0.50000000000000

0.47562500000000

0.45125000000000

0.45125000000000

0.47656250000000

0.50000000000000

0.48281250000000

0.48468750000000

0.46937500000000
C

0.49561523437690

0.49604248046834

0.49653076171875

0.49706481933594

0.49750732421875

0.49808715820312

0.49875854492187

0.49939941406230

0.50007080078125

0.50062011718750

0.50123046875826

Figura 3.11: Dez primeiros pontos de três Eletrocardiogramas (Keogh et al., 2007).

figura, são de pacientes que sofrem de um mesmo problema cardíaco. Com a adição de algumas centenas de dados, aos apresentados na Figura 3.11, é possível observar, a olho nu ou por meio de distância Euclidiana, o agrupamento de seqüências cardíacas $((\mathbf{A}, \mathbf{C}), \mathbf{B})$.

No entanto, a CDM tem dificuldades em mensurar a similaridade desse tipo de dado. Nota-se que para CDM, as seqüências com maior similaridade são A e B. Isso ocorre pois essas apresentam a ocorrência de muitos 0000000's, o que tende a sobrepor a relevância de demais valores, tornando-se o aspecto mais representativo nos cálculos após compressão.

Para resolver tal problema, as séries precisam ser traduzidas para outro formato capaz de preservar suas características originais e, ao mesmo tempo, contribuir positivamente com a metodologia utilizada pela CDM. O SAX cumpre tais requisitos, e por esse motivo é utilizado, nesta dissertação de mestrado, para dar suporte ao cálculo da CDM. 


\subsection{Considerações Finais}

Este capítulo apresentou conceitos sobre cadeias de Markov, teoria da informação, redes neurais e medidas de similaridade, os quais são utilizados no contexto desta dissertação de mestrado a fim de representar, identificar e comparar perfis de comportamento de usuários. 


\section{Classificação e Deteç̧ão de Variações de Comportamento de Usuários}

\subsection{Considerações Iniciais}

Neste capítulo são apresentados o objetivo desta dissertação de mestrado e a descrição da metodologia, dentro do foco de aplicação adotado para sua validação (reconhecimento de assinaturas).

\subsection{Objetivo}

Motivado por trabalhos de análise comportamental em sistemas computacionais, esta dissertação estudou técnicas de classificação de padrões de comportamento de usuários, e propôs uma metodologia a fim de identificá-los em função de suas variações. Essa metodologia detecta perfis de usuários a fim de auxiliar a compreensão de seus comportamentos em diferentes circunstâncias. Essa ainda pode ser aplicada para diferentes fins, contudo, focou-se no reconhecimento de assinaturas manuscritas, permitindo assim, a verificação, por meio do comportamento de usuário, da autenticidade de assinaturas (verdadeira ou falsa). Resultados obtidos foram correlacionados a fim de detectar características individuais que diferenciam usuários (perfil da assinatura do usuário).

\subsection{Metodologia}

A metodologia de classificação de perfis de usuários proposta neste trabalho é composta pelas seguintes etapas: 
1. Definição de distribuições dos dados disponíveis de interação de usuários;

2. Classificação por redes neurais artificiais (RNAs), e representação de padrões de comportamento de usuários por meio de cadeias de Markov;

3. Medida da variação de energia entre cadeias de Markov (entropia);

4. Comparação de perfis de usuários.

Para exemplificar e validar a metodologia proposta, utilizou-se uma base de dados contendo informações sobre assinaturas de usuários. Essa base foi utilizada em um campeonato de reconhecimento de assinaturas manuscritas realizado em 2004 (SVC2004: First International Signature Verification Competition ${ }^{1}$ ) (Yeung et al., 2004), a qual contém informações sobre assinaturas de 40 usuários distintos, onde, para cada usuário, foram armazenadas 40 assinaturas. Dessas 40 assinaturas, as 10 primeiras ( $S 1$ - S10) são verdadeiras, tendo sido consecutivamente assinadas (usadas para treinamento), as próximas 10 assinaturas (S11 - S20) também são verdadeiras, mas foram registradas em intervalos de uma semana (simula situação real de uso). As 20 últimas assinaturas ( $S 21$ - S40) são falsas treinadas.

Essa base de dados também é divida em duas partes: Task1 e Task2. Ambas (Task1 e Task2) contêm informações sobre assinaturas de 40 usuários conforme descrito anteriormente. O que difere Task1 e Task2 são as informações armazenadas de cada assinatura. Task 1 contém quatro atributos para cada assinatura: coordenada $X$, coordenada $Y$, timestamp e informações do botão ${ }^{2}(1=$ caneta baixa, $0=$ caneta alta). Task2 armazena outros três atributos adicionais: azimute (rotação da caneta), altitude e pressão da caneta. Tanto as informações de Task1 quanto Task2 são armazenadas em arquivos texto nomeados como UXSY.TXT, onde $X$ corresponde ao identificador do usuário (de 1 a 40) e $Y$ ao da assinatura (de 1 a 40). As informações desse conjunto de dados foram digitalizadas utilizando um tablet WACOM Intous. Os dados foram capturados a uma taxa de amostragem de 10 milissegundos.

A Task 1 foi utilizada como base de dados para os experimentos realizados neste trabalho. Nas seções seguintes são apresentadas, em detalhes, cada uma das etapas da metodologia proposta, utilizando como exemplo, os dados sobre assinaturas de usuários.

Seguindo as etapas da metodologia, são detalhadas as representações dos dados (Seção 4.3.1), a classificação dos dados e representação do comportamento de usuário utilizando cadeias de Markov (Seção 4.3.2), a medida da variação de energia (Seção 4.3.3) e por último a comparação das curvas que representam perfis de usuários (Seção 4.3.4).

\footnotetext{
${ }^{1}$ http://www.cse.ust.hk/svc2004/

${ }^{2}$ Indica se a caneta está ou não em contato com o tablet.
} 


\subsubsection{Etapa 1 - Distribuição dos dados}

Na primeira etapa, os dados de interação de usuários são analisados e representados por diversas distribuições de dados. No caso da base de dados Task1, são disponíveis informações sobre as coordenadas de pontos e o timestamp das assinaturas. Para melhor representar tais dados, foram criadas diferentes distribuições de dados, a fim de avaliar qual, ou quais, melhor representam o comportamento de assinaturas (Seção 5.2). Na Figura 4.1 é apresentada um exemplo de algumas distribuições geradas.

Um exemplo do desenho da assinatura verdadeira do usuário 1, armazenado no banco de dados, é apresentado na Figura 4.1(a). A distribuição 1 (DD1 - Figura 4.1(b)) foi gerada calculando as diferenças entre as coordenadas $X$ e $Y$ em cada momento de amostragem capturado pelo tablet durante a assinatura do usuário. Na Figura 4.1(c) é representada uma distribuição $(D D 2)$ que foi gerada calculando o tempo gasto em cada ponto grafado na assinatura. Na Figura 4.1(d) (DD3) tem-se a freqüência de cada ponto da assinatura, isto é, um rótulo é definido para cada ponto distinto da assinatura, quando um ponto se repetir, ele recebe o mesmo rótulo. As distribuições 4 e 5 (DD4 - Figuras 4.1(e) e DD5 - 4.1(f), respectivamente) foram geradas calculando a derivada entre pontos da assinatura, mas, na distribuição 5, essa derivada é dividida pelo tempo. Nas Figuras $4.1(\mathrm{~g})$ e 4.1(h) são apresentadas, respectivamente, as distribuições 6 (DD6) e $7(D D 7)$. A primeira representa as distâncias entre os pontos da assinatura. A segunda divide essa distância pelo tempo (velocidade da assinatura).

A importância de se criar diversas distribuições de dados para representar a interação de usuários é observada na Seção 5.2, onde são apresentados resultados experimentais. Durante os experimentos observou-se que, para cada usuário, existe uma distribuição que melhor representa seu comportamento de interação.

\subsubsection{Etapa 2 - Classificação e representação com cadeias de Markov}

Nesta etapa, as distribuições dos dados de interação de usuários (Etapa 1), são classificadas por meio de uma rede neural artificial e o comportamento de usuários é representado por cadeias de Markov (Seção 3.2.1).

Os experimentos consideraram a rede neural SONDE $^{3}$ (Seção 3.3.2). Essa rede classifica dados e gera, automaticamente, cadeias de Markov e curvas de variação de energia. Para isso, a SONDE classifica, em um mesmo cluster, padrões de entrada similares e, em novos clusters, padrões distintos ao modelo de conhecimento adquirido. A Figura 4.2 ilustra como os padrões de entrada de uma série temporal são classificados.

A cada instante de tempo, o usuário possui um comportamento. Por esse motivo,

\footnotetext{
${ }^{3} \mathrm{Na}$ realização dos experimentos, foram adotados os parâmetros de $\gamma=0,00, \Omega=0,00$ e $\alpha=0,90$.
} 


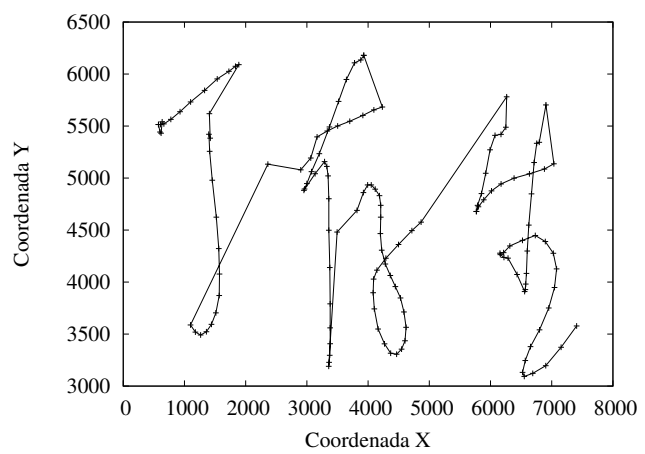

(a) Assinatura

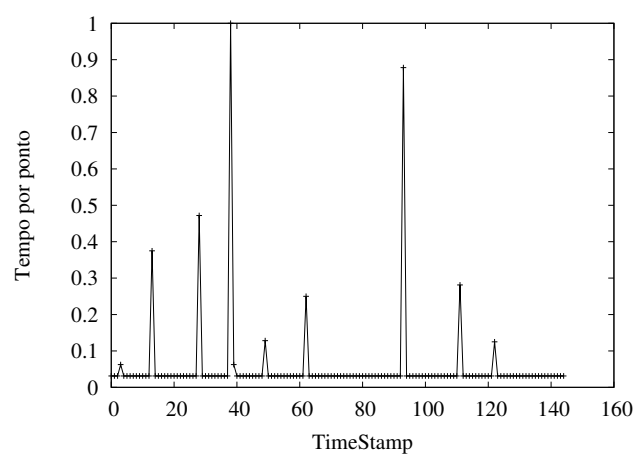

(c) DD2 - tempo por ponto

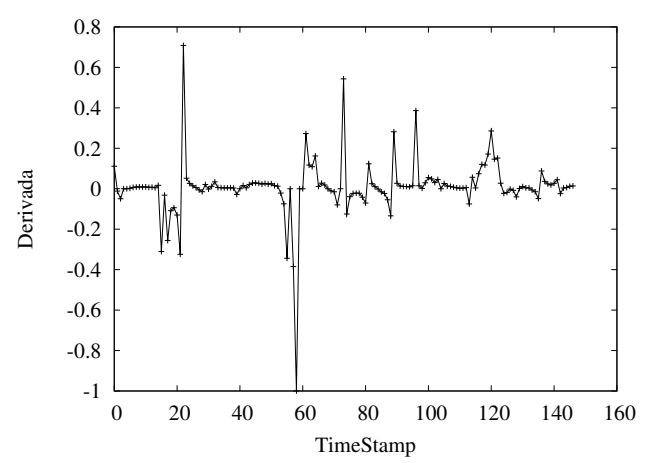

(e) DD4 - derivada entre as coordenadas da amostragem

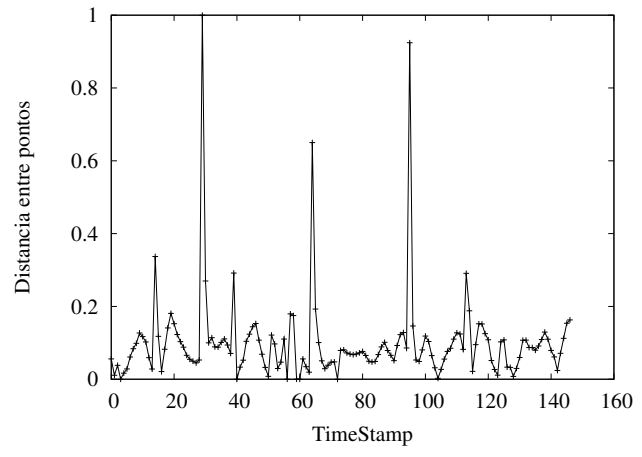

(g) DD6 - distância entre os pontos

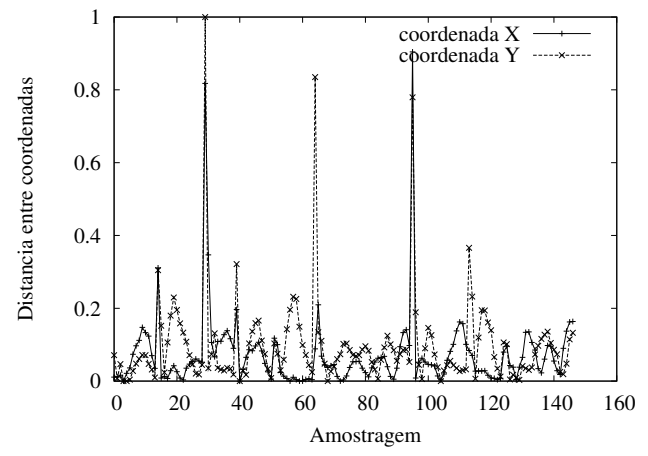

(b) DD1 - diferença entre as coordenadas da amostragem

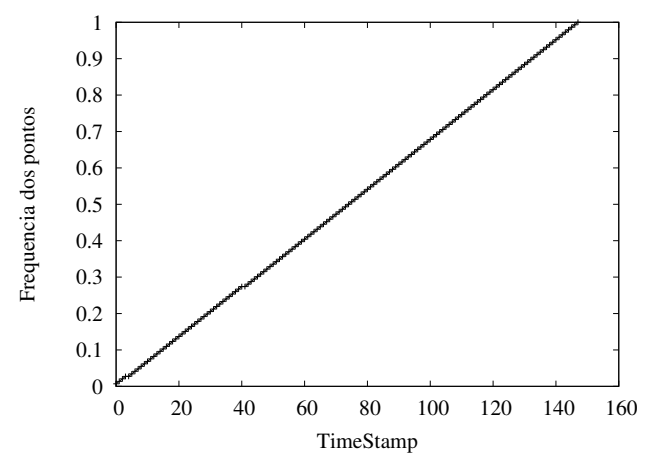

(d) DD3 - frequiência dos pontos

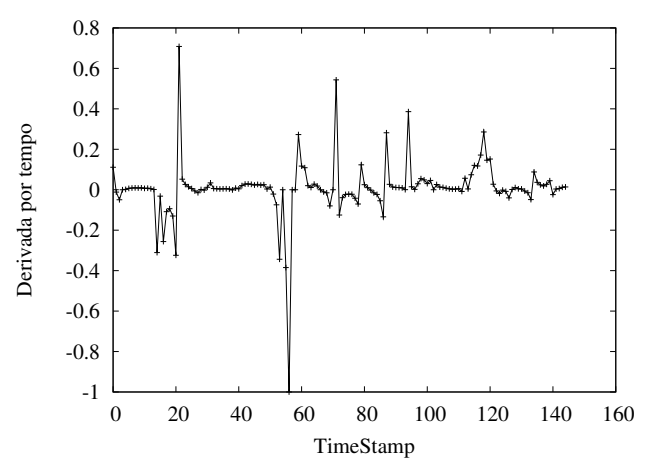

(f) DD5 - derivada entre os pontos por tempo

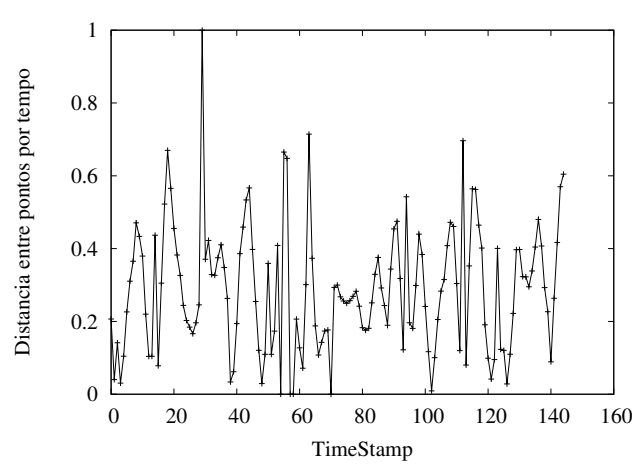

(h) DD7 - distância por tempo (velocidade)

Figura 4.1: Exemplo de distribuições de dados geradas a partir dos dados sobre assinaturas de usuários armazenados na base de dados do SVC2004.

a cada instante de tempo, o comportamento do usuário é representado por uma cadeia de Markov distinta. Cada estado da cadeia de Markov é representado por um cluster gerado 

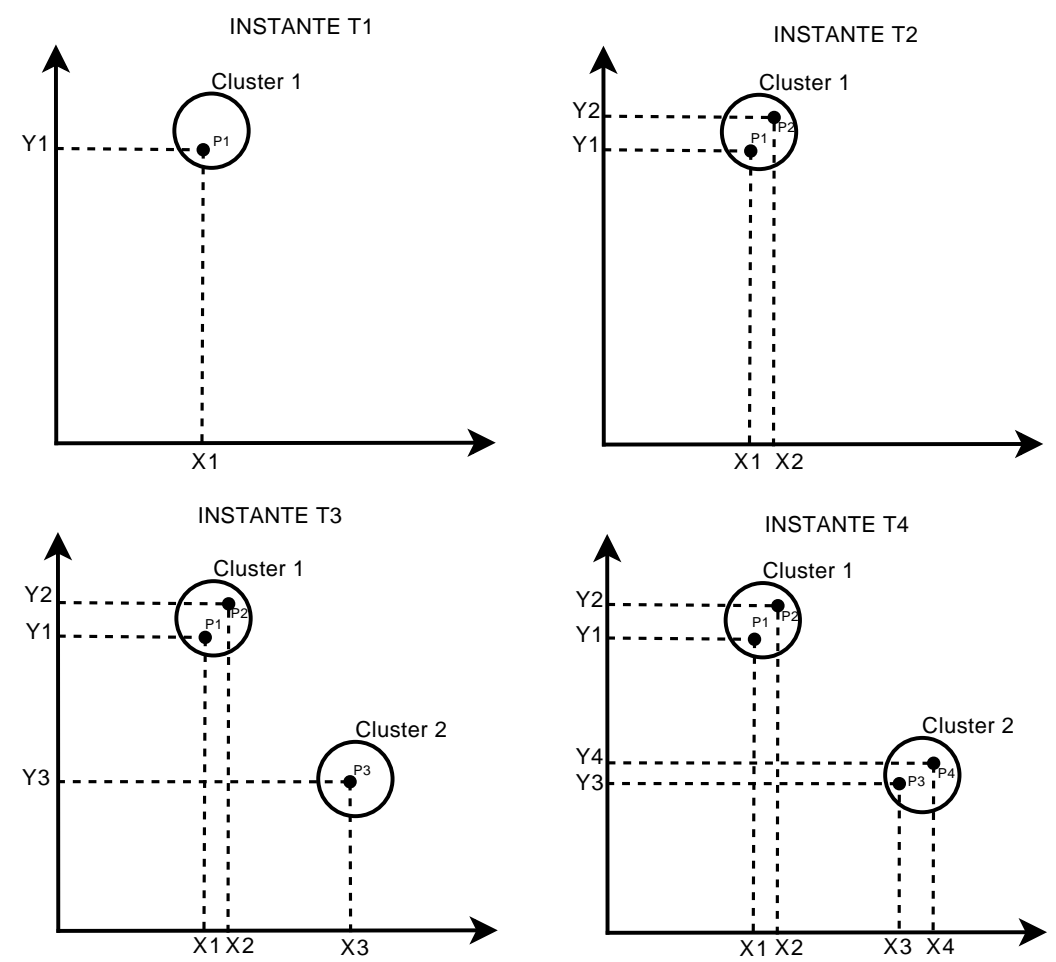

Figura 4.2: Exemplo de classificação de uma série temporal.

pela SONDE. Conforme a SONDE classifica os padrões de entrada, uma nova cadeia de Markov é gerada, representando o comportamento do usuário naquele instante de tempo.

Usando o mesmo exemplo apresentado na Figura 4.2, a Figura 4.3 apresenta as matrizes de transições e as cadeias de Markov em cada um dos instantes de tempo para determinada assinatura grafada. A matriz de transições é atualizada a cada nova classificação realizada pela SONDE, isto é, a matriz armazena a transição realizada DO estado $x$ PARA o estado $y$. Conforme o exemplo apresentado na Figura 4.3, no instante 1 foi classificado o primeiro padrão de entrada como Est_0, porém sem transições. No instante2, um segundo padrão também foi classificado como Est_0, mas neste caso, como é o segundo padrão de entrada, ocorre uma transição entre o primeiro e o segundo padrão, com isso, a matriz de transições é atualizada, indicando uma transição DO Est_0 PARA o Est_0. Seguindo tais passos, para cada novo padrão de entrada, a matriz de transições é atualizada.

Após classificar, identificar as probabilidades de transição entre estados (matriz de transições) e representar o comportamento de usuários em cada instante de tempo por meio de cadeias de Markov, tem-se um conjunto de cadeias as quais permitem apresentar variações de comportamento do usuário. A próxima etapa da metodologia consiste em calcular a variação de energia (entropia) entre esses conjuntos de cadeias de Markov e, com isso, representar o perfil de usuário. 
INSTANTE 1

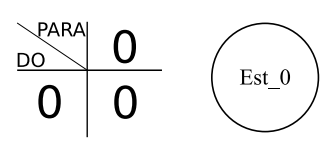

INSTANTE 3

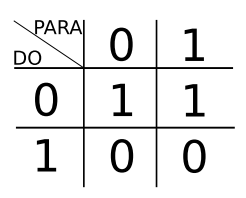

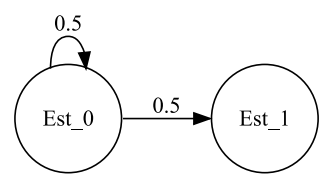

INSTANTE 2

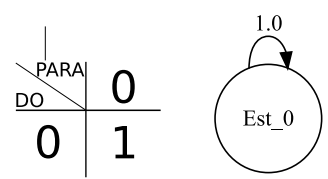

INSTANTE 4

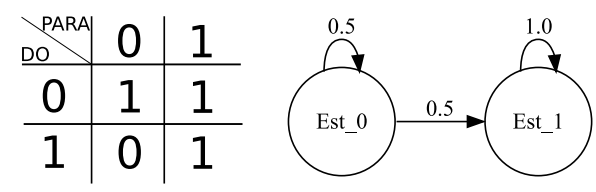

Figura 4.3: Exemplos de matriz de transições e cadeias de Markov representando o comportamento do usuário em cada instante de tempo.

\subsubsection{Etapa 3 - Medida de energia}

Depois de classificar as sete distribuições previamente apresentadas (distribuições geradas na Etapa 1), tem-se um conjunto de cadeias de Markov para cada uma das distribuições de dados. Em seguida realiza-se a medição da variação de energia entre cadeias de Markov de uma distribuição utilizando entropia (Seção 3.2.2).

Portanto, para cada distribuição de dados sobre a assinatura de usuários é gerada uma curva de variação de energia entre cadeias de Markov, o qual representa as alterações comportamentais do usuário. Na Figura 4.4 são representados exemplos de curvas de variação de energia (perfil do usuário) para cada distribuição criada ( $D D 1, D D 2, D D 3$, $D D 4, D D 5, D D 6$ e $D D 7)$.

Cada uma dessas curvas de variação de energia, apresentadas na Figura 4.4, representa o comportamento de uma assinatura de um usuário. Mais adiante será possível observar que cada usuário tem uma distribuição que melhor expressa seu comportamento durante a assinatura.

O próximo passo, depois de classificar e obter as curvas de variação de energia de cada umas das sete distribuições de dados sobre assinaturas de usuários, consiste em realizar comparações entre os perfis (curvas de entropia) de usuários em cada assinatura.

\subsubsection{Etapa 4 - Medida de similaridade}

Nessa etapa são realizadas comparações entre perfis de assinaturas de usuários a fim de diferenciar falsas de verdadeiras e, ao mesmo tempo, validar a eficiência da metodologia proposta nesta dissertação.

Para realizar a comparação das curvas de variação de energia, é necessária a aplicação de medidas de similaridade. Para obter tais medições foram utilizadas as técnicas 


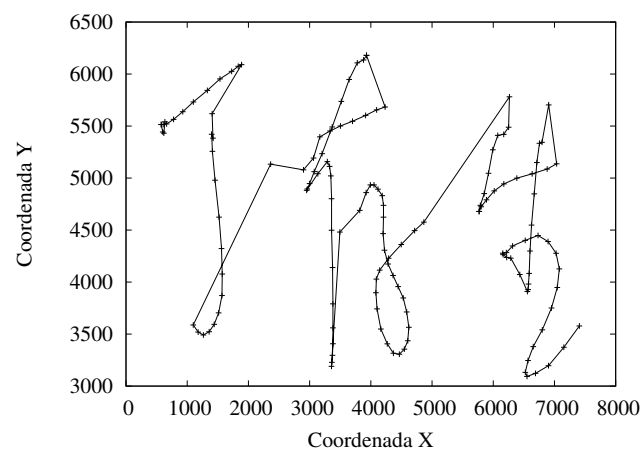

(a) Assinatura

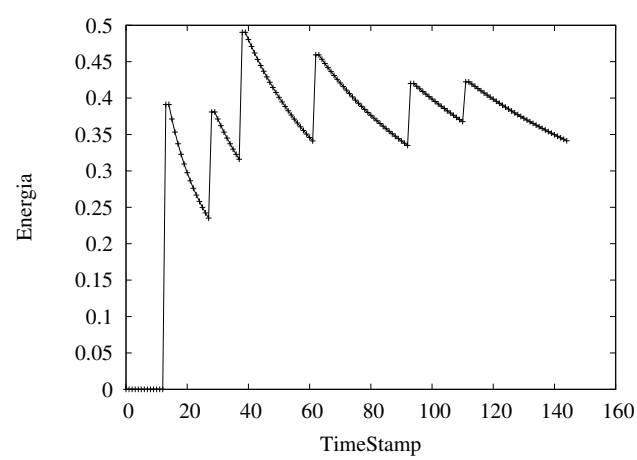

(c) DD2 - tempo por ponto

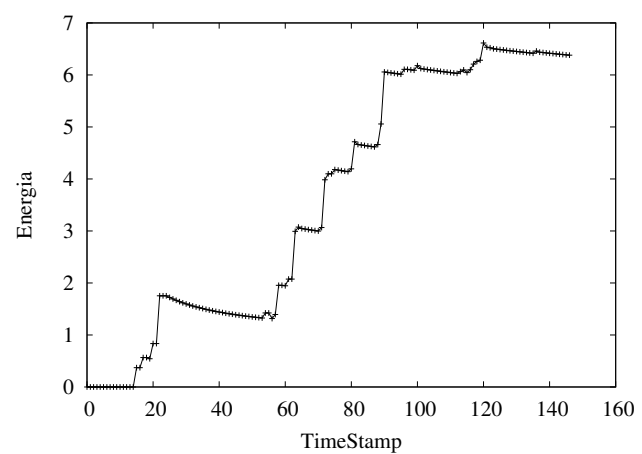

(e) DD4 - derivada entre as coordenadas da amostragem

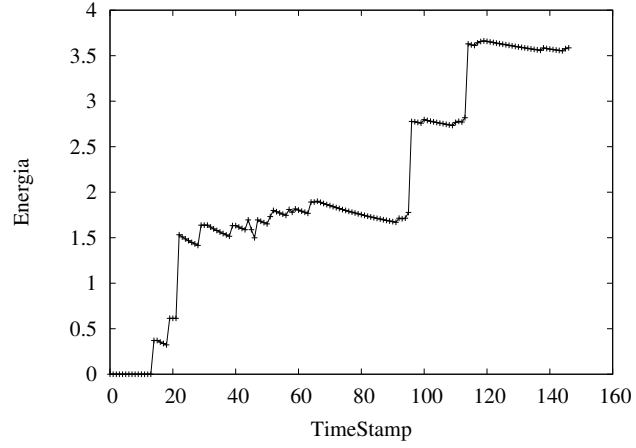

(g) DD6 - distância entre os pontos

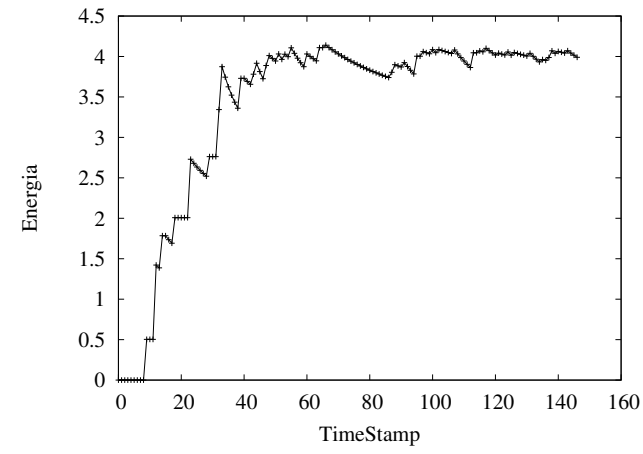

(b) DD1 - diferença entre as coordenadas da amostragem

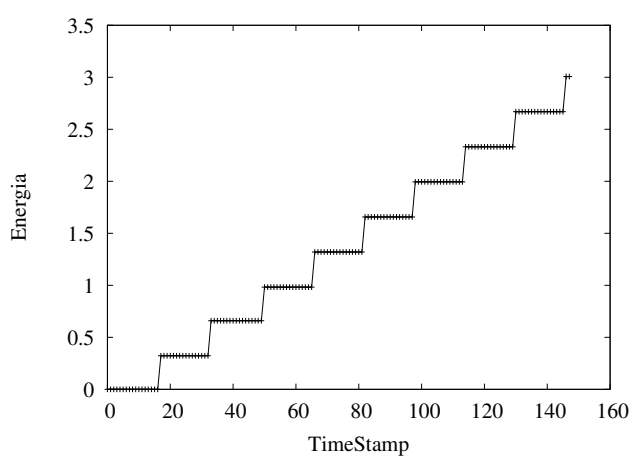

(d) DD3 - freqüência dos pontos

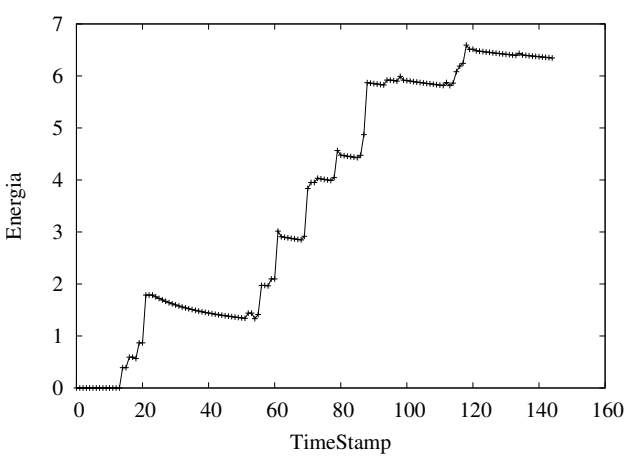

(f) DD5 - derivada entre os pontos por tempo

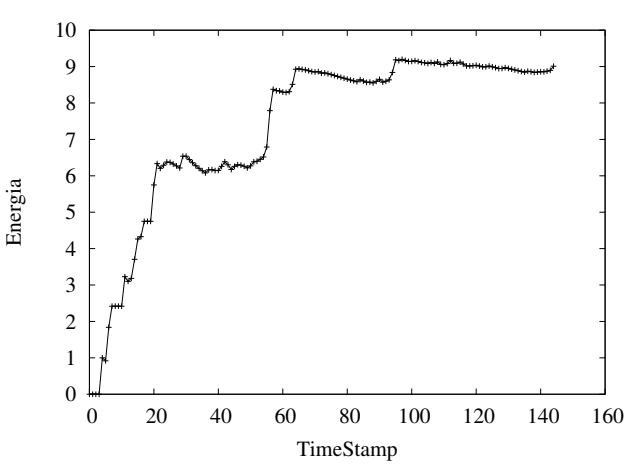

(h) DD7 - distância por tempo (velocidade)

Figura 4.4: Curvas que representam o perfil de comportamento de uma assinatura de usuário representados por sete diferentes distribuições.

DTW (Dynamic Time Warping - Seção 3.4.1) e CDM (Compression-based Dissimilarity Measure - Seção 3.4.2). 
A análise dos resultados obtidos nos experimentos foi feita comparando curvas de variação de energia de uma assinatura verdadeira com outra falsa (considerando o mesmo usuário e distribuição). O esperado é que as assinaturas verdadeiras de um mesmo usuário apresentem variações similares de energia. Na Figura 4.5 é demonstrada a diferença de comportamento existente entre assinaturas verdadeiras e falsas de um mesmo usuário em uma mesma distribuição de dados. Nesse cenário nota-se um alto grau de similaridade entre assinaturas verdadeiras (Figuras 4.5(a) e 4.5(b)) e baixo, em relação às assinaturas falsas (Figuras 4.5(c) e 4.5(d)). As assinaturas verdadeiras apresentam funções de distribuição, níveis de energia e timestamps parecidos. Por outro lado, as assinaturas falsas apresentam níveis de energia inferiores e maiores timestamps (aparentemente, necessita-se de tempo adicional para falsificar uma assinatura).

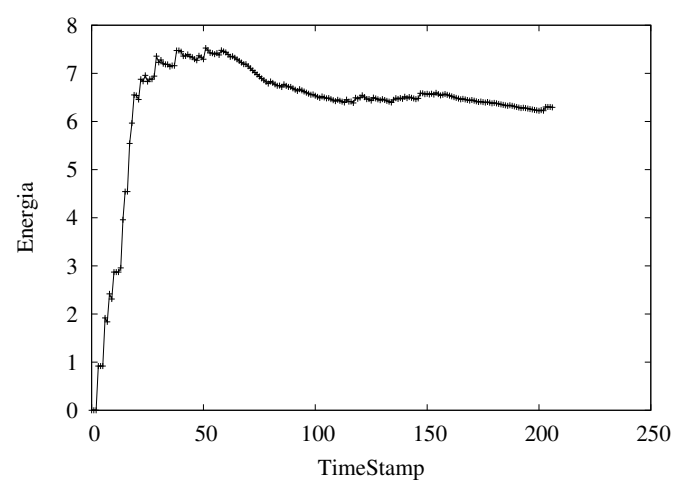

(a) Assinatura 1 - Verdadeira

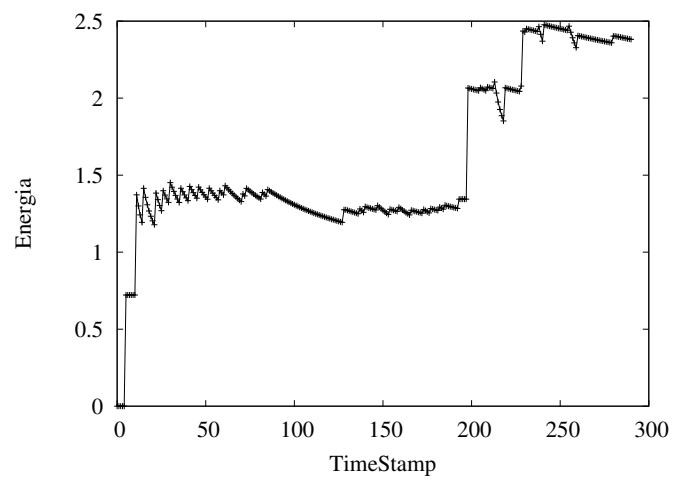

(c) Assinatura 21 - Falsa

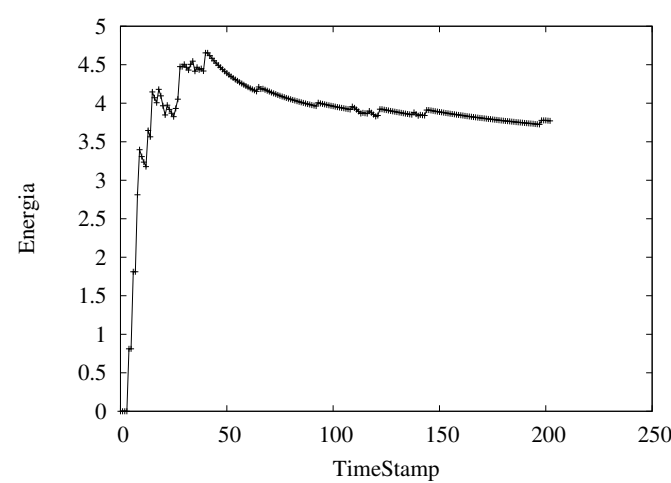

(b) Assinatura 2 - Verdadeira

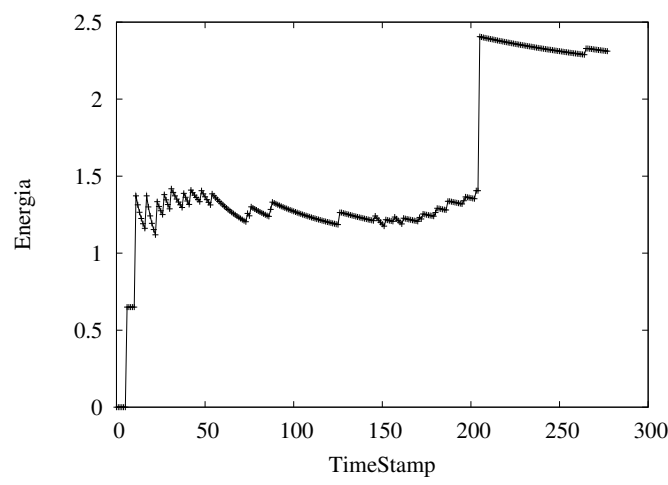

(d) Assinatura 22 - Falsa

Figura 4.5: Comparação de comportamento entre as assinaturas verdadeiras (1 e 2) e as assinaturas falsas (21 e 22) de um mesmo usuário.

No caso desse exemplo, não é difícil diferenciar, visualmente, um perfil de usuário falso de um verdadeiro. Mas para realizar essa comparação de uma maneira computacional, é necessário utilizar medidas de similaridade tais como DTW e CDM.

No próximo capítulo, são apresentados alguns resultados de experimentos comparando os comportamentos de usuários em assinaturas verdadeiras e falsas utilizando cada umas das sete distribuições de dados geradas. Tais comparações são conduzidas adotando-se duas técnicas de similaridade (DTW e CDM). 


\subsection{Considerações Finais}

Foram apresentados neste capítulo os objetivos e a metodologia proposta no trabalho. Tal metodologia foi apresentada ilustrando uma aplicação prática de reconhecimento de assinaturas digitalmente grafadas.

No próximo capítulo são apresentados resultados de experimentos realizados com assinaturas de usuários, realizando comparações com dados de outros trabalhos submetidos no SVC2004, e resultados extras de experimentos realizados em uma outra aplicação. Esses experimentos adicionais foram realizados, no início deste trabalho de mestrado, com o intuito de verificar a viabilidade das técnicas adotadas. 


\subsection{Considerações Iniciais}

Neste capítulo são apresentados os resultados dos experimentos realizados sobre reconhecimento de assinaturas por meio da análise de comportamento de usuários. Além disso, são apresentados resultados de experimentos realizados no início do desenvolvimento deste trabalho de mestrado.

\subsection{Resultados de Experimentos sobre Assinaturas de Usuários}

Uma série de experimentos foram realizados tomando como base as mesmas regras utilizadas no SVC2004. Conforme as regras desse campeonato, para cada usuário são realizados 10 testes utilizando, aleatoriamente, 5 assinaturas verdadeiras dentre as 10 primeiras assinaturas de treinamento $(S 1-S 10)$ da base de dados. Em cada teste, resultados de treinamento são comparados com as assinaturas verdadeiras, grafadas em intervalos de uma semana (S11 - S20), 20 assinaturas falsas treinadas (S21 - S40), e com 20 assinaturas falsas aleatoriamente escolhidas (dentre assinaturas verdadeiras de outros usuários). Sendo assim, cada usuário é testado 10 vezes, comparando sua assinatura de treinamento com outras 10 verdadeiras e 40 falsas, resultando em 50 comparações para cada teste.

A Figura 5.1 apresenta os resultados de similaridade obtidos empregando a medida DTW utilizando as sete distribuições de dados descritas na Seção 4.3.1. Nessa figura são representados, em cada distribuição, a média do somatório de erro e o intervalo de confi- 
ança $^{1}$ de 50 assinaturas, sendo as 10 primeiras verdadeiras, as 20 consecutivas (entre 11 e 30) falsas e as 20 últimas compostas por assinaturas de outros usuários (aleatoriamente escolhidas). Vale ressaltar que, para esse experimento em específico, foi utilizado escala logarítmica para uma melhor representação dos dados. Nota-se por meio desses experimentos, que as Figuras 5.1(b), 5.1(c) e 5.1(d) apresentam médias de erro entre assinaturas verdadeiras (1 a 10) inferiores às obtidas com assinaturas falsas (11 a 50). Isso demonstra que é possível diferenciar assinaturas verdadeiras de falsas segundo a metodologia proposta. Contudo, nas Figuras 5.1(e), 5.1(f), 5.1(g) e 5.1(h) não é possível diferenciar assinaturas verdadeiras, o que confirma que as distribuições 4, 5, 6 e 7 não representam, de maneira satisfatória, as características de comportamento desse usuário. Outra característica interessante observada é que as assinaturas verdadeiras de outros usuários (31 - 50), comparadas com a assinatura do usuário atual, apresentam erros médios mais elevados em relação às falsas treinadas do mesmo usuário (11 - 30).

Da mesma forma que a DTW, a medida de similaridade CDM também foi utilizada nos experimentos. A Figura 5.2 ilustra os resultados dos experimentos utilizando a medida CDM sobre o mesmo conjunto de dados da Figura 5.1. Conforme observado, a CDM apresenta resultados similares à DTW para a situação em questão, sendo possível diferenciar assinaturas falsas (maiores índices de erro) de verdadeiras (menores índices de erro) de acordo com algumas distribuições, tais como as representadas pelas Figuras 5.2(b), 5.2(c) e 5.2(d). Da mesma forma que na DTW, na CDM as distribuições, mostradas nas Figuras 5.2(e), 5.2(f), 5.2(g) e 5.2(h), não representam, satisfatoriamente, o comportamento do usuário avaliado.

Os experimentos anteriormente apresentados foram realizados utilizando informações sobre a assinatura de um usuário (usuário 1 da base de dados Task1 do SVC2004). Os mesmos experimentos foram conduzidos para os demais 40 usuários da base de dados, utilizando as medidas de similaridade DTW e CDM para comparar perfis. Os resultados de todos os experimentos constam, respectivamente, nos Apêndices A e B.

Como a quantidade de informação gerada pelos experimentos é muito grande (sete distribuições por usuário em um total de 40 usuários, usando 2 medidas distintas de similaridade), a análise desses resultados torna-se complexa. Por esse motivo, uma técnica muito utilizada pela comunidade, denominada Receiver Operating Characteristic ou simplesmente curva ROC, foi utilizada para melhor avaliá-los.

A curva ROC permite estudar a variação da sensibilidade ${ }^{2}$ e especificidade ${ }^{3}$ para

\footnotetext{
${ }^{1}$ Intervalo de confiança de $95 \%$ - devido ao pequeno número de amostras, igual a 10 (número de testes em função do conjunto de dados considerado), adotou-se a distribuição de probabilidades t-student para caracterizar esse intervalo $\left(t_{0,025-10}=2,228\right)$.

${ }^{2}$ Consiste no número de Verdadeiro Positivo dividido pelo número de Verdadeiro Positivo mais o número de Falso Negativo, ou simplesmente a Taxa de Verdadeiro Positivo.

${ }^{3}$ Consiste no número de Verdadeiro Negativo dividido pelo número de Verdadeiro Negativo mais o número de Falso Positivo, simplesmente a Taxa de Verdadeiro Negativo ou 1 menos a Taxa de Falso Positivo.
} 


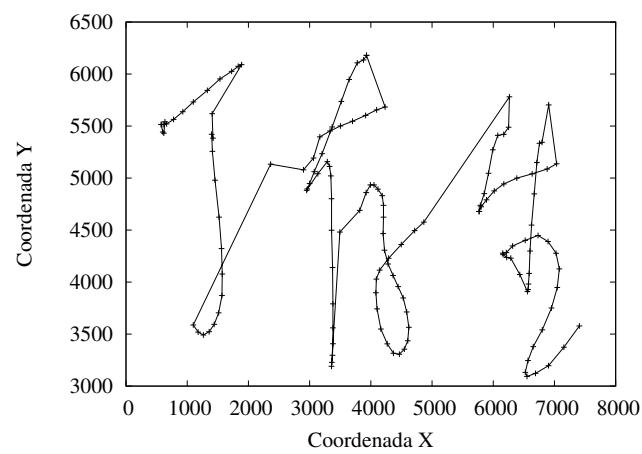

(a) Assinatura

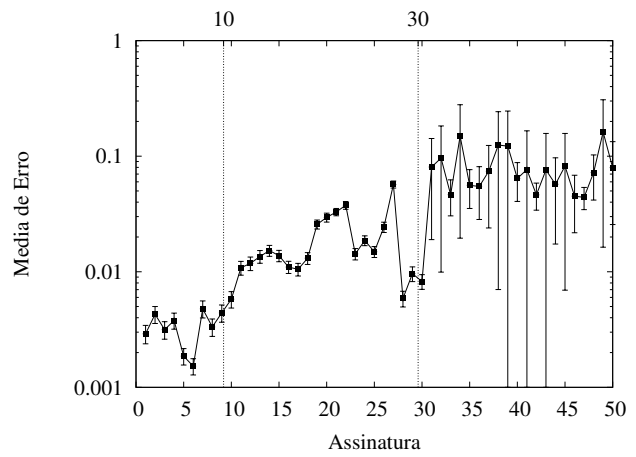

(c) DD2 - tempo por ponto

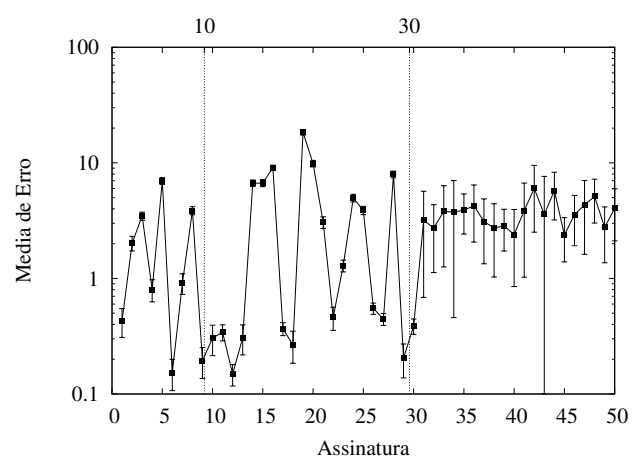

(e) DD4 - derivada entre as coordenadas da amostragem

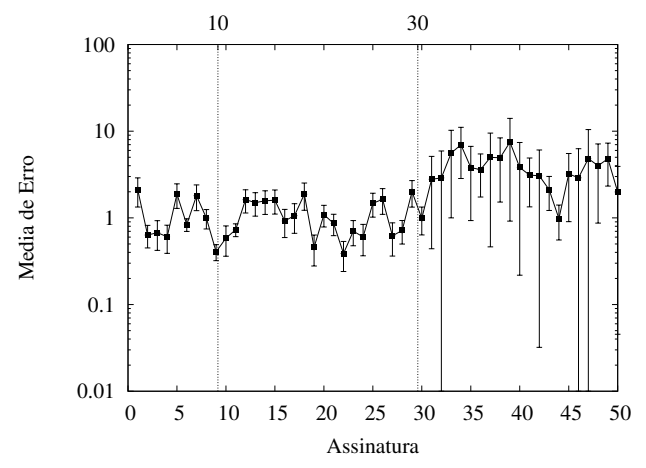

(g) DD6 - distância entre os pontos

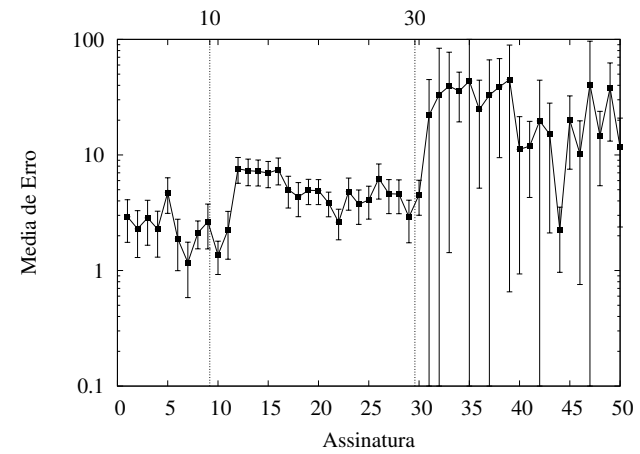

(b) DD1 - diferença entre as coordenadas da amostragem

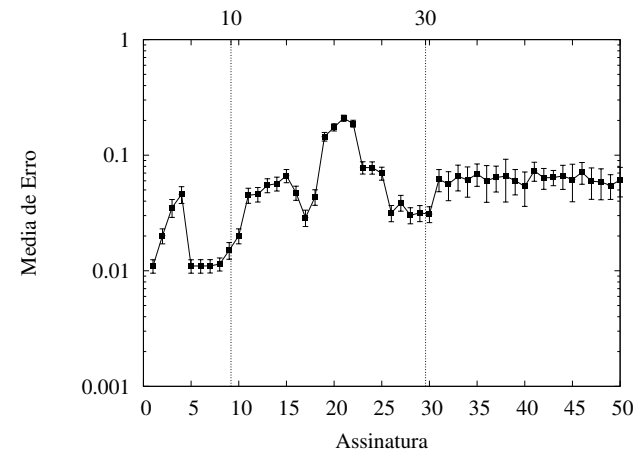

(d) DD3 - freqüência dos pontos

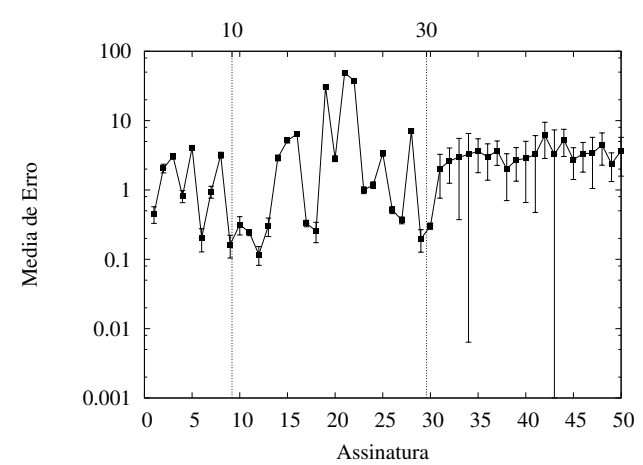

(f) DD5 - derivada entre os pontos por tempo

\begin{abstract}
5.1: Sã
\end{abstract}
Figura 5.1: São apresentados a média do somatório de erro e o intervalo de confiança obtidos pela comparação do treinamento das primeiras 10 assinaturas verdadeiras com as demais 40 (20 falsas treinadas e 20 de outros usuários) utilizando a medida de similaridade DTW. 


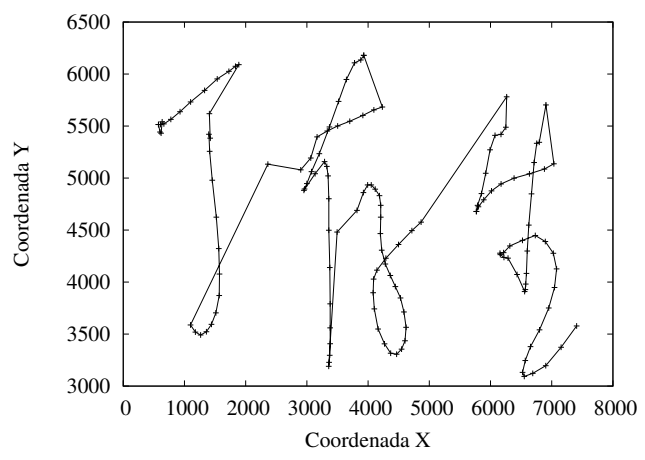

(a) Assinatura

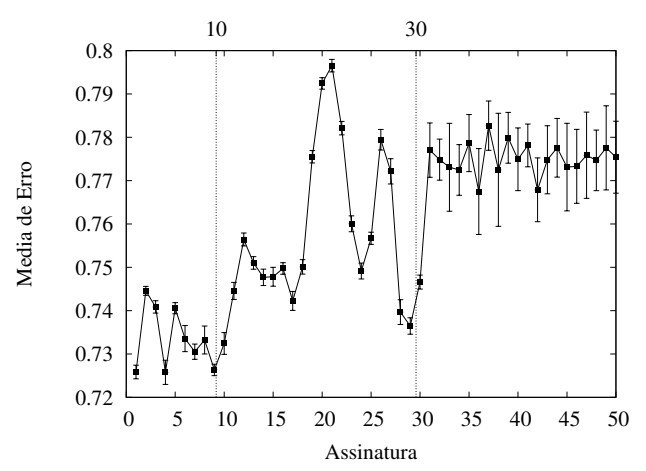

(c) DD2 - tempo por ponto

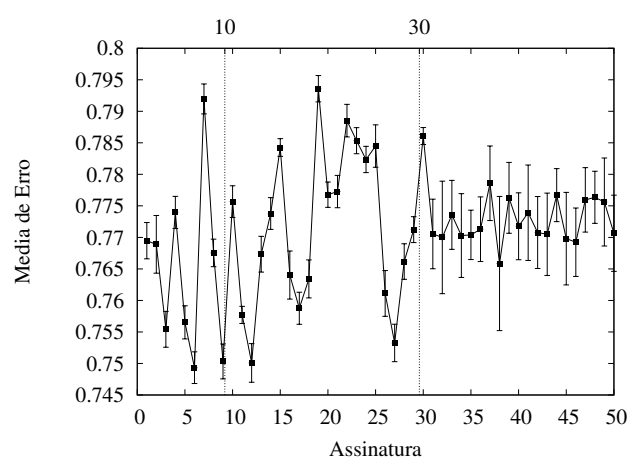

(e) DD4 - derivada entre as coordenadas da (f) DD5 - derivada entre os pontos por tempo amostragem

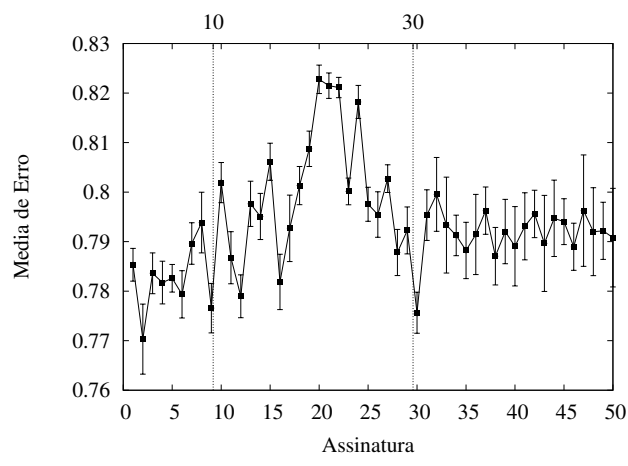

(g) DD6 - distância entre os pontos

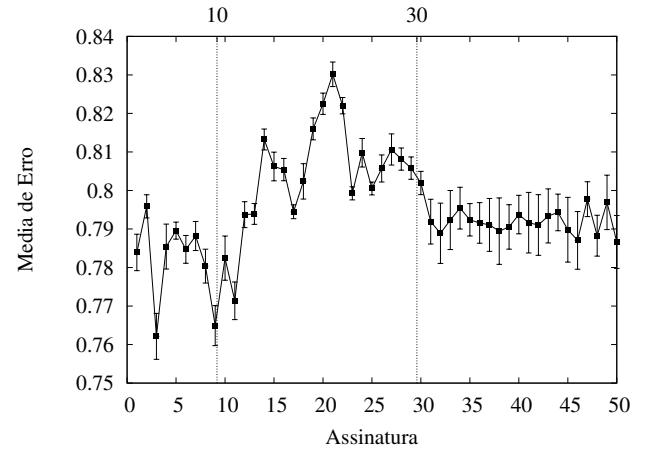

(b) DD1 - diferença entre as coordenadas da amostragem

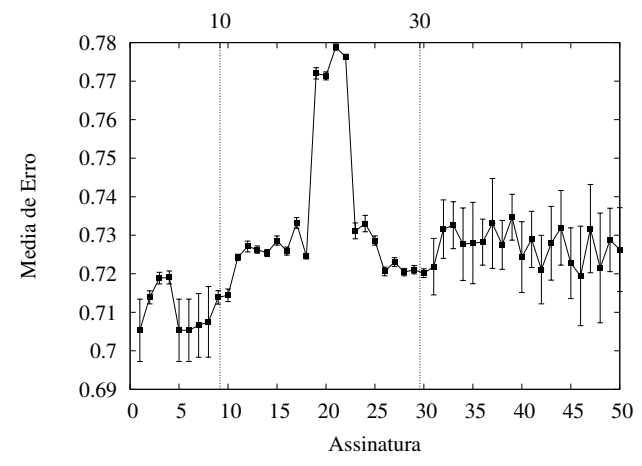

(d) DD3 - freqüência dos pontos

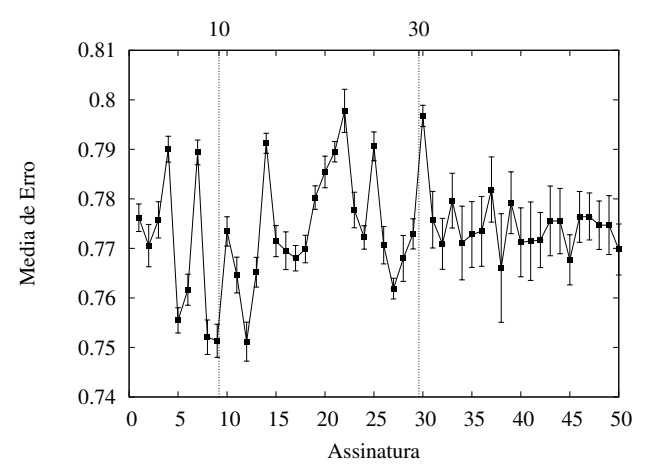

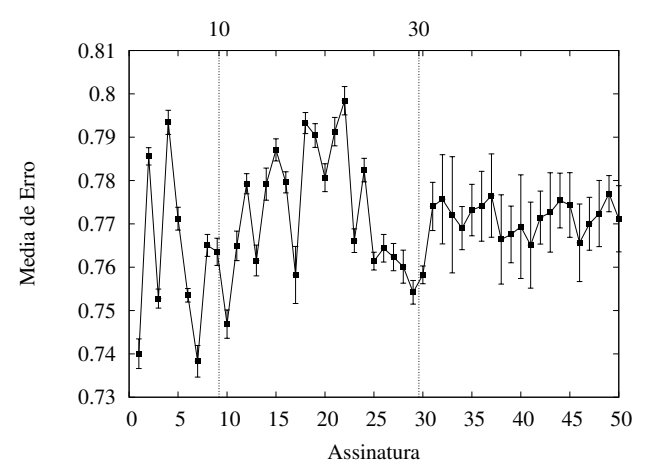

(h) DD7 - distância por tempo (velocidade)

Figura 5.2: São apresentados a média do somatório de erro e o intervalo de confiança obtidos pela comparação do treinamento das primeiras 10 assinaturas verdadeiras com as demais 40 (20 falsas treinadas e 20 de outros usuários) utilizando a medida de similaridade CDM. 
diferentes valores de corte. No contexto desses experimentos, os Falsos Positivos são representado pelas assinaturas falsas identificadas como verdadeiras e, os Verdadeiros Positivos, são as assinaturas verdadeiras identificadas corretamente. Uma curva ideal é aquela que mais se aproxima da extremidade superior esquerda da curva, isto é, quanto maior forem os valores de verdadeiro positivo e menor de falso positivo.

Para cada curva de erro gerada utilizando dados experimentais (Apêndices A e B), foram percorridos todos os valores de erro ao longo do eixo $Y$ (Medida de Erro) e, para cada valor de erro (valor de corte), foram calculadas as taxas de falso positivo e verdadeiro positivo. Os resultados do campeonato SVC2004 apresentam curvas ROC comparando as assinaturas verdadeiras às falsas treinadas, comparando os erros resultados. Em uma segunda etapa, esse campeonato gera curvas ROC comparando as mesmas assinaturas verdadeiras às 20 aleatoriamente escolhidas de outros usuários. Esse mesmo processo é realizado neste trabalho (maiores detalhes na Seção 5.3). Assim, para cada distribuição, de cada usuário, tem-se duas curvas da taxa de verdadeiro positivo pela taxa de falso positivo conforme a variação de um valor de corte (curva ROC).

A partir da curva ROC é possível visualizar todas as relações entre taxas de verdadeiro e falso positivo de uma distribuição de dados de interação de um usuário. As Figuras 5.3 e 5.4 resumem, respectivamente, todos os resultados experimentais contendo as comparações de assinaturas verdadeiras às falsas treinadas e às de outros usuários, utilizando a medida de similaridade DTW. Essas figuras apresentam resultados em termos de curvas ROC para as sete distribuições de dados de cada usuário, além de curvas ROC resumo contendo as médias, medianas, primeiro e segundo quartis, intervalos de confiança e outliers, ou seja, valores extremos (para isso utiliza-se a representação de Box-Plot).

Da mesma forma que na DTW, também foram geradas curvas ROC para resumir os experimentos realizados utilizando a medida de similaridade CDM, as quais são apresentadas nas Figuras 5.5 e 5.6.

Analisando as curvas ROC, tanto obtidas aplicando a técnica DTW quanto a CDM, observa-se que, para assinaturas falsas treinadas, a distribuição DD3 apresentou os melhores resultados de identificação de perfis (maior quantidade de verdadeiro positivo e menor de falso positivo). Ao analisar as curvas ROC que resumem a comparação de assinaturas verdadeiras às de outros usuários, observa-se que, empregando a técnica DTW, obtém-se melhores resultados com a distribuição DD1 e, empregando CDM, com a distribuição DD2. Uma estatística mostrando o percentual das melhores distribuições para cada usuário, utilizando ambas medidas de similaridade, pode ser observada na Tabela 5.1 .

Contudo, isso não significa que exista, somente, uma melhor representação para todos usuários avaliados. Conforme mencionado na Seção 4.3.1, cada usuário possui uma distribuição que melhor representa sua interação e, conseqüentemente, seu comporta- 


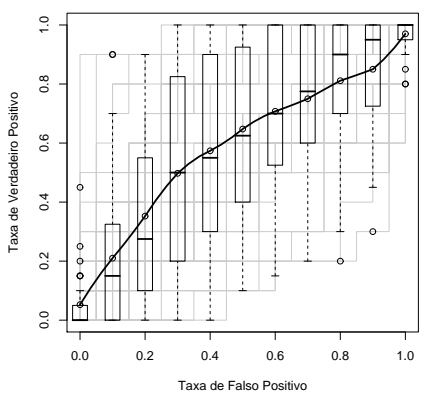

(a) DD1 - diferença entre as coordenadas da amostragem

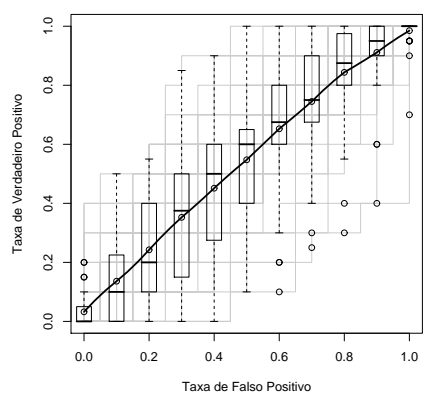

(d) DD4 - derivada entre as coordenadas da amostragem

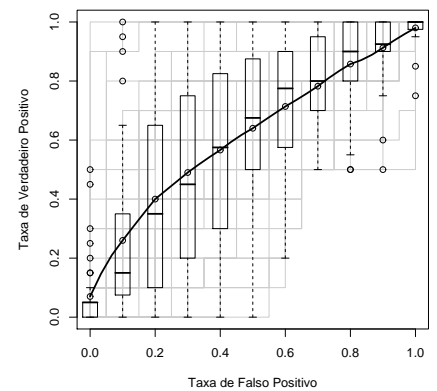

(b) DD2 - tempo por ponto

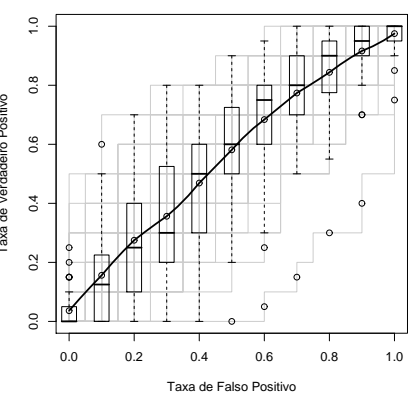

(e) DD5 - derivada entre os pontos por tempo

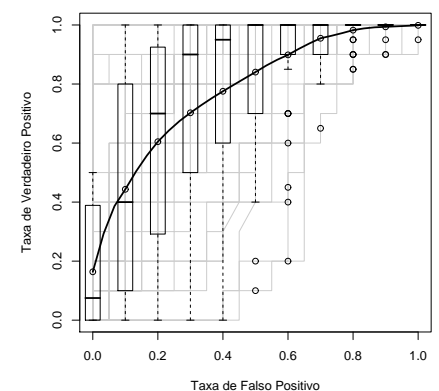

(c) DD3 - freqüência dos pontos

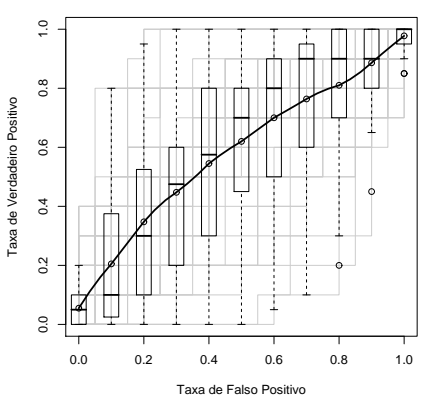

(f) DD6 - distância entre os pontos

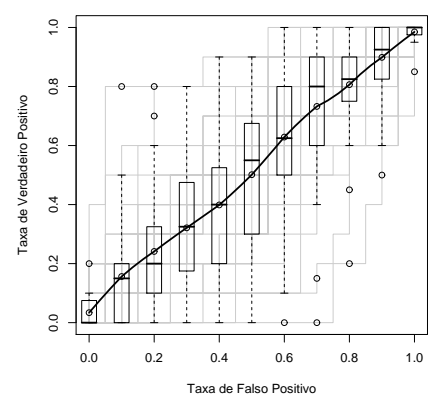

(g) DD7 - distância por tempo (velocidade)

Figura 5.3: Média das curvas ROC para cada distribuição dos 40 usuários utilizando a DTW como medida de similaridade, considerando a comparação de assinaturas verdadeiras às falsas treinadas.

mento. Para comprovar esse conceito foram geradas quatro curvas ROC, duas contendo resultados de comparação de assinaturas verdadeiras às falsas treinadas, mais duas contendo comparações com as de outros usuários. Essas curvas (Figura 5.7) apresentam resultados para ambas técnicas de similaridade, média, mediana, quartis e outliers que sumarizam resultados para cada um dos 40 usuários considerando suas melhores distribuições.

Conforme esperado, os resultados apresentados nas Figuras 5.7(a), 5.7(b), 5.7(c) e 5.7(d) são melhores do que a melhor distribuição apresentada nas Figuras 5.3, 5.5, 5.4 


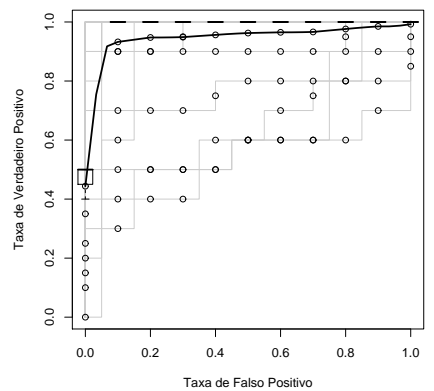

(a) DD1 - diferença entre as coordenadas da amostragem

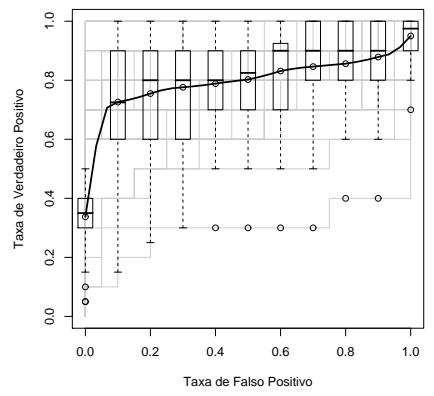

(d) DD4 - derivada entre as coordenadas da amostragem

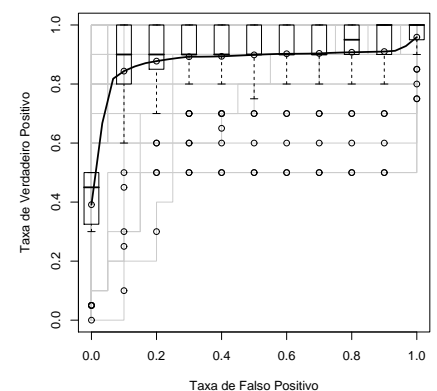

(b) DD2 - tempo por ponto

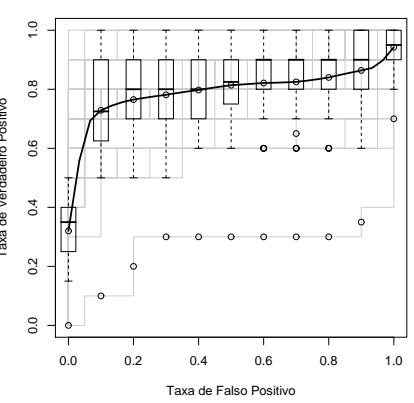

(e) DD5 - derivada entre os pontos por tempo

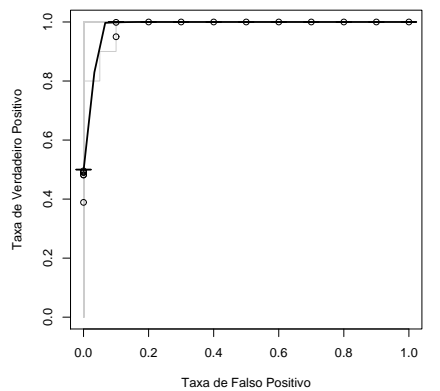

(c) DD3 - freqüência dos pontos

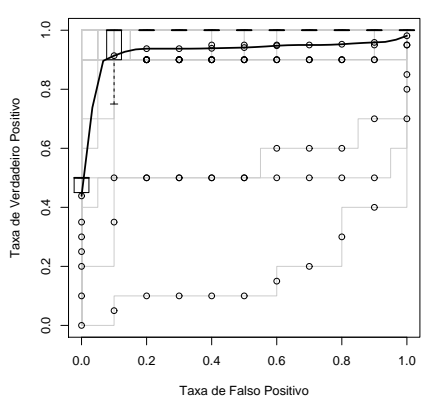

(f) DD6 - distância entre os pontos

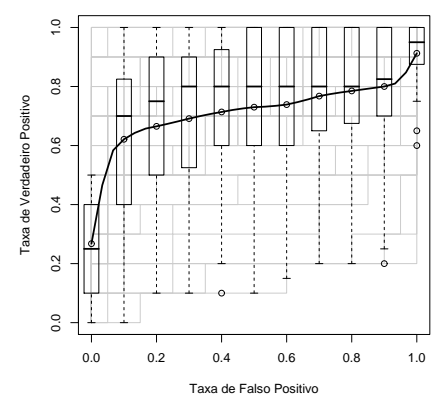

(g) DD7 - distância por tempo (velocidade)

Figura 5.4: Média das curvas ROC de cada distribuição dos 40 usuários utilizando a DTW como medida de similaridade, considerando a comparação de assinaturas verdadeiras às de outros usuários.

e 5.6, respectivamente. Esse resultado reafirma a idéia de que cada usuário possui uma distribuição que melhor descreve seu comportamento, conforme pode ser observado na Figura 5.7, onde são apresentadas as médias das curvas ROC das melhores distribuições em cada um dos experimentos realizados.

Outro fator que foi observado com os resultados apresentados pelas curvas ROC é o fato de uma das medidas de similaridade, assim como as distribuições, melhor caracterizar o comportamento de derterminados usuários. Os experimentos comparando assinaturas verdadeiras às falsas treinadas apresentaram melhores resultados com a medida de simi- 


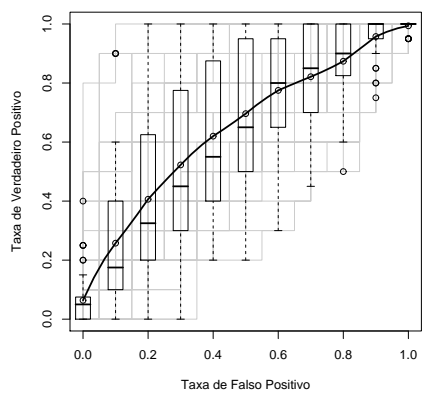

(a) DD1 - diferença entre as coordenadas da amostragem

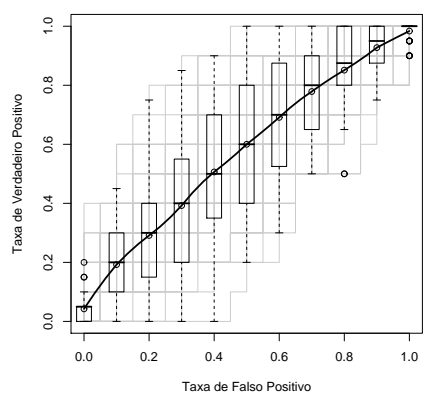

(d) DD4 - derivada entre as coordenadas da amostragem

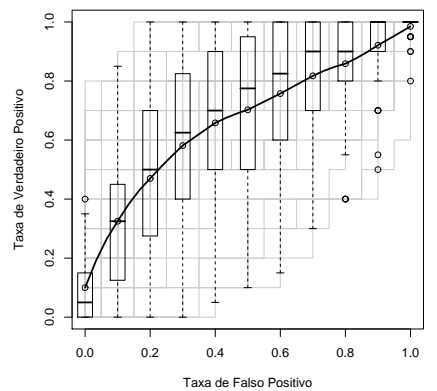

(b) DD2 - tempo por ponto

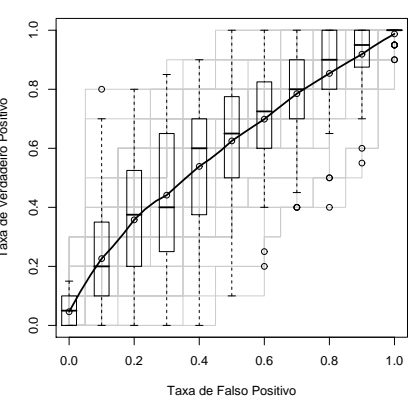

(e) DD5 - derivada entre os pontos por tempo

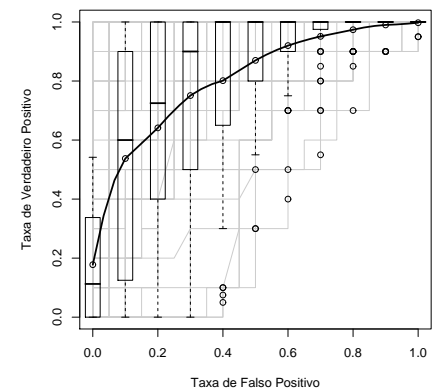

(c) DD3 - freqüência dos pontos

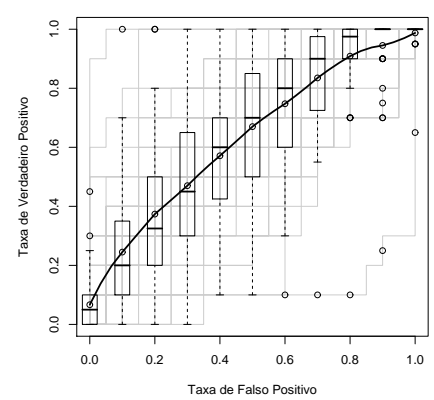

(f) DD6 - distância entre os pontos

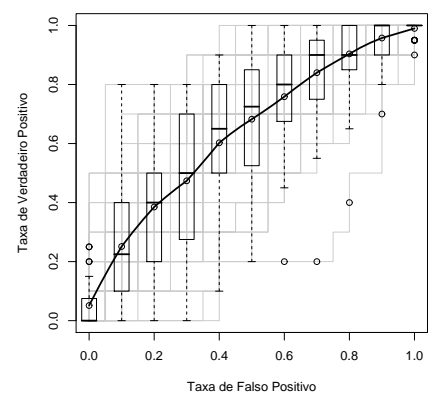

(g) DD7 - distância por tempo (velocidade)

Figura 5.5: Média das curvas ROC de cada distribuição dos 40 usuários utilizando a CDM como medida de similaridade, considerando a comparação de assinaturas verdadeiras às falsas treinadas.

laridade CDM, conforme pode ser observado nas Figuras 5.5 e 5.3 respectivamente. Nos experimentos comparando assinaturas verdadeiras às de outros usuários, a medida de similaridade DTW gerou melhores resultados, respectivamente apresentados nas Figuras 5.4 e 5.6. Assim como para as distribuições, a medida de similaridade também não pode ser generalizada para todos os usuários. 


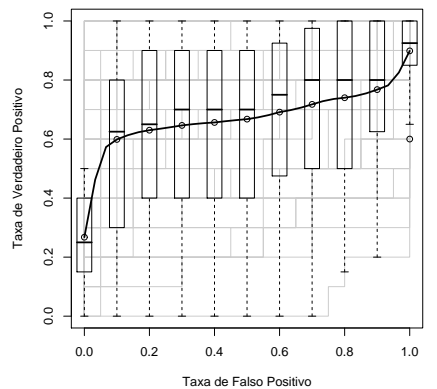

(a) DD1 - diferença entre as coordenadas da amostragem

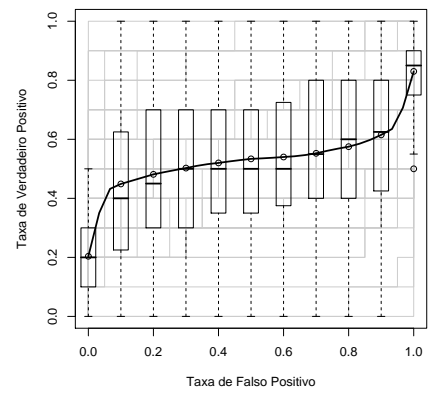

(d) DD4 - derivada entre as coordenadas da amostragem

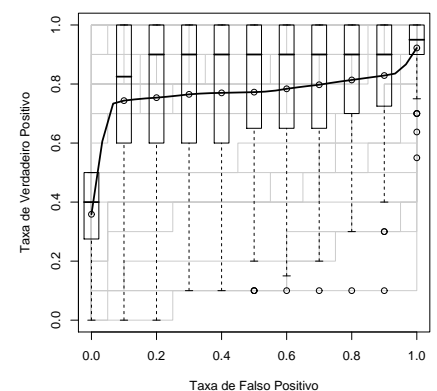

(b) DD2 - tempo por ponto

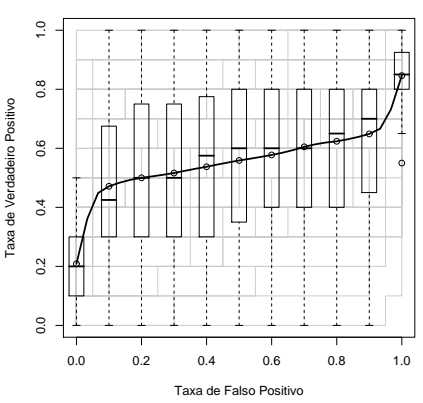

(e) DD5 - derivada entre os pontos por tempo

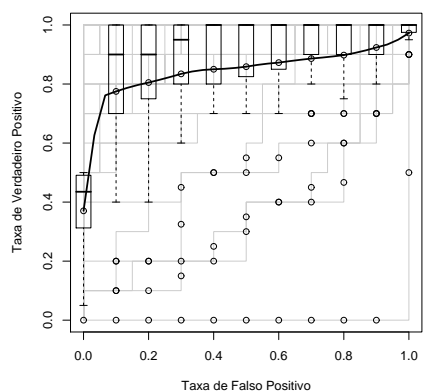

(c) DD3 - freqüência dos pontos

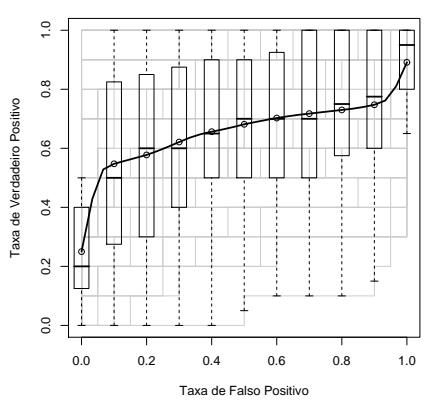

(f) DD6 - distância entre os pontos

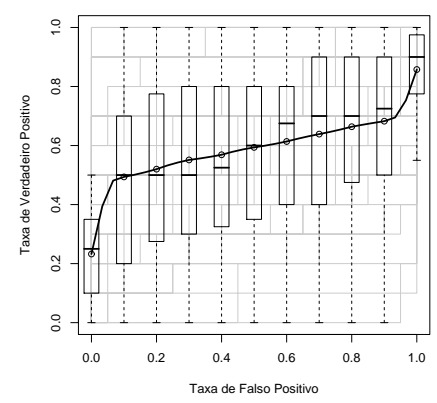

(g) DD7 - distância por tempo (velocidade)

Figura 5.6: Média das curvas ROC de cada distribuição dos 40 usuários utilizando a CDM como medida de similaridade, considerando a comparação de assinaturas verdadeiras às de outros usuários.

\subsection{Avaliação dos resultados dos experimentos reali- zados}

Esta seção compara os resultados obtidos neste trabalho de mestrado aos apresentados no SVC2004, utilizando a medida Equal Error Rate (EER), adotada em tal campeonato. O EER representa o menor índice de falso positivo e falso negativo para um mesmo valor de corte (threshold). A Figura 5.8 mostra as taxas de falso positivo e negativo conforme a variação do valor de corte. Nota-se nessa figura, que obtém-se melho- 
Tabela 5.1: Tabela contendo a porcentagem das melhores distribuições para os experimentos realizados.

\begin{tabular}{|c||c|c||c|c|}
\hline \multirow{2}{*}{ Dist. } & \multicolumn{2}{c||}{ DTW } & \multicolumn{2}{c|}{ CDM } \\
\cline { 2 - 5 } & Falsas Treinadas & Outros Usuários & Falsas Treinadas & Outros Usuários \\
\hline \hline DD1 & $20,0 \%$ & $72,5 \%$ & $22,5 \%$ & $30,0 \%$ \\
$D D 2$ & $17,5 \%$ & $10,0 \%$ & $15,0 \%$ & $35,0 \%$ \\
$D D 3$ & $47,5 \%$ & $17,5 \%$ & $52,0 \%$ & $30,0 \%$ \\
$D D 4$ & $7,5 \%$ & $0,0 \%$ & $2,5 \%$ & $0,0 \%$ \\
$D D 5$ & $2,5 \%$ & $0,0 \%$ & $0,0 \%$ & $0,0 \%$ \\
$D D 6$ & $5,0 \%$ & $0,0 \%$ & $2,5 \%$ & $5,0 \%$ \\
$D D 7$ & $0,0 \%$ & $0,0 \%$ & $5,0 \%$ & $0,0 \%$ \\
\hline
\end{tabular}

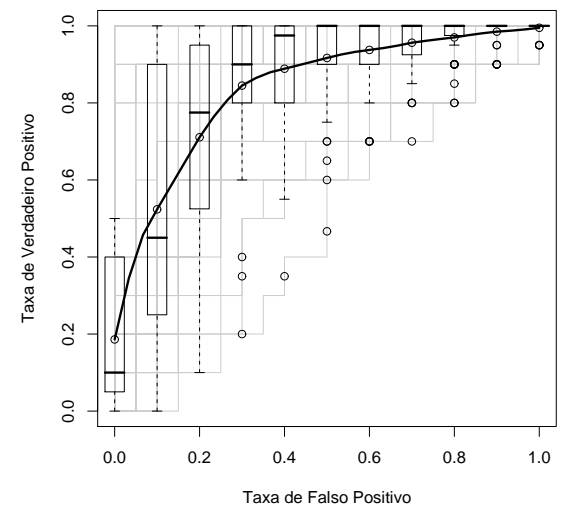

(a) DTW - falsas treinadas

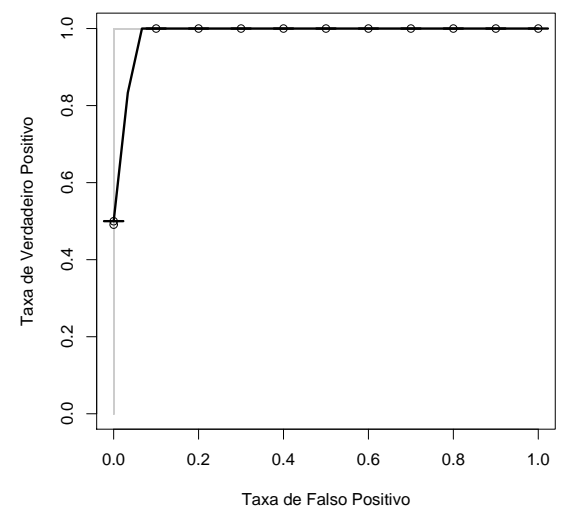

(c) DTW - outros usuários

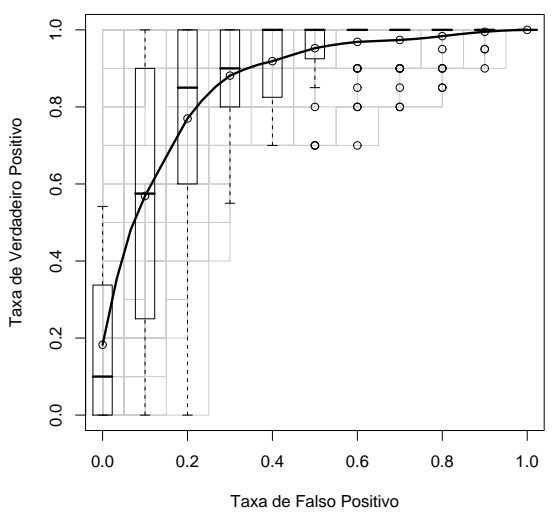

(b) CDM - falsas treinadas

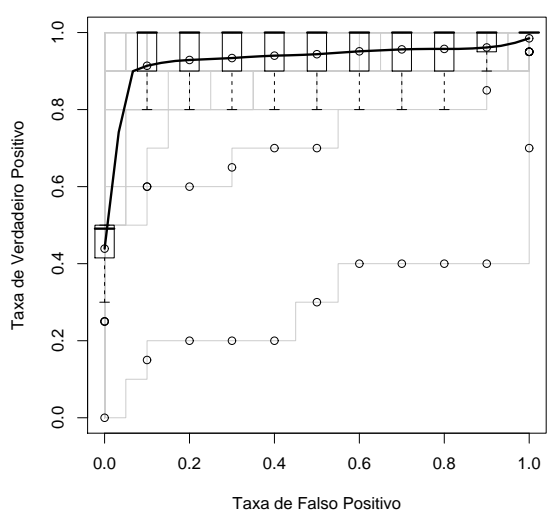

(d) CDM - outros usuários

Figura 5.7: Média das curvas ROC, contendo comparações das assinaturas verdadeiras às falsas treinadas e às de outros usuários, utilizando DTW e CDM. As distribuições que melhor representam o comportamento de cada usuário foram adotadas.

res resultados no ponto de cruzamento que melhor segmenta as distribuições de taxas de falso positivo e negativo, onde nesse caso, o valor de corte foi próximo de 3 (precisamente 2,84787) e o EER é igual a 0,3 (30\%). Dessa forma, quanto menor o EER, melhor será 
a precisão da técnica avaliada.

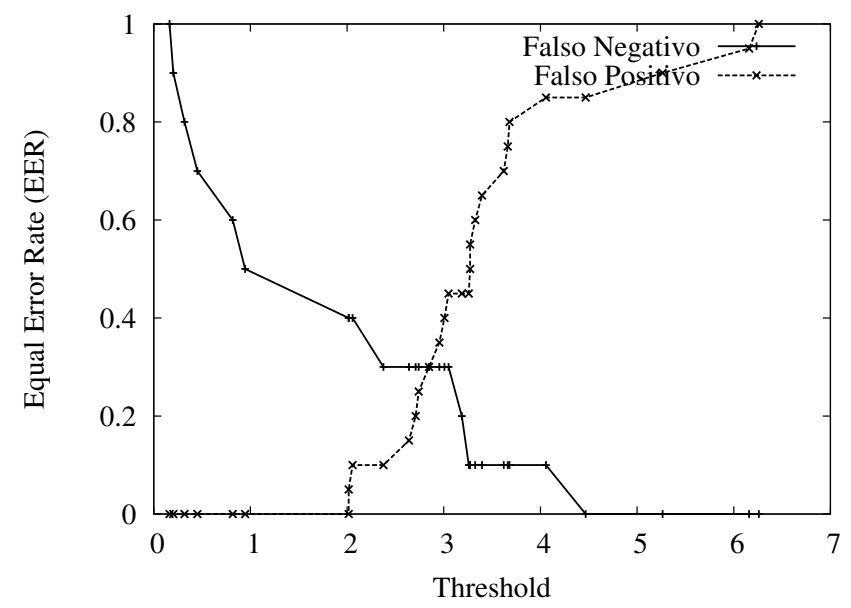

Figura 5.8: Exemplo de distribuição das taxas de falso positivo e negativo. O ponto de cruzamento entre as distribuições representa o Equal Error Rate (EER).

No contexto deste trabalho, a EER foi calculada para todos os experimentos realizados. Portanto, para cada experimento, obteve-se a média, o desvio padrão e o maior valor de EER para cada distribuição de dados de usuários $(D D 1, \ldots, D D 7)$. Além disso, assim como apresentado na seção anterior, selecionou-se e realizou-se experimentos utilizando as distribuições mais indicadas para caracterizar o perfil de cada usuário. As Tabelas 5.2 e 5.3 apresentam as EERs dos resultados experimentais realizados com a DTW e a CDM, respectivamente.

Tabela 5.2: EERs dos experimentos utilizando a medida de similaridade DTW.

\begin{tabular}{|c||c|c|c||c|c|c|}
\hline \multicolumn{1}{|c||}{\multirow{2}{*}{ Distri. }} & \multicolumn{3}{c||}{ Falso Treinado } & \multicolumn{3}{c|}{ Outros Usuários } \\
\cline { 2 - 7 } & Média & D. Padrão & Maior & Média & D. Padrão & Maior \\
\hline \hline$D D 1$ & $41,63 \%$ & $18,34 \%$ & $80,00 \%$ & $5,38 \%$ & $12,32 \%$ & $45,00 \%$ \\
$D D 2$ & $39,75 \%$ & $16,25 \%$ & $65,00 \%$ & $11,63 \%$ & $14,47 \%$ & $50,00 \%$ \\
$D D 3$ & $25,13 \%$ & $18,34 \%$ & $65,00 \%$ & $0,25 \%$ & $1,58 \%$ & $10,00 \%$ \\
$D D 4$ & $46,38 \%$ & $10,92 \%$ & $70,00 \%$ & $23,00 \%$ & $16,16 \%$ & $70,00 \%$ \\
$D D 5$ & $44,63 \%$ & $10,71 \%$ & $75,00 \%$ & $22,50 \%$ & $13,16 \%$ & $70,00 \%$ \\
$D D 6$ & $43,25 \%$ & $16,59 \%$ & $80,00 \%$ & $8,00 \%$ & $16,12 \%$ & $80,00 \%$ \\
$D D 7$ & $49,13 \%$ & $12,40 \%$ & $80,00 \%$ & $30,00 \%$ & $23,45 \%$ & $80,00 \%$ \\
\hline Melhores & $18,25 \%$ & $12,07 \%$ & $40,00 \%$ & $\mathbf{0 , 0 0 \%}$ & $\mathbf{0 , 0 0} \%$ & $\mathbf{0 , 0 0} \%$ \\
\hline
\end{tabular}

Analisando os resultados da DTW apresentados na Tabela 5.2, observa-se que a EER média das melhores distribuições de usuários, contendo comparações com assinaturas de outros usuários, foi zero. Isso demostra que a metodologia proposta neste trabalho de mestrado, foi capaz de diferenciar, totalmente, os perfis de usuários, isto é, conseguiu segmentar as assinaturas de usuários distintos. Nos experimentos realizados comparando assinaturas verdadeiras às falsas treinadas, a EER das melhores distribuições resultou em 
Tabela 5.3: EER dos experimentos utilizando a medida de similaridade CDM.

\begin{tabular}{|c||c|c|c||c|c|c|}
\hline \multicolumn{1}{|c||}{\multirow{2}{*}{ Distri. }} & \multicolumn{3}{c||}{ Falso Treinado } & \multicolumn{3}{c|}{ Outros Usuários } \\
\cline { 2 - 7 } & Média & D. Padrão & Maior & Média & D. Padrão & Maior \\
\hline \hline DD1 & $38,38 \%$ & $15,29 \%$ & $65,00 \%$ & $33,38 \%$ & $24,48 \%$ & $80,00 \%$ \\
$D D 2$ & $36,50 \%$ & $16,49 \%$ & $70,00 \%$ & $23,25 \%$ & $26,03 \%$ & $90,00 \%$ \\
$D D 3$ & $23,00 \%$ & $17,53 \%$ & $60,00 \%$ & $17,25 \%$ & $21,66 \%$ & $60,00 \%$ \\
$D D 4$ & $44,25 \%$ & $11,91 \%$ & $65,00 \%$ & $47,63 \%$ & $24,07 \%$ & $90,00 \%$ \\
$D D 5$ & $41,75 \%$ & $12,22 \%$ & $65,00 \%$ & $44,13 \%$ & $22,87 \%$ & $95,00 \%$ \\
$D D 6$ & $40,63 \%$ & $14,90 \%$ & $85,00 \%$ & $34,75 \%$ & $23,53 \%$ & $90,00 \%$ \\
$D D 7$ & $39,63 \%$ & $11,90 \%$ & $75,00 \%$ & $41,63 \%$ & $25,43 \%$ & $95,00 \%$ \\
\hline Melhores & $\mathbf{1 7 , 6 3 \%}$ & $\mathbf{1 1 , 4 9 \%}$ & $\mathbf{4 0 , 0 0 \%}$ & $8,00 \%$ & $13,05 \%$ & $70,00 \%$ \\
\hline
\end{tabular}

18, 25\%. Esse valor justifica-se, pois nesse caso, a assinatura falsa foi treinada e, com isso, o comportamento obtido aproxima-se daquele presente na assinatura original do usuário.

Comportamento similar foi observado com o emprego da técnica CDM, conforme resultados apresentados na Tabela 5.3. Contudo, nesse caso, os resultados experimentais comparando assinaturas verdadeiras às de outros usuários (utilizando as melhores distribuições de usuários) são piores que os obtidos pela técnica DTW. CDM apresenta EER igual a 8,00\% contra 0,00\% da DTW. Entretanto, nos experimentos realizados comparando assinaturas verdadeiras às falsas treinadas, a medida de similaridade CDM apresentou melhores resultados. Com a CDM, utilizando as melhores distribuições de usuários, a EER obtida foi de 17,63\% enquanto a da DTW foi de 18, 25\%.

Para uma melhor avaliação, os resultados obtidos na forma de EERs são comparados com os do campeonato $S V C 2004$. A Tabela 5.4 apresenta os resultados dos trabalhos submetidos ao campeonato ordenados por seu desempenho. Analisando a Tabela 5.4, observa-se que o melhor resultado possui EER igual a 2,84\% para experimentos realizados comparando assinaturas verdadeiras às falsas treinadas (equipe 6) e, EER igual a 1,85\% para experimentos com assinaturas de outros usuários (equipe 24). Nesse cenário, os resultados obtidos neste mestrado ficariam em penúltimo lugar utilizando a técnica CDM (EER 17, 25\%) no segmento de trabalhos que comparam assinaturas verdadeiras às falsas treinadas e, em primeiro lugar utilizando a técnica DTW (EER 0,00\%) quanto aos trabalhos que comparam assinaturas verdadeiras às de outros usuários.

Os três primeiros trabalhos apresentados na Tabela 5.4 (equipes 6, 24 e 26) foram propostos pelos mesmos autores referenciados na Seção 2.3. Isso não significa, necessariamente, que os trabalhos apresentados na Seção 2.3, sejam os mesmos submetidos no SVC2004. O objetivo do SVC2004 foi de promover uma competição visando a avaliação de diferentes metodologias e compará-las, por isso, o campeonato não divulgou informações adicionais sobre os trabalhos submetidos, apenas dados autorizados pelas equipes (tais como nomes dos participantes e das instituições envolvidas). 
Tabela 5.4: Resultados dos trabalhos submetidos ao campeonato de reconhecimento de assinaturas SVC2004 (Yeung et al., 2004).

\begin{tabular}{|c||c|c|c||c|c|c|}
\hline \multicolumn{1}{|c||}{$\begin{array}{c}\text { ID das } \\
\text { Equipes }\end{array}$} & \multicolumn{3}{c||}{ Falsas Treinadas } & \multicolumn{3}{c|}{ Outros Usuários } \\
\cline { 2 - 7 } & Média & D. Padrão & Maior & Média & D. Padrão & Maior \\
\hline \hline $\mathbf{6}$ & $\mathbf{2 . 8 4 \%}$ & $\mathbf{5 . 6 4 \%}$ & $\mathbf{3 0 . 0 0 \%}$ & $2.79 \%$ & $5.89 \%$ & $50.00 \%$ \\
$\mathbf{2 4}$ & $4.37 \%$ & $6.52 \%$ & $25.00 \%$ & $\mathbf{1 . 8 5 \%}$ & $\mathbf{2 . 9 7 \%}$ & $\mathbf{1 5 . 0 0 \%}$ \\
26 & $5.79 \%$ & $10.30 \%$ & $52.63 \%$ & $5.11 \%$ & $9.06 \%$ & $50.00 \%$ \\
$19 b$ & $5.88 \%$ & $9.21 \%$ & $50.00 \%$ & $2.12 \%$ & $3.29 \%$ & $15.00 \%$ \\
$19 c$ & $6.05 \%$ & $9.39 \%$ & $50.00 \%$ & $2.13 \%$ & $3.29 \%$ & $15.00 \%$ \\
15 & $6.22 \%$ & $9.38 \%$ & $50.00 \%$ & $2.04 \%$ & $3.16 \%$ & $15.00 \%$ \\
$19 a$ & $6.88 \%$ & $9.54 \%$ & $50.00 \%$ & $2.18 \%$ & $3.54 \%$ & $22.50 \%$ \\
14 & $8.77 \%$ & $12.24 \%$ & $57.14 \%$ & $2.93 \%$ & $5.91 \%$ & $40.00 \%$ \\
18 & $11.81 \%$ & $12.90 \%$ & $50.00 \%$ & $4.39 \%$ & $6.08 \%$ & $40.00 \%$ \\
17 & $11.85 \%$ & $12.07 \%$ & $70.00 \%$ & $3.83 \%$ & $5.66 \%$ & $40.00 \%$ \\
16 & $13.53 \%$ & $12.99 \%$ & $70.00 \%$ & $3.47 \%$ & $6.90 \%$ & $52.63 \%$ \\
4 & $16.22 \%$ & $13.49 \%$ & $66.67 \%$ & $6.89 \%$ & $9.20 \%$ & $48.57 \%$ \\
12 & $28.89 \%$ & $15.95 \%$ & $80.00 \%$ & $12.47 \%$ & $10.29 \%$ & $55.00 \%$ \\
\hline
\end{tabular}

Vale ressaltar que, apesar dos bons resultados obtidos, os experimentos realizados neste trabalho não tem como foco o desenvolvimento de um aplicativo para reconhecimento de assinaturas, e sim, uma metodologia para classificação de perfis de usuários. Conseqüentemente, os experimentos realizados não foram otimizados para obter o melhor aproveitamento no reconhecimento de assinaturas (focando apenas na validação da metodologia proposta). Por esses motivos, as comparações realizadas valem apenas como referência e para destacar a capacidade da metologia proposta em caracterizar quaisquer perfis embutidos em séries temporais.

\subsection{Resultados Complementares sobre Comporta- mentos de Usuários}

No início deste trabalho de mestrado, alguns experimentos exploratórios foram realizados com o intuito de avaliar a relevância da metodologia proposta. Para isso, foram estudados comportamentos de usuários interagindo com um sistema de produção de documentos hipermídia, denominado iClass. Resultados desses experimentos são apresentados nesta seção.

O sistema iClass, desenvolvido pelo Laboratório Intermídia do ICMC-USP, captura informações de ambientes convencionais por meio de uma whiteboard (tais como salas de aula), permitindo a produção de documentos hipermídia que, posteriormente, são apresentados na Web (Cattelan et al., 2003). Esse sistema tem sido adotado como ferramenta de apoio a aulas por professores da Universidade de São Paulo que projetam imagens 
sobre uma lousa e utilizam equipamentos de captura $\left.{ }^{4}\right)$. Alunos podem realizar anotações e utilizar esse conteúdo, por meio de tablets ou computadores pessoais, para o estudo de disciplinas.

Experimentos foram realizados a fim de, em um primeiro momento, observar o comportamento de usuários em situações tais como: durante aulas, em experimentos e testes. Resultados obtidos seriam correlacionados a fim de detectar características individuais e similares entre usuários. Diversos experimentos foram então conduzidos e seus resultados publicados no The 2007 IFIP International Conference on Embedded and Ubiquitous Computing (dos Santos et al., 2007).

Para a realização de tais experimentos, necessitou-se estudar a forma de armazenamento de informações do iClass e como essas poderiam ser utilizadas. Esse sistema mantém informações de interações de usuários em arquivos no formato XML. Esses arquivos apresentam tags que detalham interações de usuário, tais como: nome do usuário, resolução de tela, cor da caneta, timestamp de cada stroke (traços), quantidade de pontos traçados em um stroke, entre outros.

Para caracterizar o comportamento de usuários durante interações, seriam necessárias informações precisas sobre o tempo despendido em traços (strokes), ou seja, os instantes iniciais e finais. Contudo, por uma limitação do iClass, somente o instante final de produção de um traço é armazenado, o que dificulta análise detalhada das interações de usuários. Imagine, por exemplo que, em uma tarefa qualquer, o usuário realizasse toda sua interação em um único traço (stroke), isto é, sem tirar a caneta da interface. Nesse cenário, o sistema iClass armazenaria todos os pontos da interação em um único stroke e, com isso, informações sobre o dinamismo da interação seriam perdidos. Para contornar esse problema, os experimentos realizados com o sistema iClass devem conter tarefas que obriguem o usuário a utilizar vários traços, como por exemplo, escrita de textos, operações matemáticas, desenhos complexos, etc.

Um parser foi projetado para extrair informações, tais como quantidade de pontos e timestamps de cada stroke, dos arquivos XML produzidos pelo iClass. Essas informações foram utilizadas para gerar distribuições de dados a fim de melhor representar comportamentos de interação. A fim de estudar tais distribuições, um primeiro experimento foi conduzido onde um usuário interagiu com o jogo Sudoku ${ }^{5}$ sobre o sistema iClass (Figura 5.9). Dados capturados foram utilizados para criar diversas distribuições de dados, as quais foram empregadas na representação de características de comportamento (Figura $5.10)$.

Utilizando-se os dados de interação obtidos no exemplo apresentado na Figura 5.9, a distribuição mostrada na Figura 5.10(a), representa a quantidade de pontos de interação

\footnotetext{
${ }^{4}$ Um exemplo de equipamento adotado no ICMC - USP é o Mimio Whiteboard Capture System-mais detalhes em http://www.magiboards.com/interactive-boards/mimio.htm.

${ }^{5}$ http://pt.wikipedia.org/wiki/Sudoku
} 


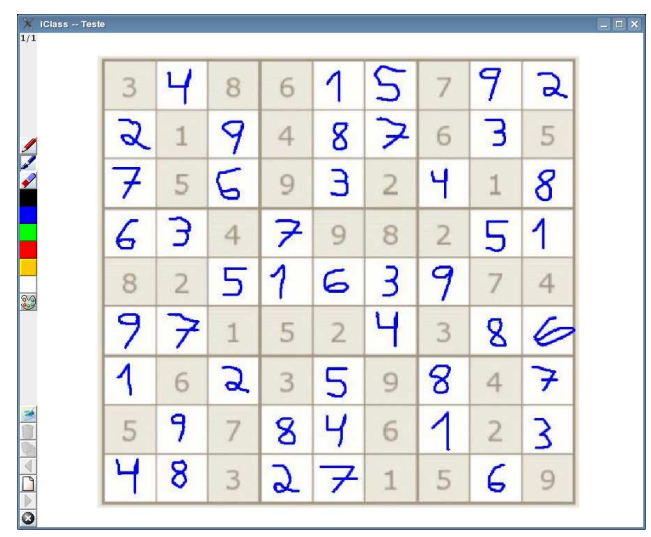

Figura 5.9: Imagem da interação de um usuário jogando Sudoku sobre o sistema iClass.

por timestamp, isto é, pontos por stroke. Na Figura 5.10(b) é apresentada a freqüência de pontos por stroke. A Figura 5.10(c) foi obtida pelo cálculo da freqüência de pontos por stroke dividida pelo intervalo de tempo consumido. A Figura 5.10(d) representa a freqüência do tempo despendido por ponto da interação. E, finalmente, a distribuição apresentada na Figura 5.10(e), representa o tempo consumido por ponto, discretizada, no eixo do tempo, em milissegundos. Nessa última distribuição, os intervalos de tempo em que o usuário interage com sistema (jogo Sudoku), correspondem aos números preenchidos na tabela do jogo. Cada desnível apresentado na curva constitui uma ação do usuário. Por esse motivo, essa última distribuição foi escolhida para representar dados de interação nos experimentos a seguir.

Após ter definido uma boa distribuição para os dados em questão, experimentos foram conduzidos a fim de avaliar a interação de dois usuários. Esses usuários interagiram, por meio do sistema iClass, com o jogo Sudoku e solucionaram um problema de Labirinto. A Figura 5.11 mostra o resultado final do jogo após sucessivas interações dos usuários 1 e 2 .

Em seguida, os comportamentos de interação de cada usuário foram representados por meio da distribuição anteriormente selecionada. As distribuições resultantes das interações de cada usuário são demonstradas na Figura 5.12, onde o comportamento do usuário 1 interagindo com o jogo Sudoku e com o Labirinto são representados, respectivamente, pelas Figuras 5.12(a) e 5.12(c) e, o comportamento do usuário 2 pelas Figuras $5.12(\mathrm{~b})$ e $5.12(\mathrm{~d})$.

Em seguida foram executados os seguintes passos: classificação das distribuições de dados (Figura 5.12), construção de cadeias de Markov e medição da variação média de energia entre as cadeias de Markov sucessivas (entropia). Essas etapas foram desenvolvidas empregando a rede neural SONDE (Seção 3.3.2). Na Figura 5.13, como ilustração, são representadas apenas as cadeias de Markov do último instante de interação de cada usuário com o jogo Sudoku e com o Labirinto (vale ressaltar que, para cada interação, gera-se uma 


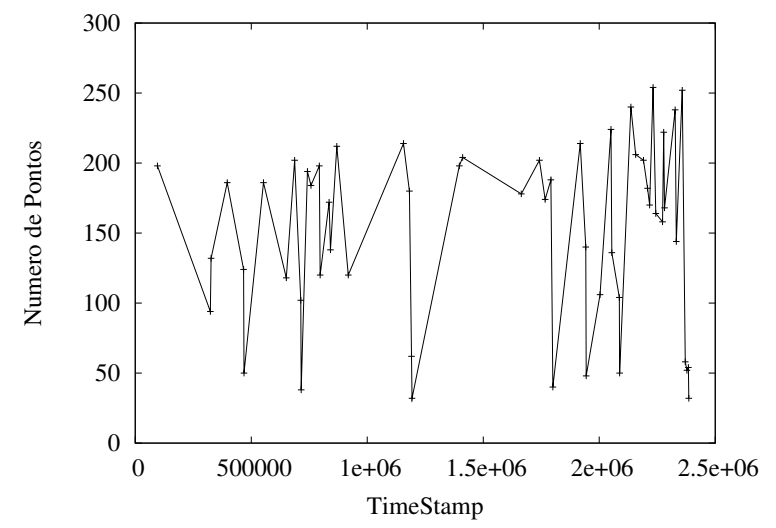

(a) Quantidade de pontos no intervalo de tempo.

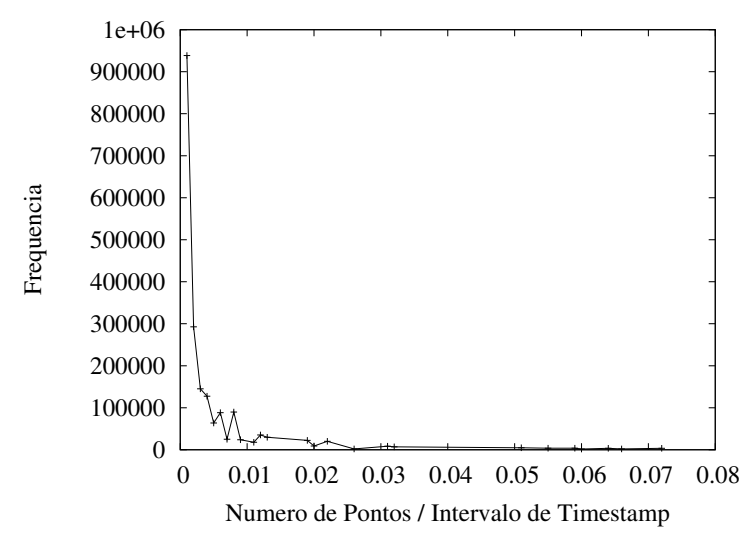

(c) Freqüência do número de pontos por segundo.

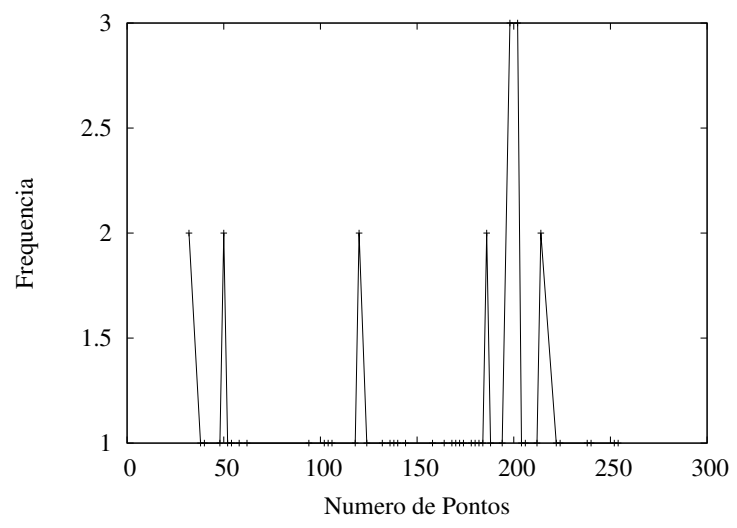

(b) Freqüência do número de pontos.

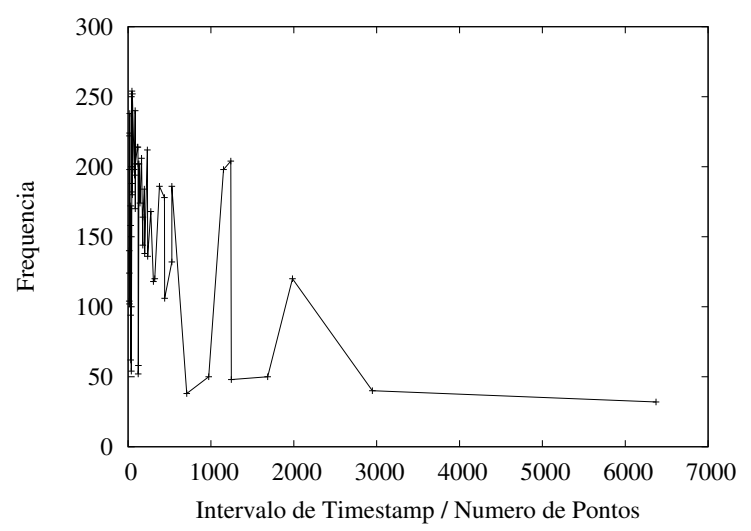

(d) Freqüência do tempo gasto por ponto.

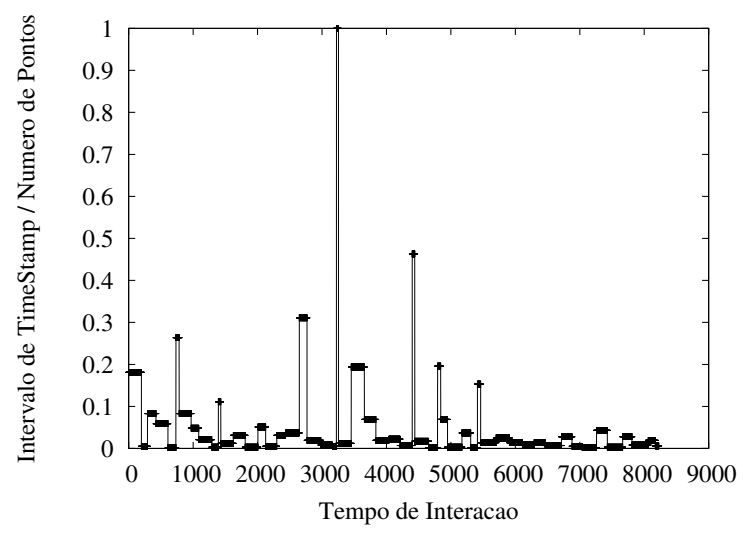

(e) Freqüência do tempo consumido por ponto, discretizada em milissegundos.

Figura 5.10: Exemplos de distribuições de dados sobre a interação de um usuário com o jogo Sudoku.

cadeia de Markov que permite compreender o comportanto instantâneo do usuário).

Calcula-se a variação de energia das cadeias de Markov obtidas (Figura 5.14), as quais representam alterações comportamentais de usuários.

Analisando a Figura 5.14, observa-se que o usuário 1 mantém determinadas características em suas interações (Sudoku e Labirinto). O mesmo ocorre com o usuário 2. Na Figura 5.14(a), são observados vários pontos de estabilidade no comportamento (declive), o que também ocorre nos resultados apresentados na Figura 5.14(c). Analisando 


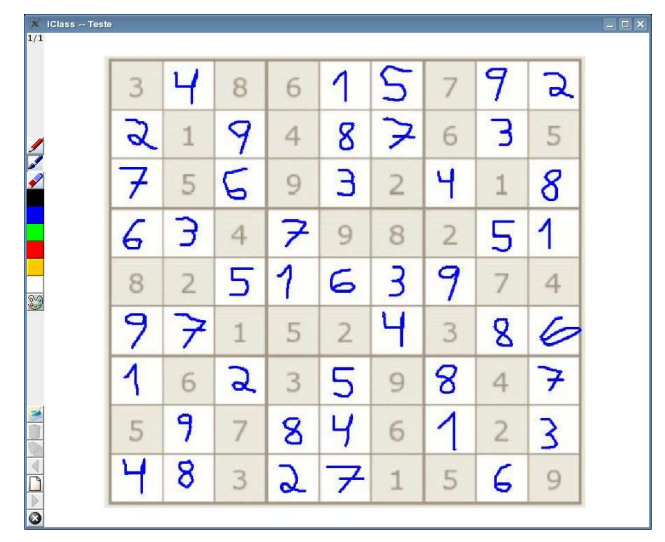

(a) Usuário 1 - Sudoku.

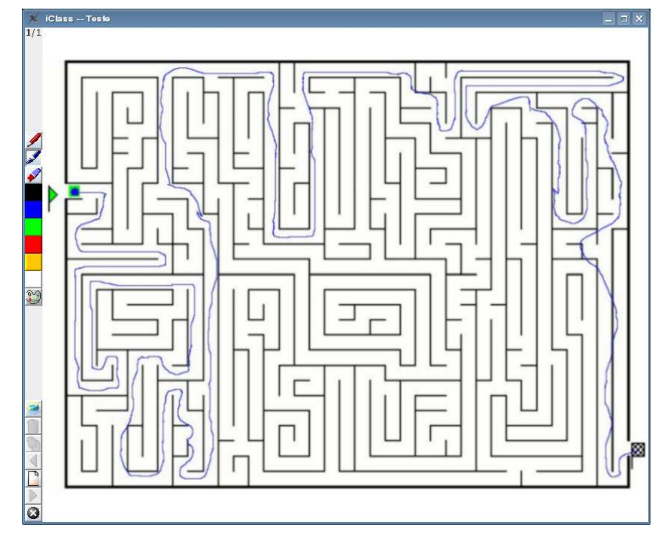

(c) Usuário 1 - Labirinto.

\begin{tabular}{|l|l|l|l|l|l|l|l|l|}
\hline 3 & 4 & 8 & 6 & 1 & 5 & 7 & 9 & 7 \\
\hline 2 & 1 & 9 & 4 & 8 & 7 & 6 & 3 & 5 \\
\hline 7 & 5 & 6 & 9 & 3 & 2 & 4 & 1 & 8 \\
\hline 6 & 3 & 4 & 7 & 9 & 8 & 2 & 5 & 1 \\
\hline 8 & 2 & 5 & 1 & 6 & 3 & 9 & 7 & 4 \\
\hline 9 & 7 & 1 & 5 & 2 & 4 & 3 & 8 & 6 \\
\hline 1 & 6 & 2 & 3 & 5 & 9 & 8 & 4 & 7 \\
\hline 5 & 9 & 7 & 8 & 4 & 6 & 1 & 2 & 3 \\
\hline 4 & 8 & 3 & 2 & 7 & 1 & 5 & 6 & 9 \\
\hline
\end{tabular}

(b) Usuário 2 - Sudoku.

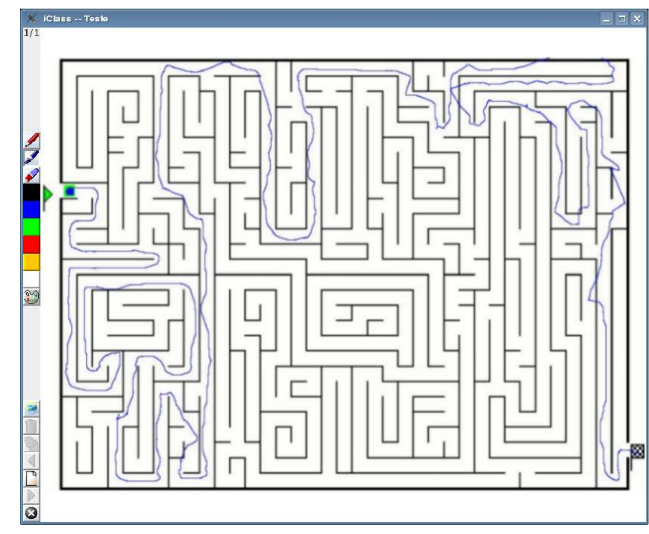

(d) Usuário 2 - Labirinto.

Figura 5.11: Exemplo de dois usuários interagindo no sistema iClass.

o usuário 2, pode-se observar, de um modo mais acentuado, a existência de um padrão de comportamento em suas interações. Na Figura 5.14(b), o nível de energia é crescente, apresentando degraus, o mesmo ocorre na Figura 5.14(d). Esses resultados permitem deduzir que o usuário 2 possui maior dinamismo em suas ações, não havendo pausas ao longo de suas interações. O usuário 1 também apresenta nível de energia crescente, contudo ele, provavelmente, faz pausas durante suas interações. Essas pausas, possivelmente, estejam relacionadas a um período de reflexão ao longo de suas interações, ao contrário do usuário 2 que tende a pensar no problema antes de começar a resolvê-lo.

\subsection{Considerações Finais}

Neste capítulo foram apresentados resultados de experimentos da área de reconhecimento de assinaturas, os quais foram, também, comparados aos obtidos em trabalhos submetidos ao campeonato $S V C 2004$. Esses resultados permitiram comprovar a eficiência da metodologia proposta na diferenciação de perfis de usuários por meio do comportamento de interação. Esse fato permite estender a aplicação da abordagem proposta para caracterizar e comparar comportamentos presentes em demais séries.

Também foram apresentados resultados experimentais realizados no início do pro- 


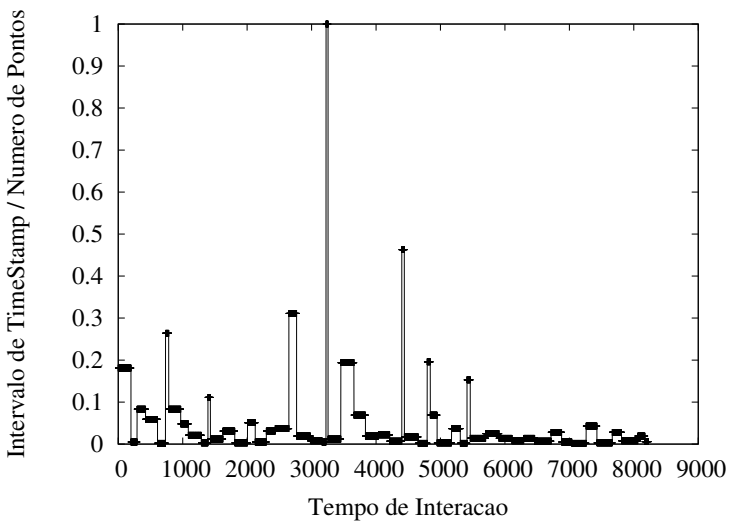

(a) Usuário 1 - Sudoku.

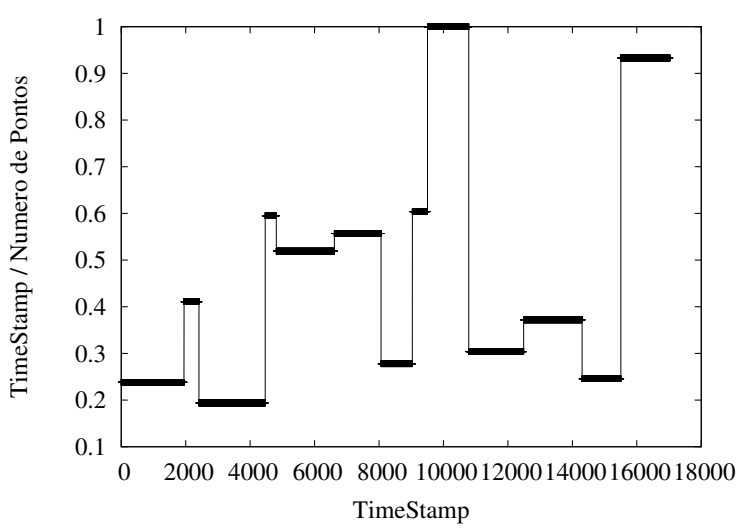

(c) Usuário 1 - Labirinto.

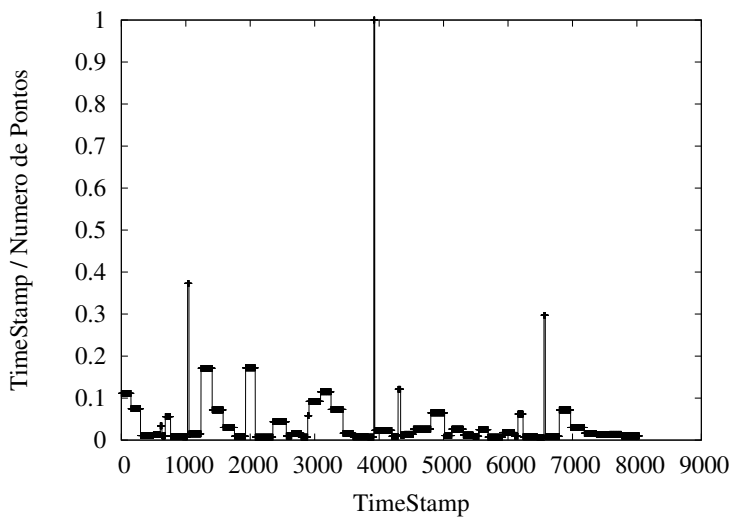

(b) Usuário 2 - Sudoku.

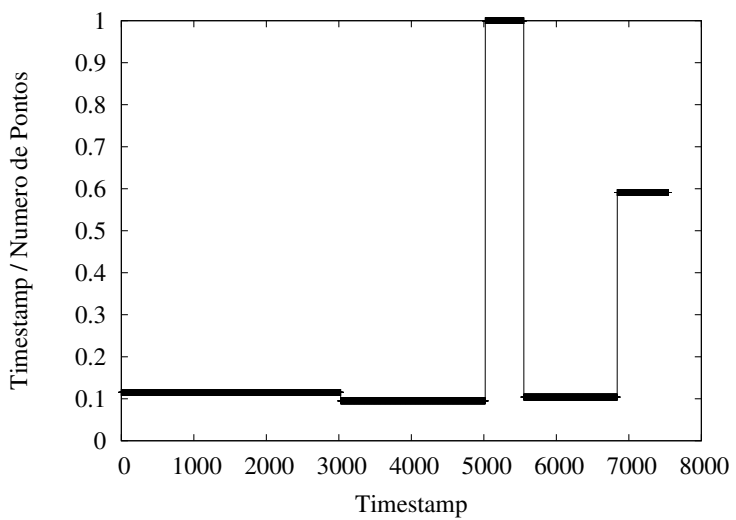

(d) Usuário 2 - Labirinto.

Figura 5.12: Distribuição de dados das informações de interação de cada usuário.

jeto, os quais permitiram avaliar a viabilidade da metodologia proposta na classificação de perfis comportamentais. Nesses experimentos foram considerados diferentes tipos de interação de usuários, utilizando o sistema iClass, a fim de estudar a variabilidade de seus comportamentos. Os resultados desses experimentos iniciais foram publicados no IFIP - International Federation for Information Processing (dos Santos et al., 2007), e contribuíram com o desenvolvimento deste trabalho de mestrado. 


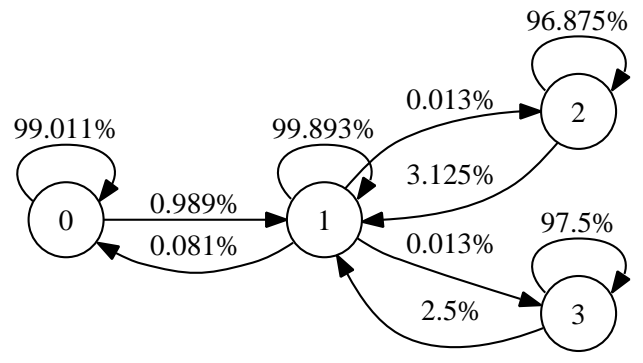

(a) Usuário 1 - Sudoku.

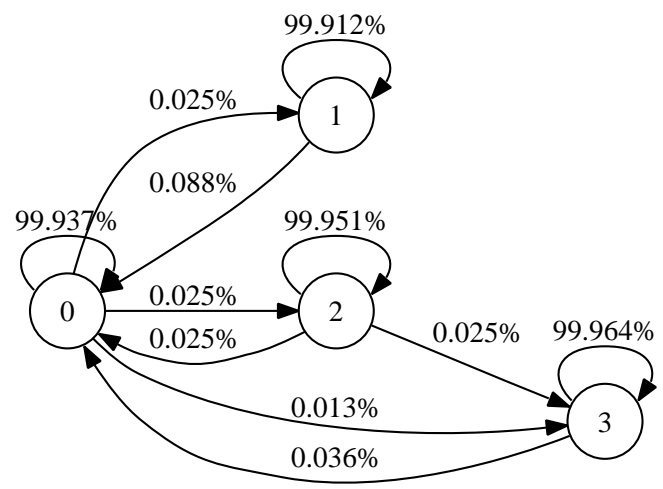

(c) Usuário 1 - Labirinto.

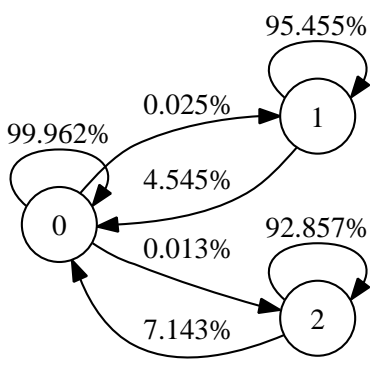

(b) Usuário 2 - Sudoku.

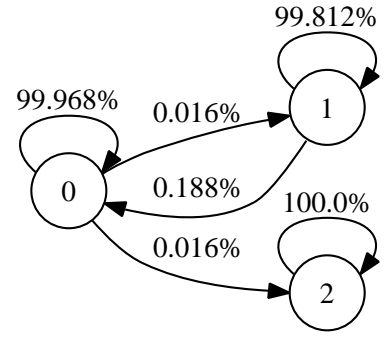

(d) Usuário 2 - Labirinto.

Figura 5.13: Cadeias de Markov representando o último instante de interação de cada usuário.

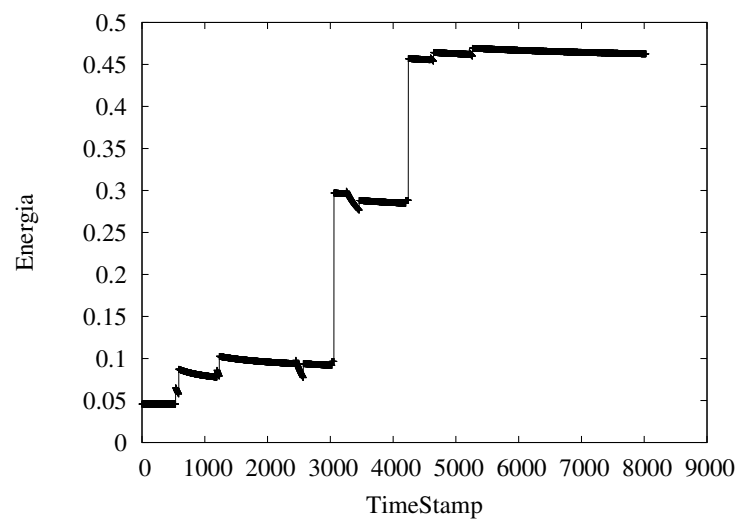

(a) Usuário 1 - Sudoku.

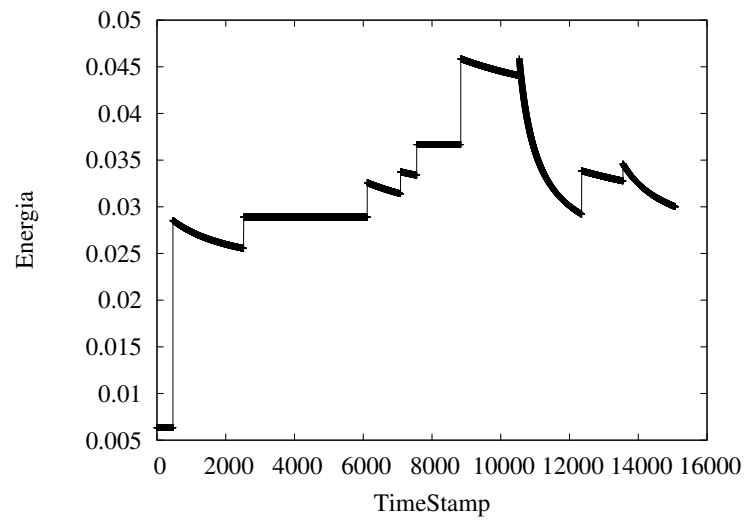

(c) Usuário 1 - Labirinto.

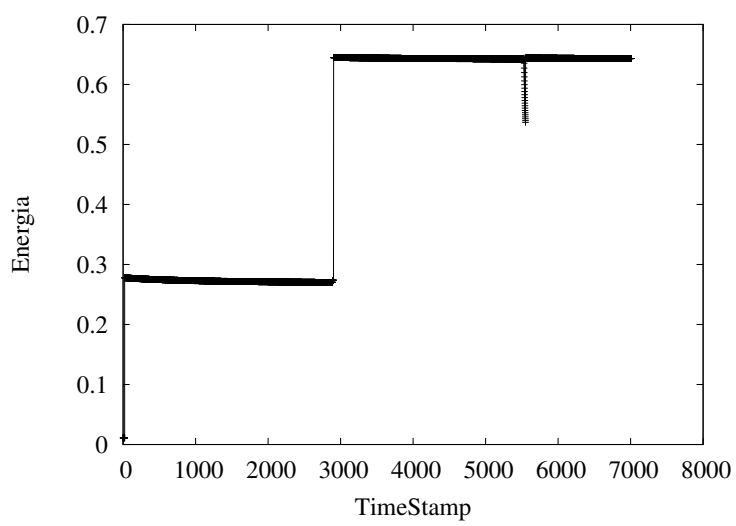

(b) Usuário 2 - Sudoku.

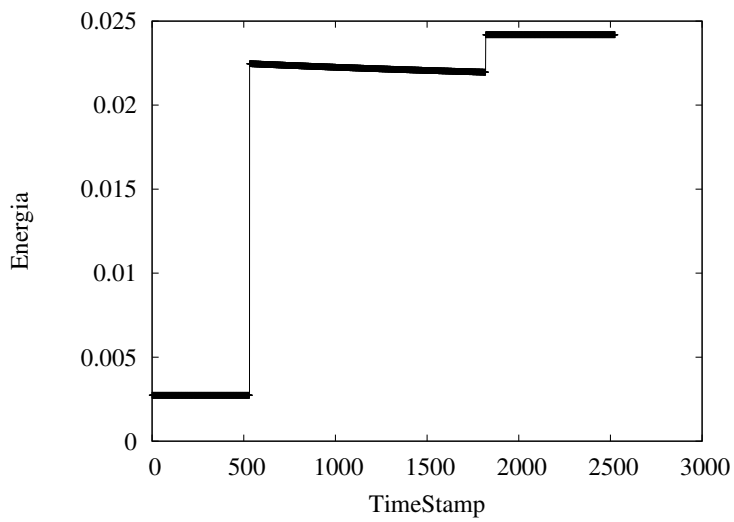

(d) Usuário 2 - Labirinto.

Figura 5.14: Variação no padrão de comportamento de cada usuário. 


\section{Conclusões e Trabalhos Futuros}

Este trabalho de mestrado visou o estudo de técnicas para identificar e classificar padrões de comportamento de usuários. A partir desses estudos, foi definida uma metodologia de classificação de perfis que emprega informações obtidas por meio da interação de usuários em sistemas computacionais.

A metodologia consiste em analisar e agrupar, continuamente, momentos de interação de usuários por meio de redes neurais. Para cada momento, é gerada uma cadeia de Markov distinta, a qual representa o comportamento instantâneo do usuário. Os estados dessas cadeias representam os grupos criados pelas redes neurais, onde transições descrevem variações comportamentais de interação. O perfil de cada usuário é representado por uma curva de variações de energia entre cadeias de Markov sucessivas. Essas variações são utilizadas para comparações entre perfis de usuários distintos utilizando medidas de similaridade (neste contexto foram adotadas as técnicas CDM e DTW).

Experimentos foram realizados para validar a metodologia proposta. Esses envolveram informações provenientes da interação de usuários ao grafar suas respectivas assinaturas. Para isso foram utilizadas as bases de dados do campeonato de assinaturas SVC2004. Resultados experimentais foram resumidos em curvas ROC que permitiram avaliar a eficiência da metodologia proposta e compará-la a demais abordagens da literatura.

A análise desses experimentos permitiu comprovar a diferenciação de perfis de usuário em função dos comportamentos empregados em grafia. Obteve-se tal conclusão em função da medida EER para a técnica DTW, igual a 0,00\%, ao comparar assinaturas verdadeiras às de outros usuários. Em experimentos comparando assinaturas verdadeiras às falsas treinadas, obteve-se uma EER igual a 17,63\% (para a técnica CDM). Esse resultado é esperado uma vez que a proposta da metodologia é a de classificar perfis 
de usuários e, assinaturas falsas treinadas, conseguem forjar determinados aspectos das originais.

Em suma, esses resultados permitem concluir que a metodologia proposta permite a classificação e identificação de perfis de usuários que podem ser empregados em diversos aspectos, os quais motivam a continuidade do trabalho e sua aplicação em outros cenários, tais como na caracterização de comportamentos de processos em execução em sistemas operacionais, usuários navegando em páginas Web, comportamentos de tráfego em redes de computadores, autenticação continuada em sistemas, entre outros. Além de empregar a metodologia tal como proposta, pode-se, também, avaliar outras técnicas de classificação de comportamento, de medição de variações comportais e de similaridade.

A partir de alguns resultados obtidos durante o desenvolvimento desta dissertação, a seguinte publicação foi gerada até a presente data: dos Santos, M. L.; de Mello, R. F.; Yang, L. T. Extraction and Classification of User Behavior. EUC - Embedded and Ubiquitous Computing, 2007, p. 493-506. 


\section{Referências Bibliográficas}

Abowd, G. D.; Dey, A. K.; Brown, P. J.; Davies, N.; Smith, M.; Steggles, P. (1999). Towards a better understanding of context and context-awareness. HUC '99: Proceedings of the 1st international symposium on Handheld and Ubiquitous Computing, p. 304-307, London, UK. Springer-Verlag.

Abowd, G. D.; Mynatt, E. D. (2000). Charting past, present, and future research in ubiquitous computing. ACM Trans. Comput.-Hum. Interact., v.7, n.1, p.29-58.

Albertini, M. K.; de Mello, R. F. (2007). A self-organizing neural network for detecting novelties. SAC '0\%: Proceedings of the 2007 ACM symposium on Applied computing, p. 462-466, New York, NY, USA. ACM.

Alencar, A. B. (2007). Mineração e visualização de coleções de séries temporais. Dissertação (mestrado), Instituto de Ciências Matemáticas e de Computação, Universidade de São Paulo, São Carlos.

Archimedes, S.; Health, T. L. (1897). The Works of Archimedes. Cambridge University.

Aristóteles (2006). De Anima. 34 Editora, 1 edição. ISBN: 8573263512.

Berndt, D. J.; Clifford, J. (1994). Using dynamic time warping to find patterns in time series. KDD Workshop, p. 359-370.

Bohmerwald, P. (2005). Uma proposta metodológica para avaliação de bibliotecas digitais: usabilidade e comportamento de busca por informação na biblioteca digital da pucminas. Ciência da Informação, v.34, p.95 - 103.

Boltzmann, L. (1896). Vorlesungen uber Gastheorie, v. 1, 2. J. A. Barth Leipzig. English Translation by S.G. Brush: Lecture on Gas Theory, Cambridge Univ. Press, Cambridge, 1964.

Brahe, T. (1925). Tychonis brahe dani opera omnia. Nature Publishing Group, v.115, p.760. 
Brosso, M. I. L. (2006). Autenticação Contínua de Usuários em Redes de Computadores. Tese de doutorado, Politécnica da Universidade de São Paulo, São Paulo, SP, Brasil.

Carpenter, G. A.; Grossberg, S.; Rosen, D. B. (1991). Art 2-a: an adaptive resonance algorithm for rapid category learning and recognition. Neural Netw., v.4, n.4, p.493-504.

Cattelan, R. G.; Andrade, A. R.; Rocha, C. F. P.; Pimentel, M. d. G. C. (2003). iclass: um sistema para captura e acesso de sessões em ambiente educacional. Revista Eletrônica de Iniciação Científica - REIC, v.3, n.1, p.10-28.

Chomsky, N. (1959). A review of b. f. skinner's verbal behavior. Language, v.35, n.1, p.26-58.

Copernicus, N. (1978). On the Revolutions. The Johns Hopkins University Press.

Darwin, C. (2004). Origem das Espécies, A. Martin Claret, 1 edição. ISBN: 8572325840.

de Mello, R.; Senger, L.; Yang, L. (2005). Automatic text classification using an artificial neural network. High Performance Computational Science and Engineering, v. 172 de IFIP International Federation for Information Processing, p. 215-238. Springer Boston.

dos Reis Justi, F. R.; de Freitas Araujo, S. (2004). Uma avaliação das críticas de chomsky ao verbal behavior à luz das réplicas behavioristas. Psicologia: Teoria e Pesquisa, v.20, n.3, p.267-274.

dos Santos, M. L.; de Mello, R. F.; Yang, L. T. (2007). Extraction and classification of user behavior. $E U C$, p. 493-506.

Eleftheriadis, G.; Theologou, M. (1994). User profile identification in future mobile telecommunicationssystems. IEEE Network, v.8, n.5, p.33-39.

Freeman, J. A.; Skapura, D. M. (1991). Neural networks: algorithms, applications, and programming techniques. Addison Wesley Longman Publishing Co., Inc., Redwood City, CA, USA.

Galilei, G. (1870). The private life of Galileo. Nichols and Noyes.

Godoy, D.; Amandi, A. (2005). User profiling for web page filtering. IEEE Internet Computing, v.9, n.4, p.56-64.

Godoy, D.; Amandi, A. (2006). Modeling user interests by conceptual clustering. Inf. Syst., v.31, n.4, p.247-265.

Goldberger, A. L.; Amaral, L. A. N.; Glass, L.; Hausdorff, J. M.; Ivanov, P. C.; Mark, R. G.; Mietus, J. E.; Moody, G. B.; Peng, C.-K.; Stanley, H. E. (2000). PhysioBank, PhysioToolkit, and PhysioNet: Components of a new research resource for complex 
physiologic signals. Circulation, v.101, n.23, p.e215-e220. Circulation Electronic Pages: http://circ.ahajournals.org/cgi/content/full/101/23/e215.

Grinstead, C. M.; Snell, J. L. (1997). Introduction to Probability. American Mathematical Society; 2nd Rev edition (July 1, 1997), United States of America.

Haykin, S. (1999). Neural Networks: A Comprehensive Foundation. Person Education Pte. Ltd., Indian Branch, 482 F.I.E. Patparganj, Delphi 110 092, India.

Hillier, F.; Lieberman, G. (2001). Introduction to operations research. McGraw-Hill. ISBN: 0072321695.

Kalera, M. K.; Srihari, S. N.; Xu, A. (2004). Offline signature verification and identification using distance statistics. IJPRAI, v.18, n.7, p.1339-1360.

Keogh, E.; Chakrabarti, K.; Pazzani, M.; Mehrotra, S. (2001). Dimensionality reduction for fast similarity search in large time series databases. Knowledge and Information Systems, v.3, n.3, p.263-286.

Keogh, E.; Lonardi, S.; Ratanamahatana, C. A.; Wei, L.; Lee, S.-H.; Handley, J. (2007). Compression-based data mining of sequential data. Data Min. Knowl. Discov., v.14, n.1, p.99-129.

Keogh, E.; Ratanamahatana, C. A. (2005). Exact indexing of dynamic time warping. Knowl. Inf. Syst., v.7, n.3, p.358-386.

Kepler, J.; Donahue, W. H. (1993). Johannes Kepler New Astronomy. Cambridge University Press. ISBN: 0521301319 EAN: 9780521301312.

Kholmatov, A.; Yanikoglu, B. (2005). Identity authentication using improved online signature verification method. Pattern Recogn. Lett., v.26, n.15, p.2400-2408.

Kohonen, T.; Kaski, S.; Lagus, K.; Salojrvi, J.; Honkela, J.; Paatero, V.; Saarela, A. (2000). Self organization of a massive document collection.

Kolmogorov (1965). Three approaches to the quantitive definition of information. Problems of Information Transmission, v.1, p.1-17.

Lee, H. K.; Vageesan, G.; Yum, K. H.; Kim, E. J. (2006). A proactive request distribution (prord) using web log mining in a cluster-based web server. ICPP '06: Proceedings of the 2006 International Conference on Parallel Processing, p. 559-568, Washington, DC, USA. IEEE Computer Society.

Li, M.; Chen, X.; Li, X.; Ma, B.; Vitányi, P. (2003). The similarity metric. SODA '03: Proceedings of the fourteenth annual ACM-SIAM symposium on Discrete algorithms, p. 863-872, Philadelphia, PA, USA. Society for Industrial and Applied Mathematics. 
Lin, J.; Keogh, E.; Lonardi, S.; Chiu, B. (2003). A symbolic representation of time series, with implications for streaming algorithms. DMKD '03: Proceedings of the 8th ACM SIGMOD workshop on Research issues in data mining and knowledge discovery, p. 2-11, New York, NY, USA. ACM.

Macedo, A. A.; Truong, K. N.; Camacho-Guerrero, J. A.; da Graça Pimentel, M. (2003). Automatically sharing web experiences through a hyperdocument recommender system. HYPERTEXT '03: Proceedings of the fourteenth ACM conference on Hypertext and hypermedia, p. 48-56, New York, NY, USA. ACM Press.

Marsland, S.; Shapiro, J.; Nehmzow, U. (2002). A self-organising network that grows when required. Neural Netw., v.15, n.8-9, p.1041-1058.

Pai, V. S.; Aron, M.; Banga, G.; Svendsen, M.; Druschel, P.; Zwaenepoel, W.; Nahum, E. (1998). Locality-aware request distribution in cluster-based network servers. ASPLOSVIII: Proceedings of the eighth international conference on Architectural support for programming languages and operating systems, p. 205-216, New York, NY, USA. ACM Press.

Pepyne, D.; Hu, J.; Gong, W. (2004). User profiling for computer security. American Control Conference, 2004. Proceedings of the 2004, v.2, p.982-987 vol.2.

Platão (2006). A República. Martins Fontes, 1 edição. ISBN: 8533623267.

Porter, M. F. (1980). An algorithm for suffix stripping. Program, v.14, n.3, p.130-137.

Qwiknet (2005). Professional neural network software. http://qwiknet.home.comcast.net/.

Rakotomalala, R. (2005). Sipina overview. http://eric.univ-lyon2.fr/ ricco/sipina.html.

Schilit, B.; Theimer, M. (1994). Disseminating active map information to mobile hosts. IEEE Network, v.8, n.5, p.22-32.

Schuler, A. J. J.; Perez, A. L. F. (2006). Análise do perfil do usuário de serviços de telefonia utilizando técnicas de mineração de dados. RESI - Revista Eletrônica de Sistemas de Informação, v.7, n.1, p.65-67.

Senger, L. J.; de Mello, R. F.; Santana, M. J.; Helena, R.; Santana, C.; Yang, L. T. (2006). An on-line approach for classifying and extracting application behavior on linux. Laurence T. Yang, M. G., editor, High-Performance Computing, p. 381-401. John Wiley \& Sons, Inc.

Shannon, C. (1948). A mathematical theory of communication. Bell System Technical Journal, v.27, p.379-423 and 623-656. 
Shefler, W. C. (1988). Statistics: Concepts and Applications. The Benjamin/Cummings.

Skinner, B. F. (1957). Verbal Behavior. Copley Publishing Group. ISBN: 1-58390-021-7.

Skinner, B. F. (1999). Sobre o Behaviorismo. Pensamento-Cultrix. ISBN: 8531603609.

Skrbek, M. (2003). Signature dynamics on a mobile electronic signature platform. GI Jahrestagung (Schwerpunkt "Sicherheit - Schutz und Zuverlässigkeit"), p. 329-332.

Wirtz, B. (1995). Stroke-based time warping for signature verification. Document Analysis and Recognition, 1995., Proceedings of the Third International Conference on, v.1, p.179-182 vol.1.

Yeung, D.-Y.; Chang, H.; Xiong, Y.; George, S.; Kashi, R.; Matsumoto, T.; Rigoll, G. (2004). SVC2004: First International Signature Verification Competition, v. 3072/2004, p. 16-22. Springer Berlin / Heidelberg.

Ypma, A.; Duin, R. P. W. (1997). Novelty detection using self-organizing maps. Kasabov, N.; Kozma, R.; Ko, K.; O’Shea, R.; Coghill, G.; Gedeon, T., editores, Progress in Connectionist-Based Information Systems, v. 2, p. 1322-1325. Springer, London.

Zhou, X.; Wu, S.-T.; Li, Y.; Xu, Y.; Lau, R. Y.; Bruza, P. D. (2006). Utilizing search intent in topic ontology-based user profile for web mining. Web Intelligence, 2006. WI 2006. IEEE/WIC/ACM International Conference on, p. 558-564. 


\section{A - Resultados de experimentos (DTW)}

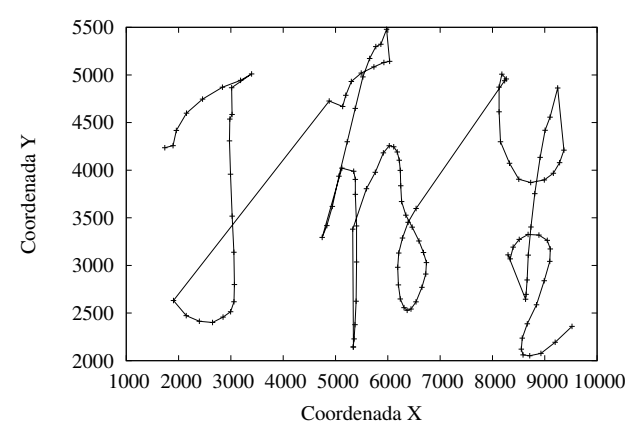

(a) Assinatura

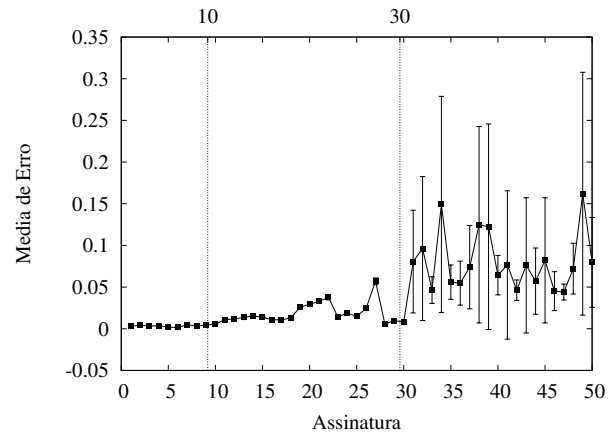

(c) DD2 - tempo por ponto

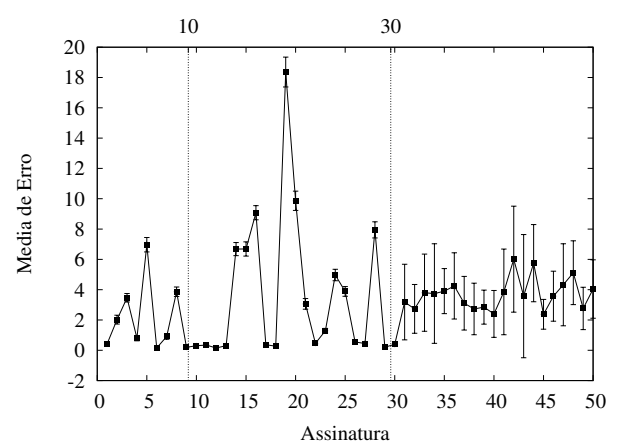

(e) DD4 - derivada entre as coordenadas da amostragem

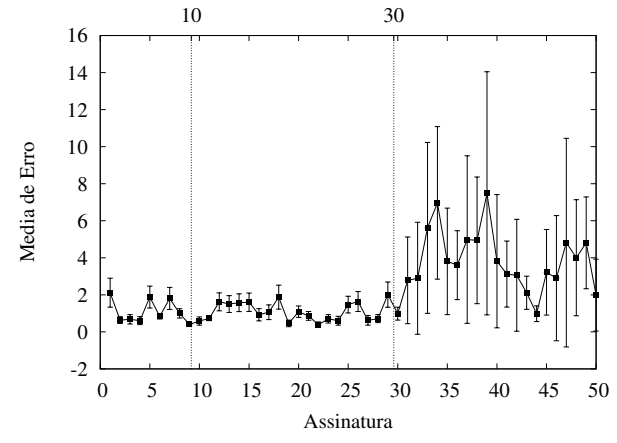

(g) DD6 - distância entre os pontos

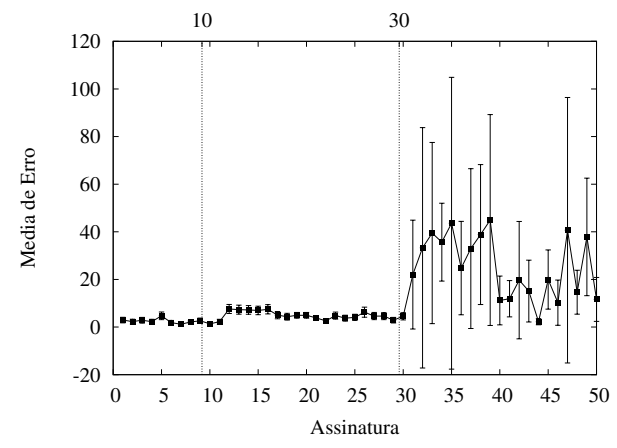

(b) DD1 - diferença entre as coordenadas da amostragem

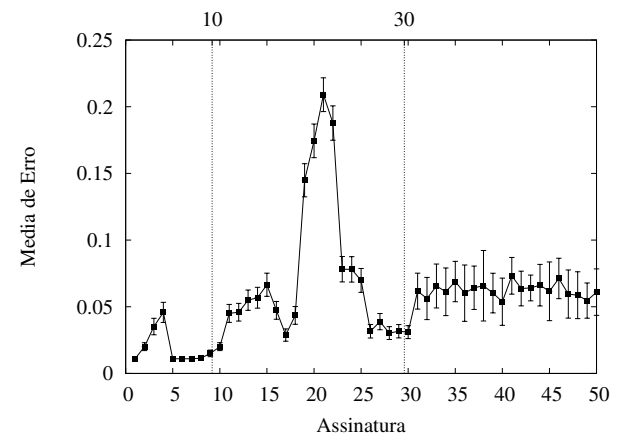

(d) DD3 - frequência dos pontos

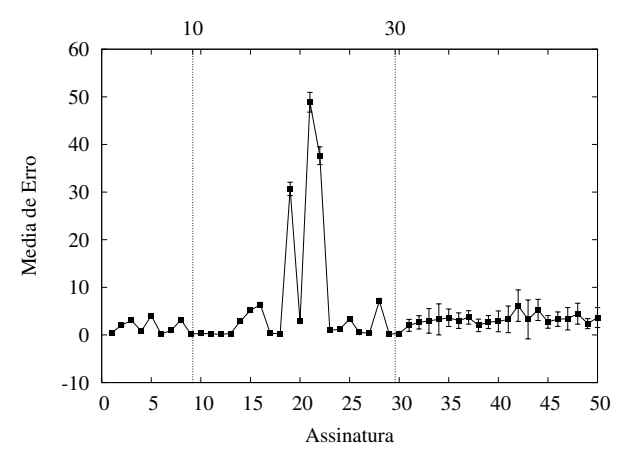

(f) DD5 - derivada entre os pontos por tempo

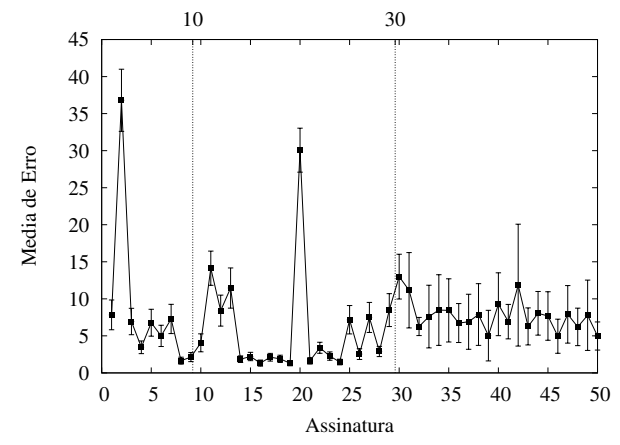

(h) DD7 - distância por tempo (velocidade)

Usuário 1 - Resultado dos experimentos utilizando a medida de similaridade DTW, onde são comparados os resultados de treinamento com 10 assinaturas verdadeiras e 40 falsas. 


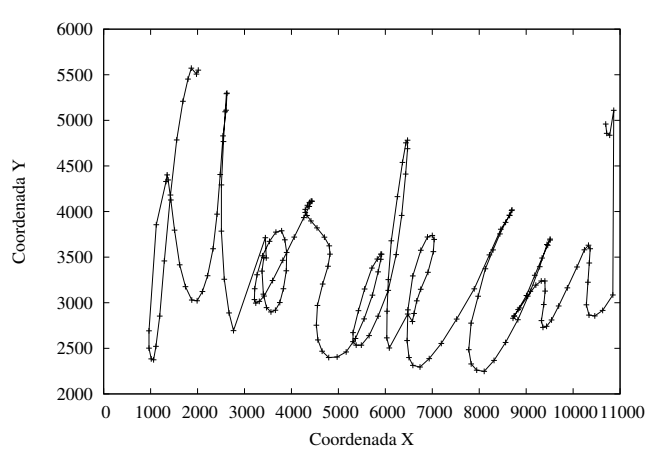

(a) Assinatura

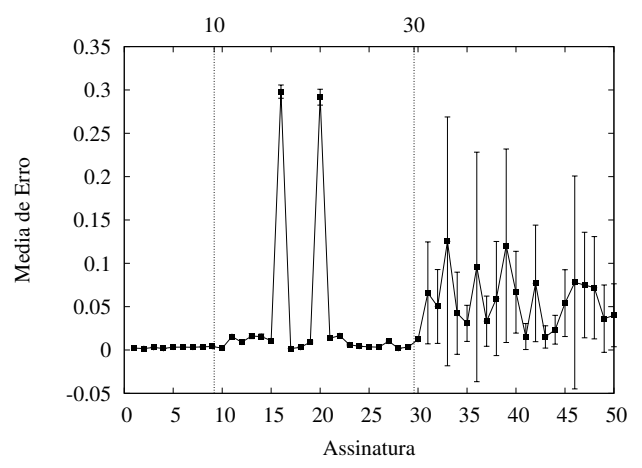

(c) DD2 - tempo por ponto

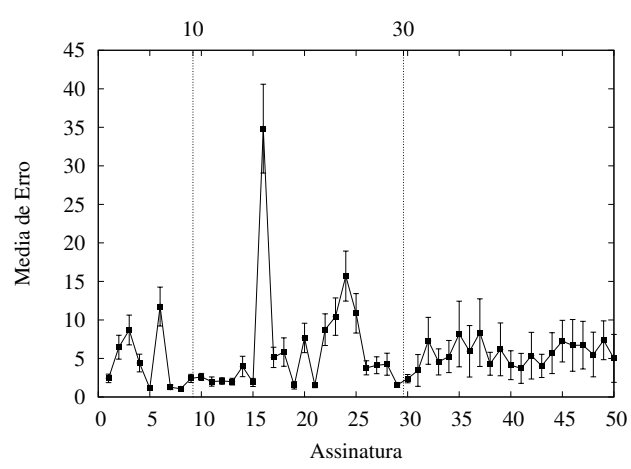

(e) DD4 - derivada entre as coordenadas da (f) DD5 - derivada entre os pontos por tempo amostragem

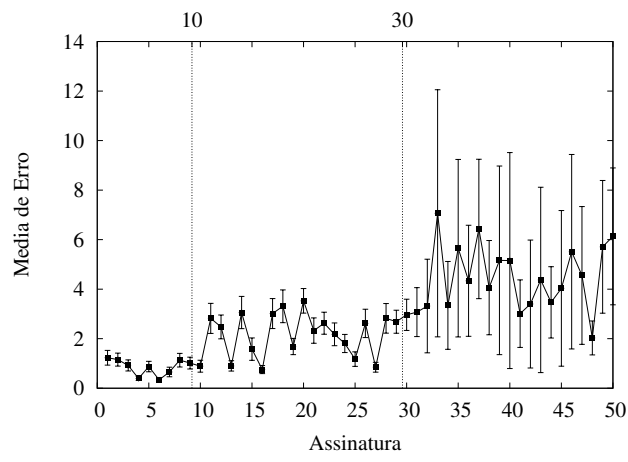

(g) DD6 - distância entre os pontos

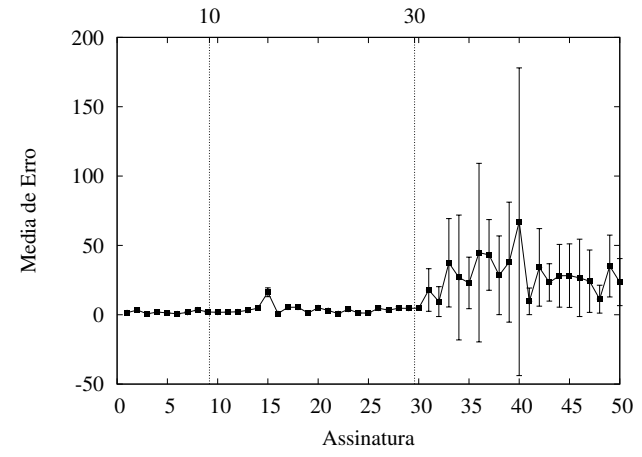

(b) DD1 - diferença entre as coordenadas da amostragem

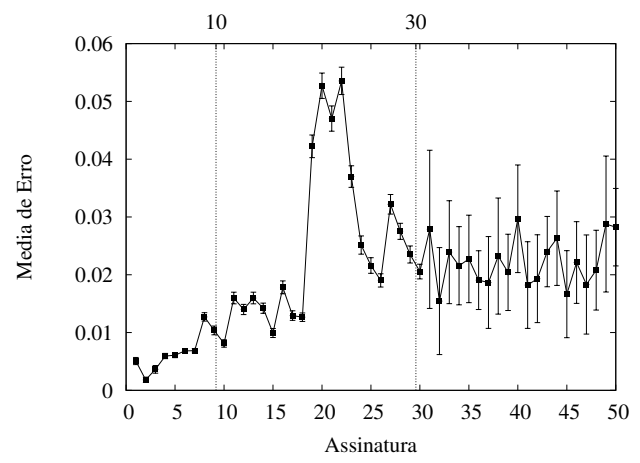

(d) DD3 - frequência dos pontos

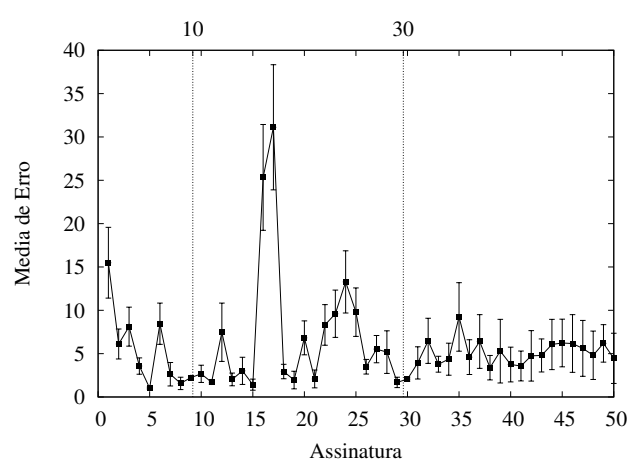

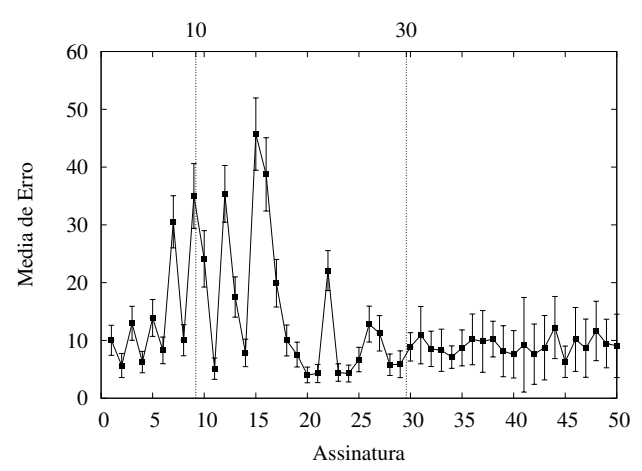

(h) DD7 - distância por tempo (velocidade)

Usuário 2 - Resultado dos experimentos utilizando a medida de similaridade DTW, onde são comparados os resultados de treinamento com 10 assinaturas verdadeiras e 40 falsas. 


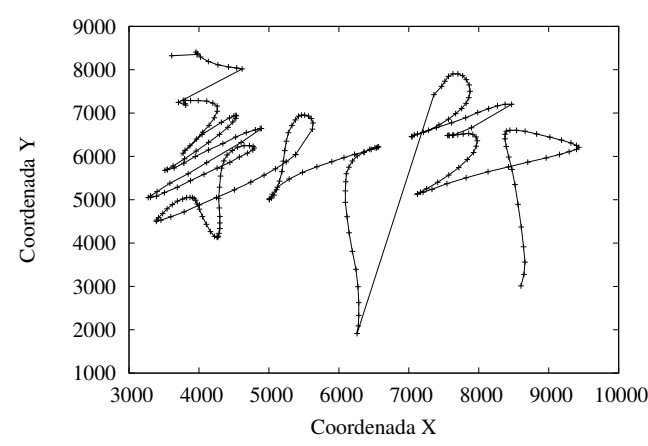

(a) Assinatura

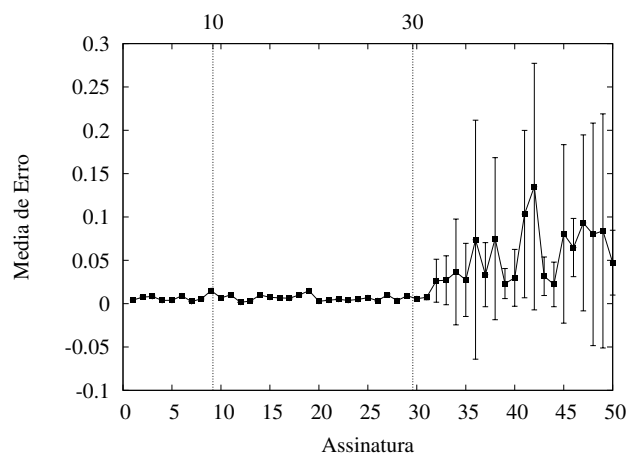

(c) DD2 - tempo por ponto

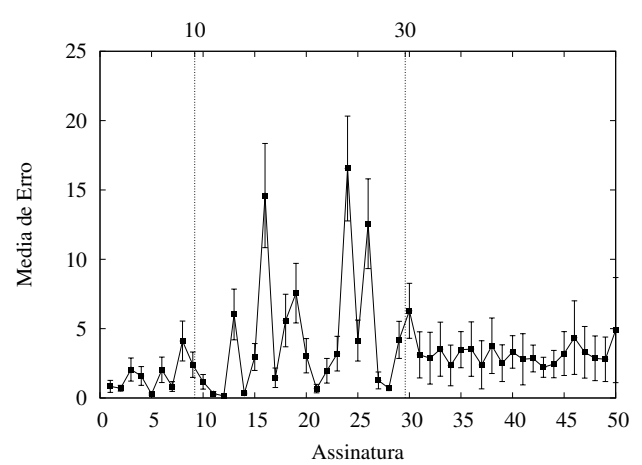

(e) DD4 - derivada entre as coordenadas da amostragem

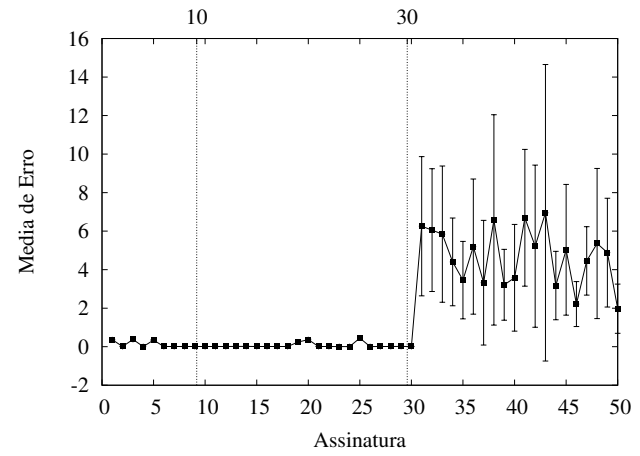

(g) DD6 - distância entre os pontos

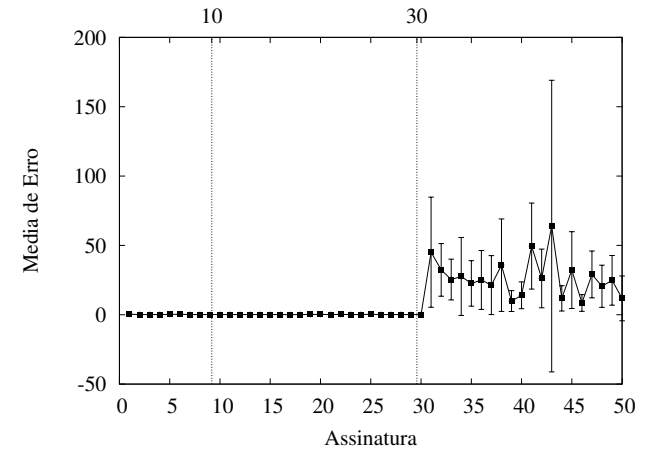

(b) DD1 - diferença entre as coordenadas da amostragem

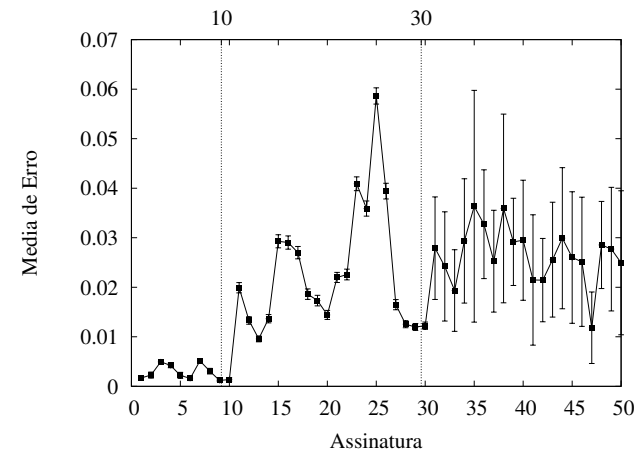

(d) DD3 - frequência dos pontos

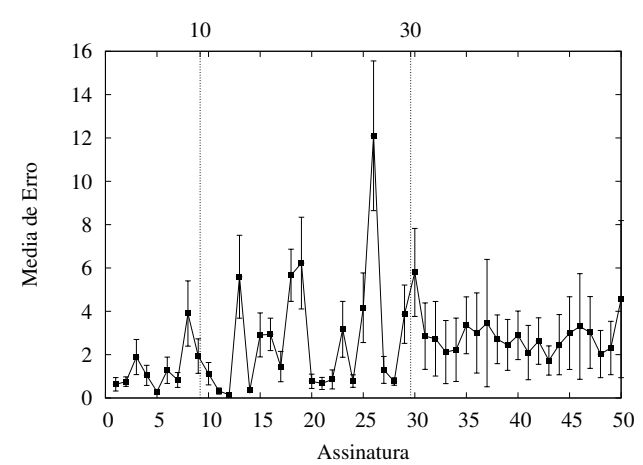

(f) DD5 - derivada entre os pontos por tempo

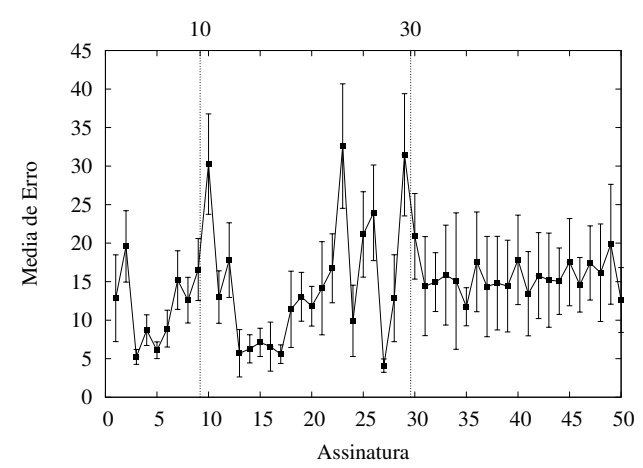

(h) DD7 - distância por tempo (velocidade)

Usuário 3 - Resultado dos experimentos utilizando a medida de similaridade DTW, onde são comparados os resultados de treinamento com 10 assinaturas verdadeiras e 40 falsas. 


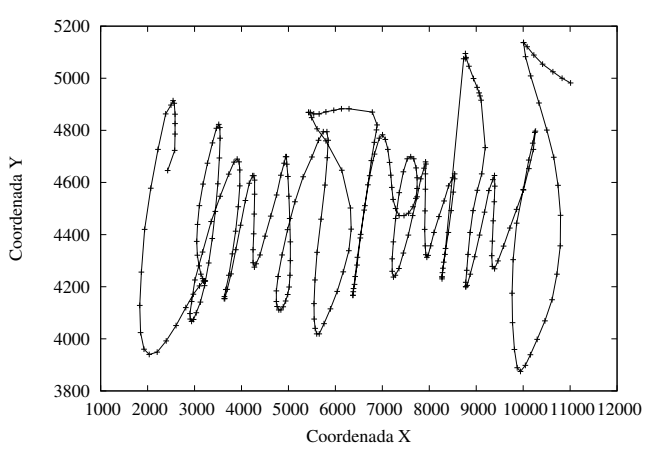

(a) Assinatura

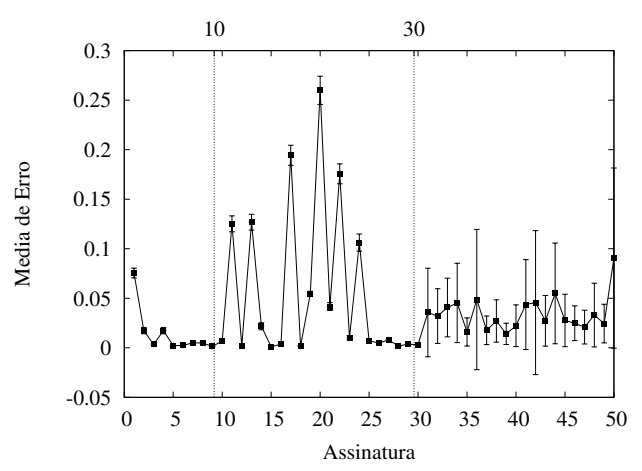

(c) DD2 - tempo por ponto

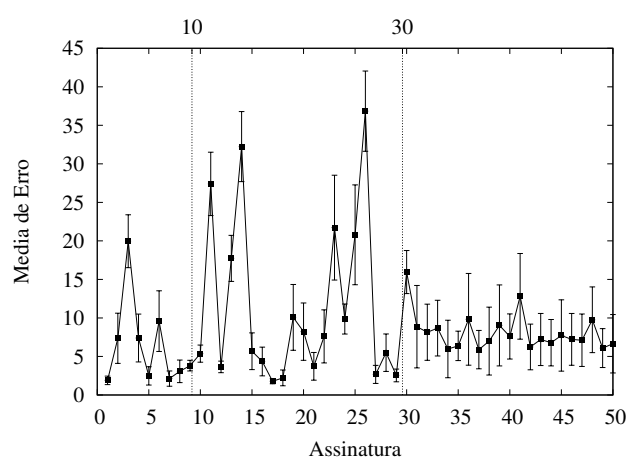

(e) DD4 - derivada entre as coordenadas da (f) DD5 - derivada entre os pontos por tempo amostragem

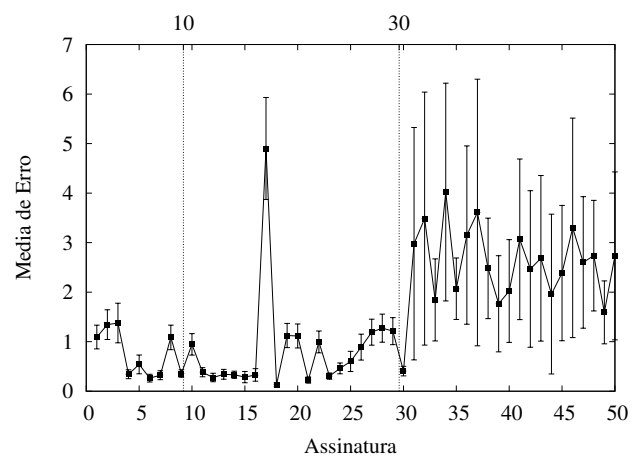

(g) DD6 - distância entre os pontos

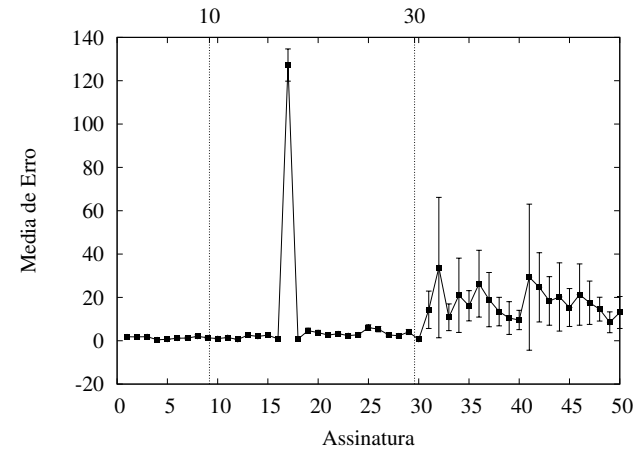

(b) DD1 - diferença entre as coordenadas da amostragem

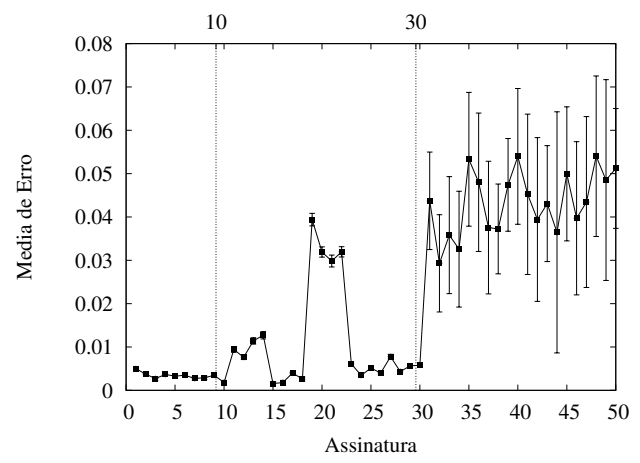

(d) DD3 - frequência dos pontos

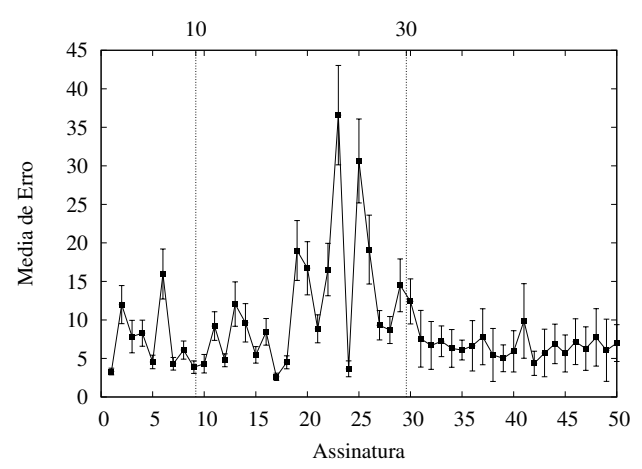

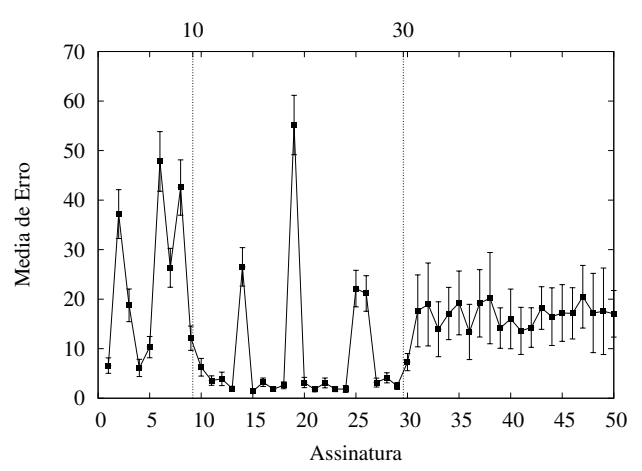

(h) DD7 - distância por tempo (velocidade)

Usuário 4 - Resultado dos experimentos utilizando a medida de similaridade DTW, onde são comparados os resultados de treinamento com 10 assinaturas verdadeiras e 40 falsas. 


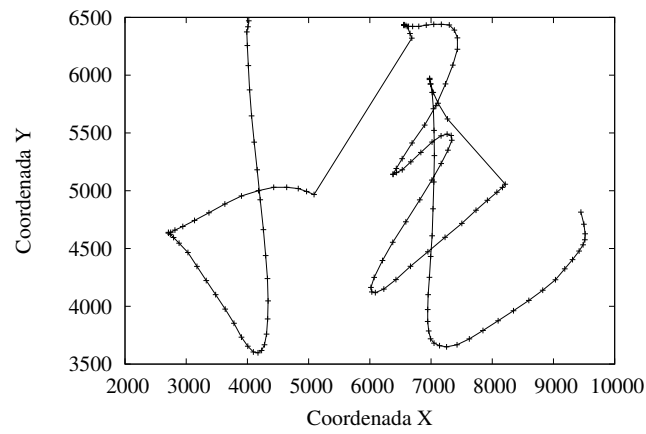

(a) Assinatura

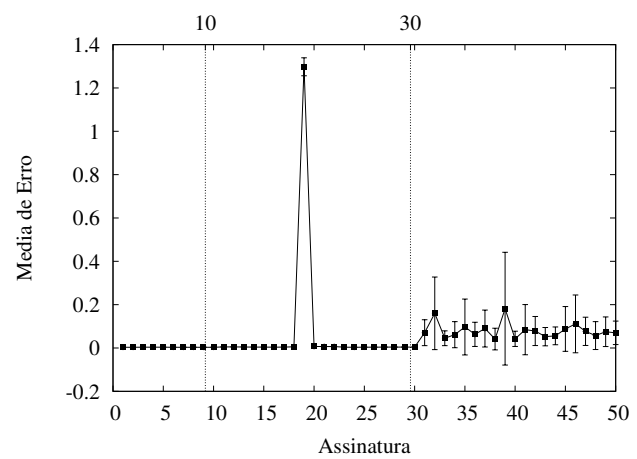

(c) DD2 - tempo por ponto

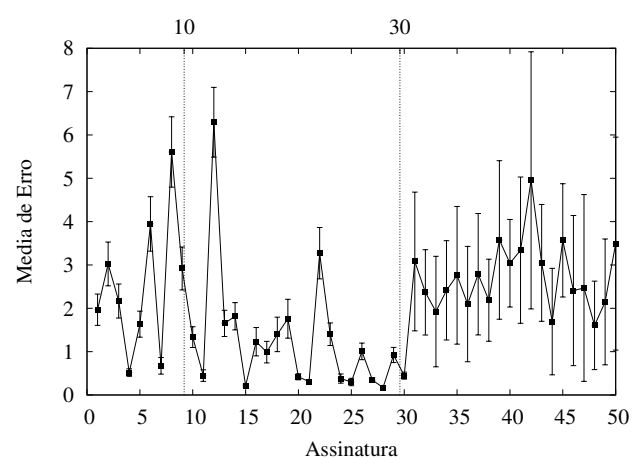

(e) DD4 - derivada entre as coordenadas da amostragem

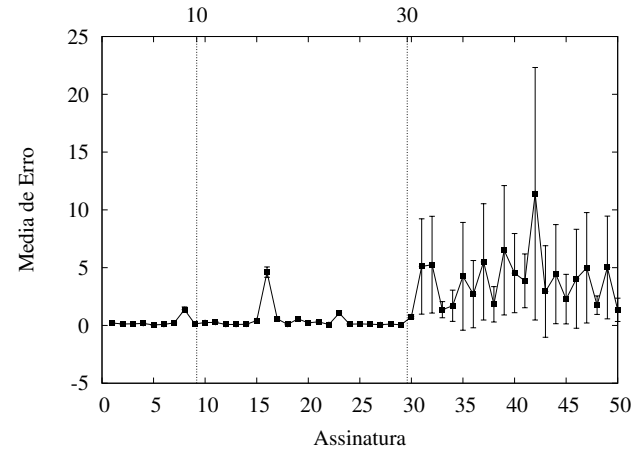

(g) DD6 - distância entre os pontos

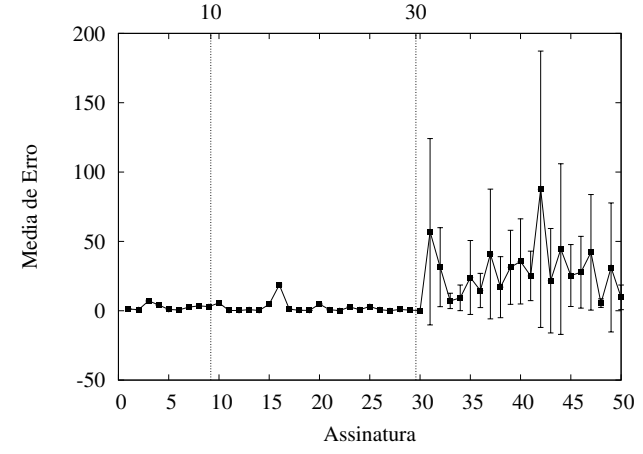

(b) DD1 - diferença entre as coordenadas da amostragem

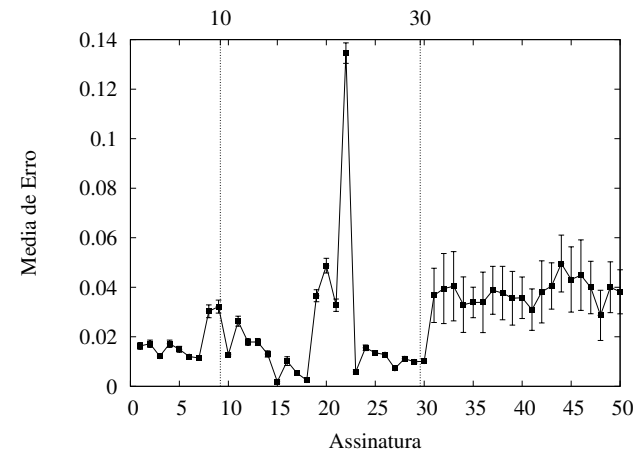

(d) DD3 - frequência dos pontos

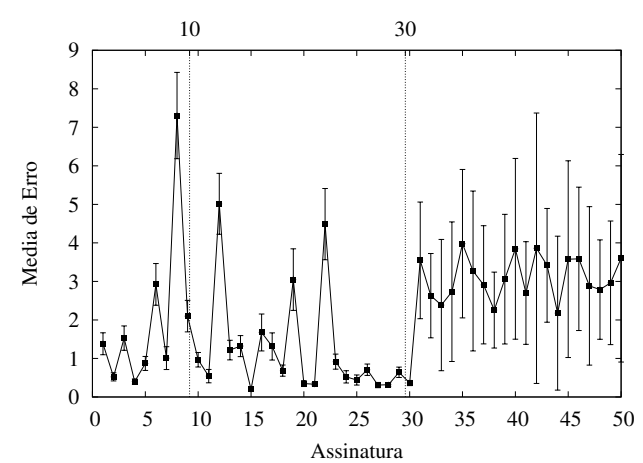

(f) DD5 - derivada entre os pontos por tempo

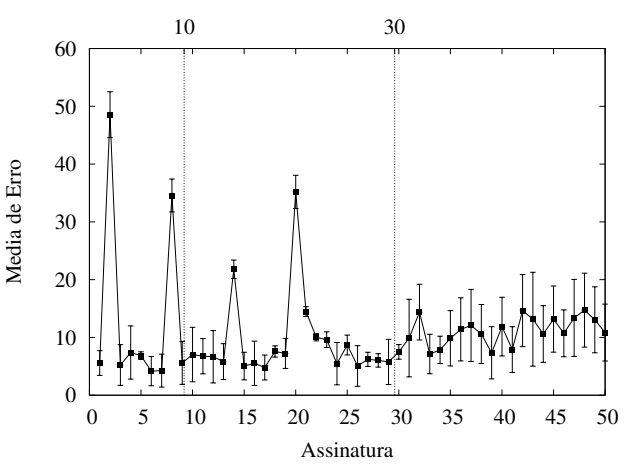

(h) DD7 - distância por tempo (velocidade)

Usuário 5 - Resultado dos experimentos utilizando a medida de similaridade DTW, onde são comparados os resultados de treinamento com 10 assinaturas verdadeiras e 40 falsas. 


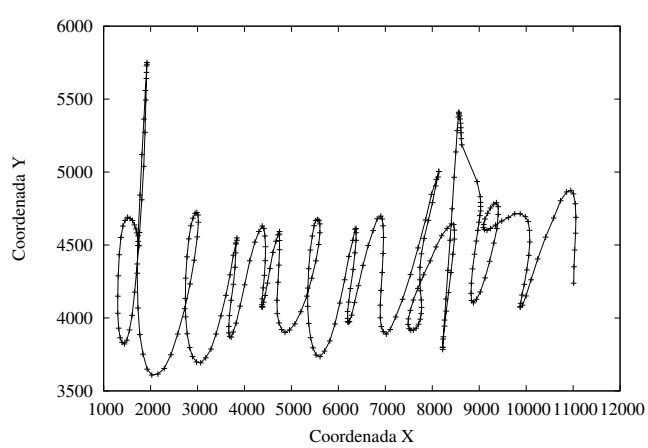

(a) Assinatura

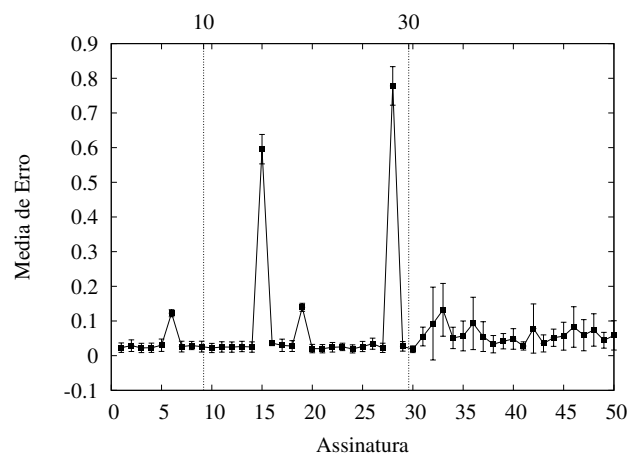

(c) DD2 - tempo por ponto

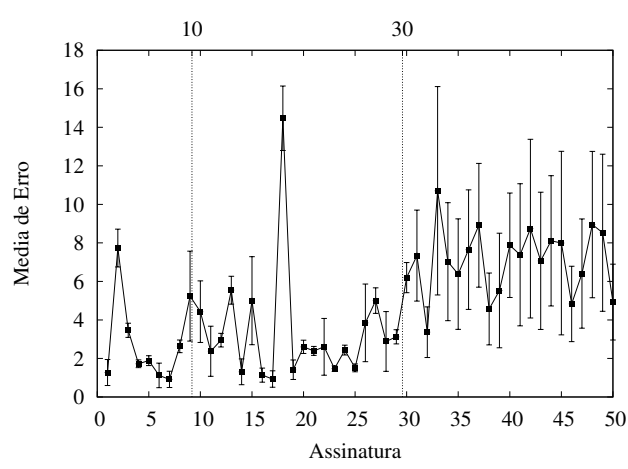

(e) DD4 - derivada entre as coordenadas da (f) DD5 - derivada entre os pontos por tempo amostragem

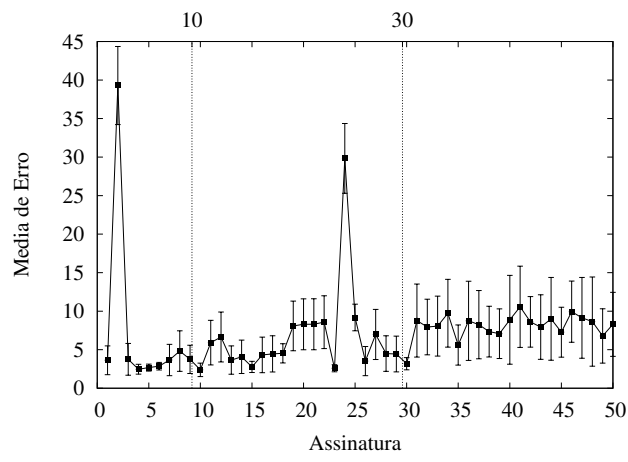

(g) DD6 - distância entre os pontos

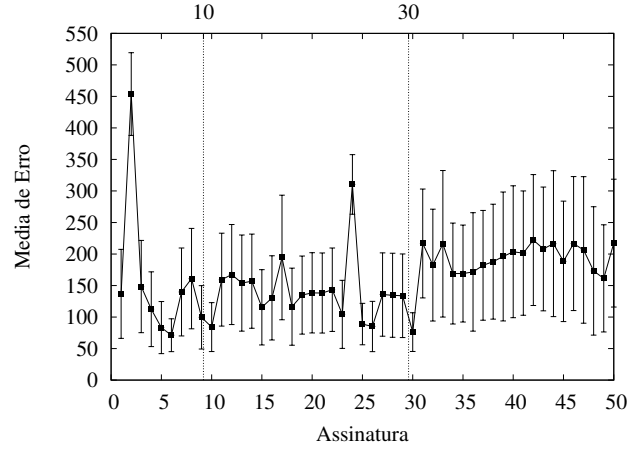

(b) DD1 - diferença entre as coordenadas da amostragem

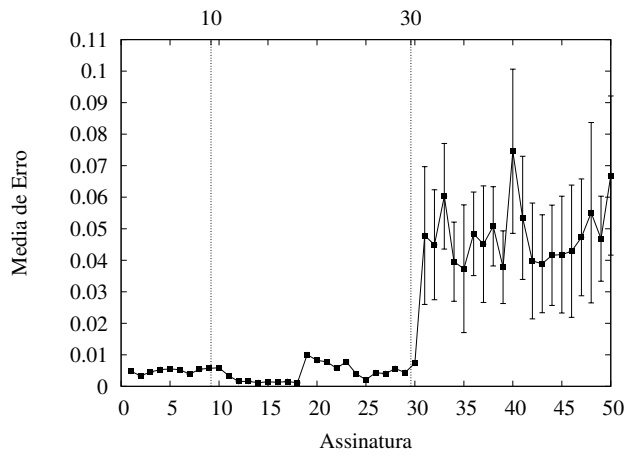

(d) DD3 - frequência dos pontos

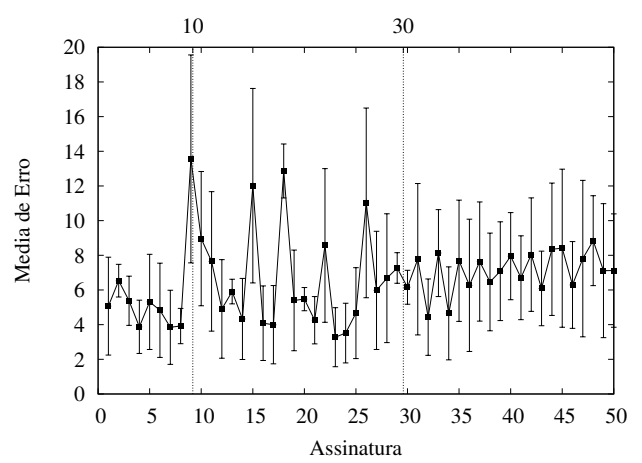

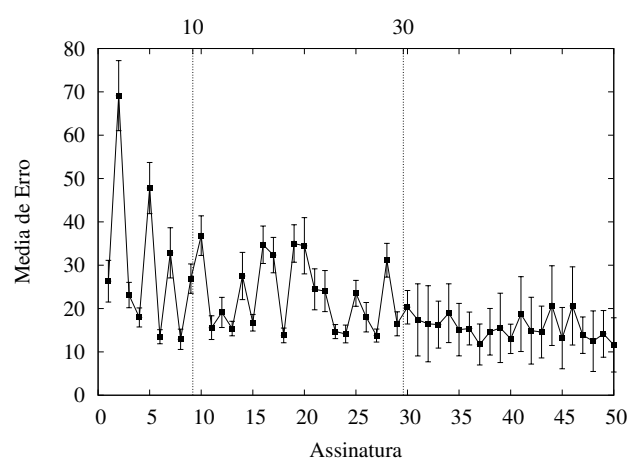

(h) DD7 - distância por tempo (velocidade)

Usuário 6 - Resultado dos experimentos utilizando a medida de similaridade DTW, onde são comparados os resultados de treinamento com 10 assinaturas verdadeiras e 40 falsas. 


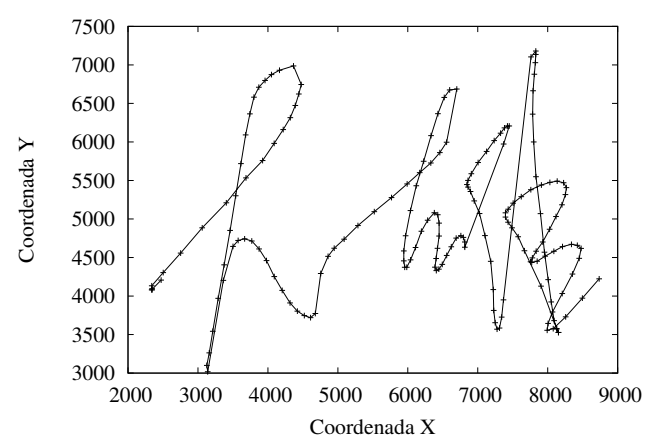

(a) Assinatura

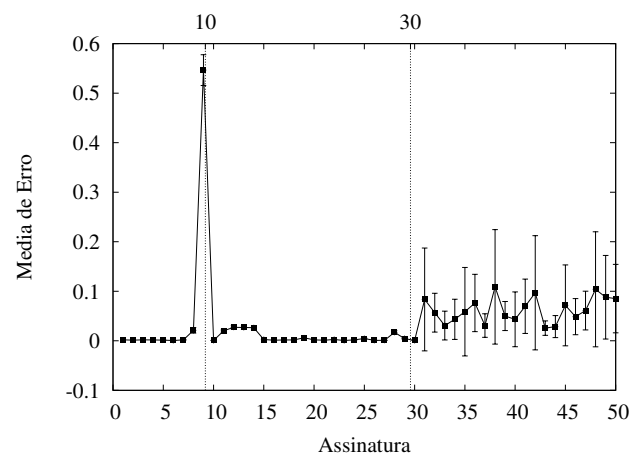

(c) DD2 - tempo por ponto

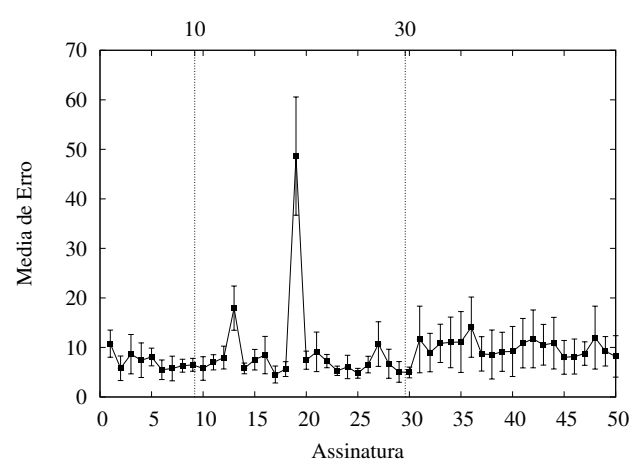

(e) DD4 - derivada entre as coordenadas da amostragem

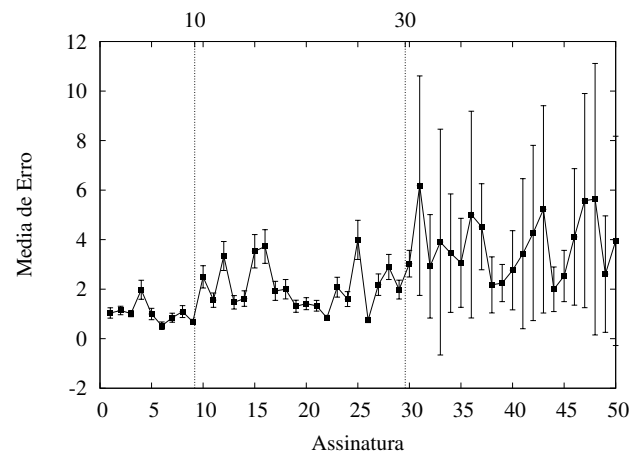

(g) DD6 - distância entre os pontos

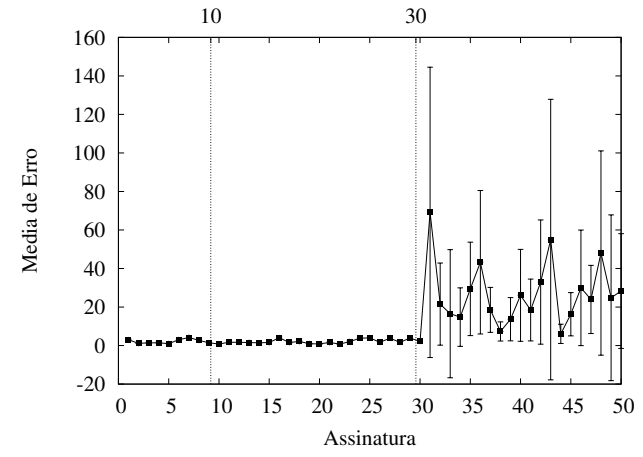

(b) DD1 - diferença entre as coordenadas da amostragem

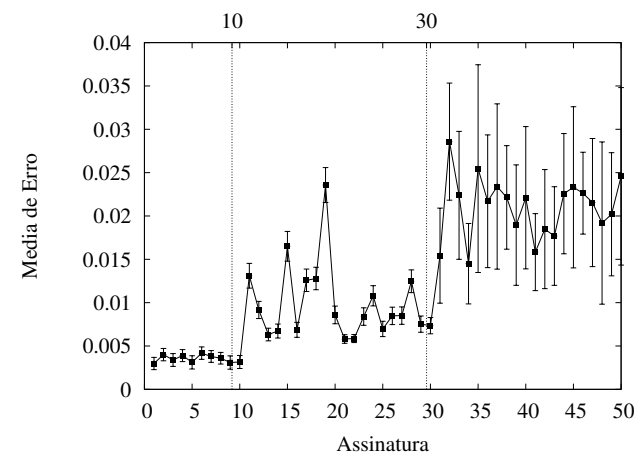

(d) DD3 - frequência dos pontos

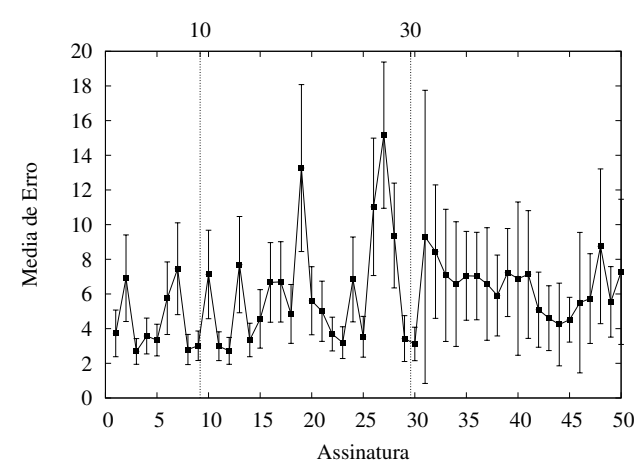

(f) DD5 - derivada entre os pontos por tempo

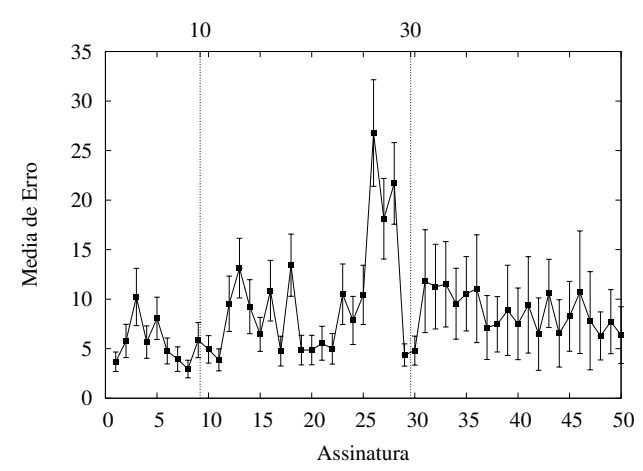

(h) DD7 - distância por tempo (velocidade)

Usuário 7 - Resultado dos experimentos utilizando a medida de similaridade DTW, onde são comparados os resultados de treinamento com 10 assinaturas verdadeiras e 40 falsas. 


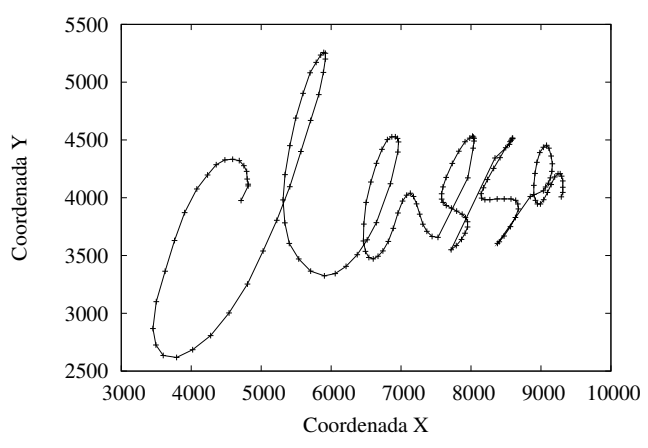

(a) Assinatura

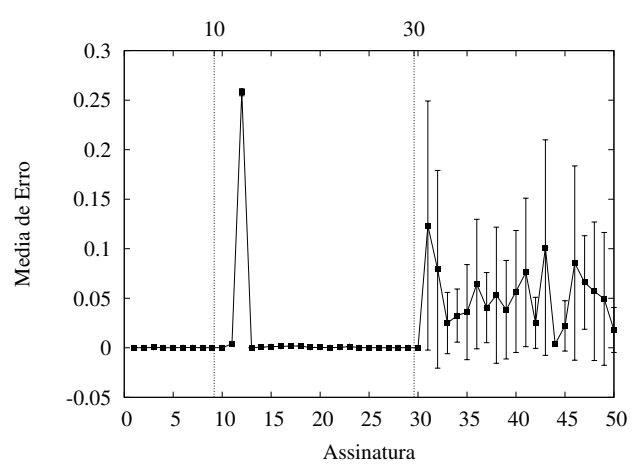

(c) DD2 - tempo por ponto

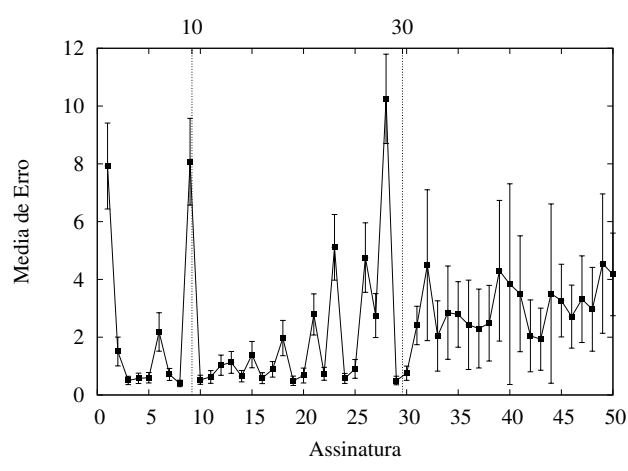

(e) DD4 - derivada entre as coordenadas da (f) DD5 - derivada entre os pontos por tempo amostragem

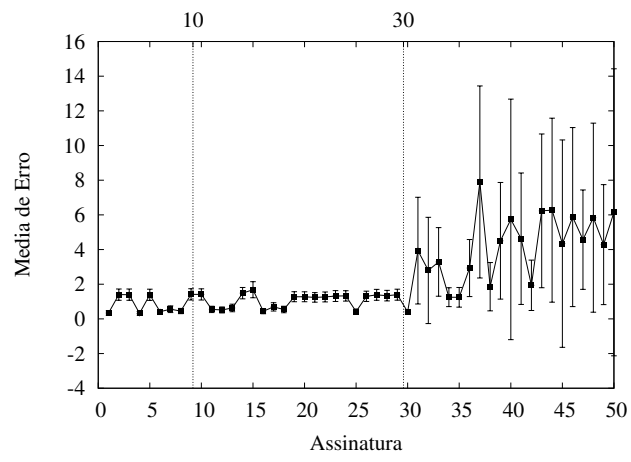

(g) DD6 - distância entre os pontos

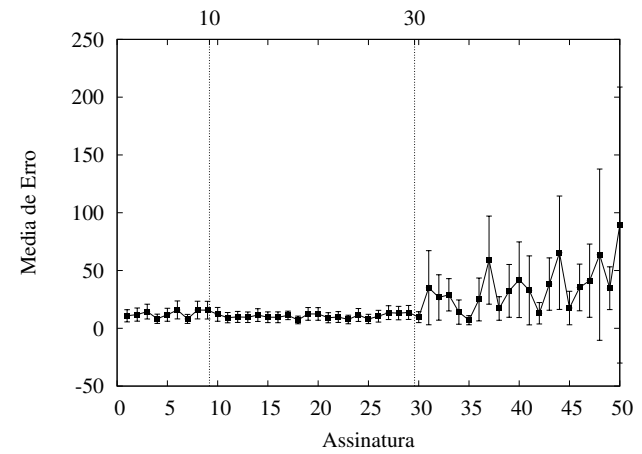

(b) DD1 - diferença entre as coordenadas da amostragem

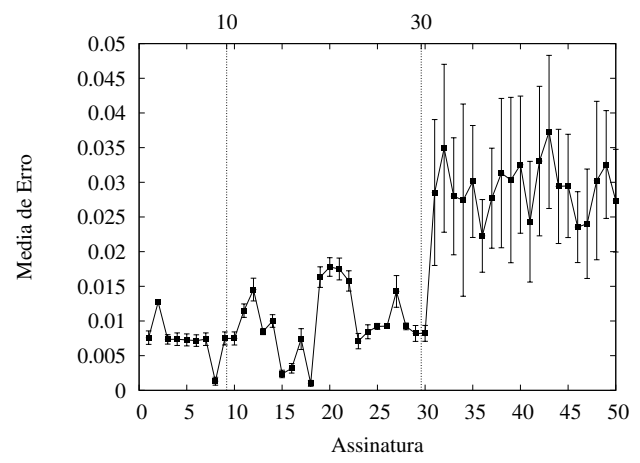

(d) DD3 - frequência dos pontos
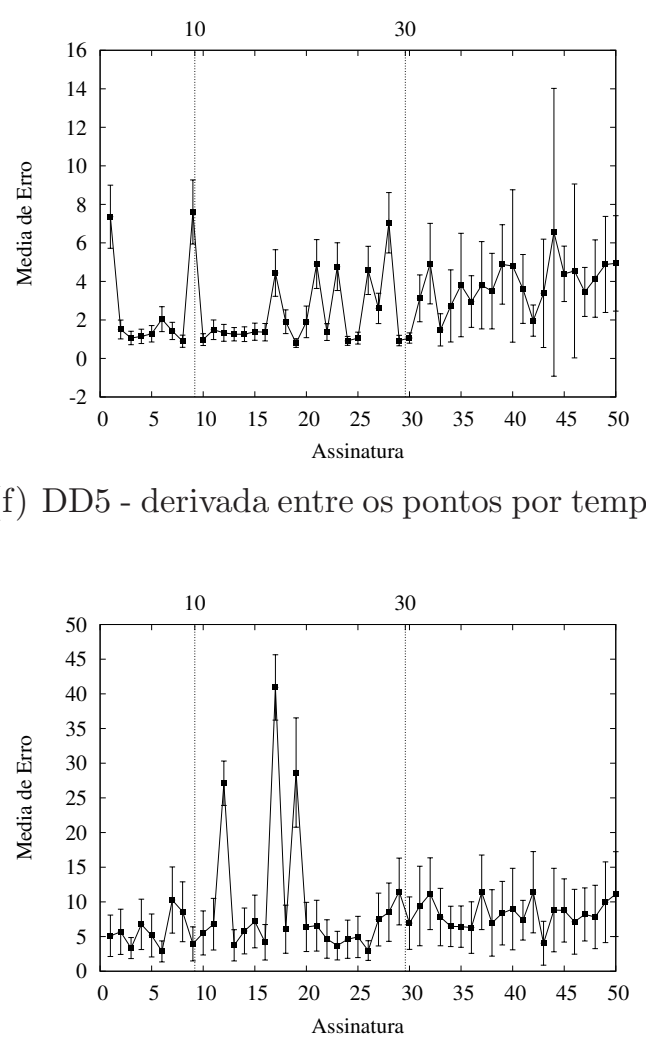

(h) DD7 - distância por tempo (velocidade)

Usuário 8 - Resultado dos experimentos utilizando a medida de similaridade DTW, onde são comparados os resultados de treinamento com 10 assinaturas verdadeiras e 40 falsas. 


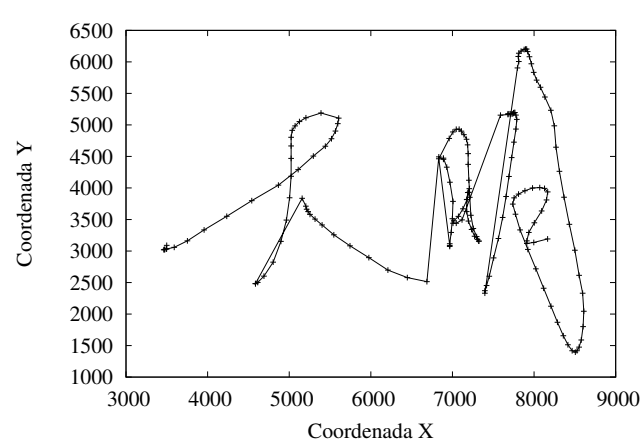

(a) Assinatura

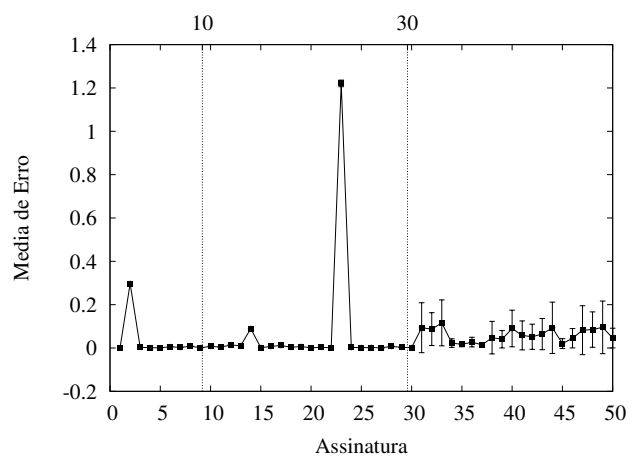

(c) DD2 - tempo por ponto

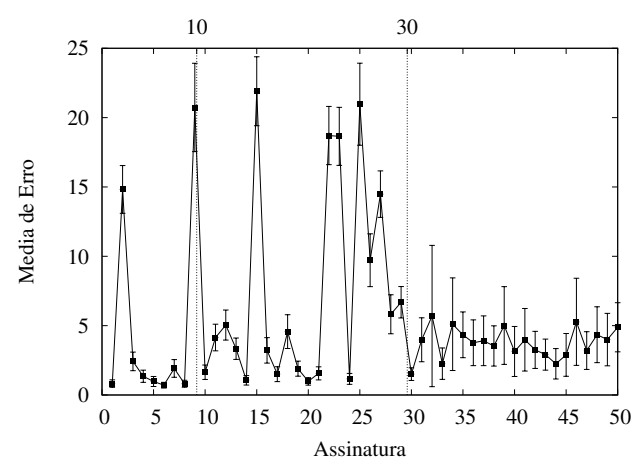

(e) DD4 - derivada entre as coordenadas da amostragem

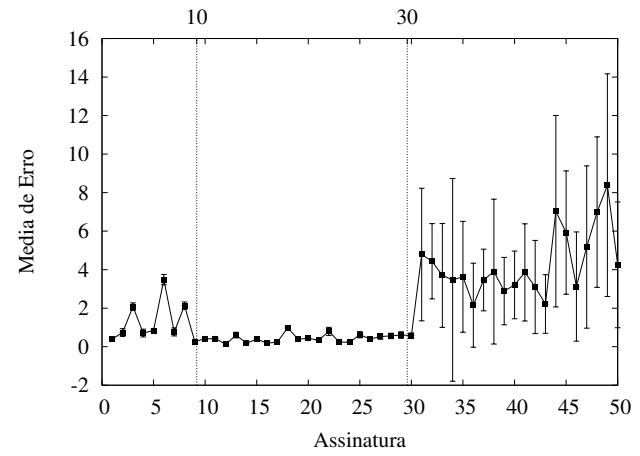

(g) DD6 - distância entre os pontos

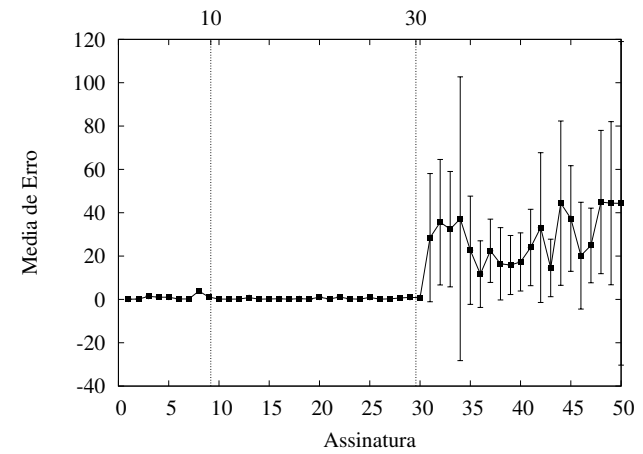

(b) DD1 - diferença entre as coordenadas da amostragem

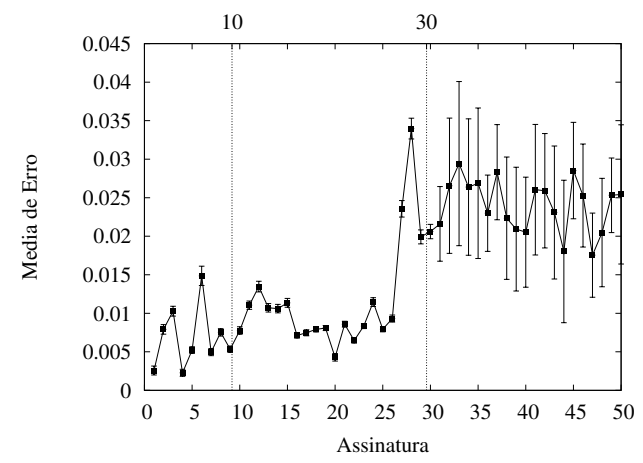

(d) DD3 - frequência dos pontos

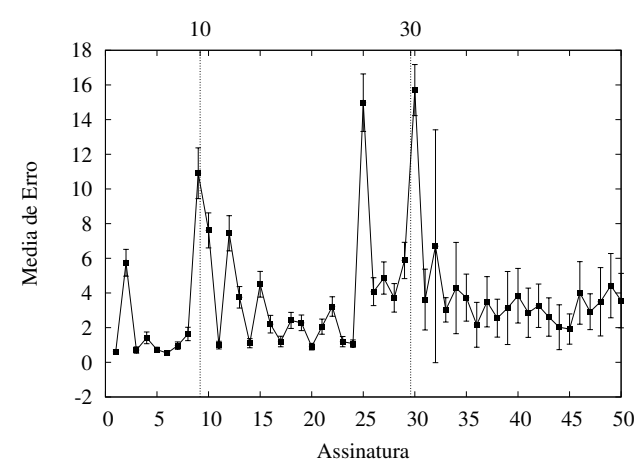

(f) DD5 - derivada entre os pontos por tempo

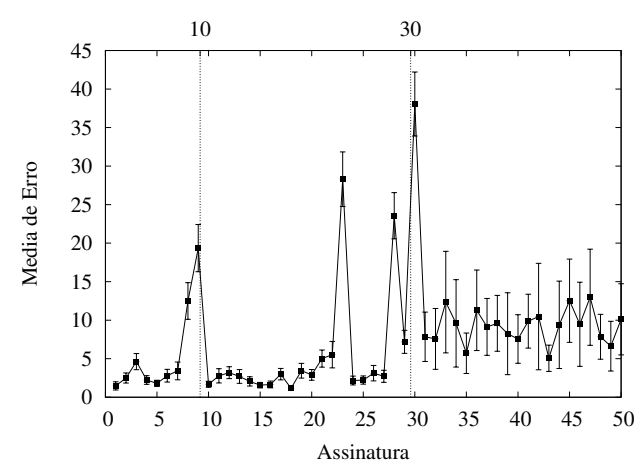

(h) DD7 - distância por tempo (velocidade)

Usuário 9 - Resultado dos experimentos utilizando a medida de similaridade DTW, onde são comparados os resultados de treinamento com 10 assinaturas verdadeiras e 40 falsas. 


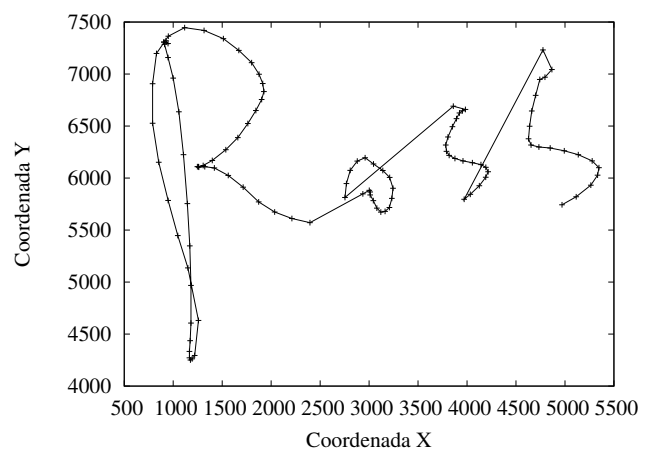

(a) Assinatura

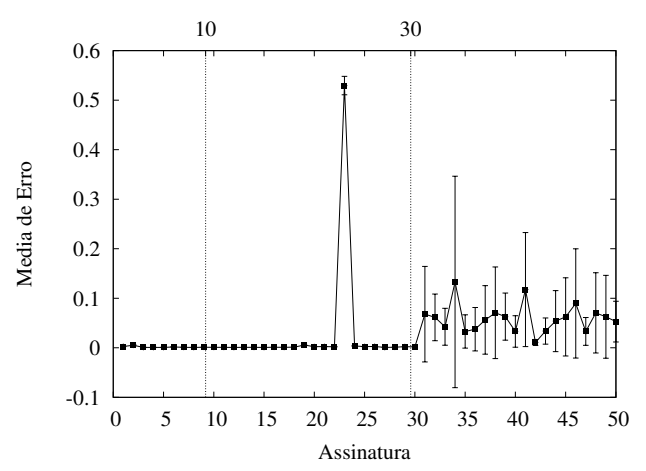

(c) DD2 - tempo por ponto

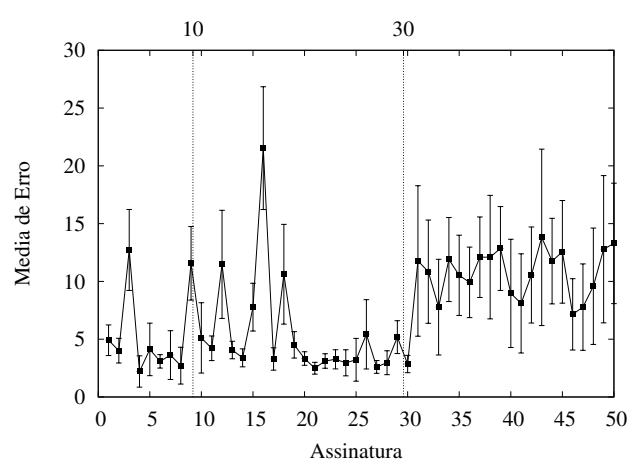

(e) DD4 - derivada entre as coordenadas da (f) DD5 - derivada entre os pontos por tempo amostragem

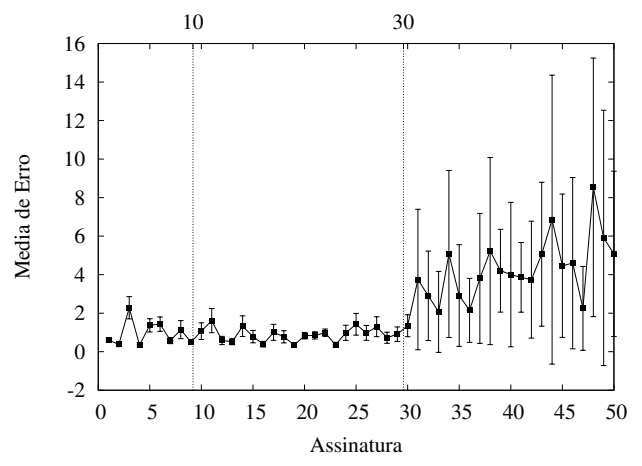

(g) DD6 - distância entre os pontos

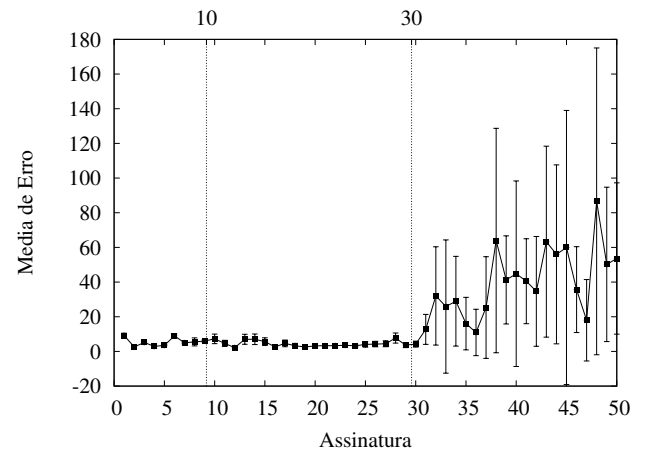

(b) DD1 - diferença entre as coordenadas da amostragem

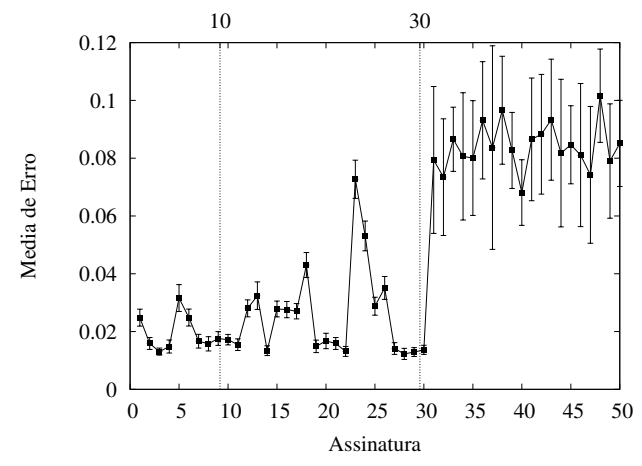

(d) DD3 - frequência dos pontos

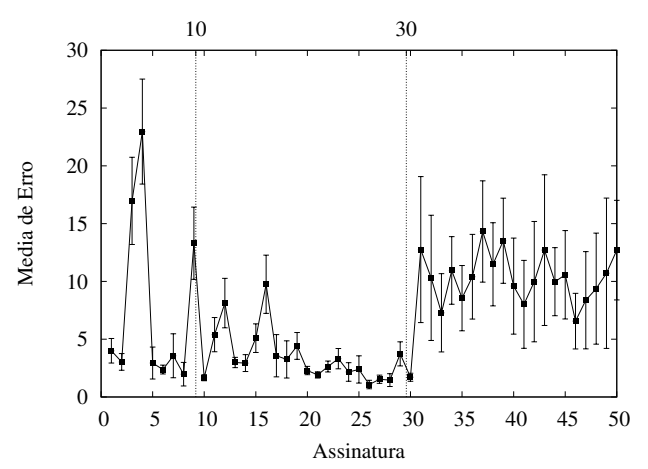

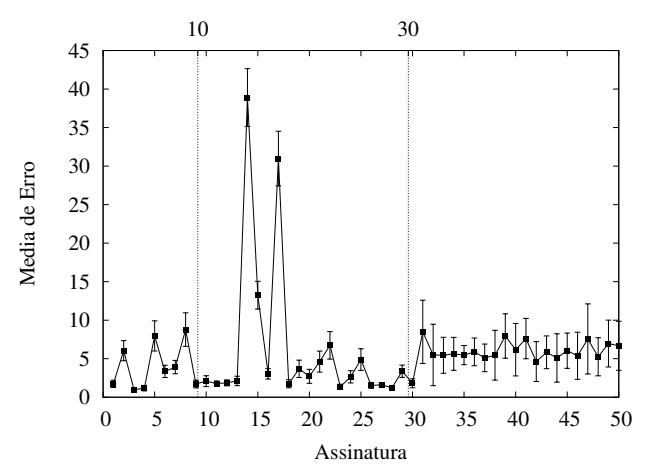

(h) DD7 - distância por tempo (velocidade)

Usuário 10 - Resultado dos experimentos utilizando a medida de similaridade DTW, onde são comparados os resultados de treinamento com 10 assinaturas verdadeiras e 40 falsas. 


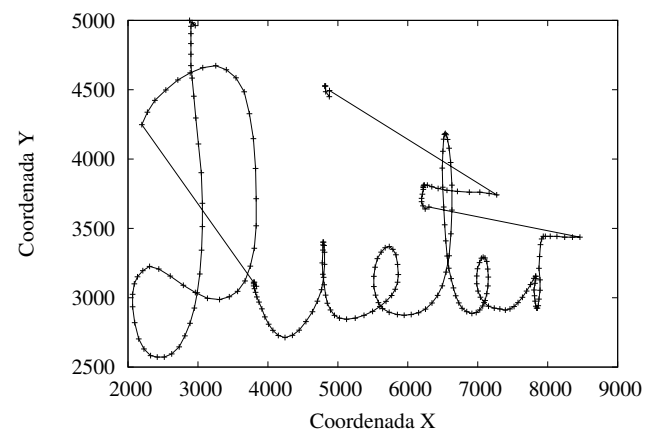

(a) Assinatura

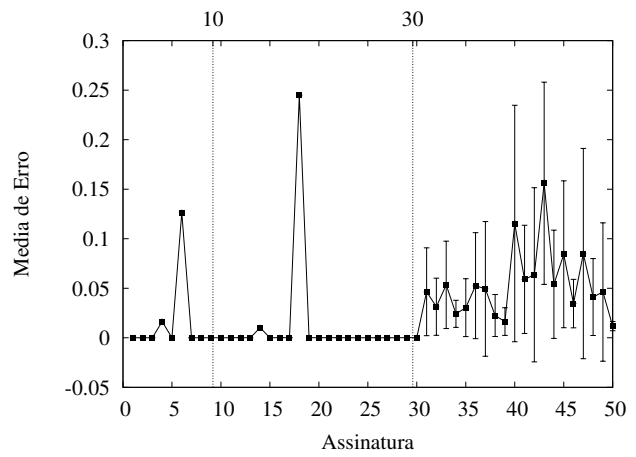

(c) DD2 - tempo por ponto

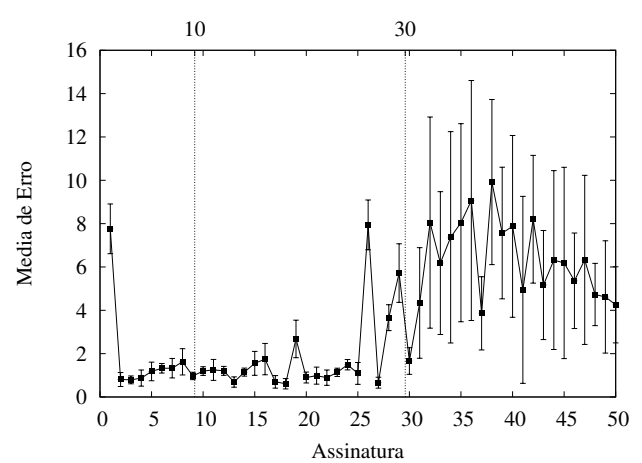

(e) DD4 - derivada entre as coordenadas da amostragem

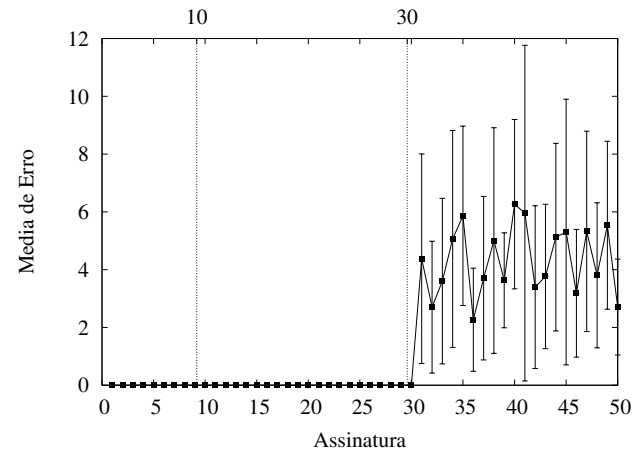

(g) DD6 - distância entre os pontos

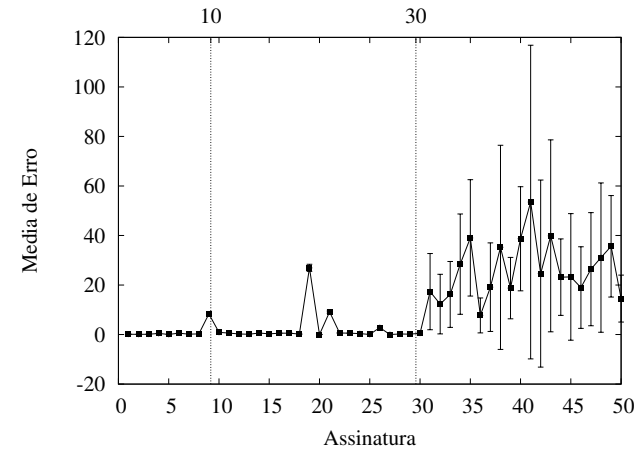

(b) DD1 - diferença entre as coordenadas da amostragem

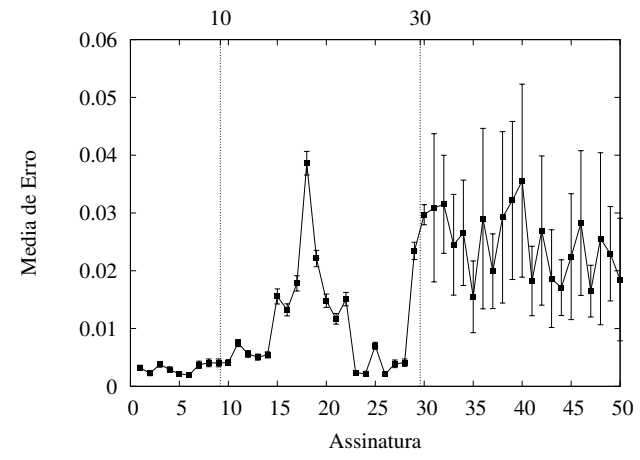

(d) DD3 - frequência dos pontos

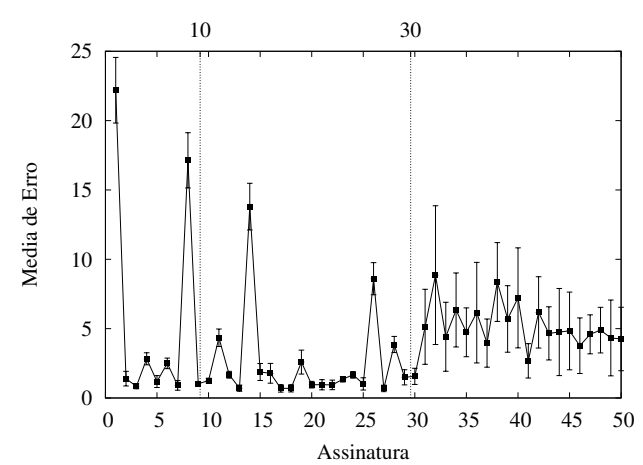

(f) DD5 - derivada entre os pontos por tempo

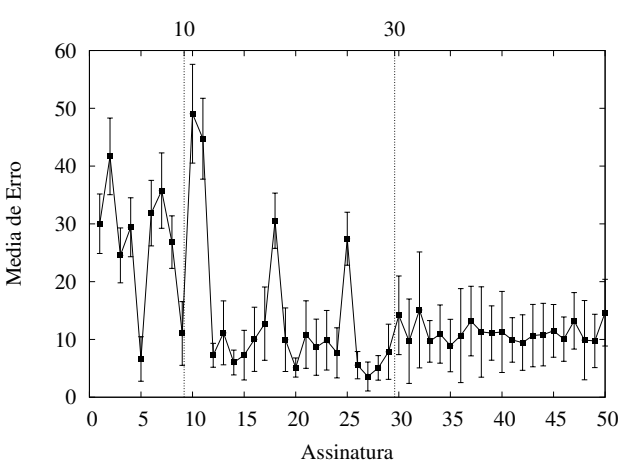

(h) DD7 - distância por tempo (velocidade)

Usuário 11 - Resultado dos experimentos utilizando a medida de similaridade DTW, onde são comparados os resultados de treinamento com 10 assinaturas verdadeiras e 40 falsas. 


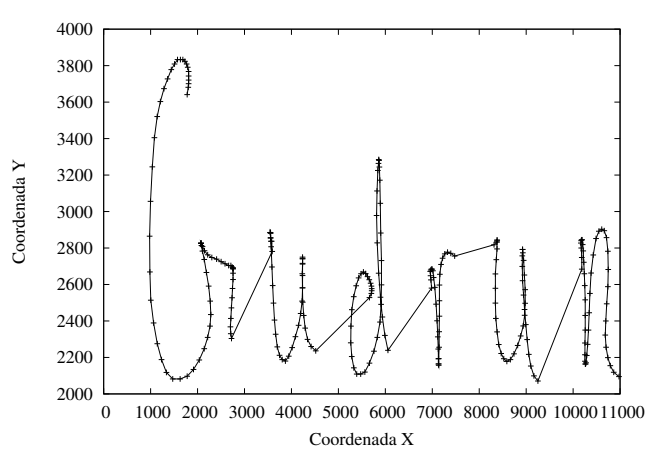

(a) Assinatura

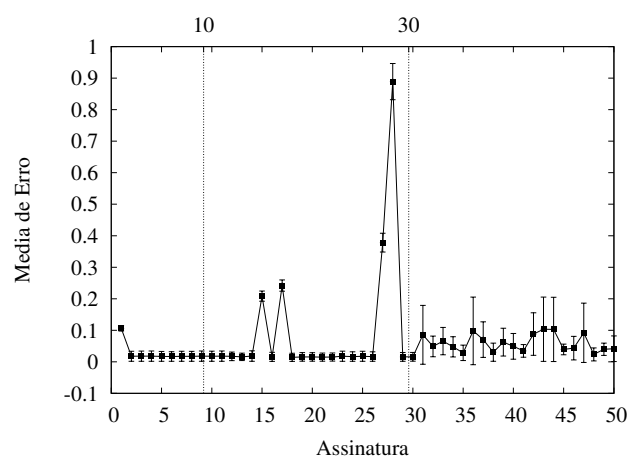

(c) DD2 - tempo por ponto

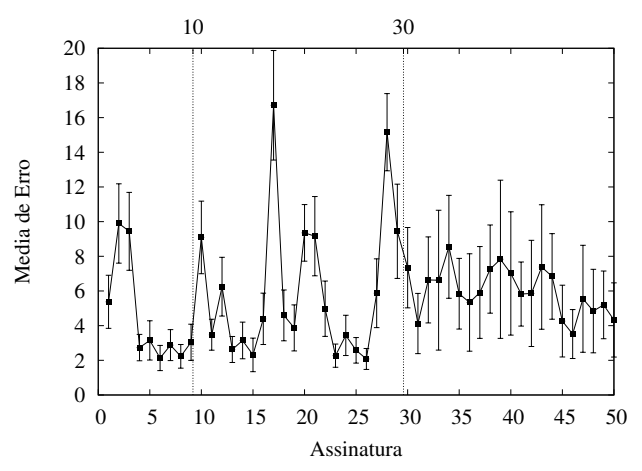

(e) DD4 - derivada entre as coordenadas da (f) DD5 - derivada entre os pontos por tempo amostragem

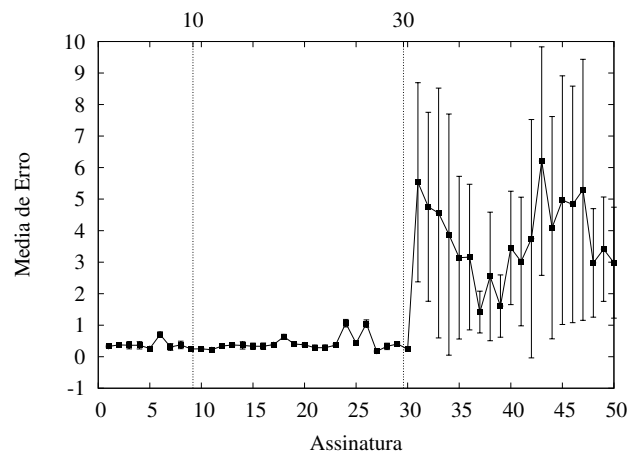

(g) DD6 - distância entre os pontos

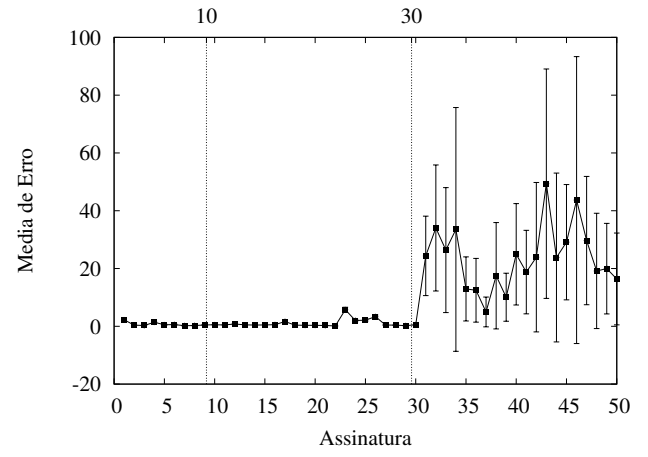

(b) DD1 - diferença entre as coordenadas da amostragem

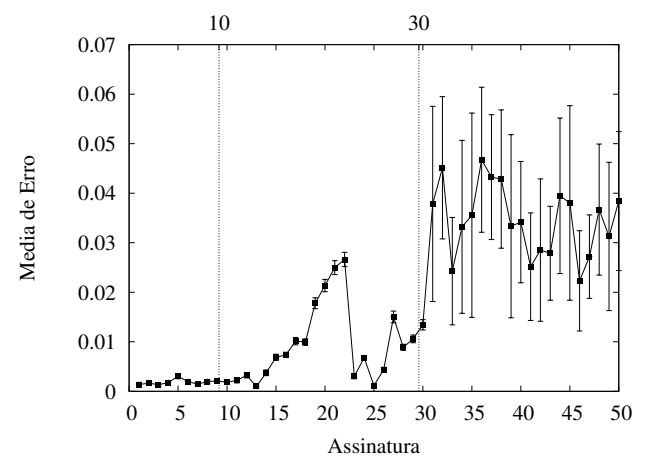

(d) DD3 - frequência dos pontos

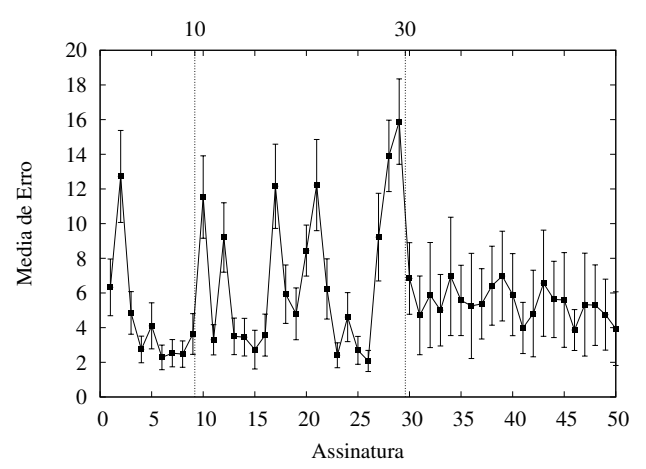

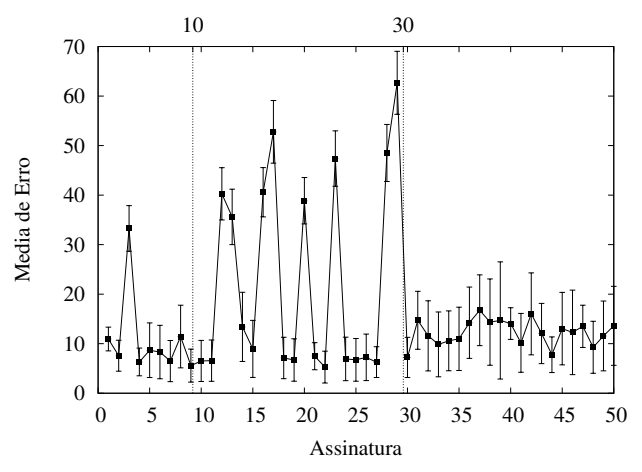

(h) DD7 - distância por tempo (velocidade)

Usuário 12 - Resultado dos experimentos utilizando a medida de similaridade DTW, onde são comparados os resultados de treinamento com 10 assinaturas verdadeiras e 40 falsas. 


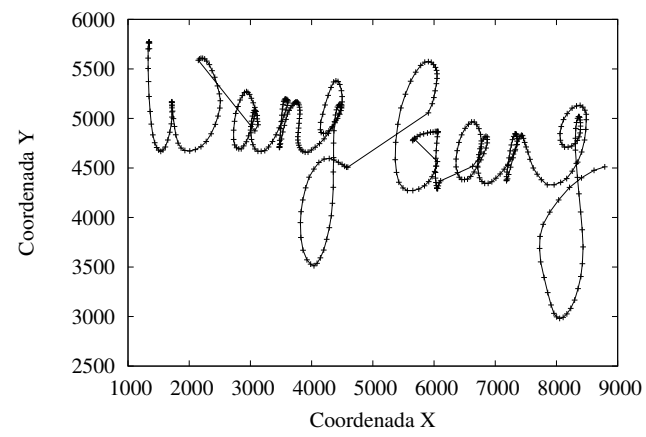

(a) Assinatura

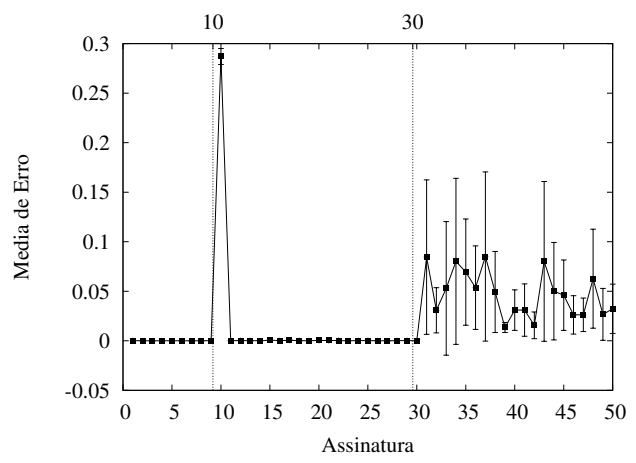

(c) DD2 - tempo por ponto

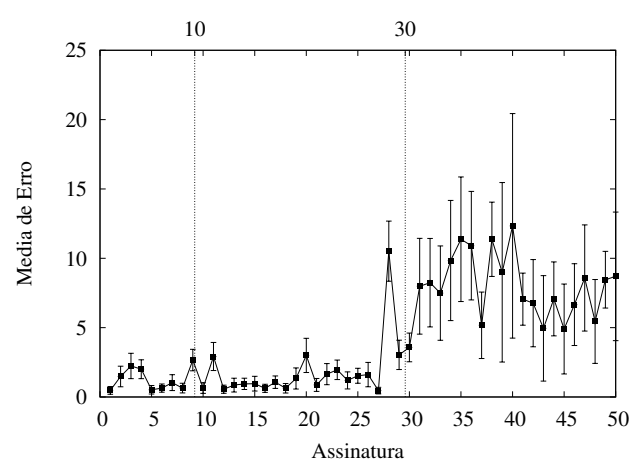

(e) DD4 - derivada entre as coordenadas da amostragem

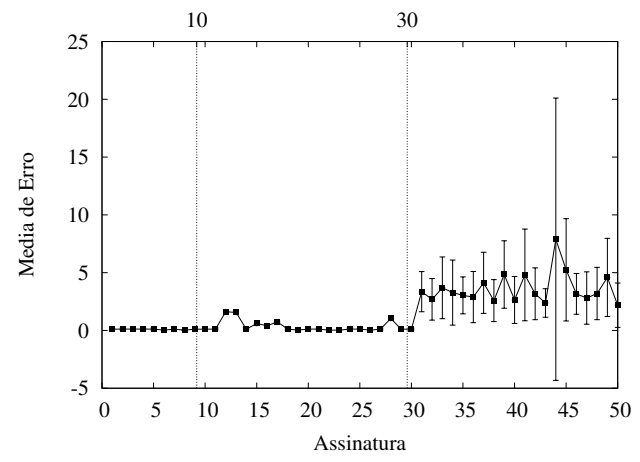

(g) DD6 - distância entre os pontos

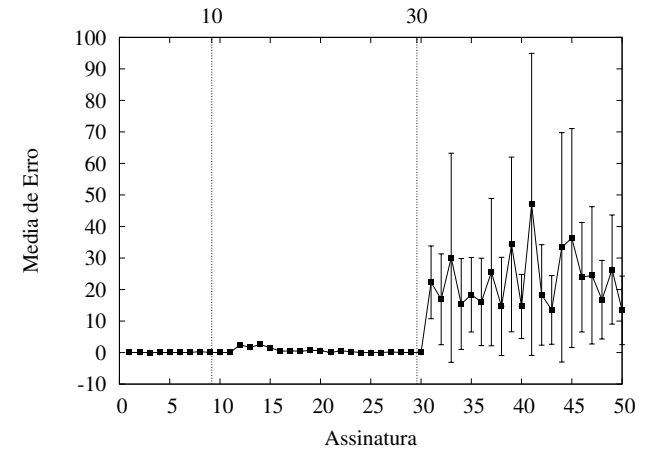

(b) DD1 - diferença entre as coordenadas da amostragem

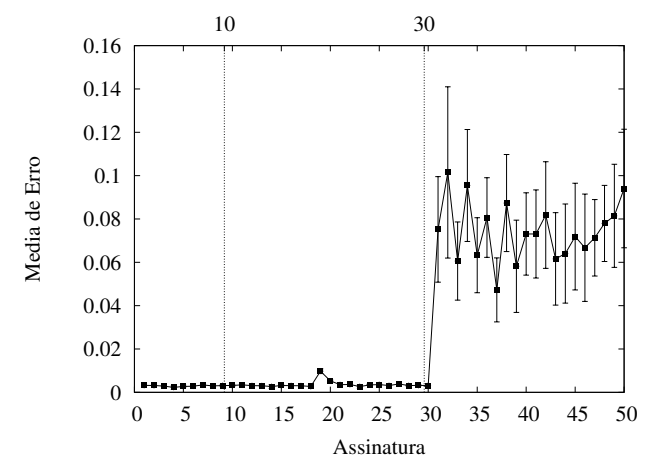

(d) DD3 - frequência dos pontos

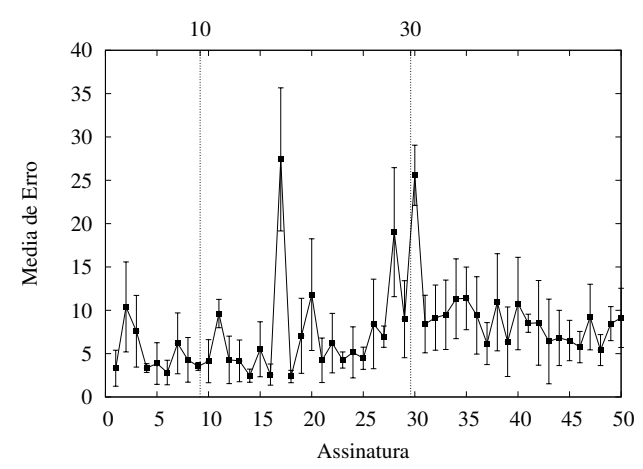

(f) DD5 - derivada entre os pontos por tempo

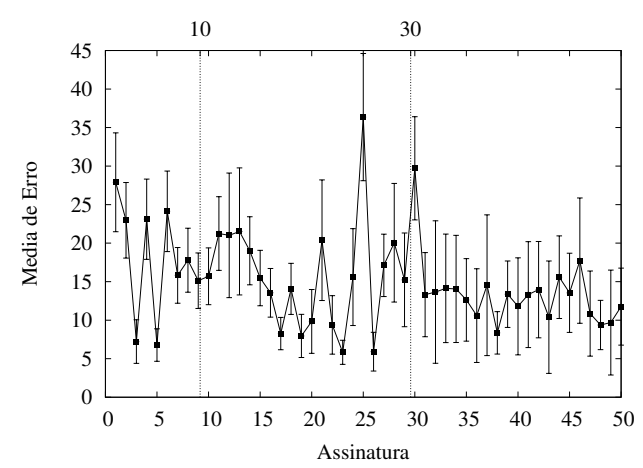

(h) DD7 - distância por tempo (velocidade)

Usuário 13 - Resultado dos experimentos utilizando a medida de similaridade DTW, onde são comparados os resultados de treinamento com 10 assinaturas verdadeiras e 40 falsas. 


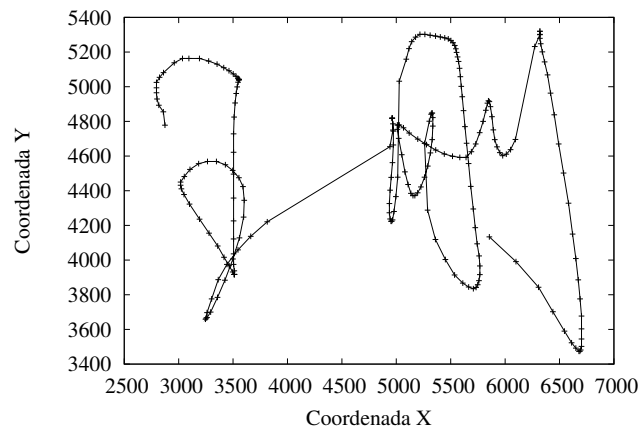

(a) Assinatura

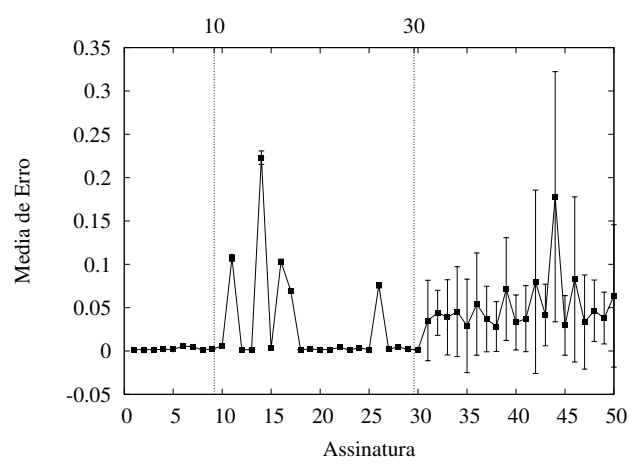

(c) DD2 - tempo por ponto

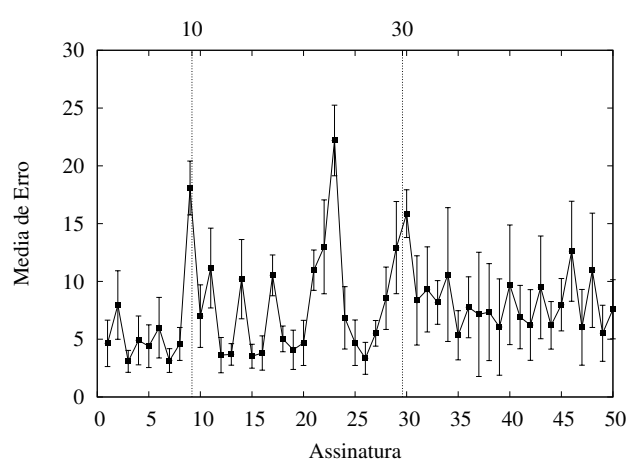

(e) DD4 - derivada entre as coordenadas da (f) DD5 - derivada entre os pontos por tempo amostragem

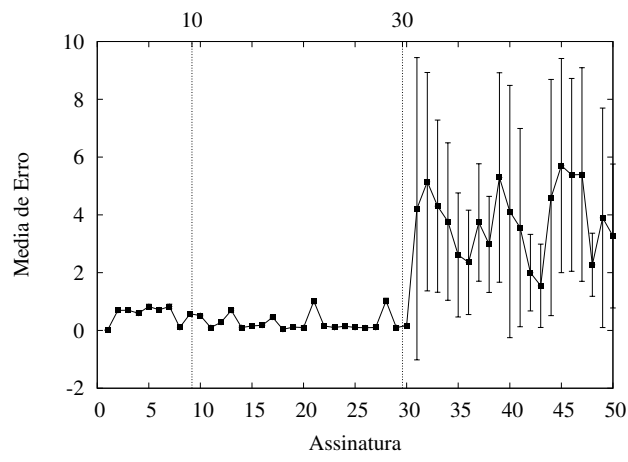

(g) DD6 - distância entre os pontos

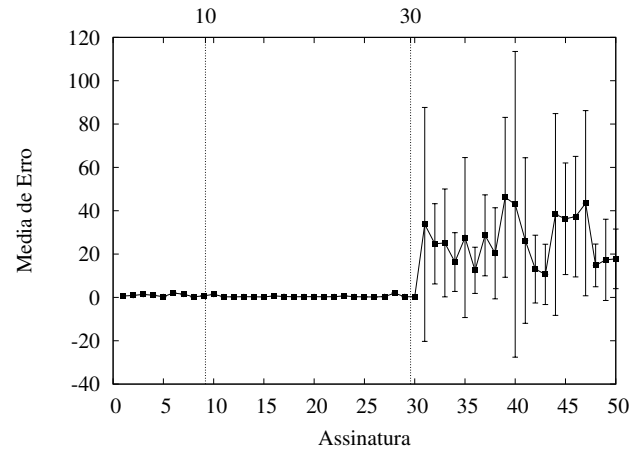

(b) DD1 - diferença entre as coordenadas da amostragem

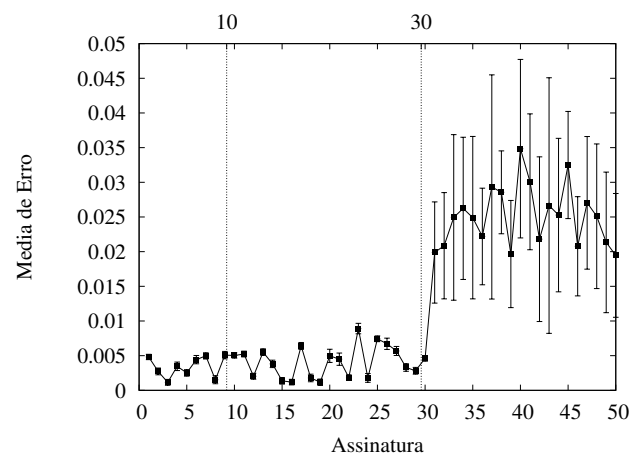

(d) DD3 - frequência dos pontos

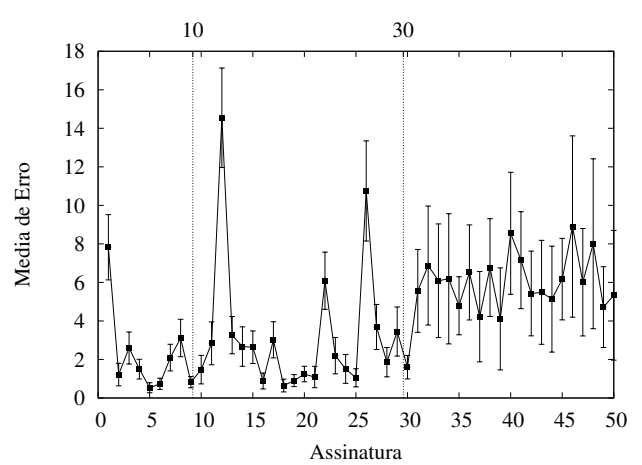

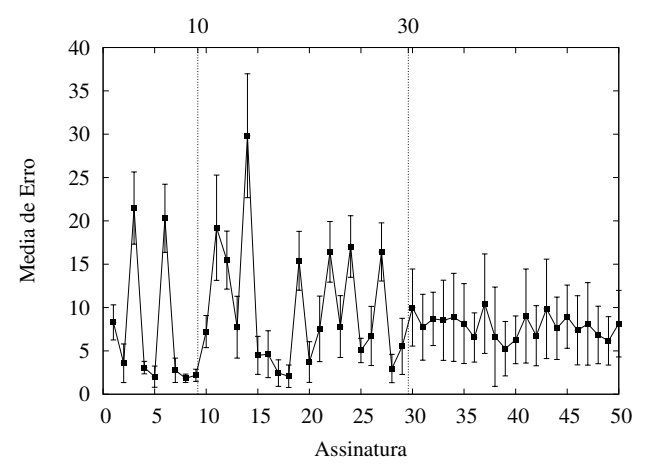

(h) DD7 - distância por tempo (velocidade)

Usuário 14 - Resultado dos experimentos utilizando a medida de similaridade DTW, onde são comparados os resultados de treinamento com 10 assinaturas verdadeiras e 40 falsas. 


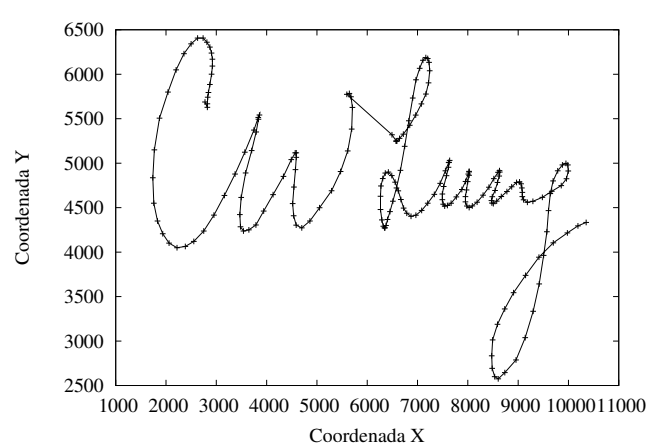

(a) Assinatura

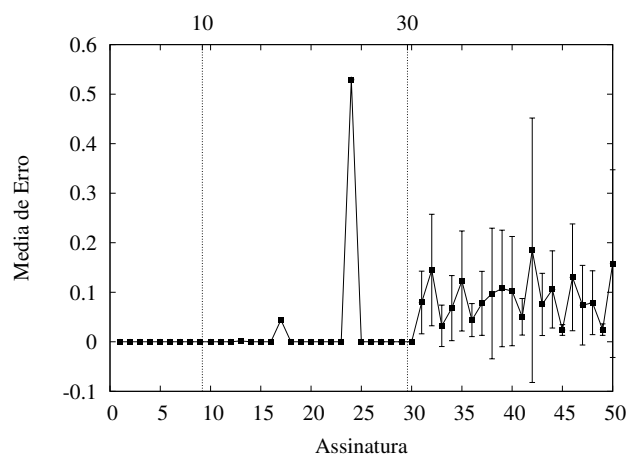

(c) DD2 - tempo por ponto

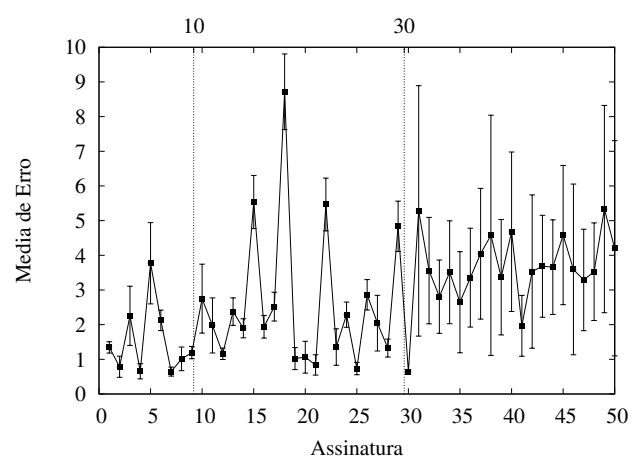

(e) DD4 - derivada entre as coordenadas da amostragem

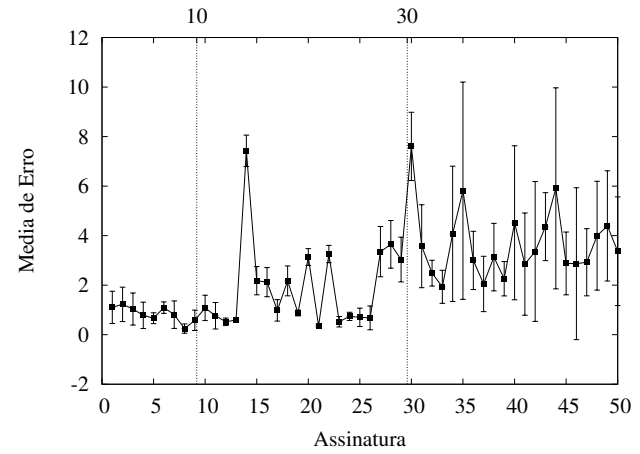

(g) DD6 - distância entre os pontos

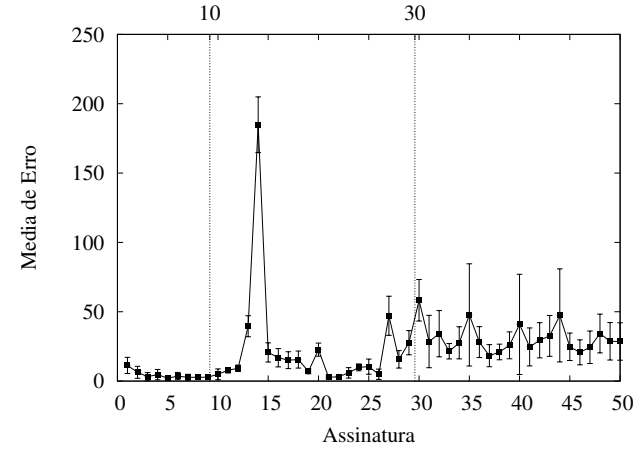

(b) DD1 - diferença entre as coordenadas da amostragem

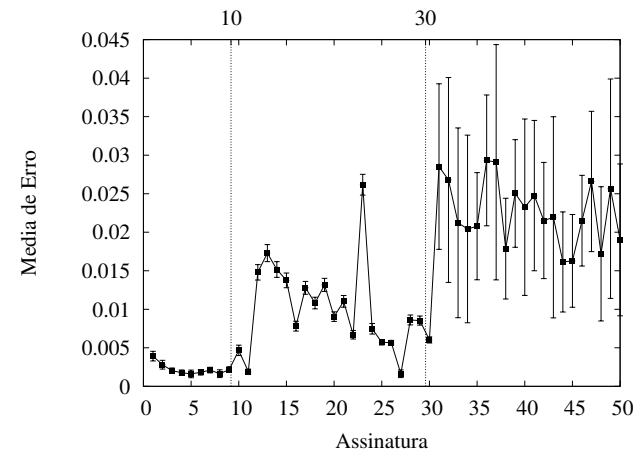

(d) DD3 - frequência dos pontos

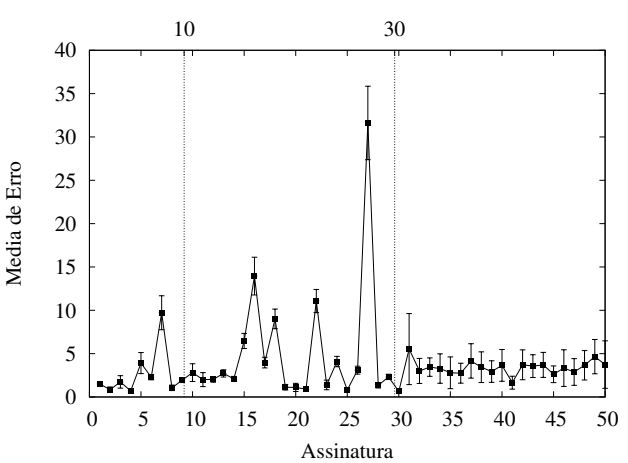

(f) DD5 - derivada entre os pontos por tempo

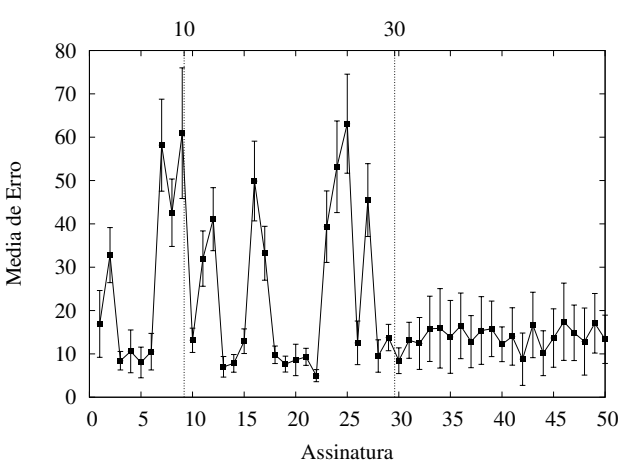

(h) DD7 - distância por tempo (velocidade)

Usuário 15 - Resultado dos experimentos utilizando a medida de similaridade DTW, onde são comparados os resultados de treinamento com 10 assinaturas verdadeiras e 40 falsas. 


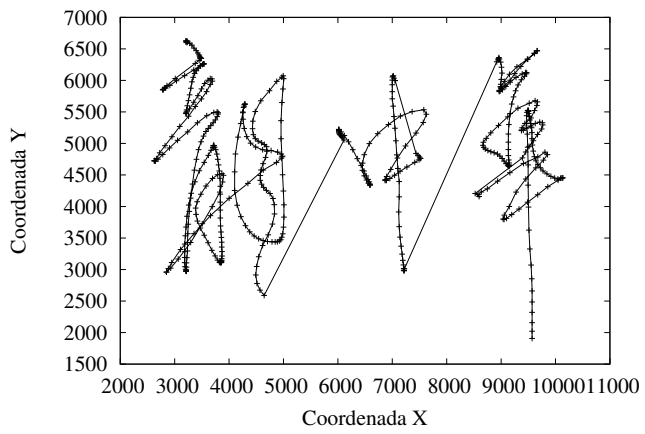

(a) Assinatura

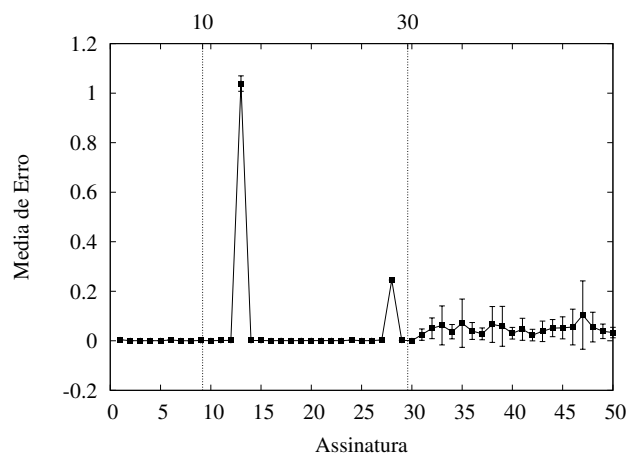

(c) DD2 - tempo por ponto

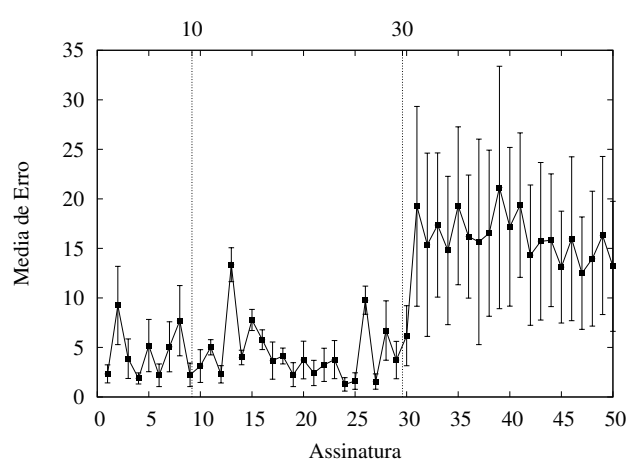

(e) DD4 - derivada entre as coordenadas da (f) DD5 - derivada entre os pontos por tempo amostragem

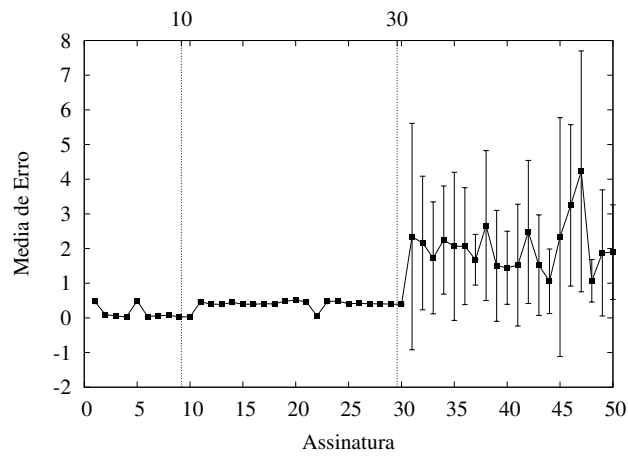

(g) DD6 - distância entre os pontos

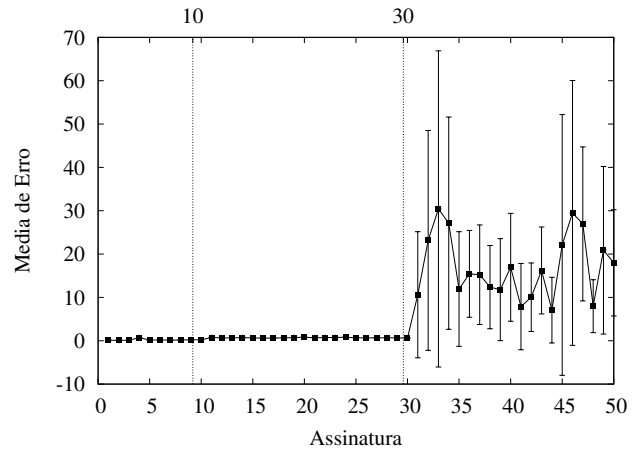

(b) DD1 - diferença entre as coordenadas da amostragem

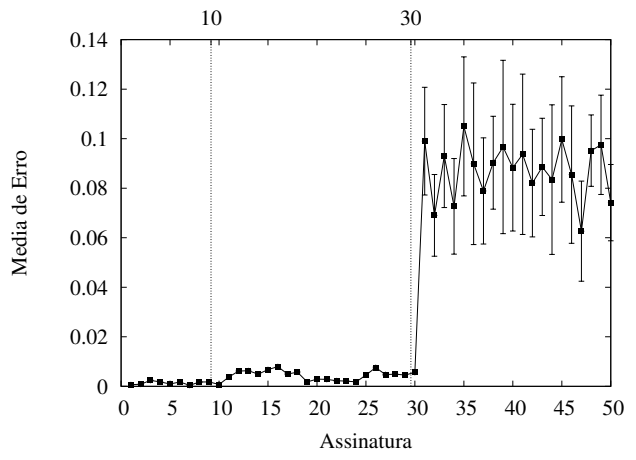

(d) DD3 - frequência dos pontos

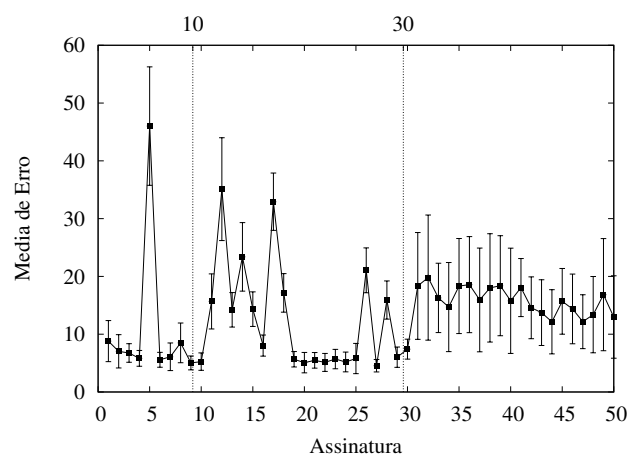

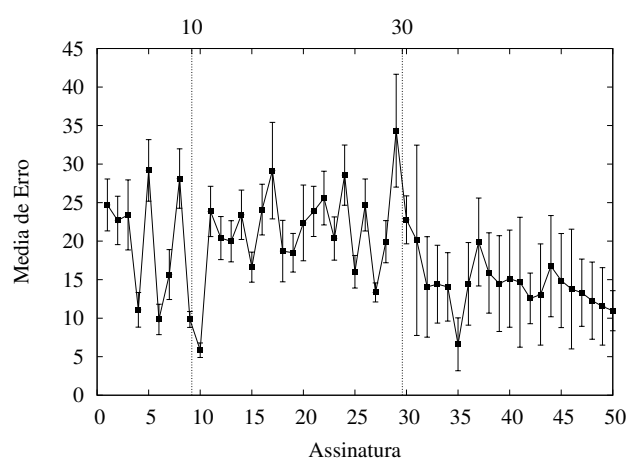

(h) DD7 - distância por tempo (velocidade)

Usuário 16 - Resultado dos experimentos utilizando a medida de similaridade DTW, onde são comparados os resultados de treinamento com 10 assinaturas verdadeiras e 40 falsas. 


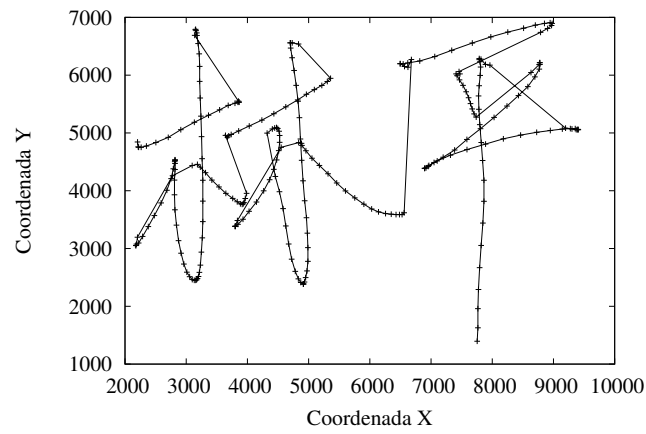

(a) Assinatura

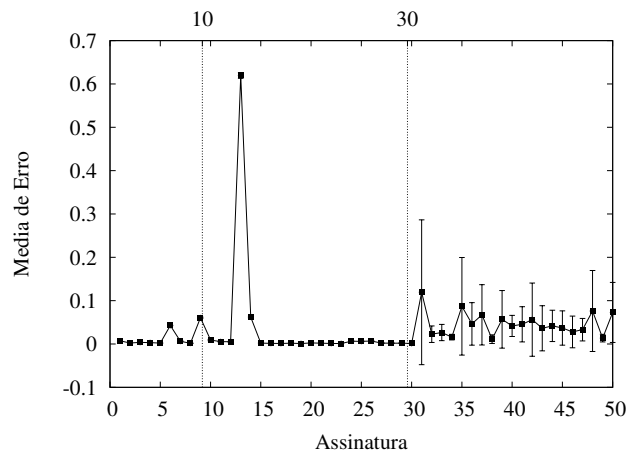

(c) DD2 - tempo por ponto

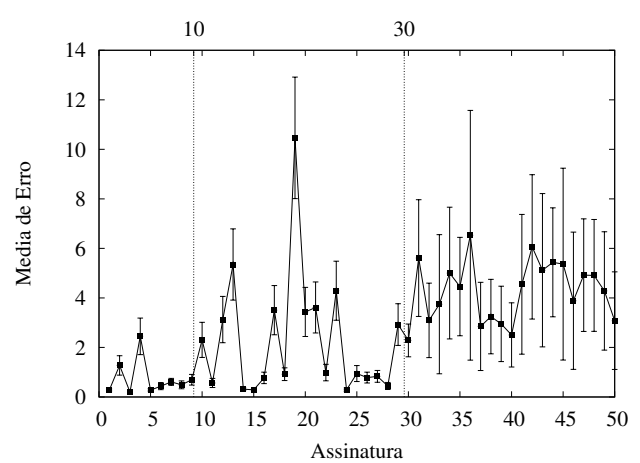

(e) DD4 - derivada entre as coordenadas da amostragem

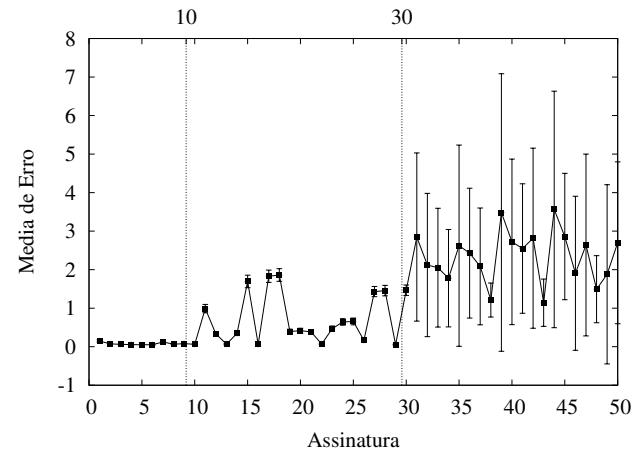

(g) DD6 - distância entre os pontos

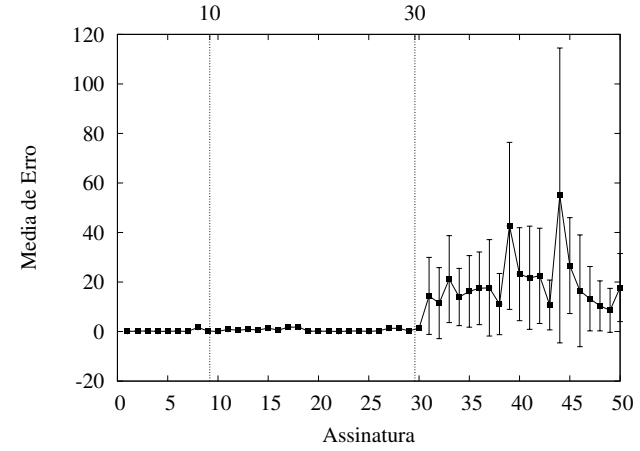

(b) DD1 - diferença entre as coordenadas da amostragem

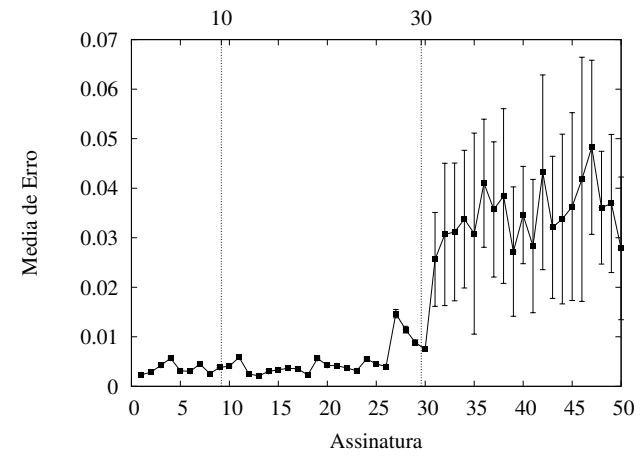

(d) DD3 - frequência dos pontos

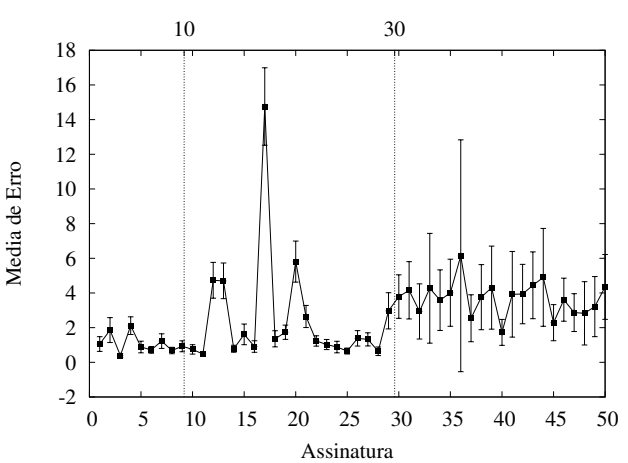

(f) DD5 - derivada entre os pontos por tempo

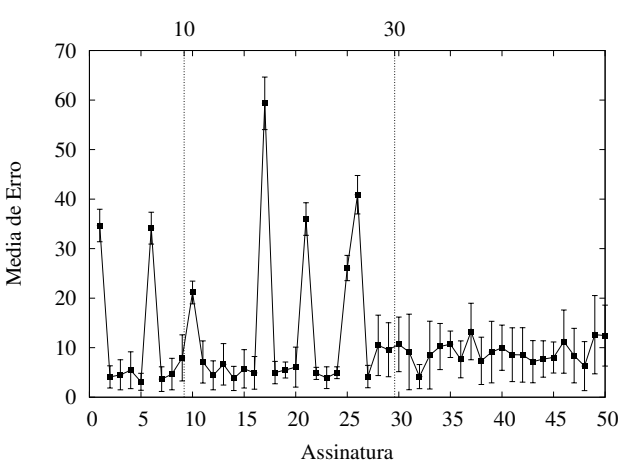

(h) DD7 - distância por tempo (velocidade)

Usuário 17 - Resultado dos experimentos utilizando a medida de similaridade DTW, onde são comparados os resultados de treinamento com 10 assinaturas verdadeiras e 40 falsas. 


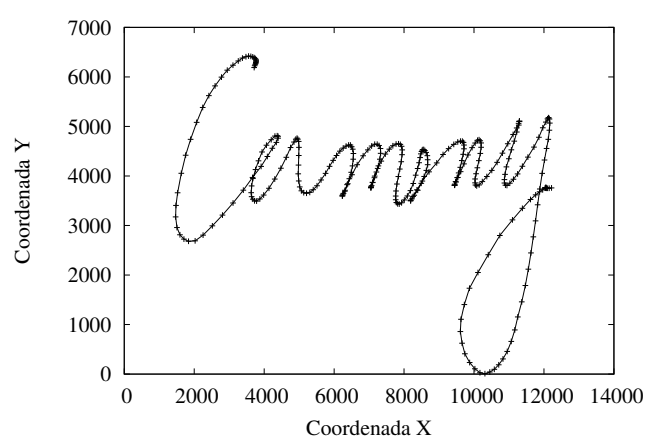

(a) Assinatura

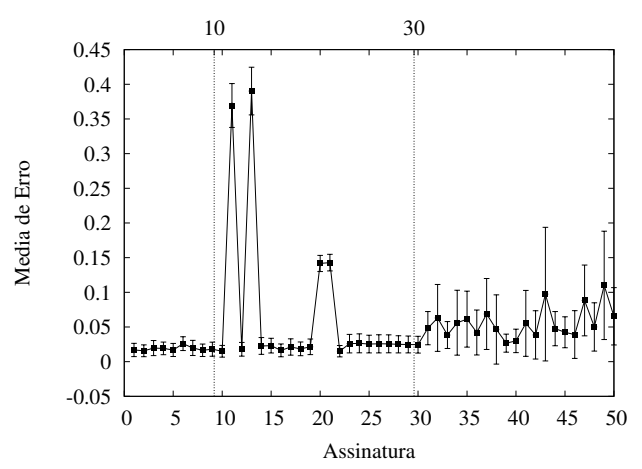

(c) DD2 - tempo por ponto

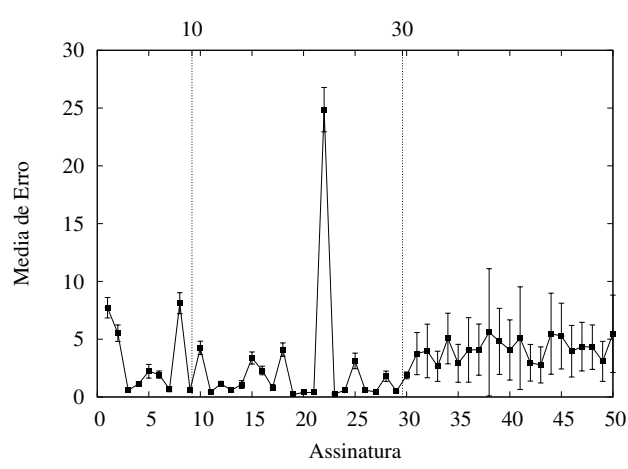

(e) DD4 - derivada entre as coordenadas da (f) DD5 - derivada entre os pontos por tempo amostragem

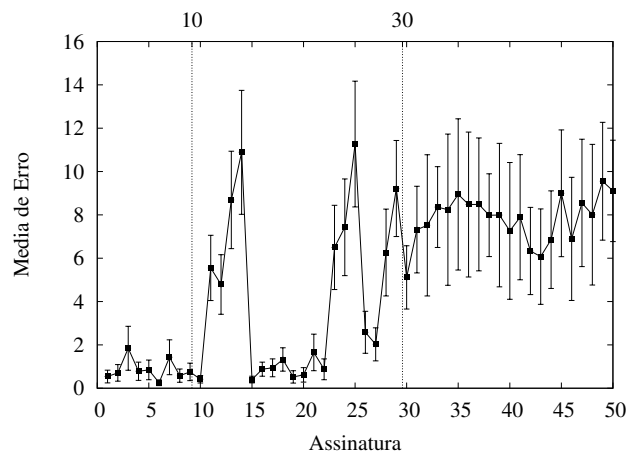

(g) DD6 - distância entre os pontos

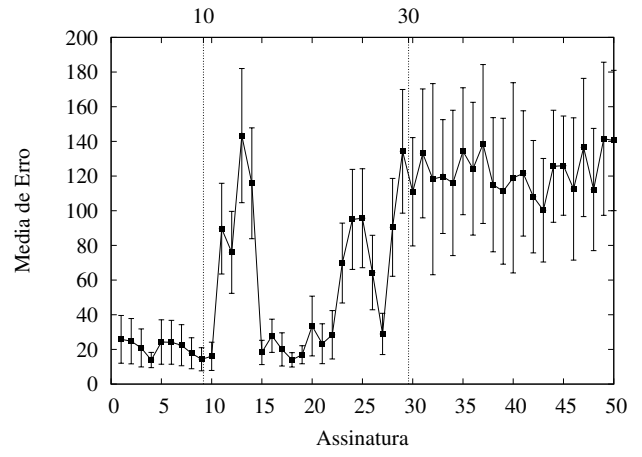

(b) DD1 - diferença entre as coordenadas da amostragem

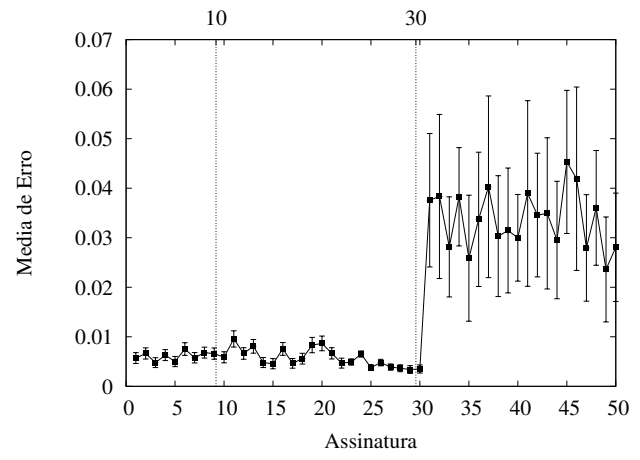

(d) DD3 - frequência dos pontos

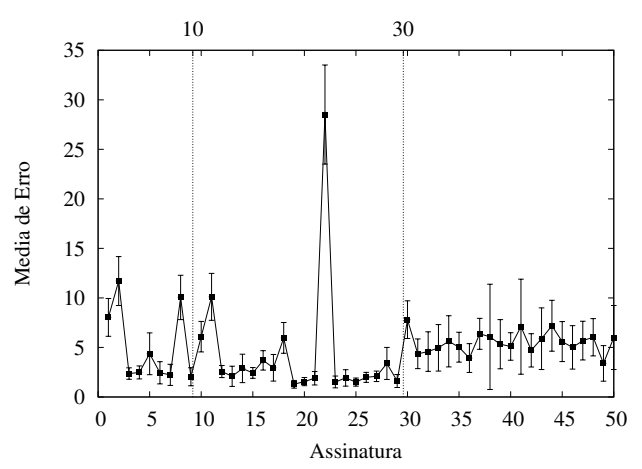

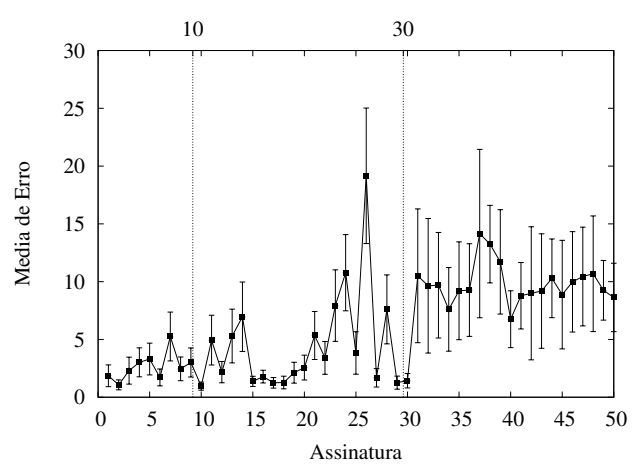

(h) DD7 - distância por tempo (velocidade)

Usuário 18 - Resultado dos experimentos utilizando a medida de similaridade DTW, onde são comparados os resultados de treinamento com 10 assinaturas verdadeiras e 40 falsas. 


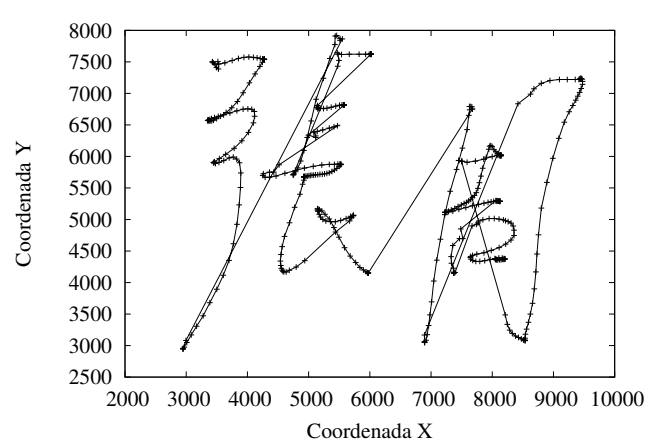

(a) Assinatura

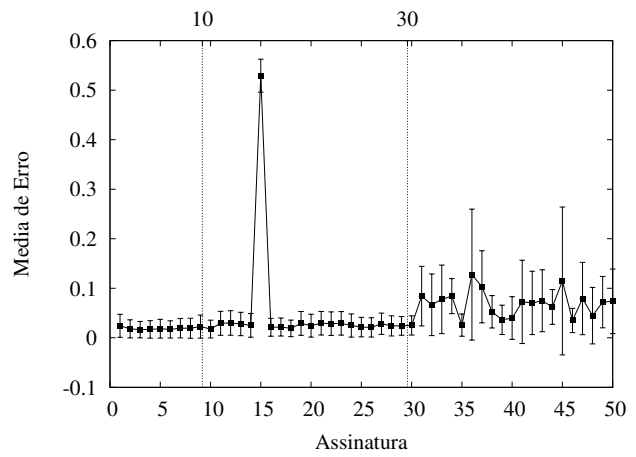

(c) DD2 - tempo por ponto

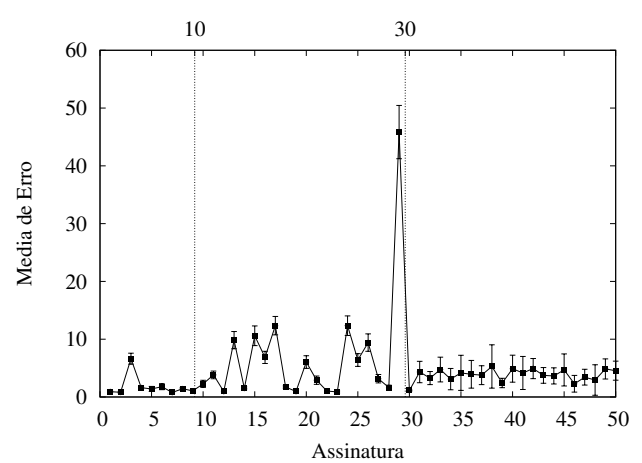

(e) DD4 - derivada entre as coordenadas da amostragem

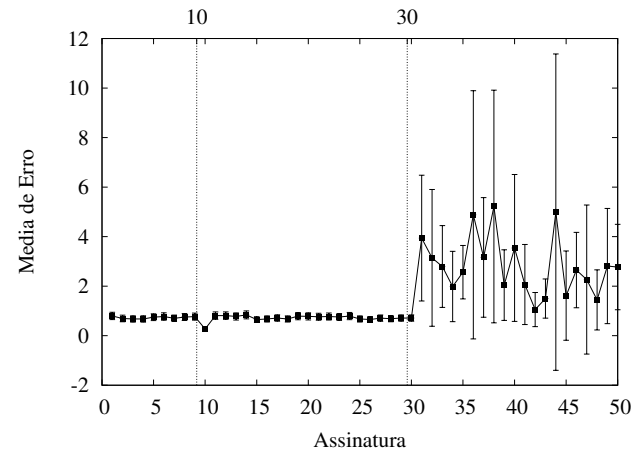

(g) DD6 - distância entre os pontos

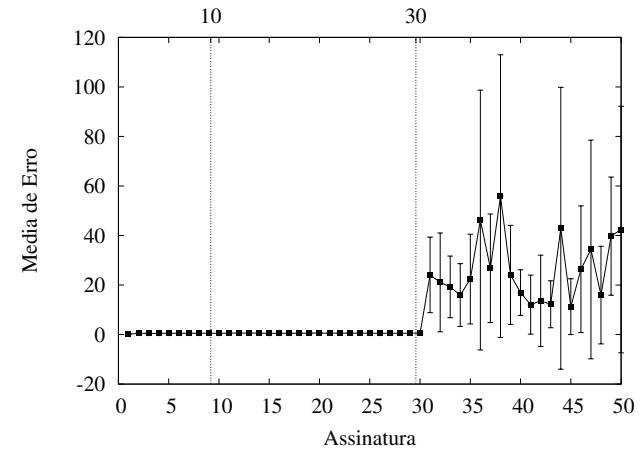

(b) DD1 - diferença entre as coordenadas da amostragem

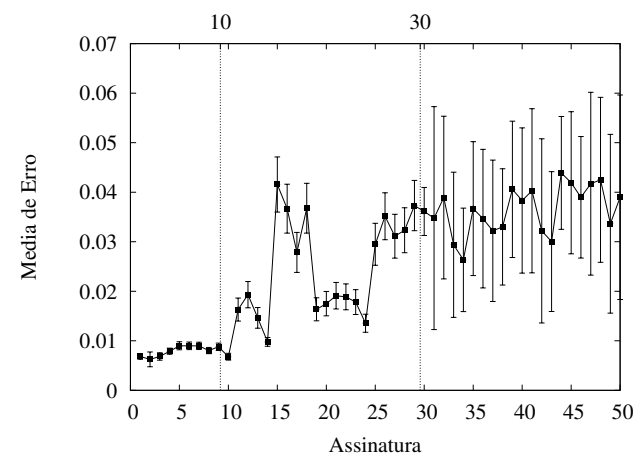

(d) DD3 - frequência dos pontos

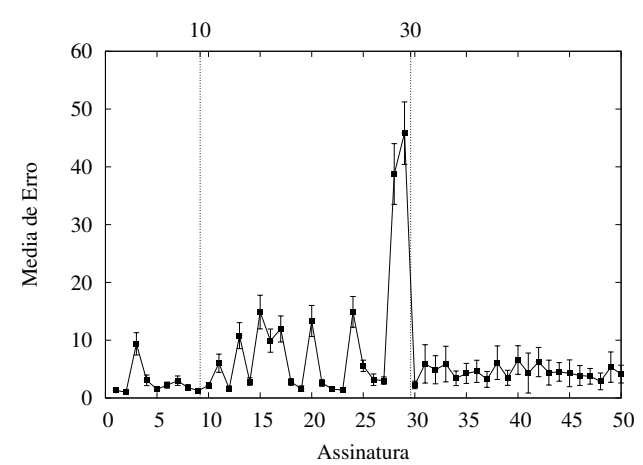

(f) DD5 - derivada entre os pontos por tempo

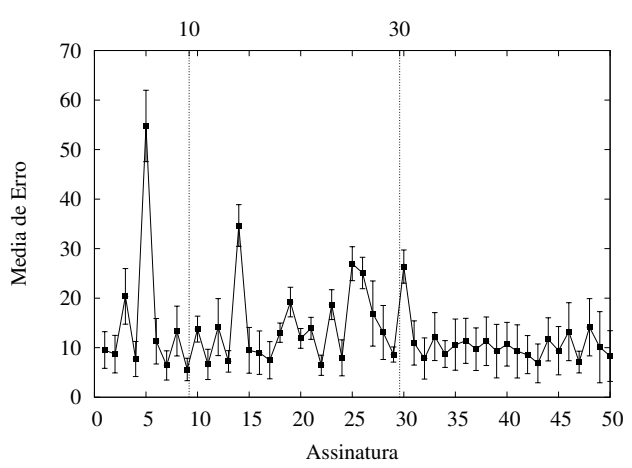

(h) DD7 - distância por tempo (velocidade)

Usuário 19 - Resultado dos experimentos utilizando a medida de similaridade DTW, onde são comparados os resultados de treinamento com 10 assinaturas verdadeiras e 40 falsas. 


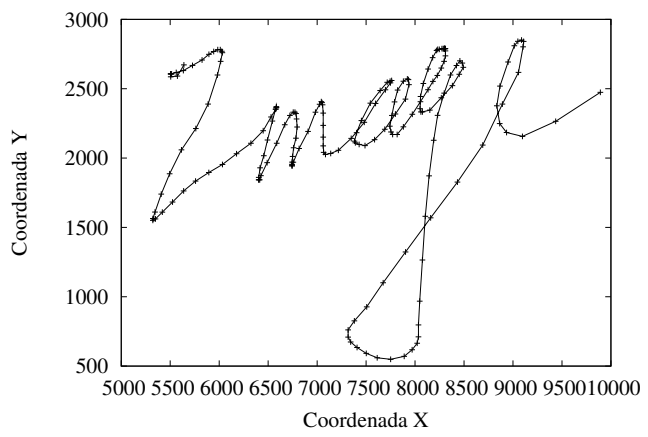

(a) Assinatura

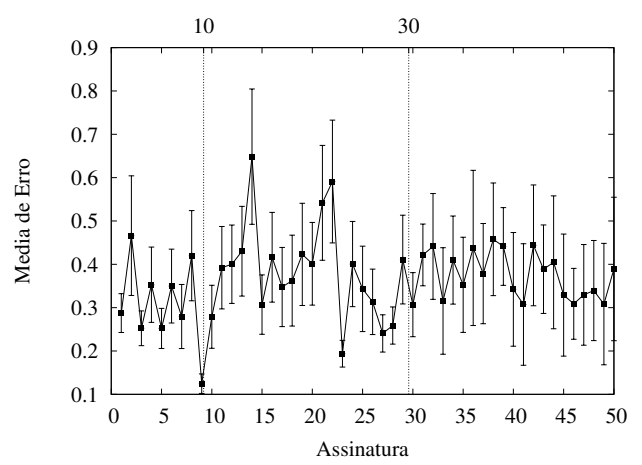

(c) DD2 - tempo por ponto

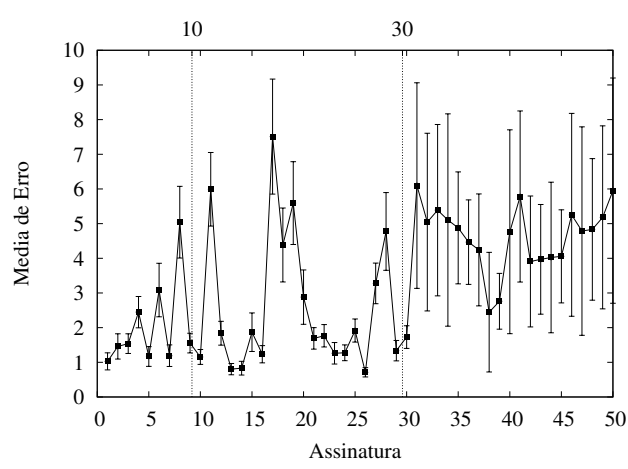

(e) DD4 - derivada entre as coordenadas da (f) DD5 - derivada entre os pontos por tempo amostragem

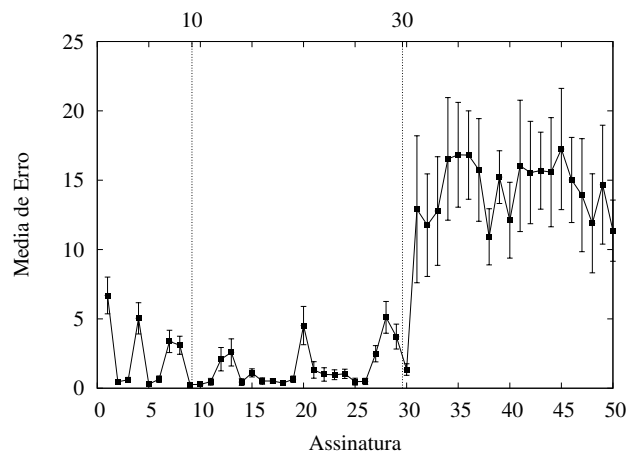

(g) DD6 - distância entre os pontos

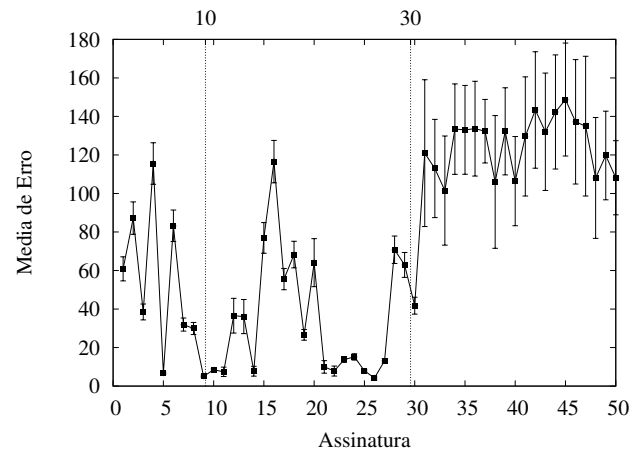

(b) DD1 - diferença entre as coordenadas da amostragem

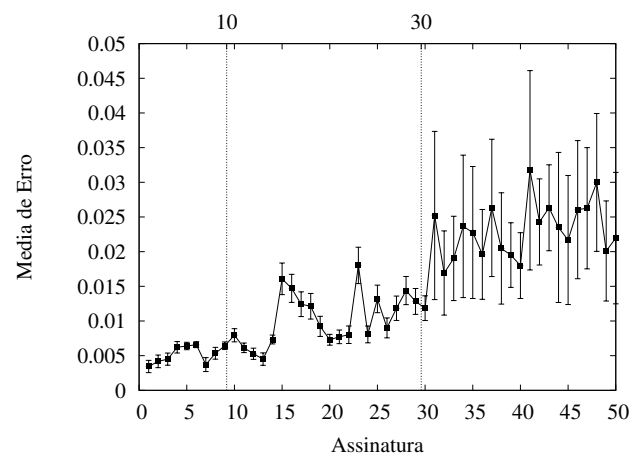

(d) DD3 - frequência dos pontos

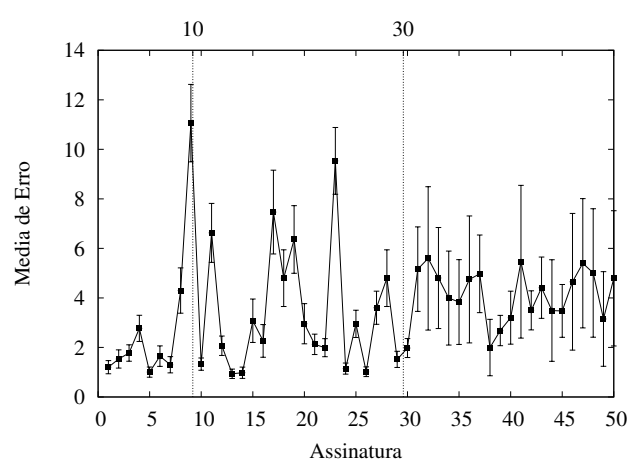

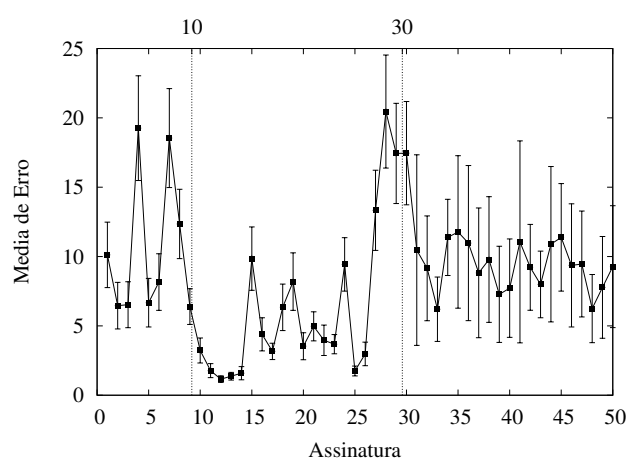

(h) DD7 - distância por tempo (velocidade)

Usuário 20 - Resultado dos experimentos utilizando a medida de similaridade DTW, onde são comparados os resultados de treinamento com 10 assinaturas verdadeiras e 40 falsas. 


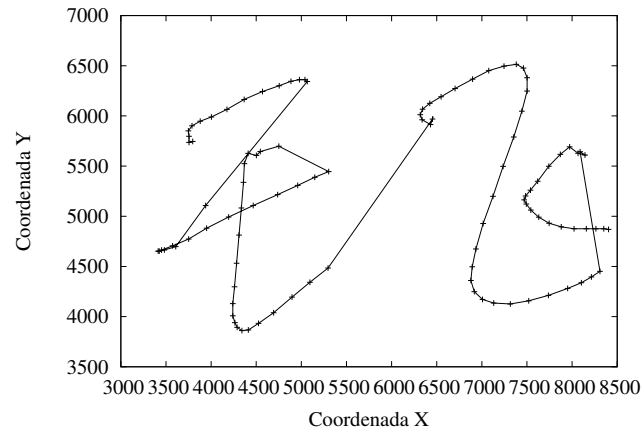

(a) Assinatura

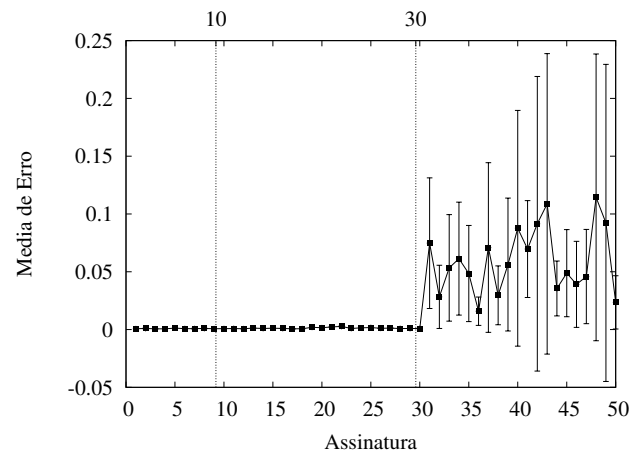

(c) DD2 - tempo por ponto

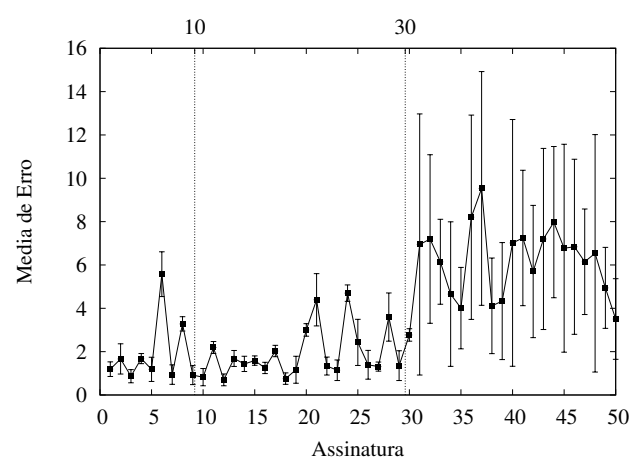

(e) DD4 - derivada entre as coordenadas da amostragem

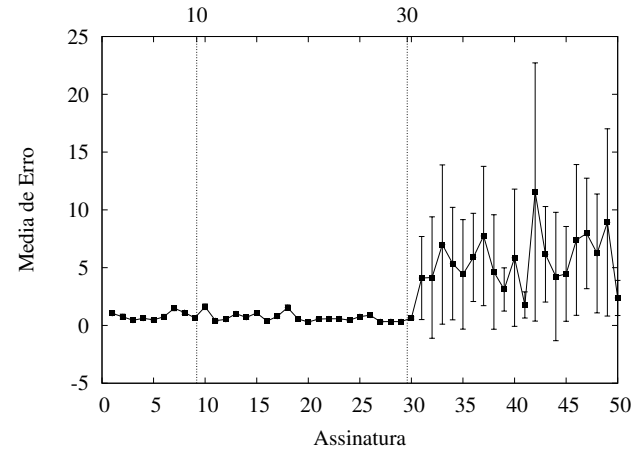

(g) DD6 - distância entre os pontos

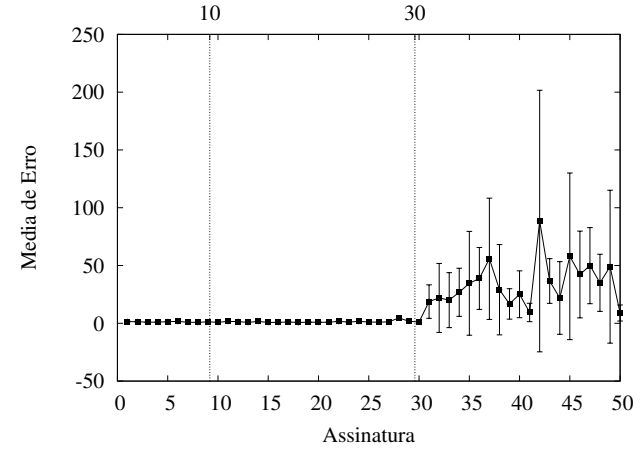

(b) DD1 - diferença entre as coordenadas da amostragem

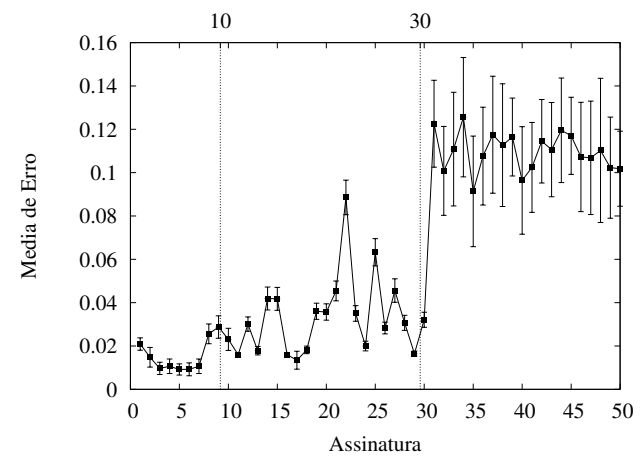

(d) DD3 - frequência dos pontos

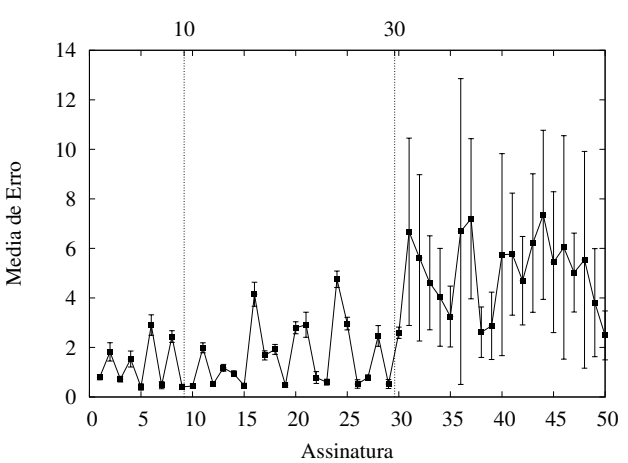

(f) DD5 - derivada entre os pontos por tempo

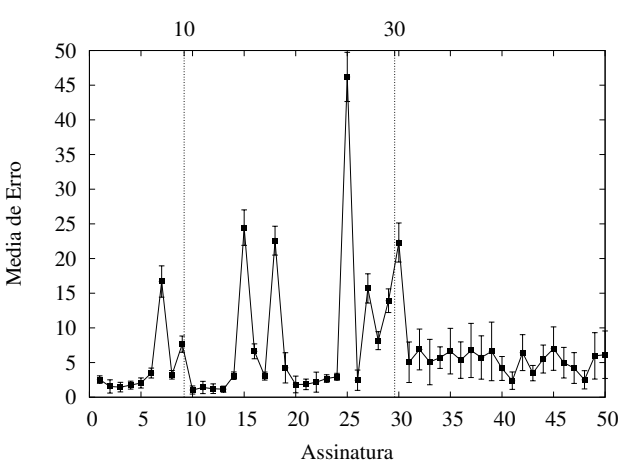

(h) DD7 - distância por tempo (velocidade)

Usuário 21 - Resultado dos experimentos utilizando a medida de similaridade DTW, onde são comparados os resultados de treinamento com 10 assinaturas verdadeiras e 40 falsas. 


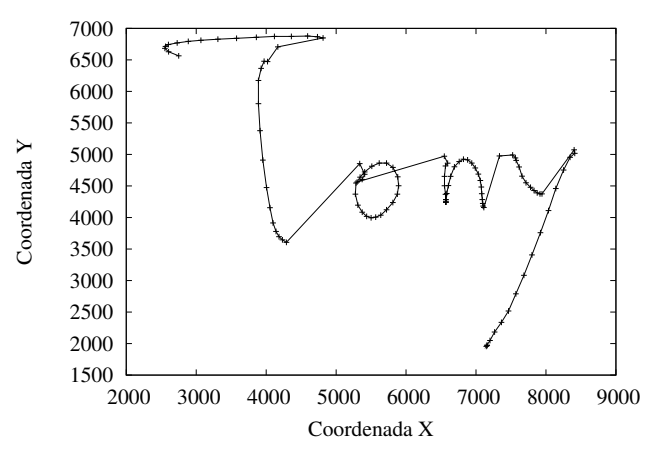

(a) Assinatura

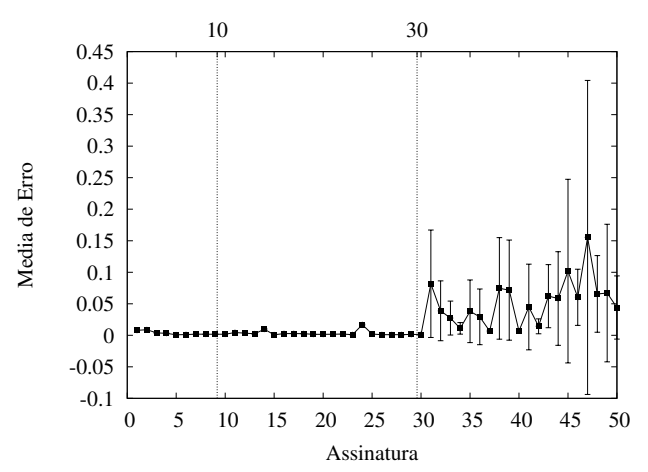

(c) DD2 - tempo por ponto

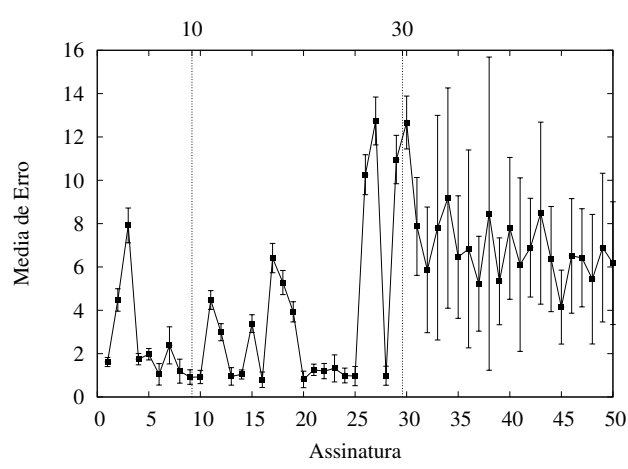

(e) DD4 - derivada entre as coordenadas da (f) DD5 - derivada entre os pontos por tempo amostragem

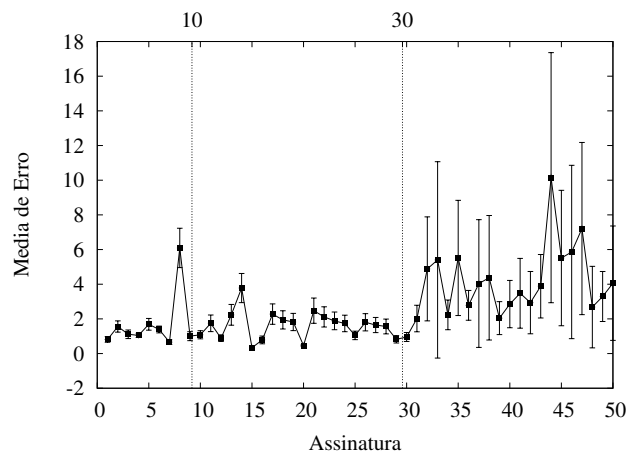

(g) DD6 - distância entre os pontos

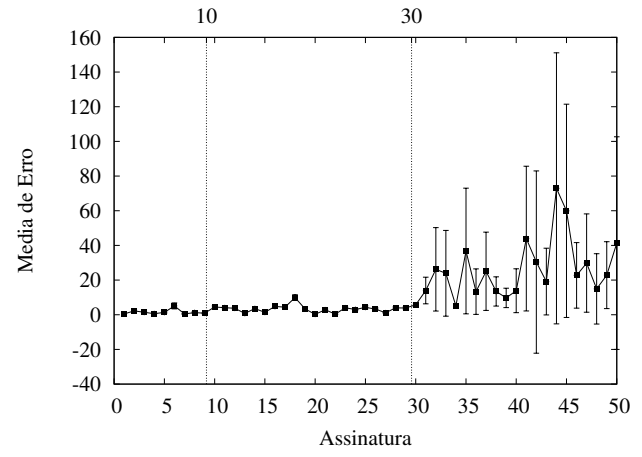

(b) DD1 - diferença entre as coordenadas da amostragem

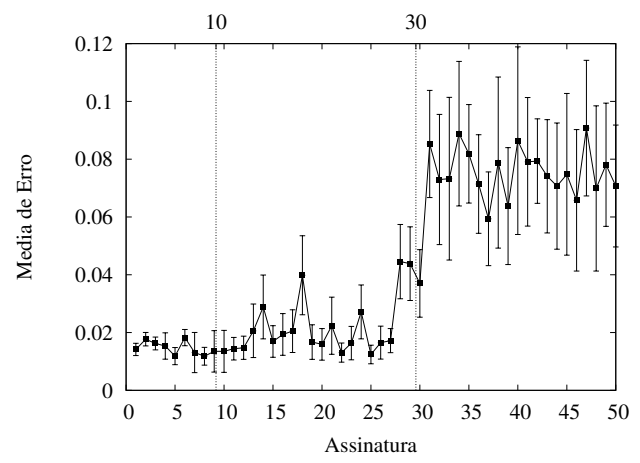

(d) DD3 - frequência dos pontos

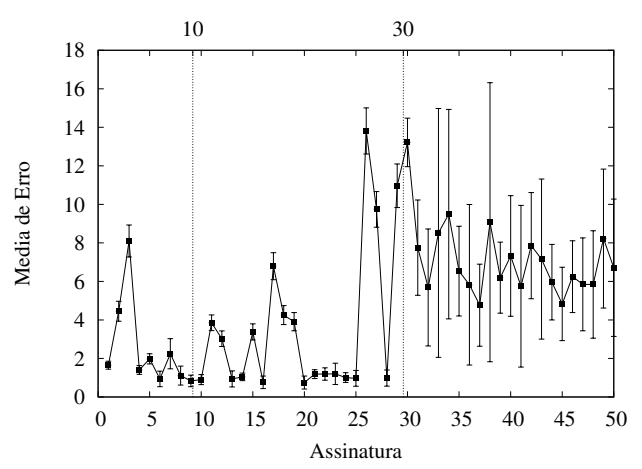

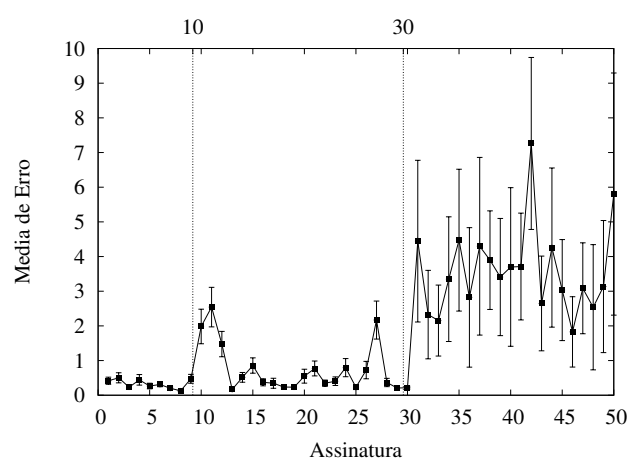

(h) DD7 - distância por tempo (velocidade)

Usuário 22 - Resultado dos experimentos utilizando a medida de similaridade DTW, onde são comparados os resultados de treinamento com 10 assinaturas verdadeiras e 40 falsas. 


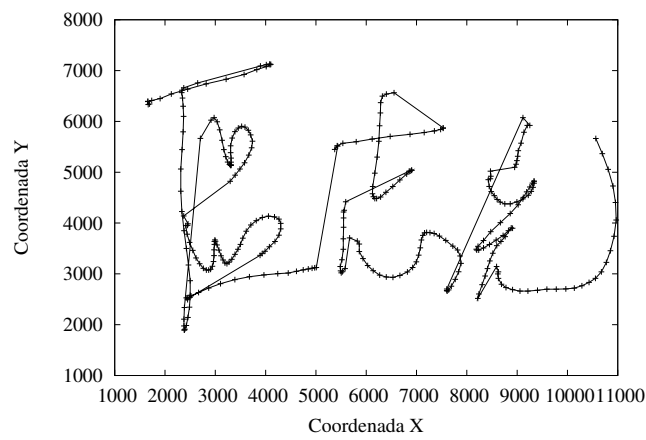

(a) Assinatura

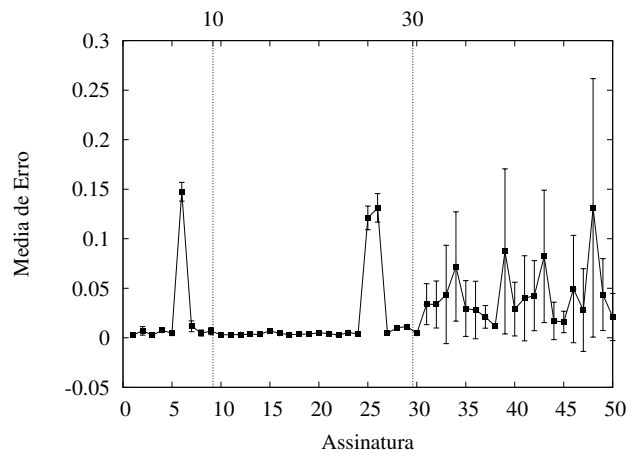

(c) DD2 - tempo por ponto

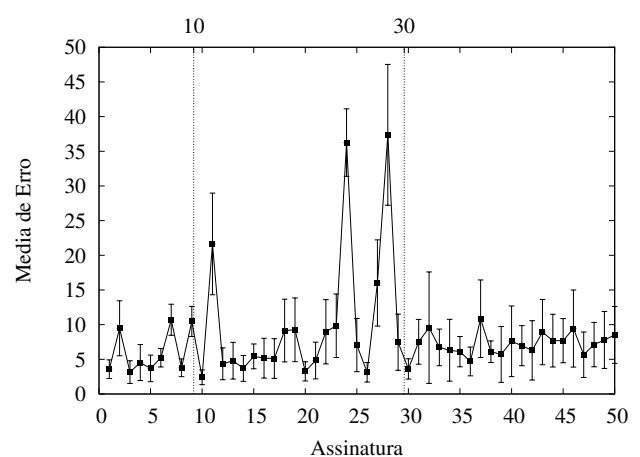

(e) DD4 - derivada entre as coordenadas da amostragem

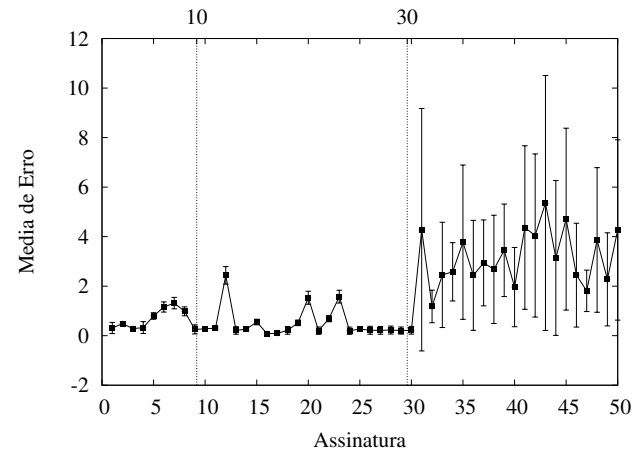

(g) DD6 - distância entre os pontos

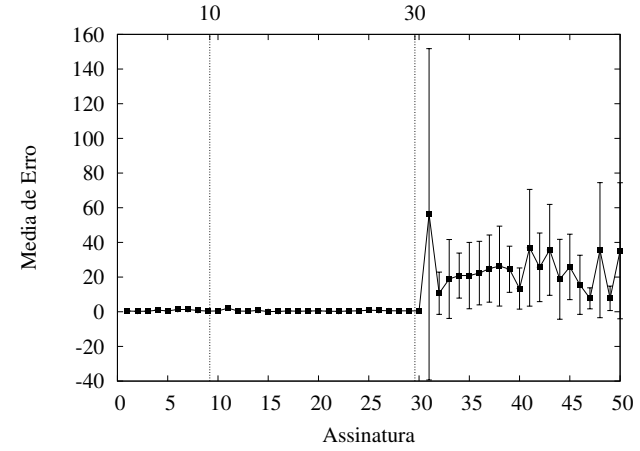

(b) DD1 - diferença entre as coordenadas da amostragem

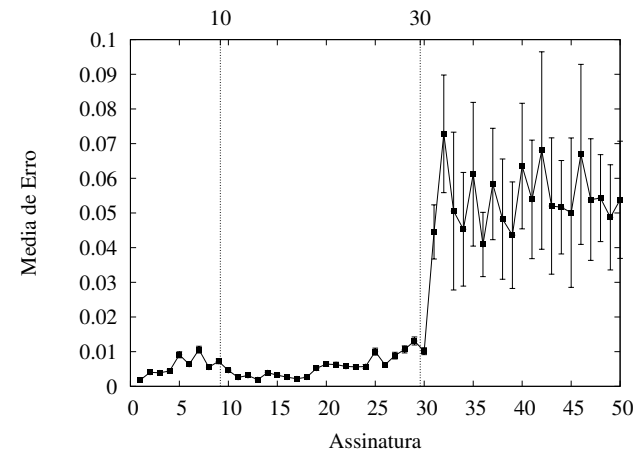

(d) DD3 - frequência dos pontos

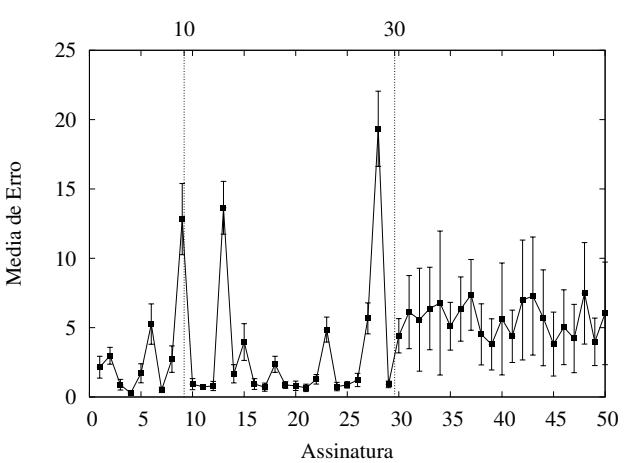

(f) DD5 - derivada entre os pontos por tempo

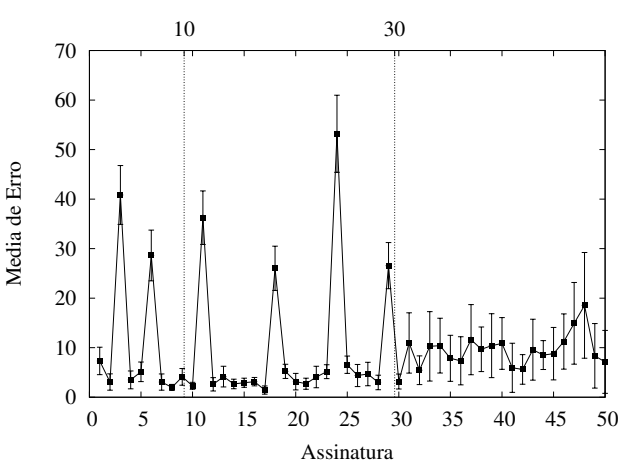

(h) DD7 - distância por tempo (velocidade)

Usuário 23 - Resultado dos experimentos utilizando a medida de similaridade DTW, onde são comparados os resultados de treinamento com 10 assinaturas verdadeiras e 40 falsas. 


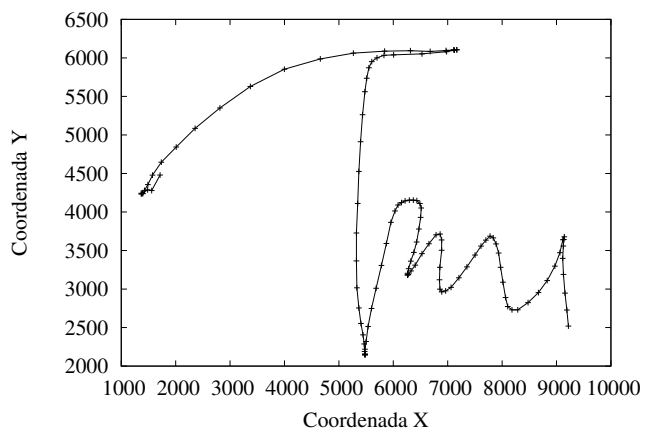

(a) Assinatura

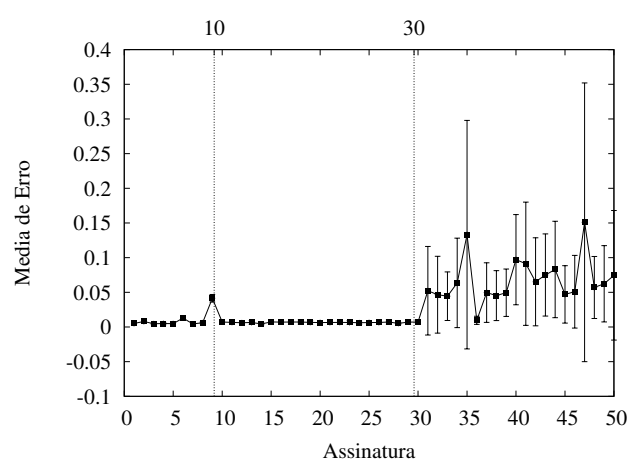

(c) DD2 - tempo por ponto

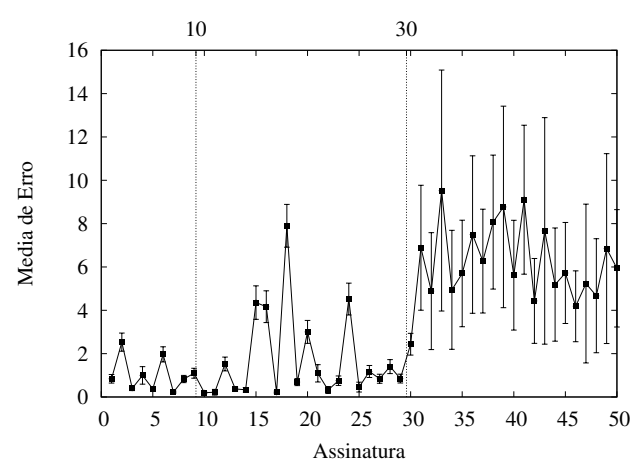

(e) DD4 - derivada entre as coordenadas da (f) DD5 - derivada entre os pontos por tempo amostragem

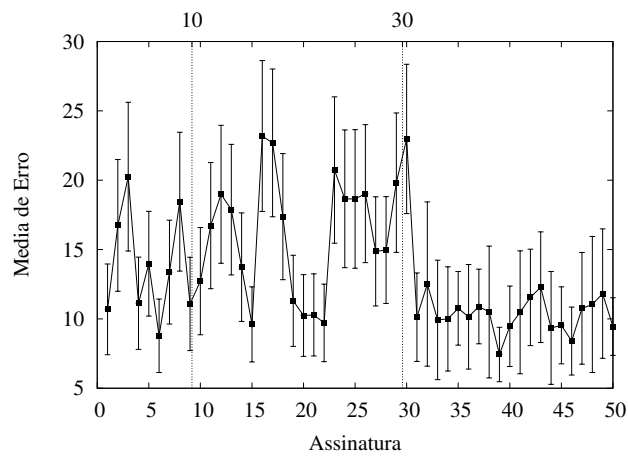

(g) DD6 - distância entre os pontos

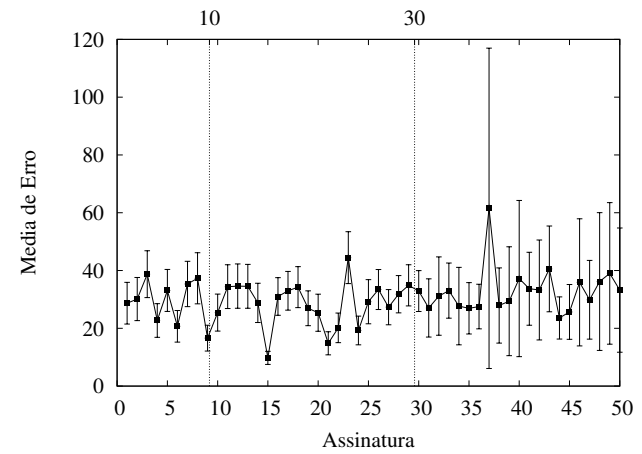

(b) DD1 - diferença entre as coordenadas da amostragem

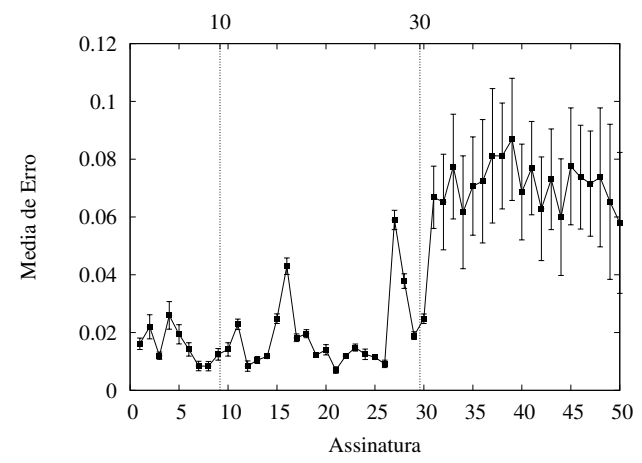

(d) DD3 - frequência dos pontos

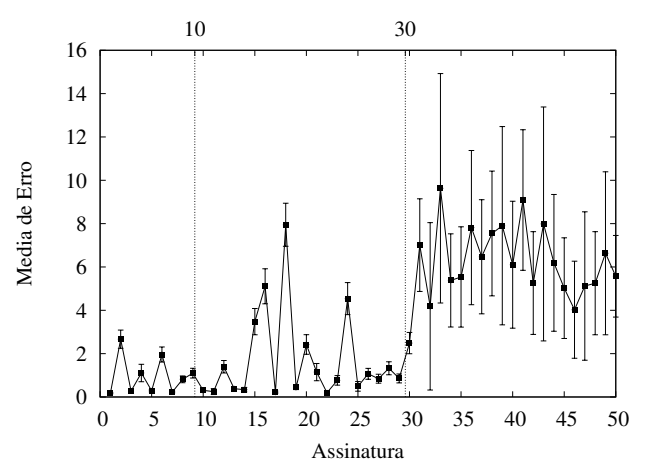

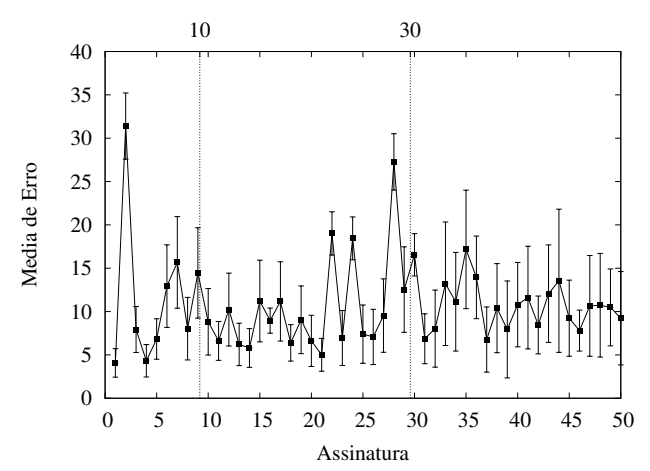

(h) DD7 - distância por tempo (velocidade)

Usuário 24 - Resultado dos experimentos utilizando a medida de similaridade DTW, onde são comparados os resultados de treinamento com 10 assinaturas verdadeiras e 40 falsas. 


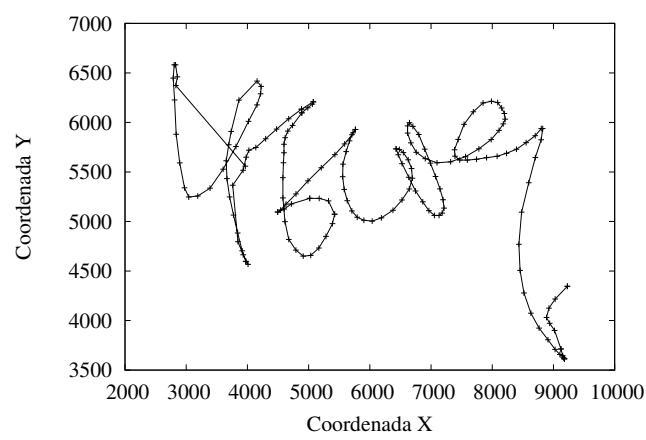

(a) Assinatura

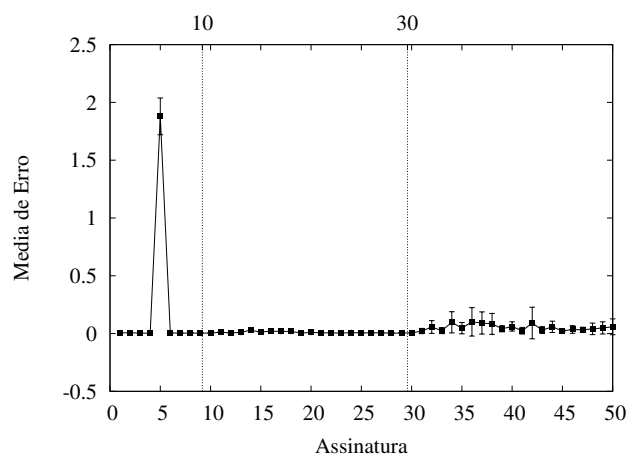

(c) DD2 - tempo por ponto

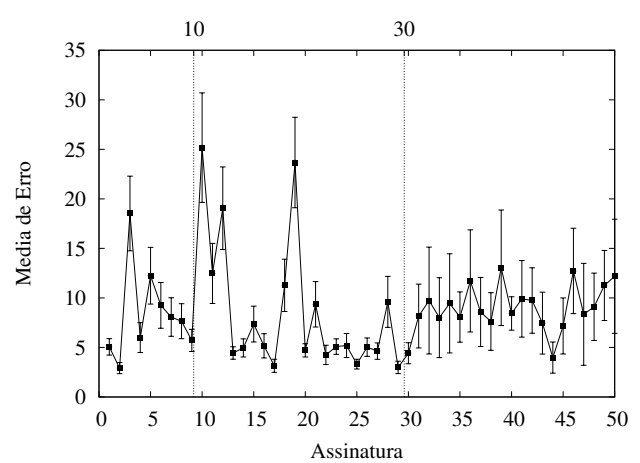

(e) DD4 - derivada entre as coordenadas da amostragem

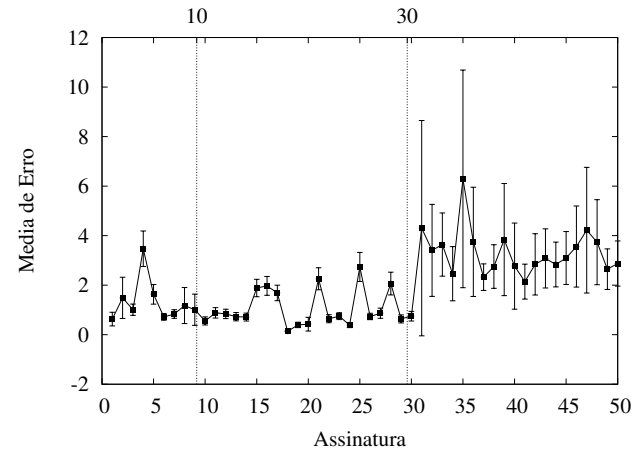

(g) DD6 - distância entre os pontos

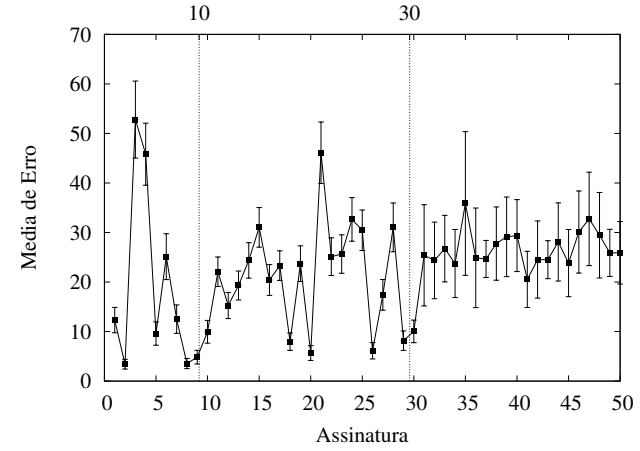

(b) DD1 - diferença entre as coordenadas da amostragem

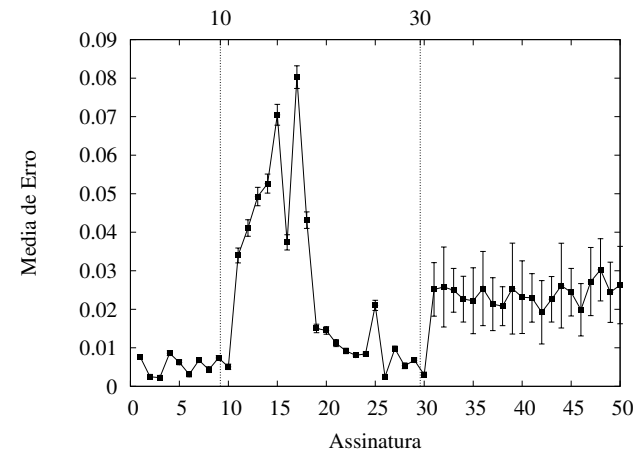

(d) DD3 - frequência dos pontos

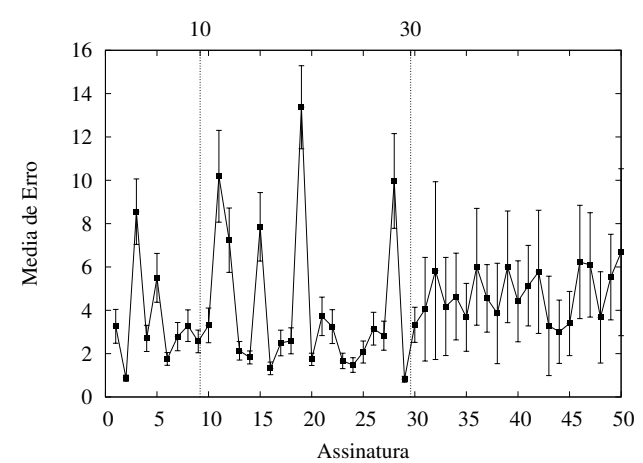

(f) DD5 - derivada entre os pontos por tempo

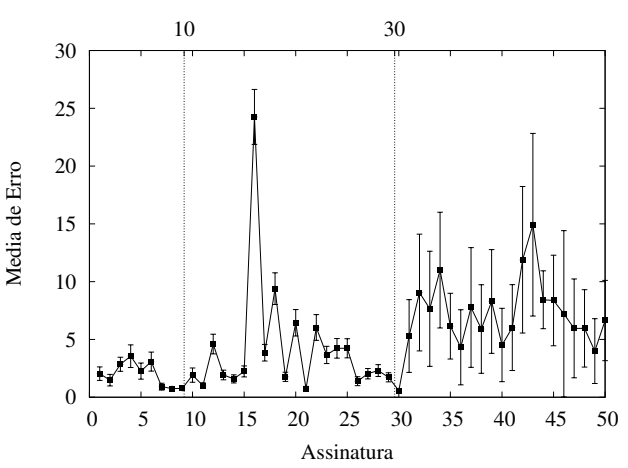

(h) DD7 - distância por tempo (velocidade)

Usuário 25 - Resultado dos experimentos utilizando a medida de similaridade DTW, onde são comparados os resultados de treinamento com 10 assinaturas verdadeiras e 40 falsas. 


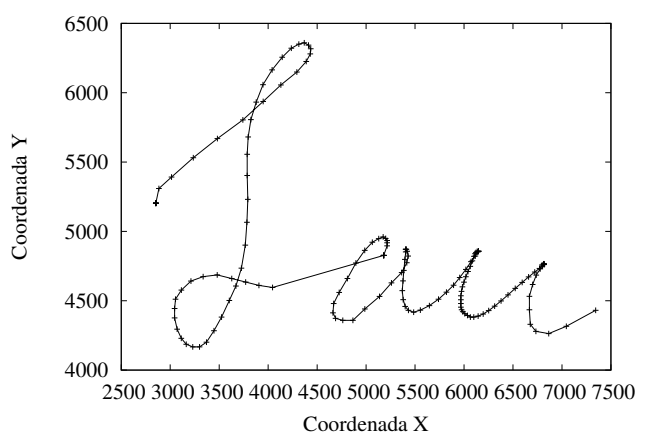

(a) Assinatura

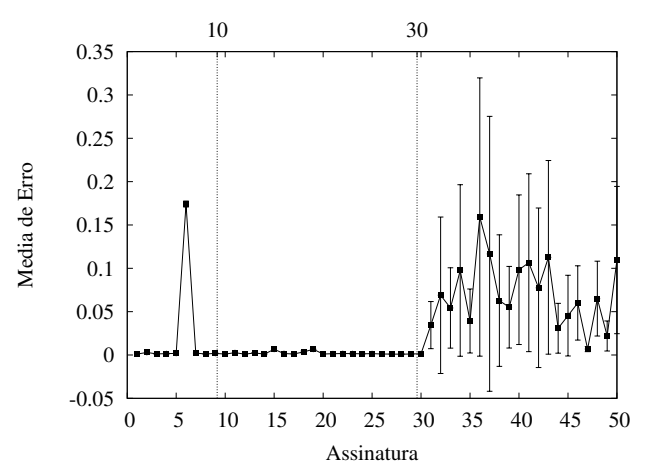

(c) DD2 - tempo por ponto

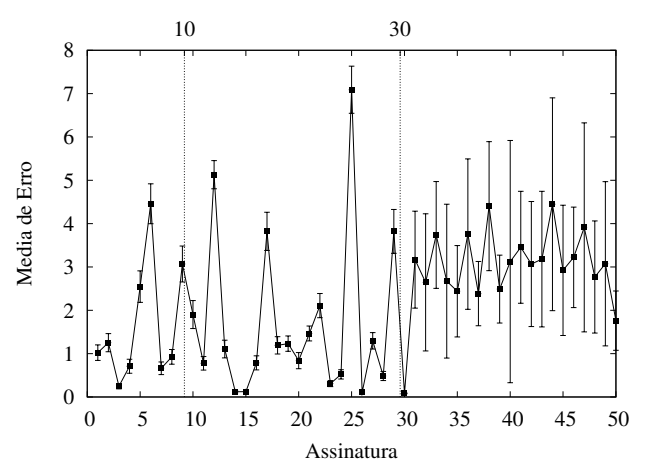

(e) DD4 - derivada entre as coordenadas da (f) DD5 - derivada entre os pontos por tempo amostragem

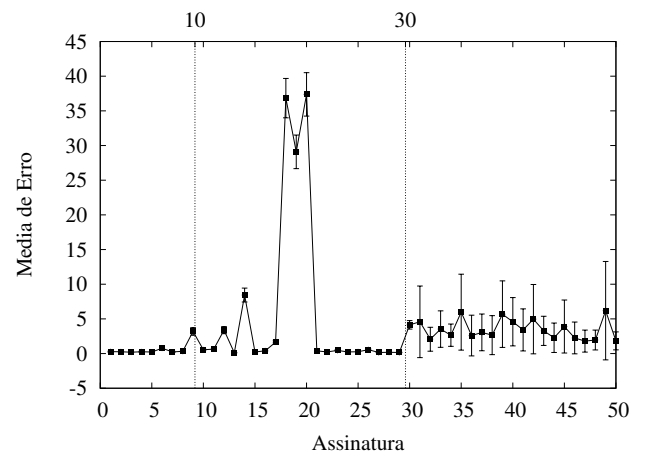

(g) DD6 - distância entre os pontos

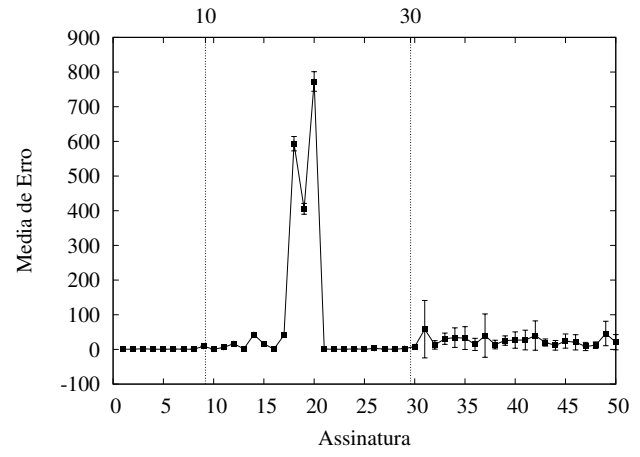

(b) DD1 - diferença entre as coordenadas da amostragem

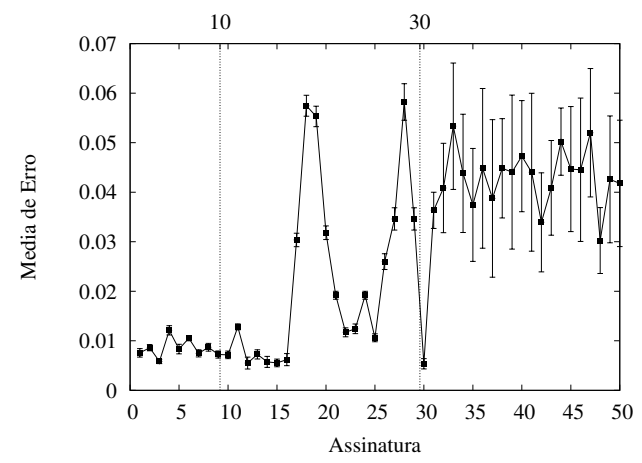

(d) DD3 - frequência dos pontos

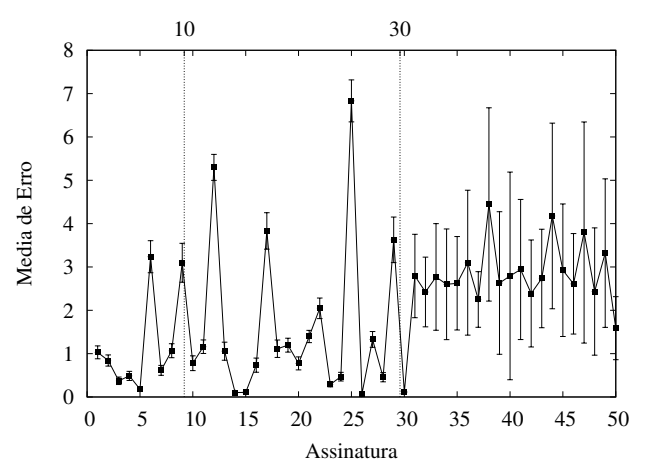

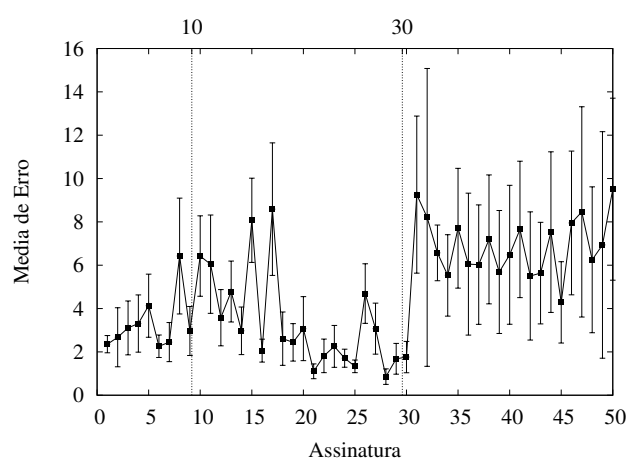

(h) DD7 - distância por tempo (velocidade)

Usuário 26 - Resultado dos experimentos utilizando a medida de similaridade DTW, onde são comparados os resultados de treinamento com 10 assinaturas verdadeiras e 40 falsas. 


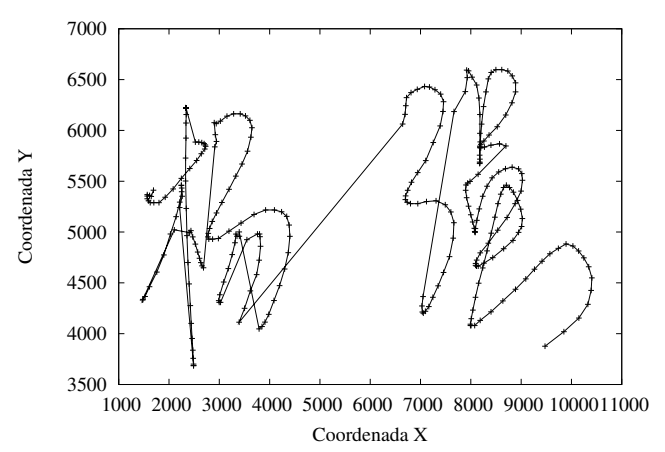

(a) Assinatura

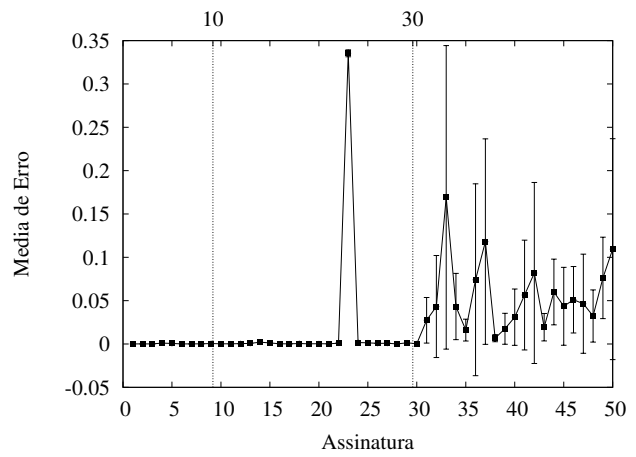

(c) DD2 - tempo por ponto

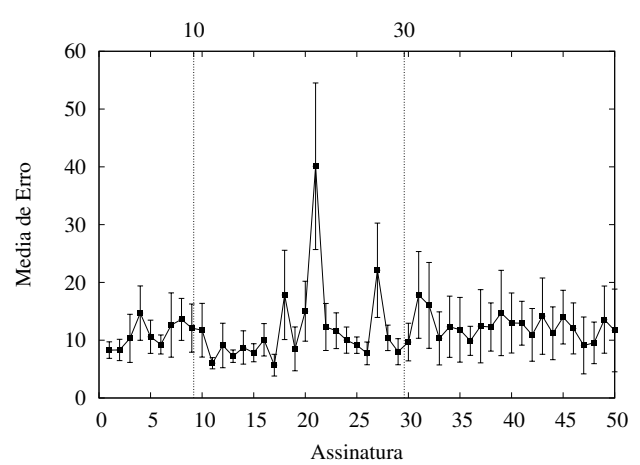

(e) DD4 - derivada entre as coordenadas da amostragem

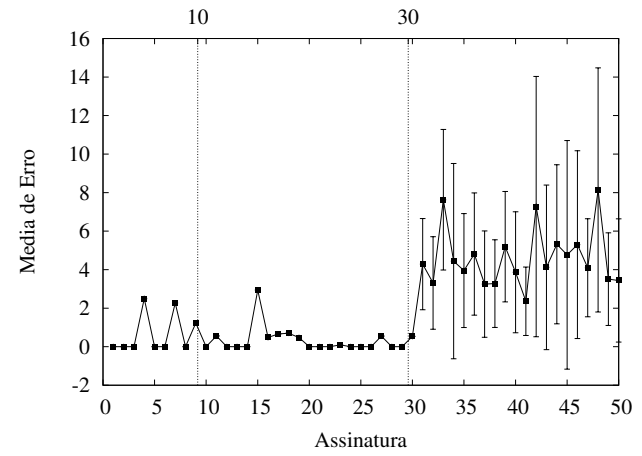

(g) DD6 - distância entre os pontos

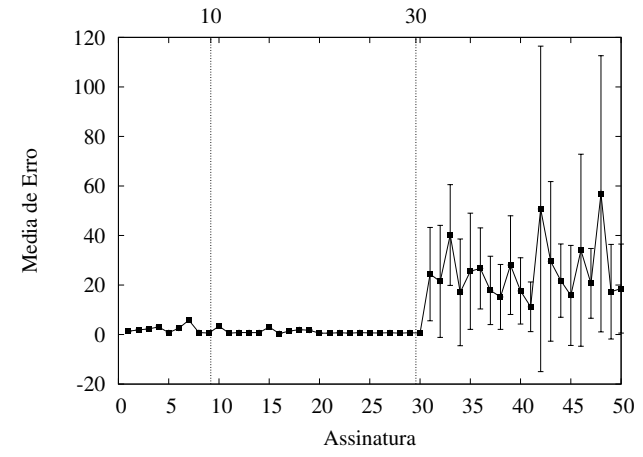

(b) DD1 - diferença entre as coordenadas da amostragem

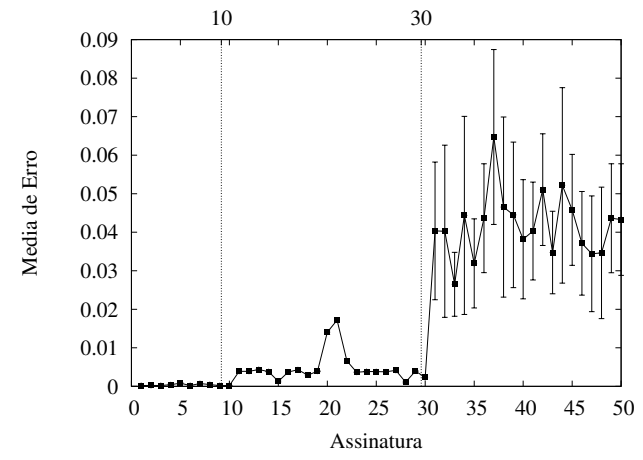

(d) DD3 - frequência dos pontos

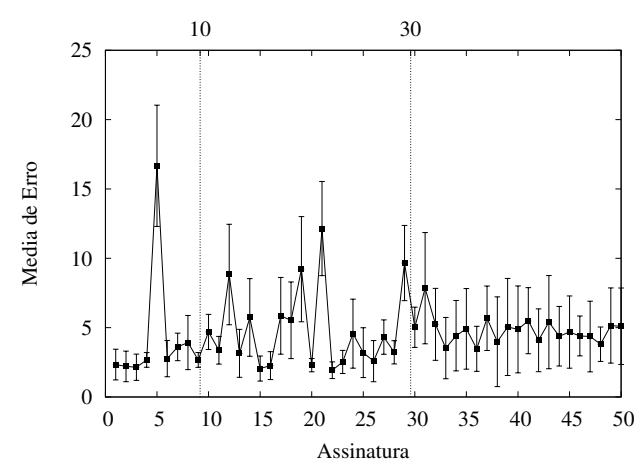

(f) DD5 - derivada entre os pontos por tempo

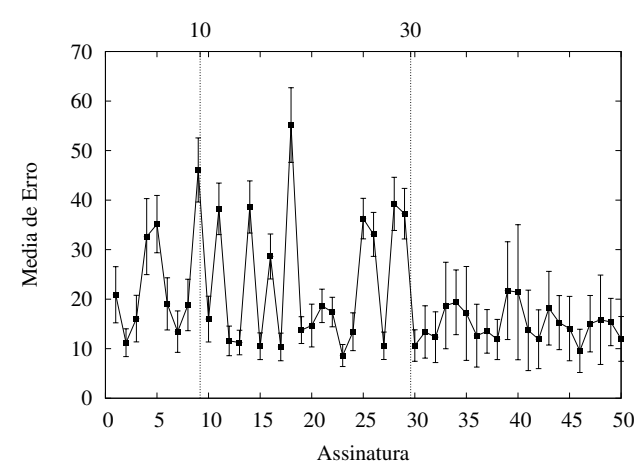

(h) DD7 - distância por tempo (velocidade)

Usuário 27 - Resultado dos experimentos utilizando a medida de similaridade DTW, onde são comparados os resultados de treinamento com 10 assinaturas verdadeiras e 40 falsas. 


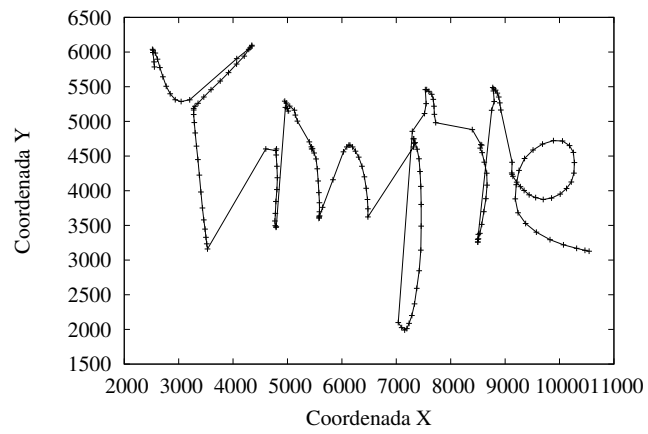

(a) Assinatura

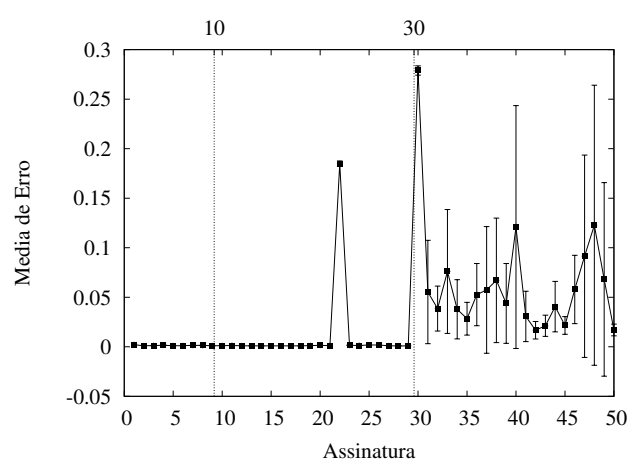

(c) DD2 - tempo por ponto

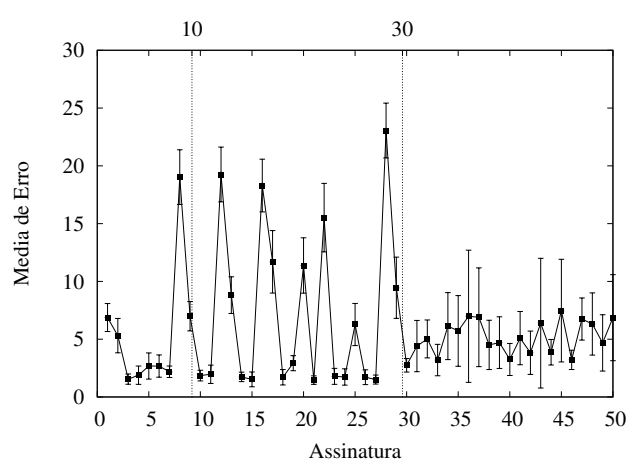

(e) DD4 - derivada entre as coordenadas da (f) DD5 - derivada entre os pontos por tempo amostragem

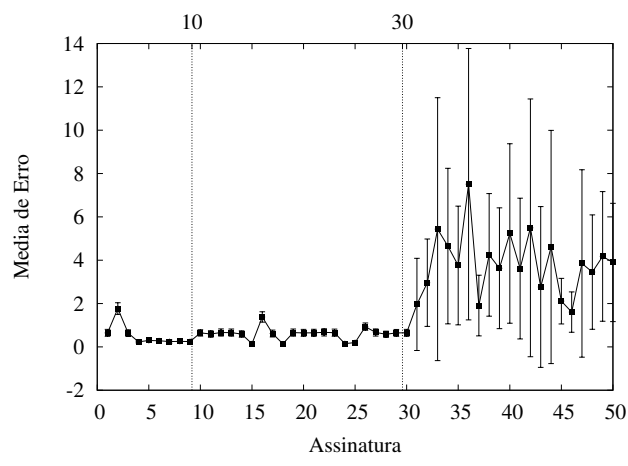

(g) DD6 - distância entre os pontos

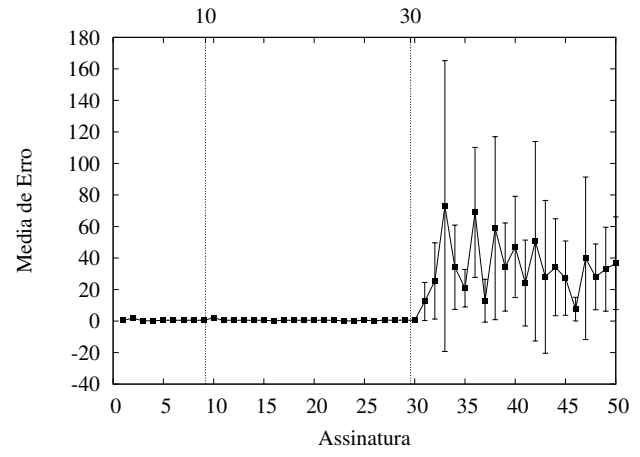

(b) DD1 - diferença entre as coordenadas da amostragem

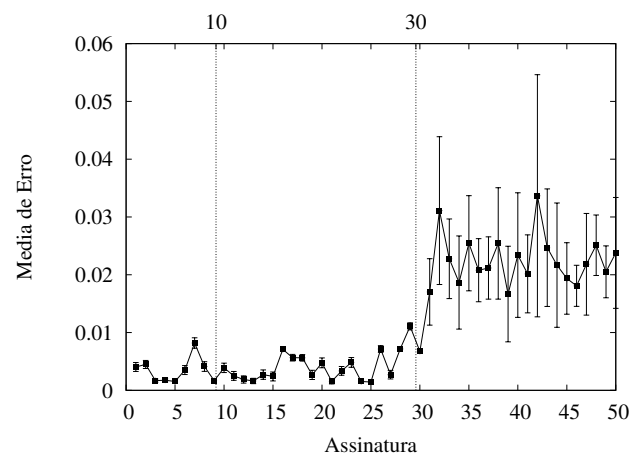

(d) DD3 - frequência dos pontos

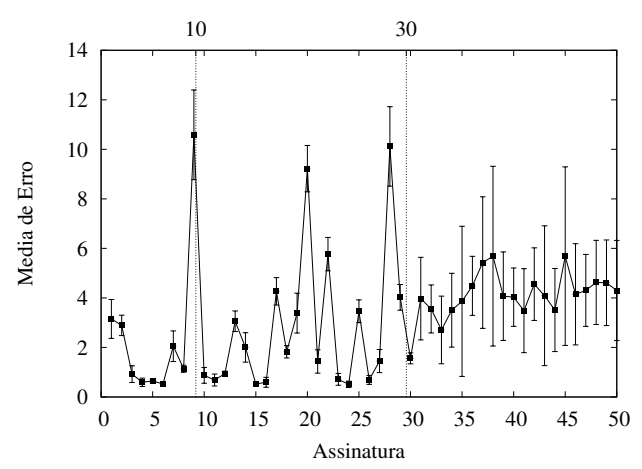

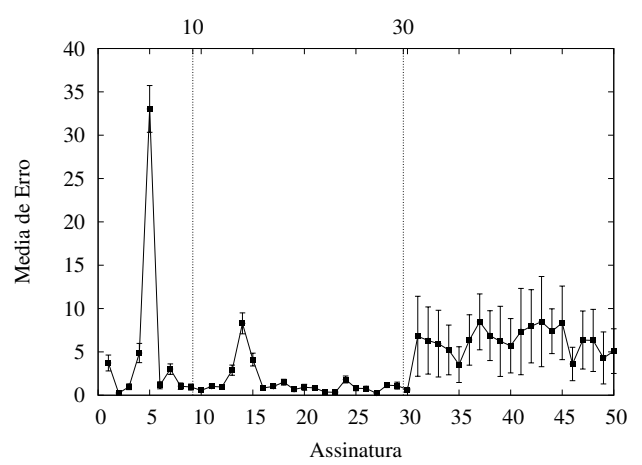

(h) DD7 - distância por tempo (velocidade)

Usuário 28 - Resultado dos experimentos utilizando a medida de similaridade DTW, onde são comparados os resultados de treinamento com 10 assinaturas verdadeiras e 40 falsas. 


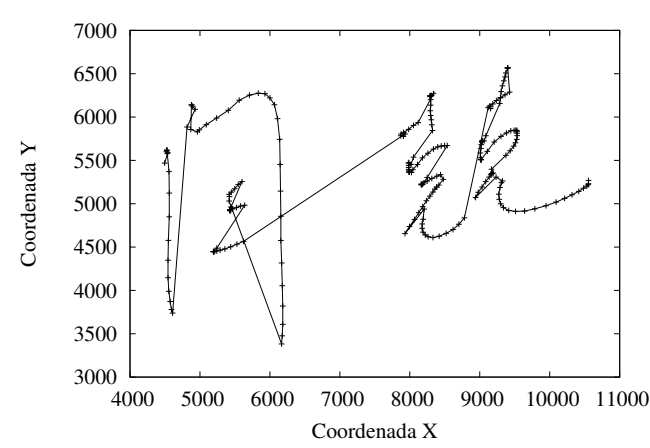

(a) Assinatura

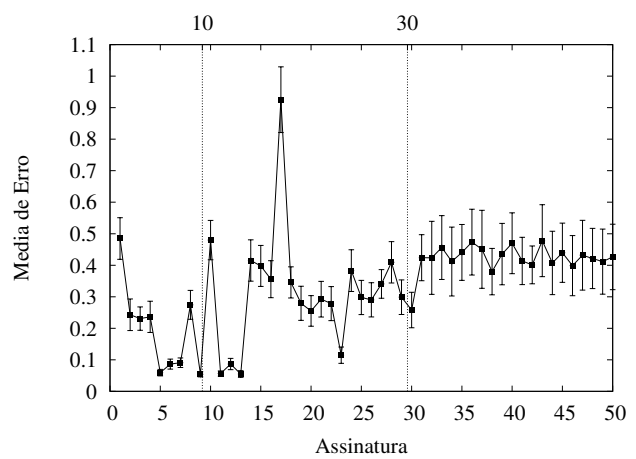

(c) DD2 - tempo por ponto

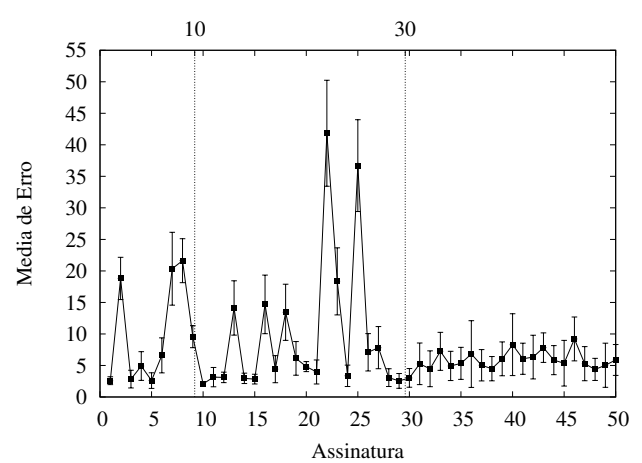

(e) DD4 - derivada entre as coordenadas da amostragem

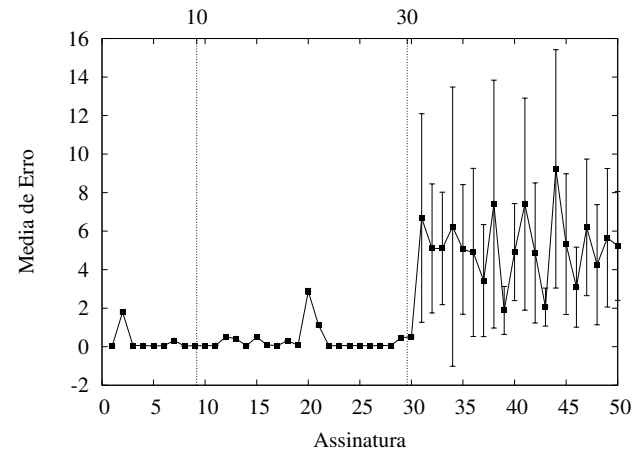

(g) DD6 - distância entre os pontos

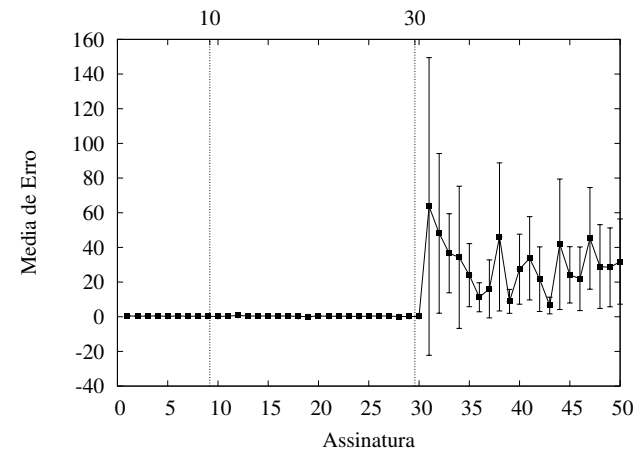

(b) DD1 - diferença entre as coordenadas da amostragem

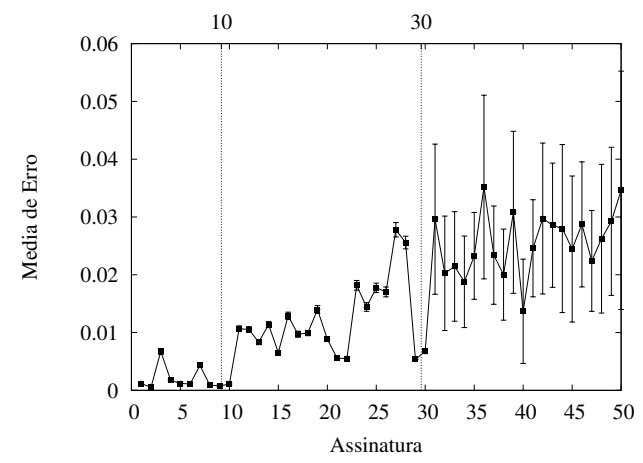

(d) DD3 - frequência dos pontos

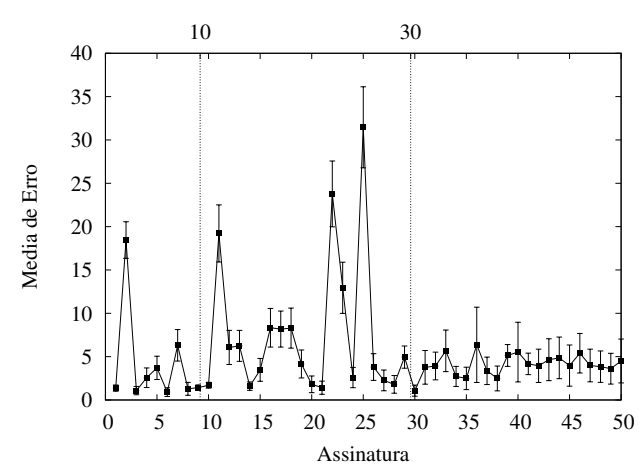

(f) DD5 - derivada entre os pontos por tempo

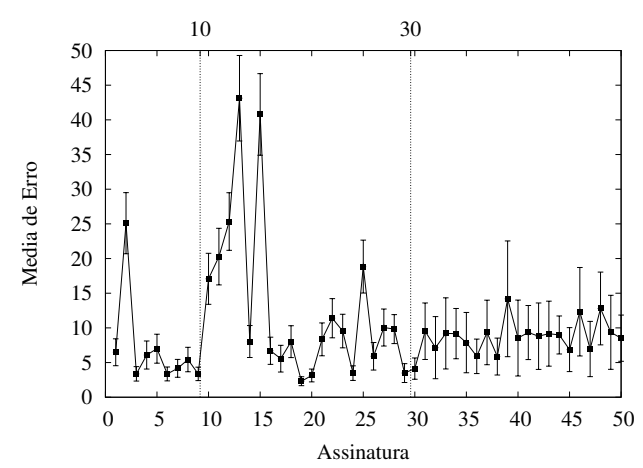

(h) DD7 - distância por tempo (velocidade)

Usuário 29 - Resultado dos experimentos utilizando a medida de similaridade DTW, onde são comparados os resultados de treinamento com 10 assinaturas verdadeiras e 40 falsas. 


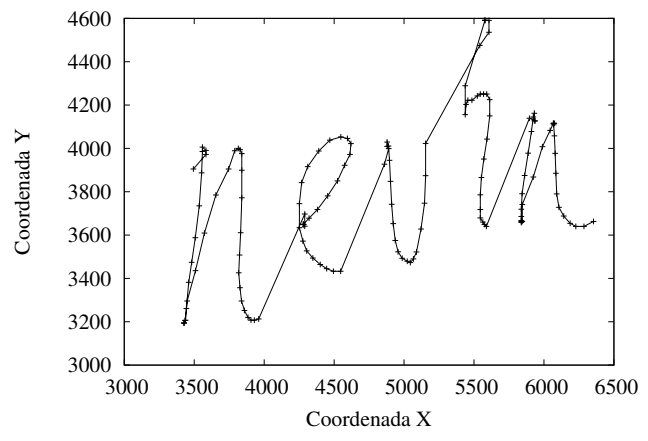

(a) Assinatura

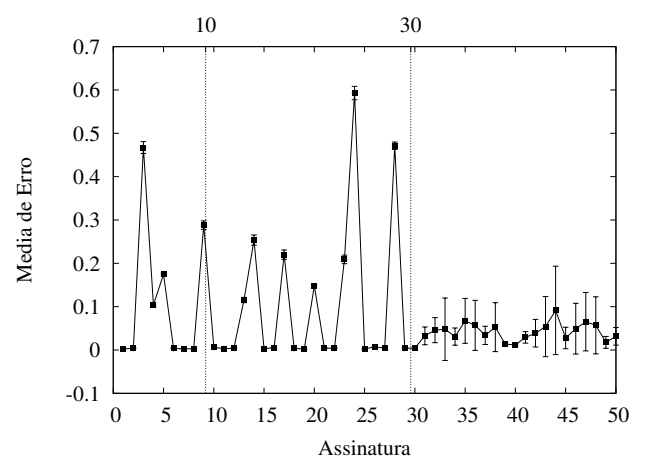

(c) DD2 - tempo por ponto

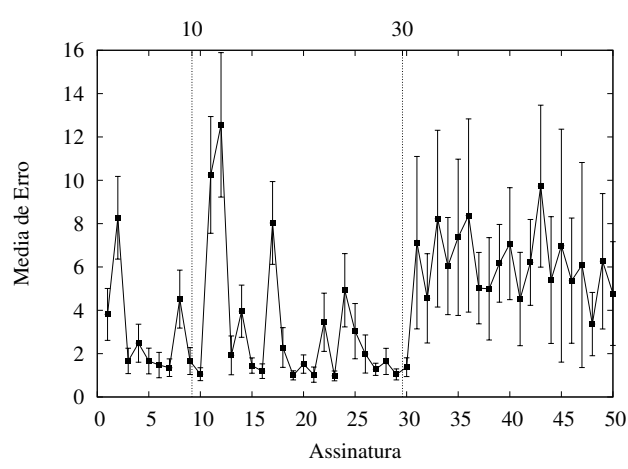

(e) DD4 - derivada entre as coordenadas da (f) DD5 - derivada entre os pontos por tempo amostragem

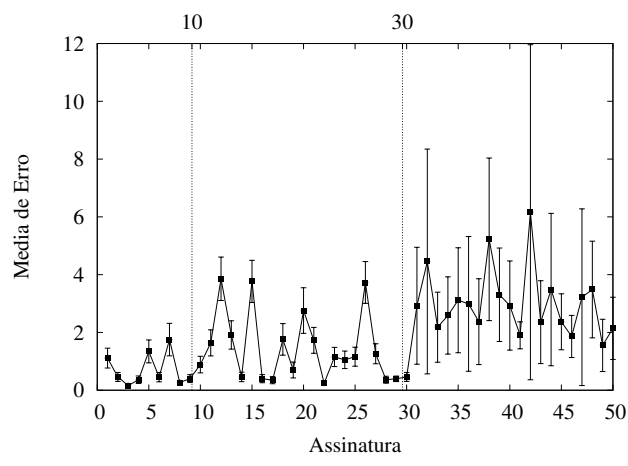

(g) DD6 - distância entre os pontos

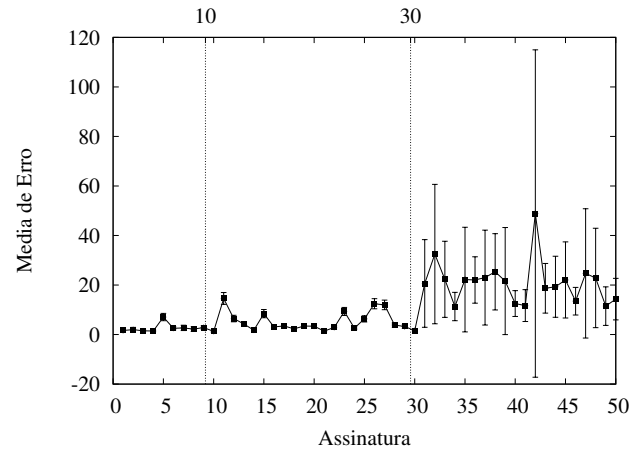

(b) DD1 - diferença entre as coordenadas da amostragem

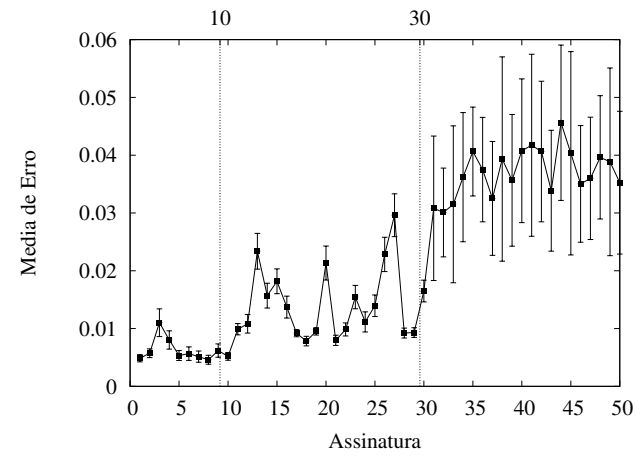

(d) DD3 - frequência dos pontos

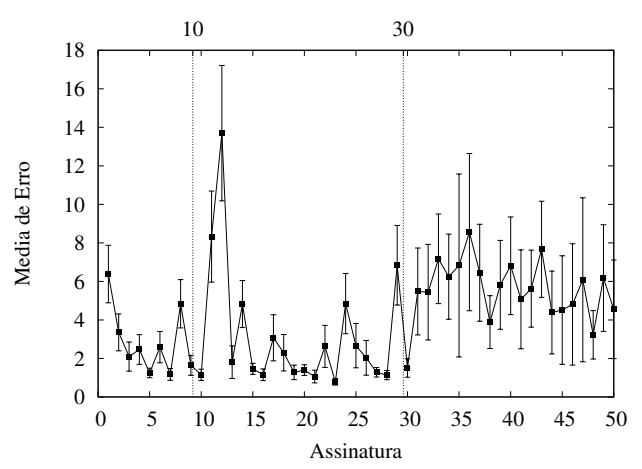

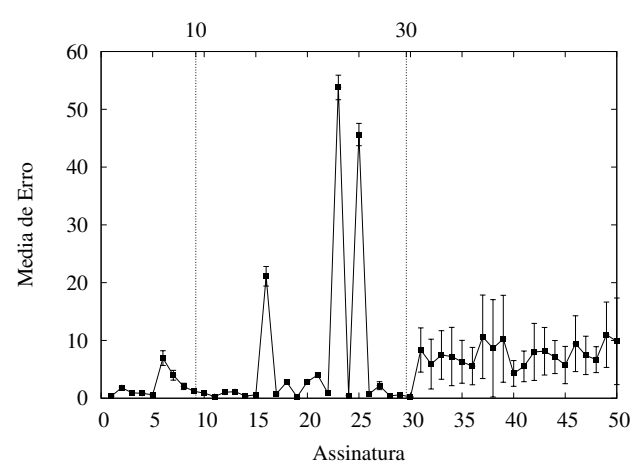

(h) DD7 - distância por tempo (velocidade)

Usuário 30 - Resultado dos experimentos utilizando a medida de similaridade DTW, onde são comparados os resultados de treinamento com 10 assinaturas verdadeiras e 40 falsas. 


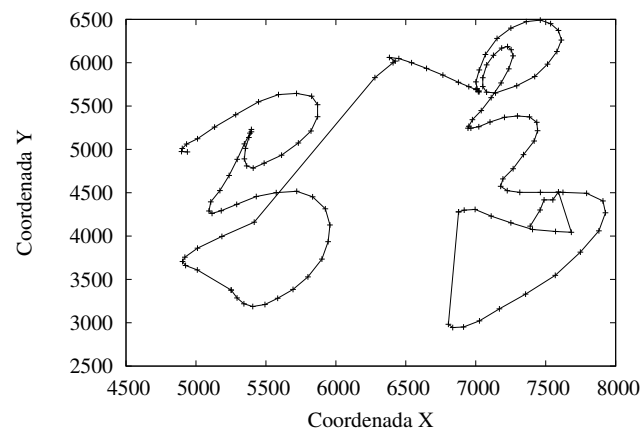

(a) Assinatura

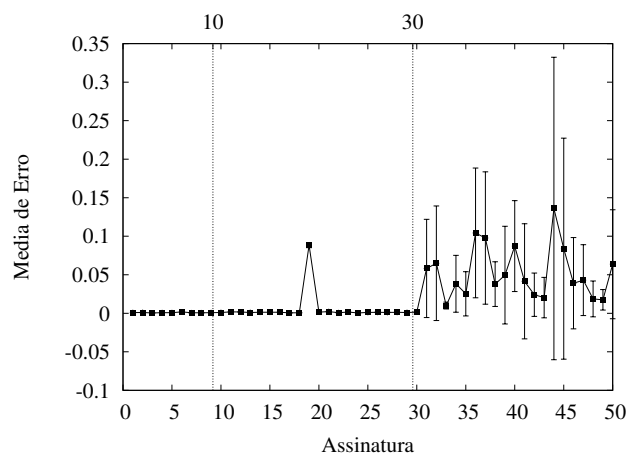

(c) DD2 - tempo por ponto

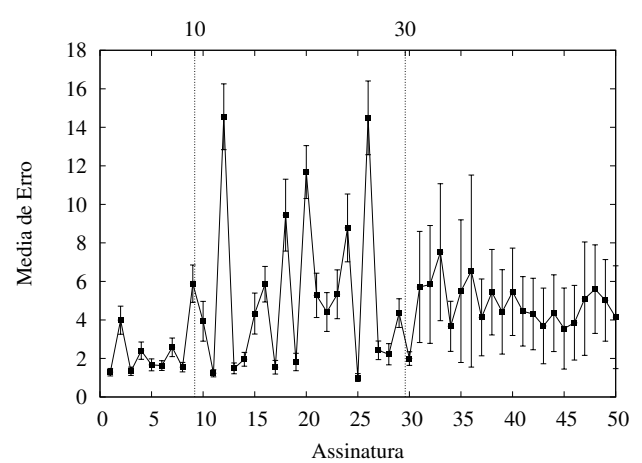

(e) DD4 - derivada entre as coordenadas da (f) DD5 - derivada entre os pontos por tempo amostragem

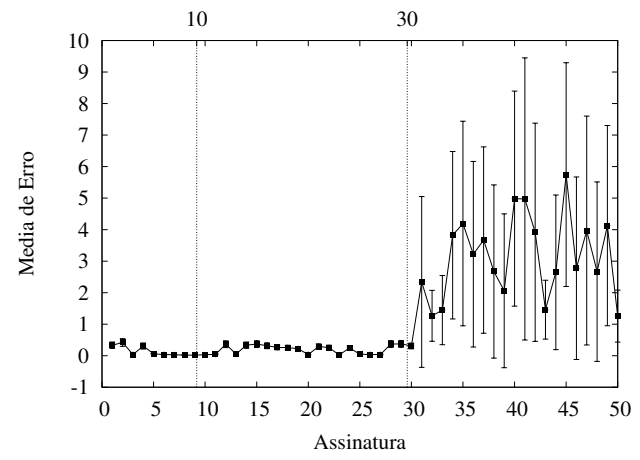

(g) DD6 - distância entre os pontos

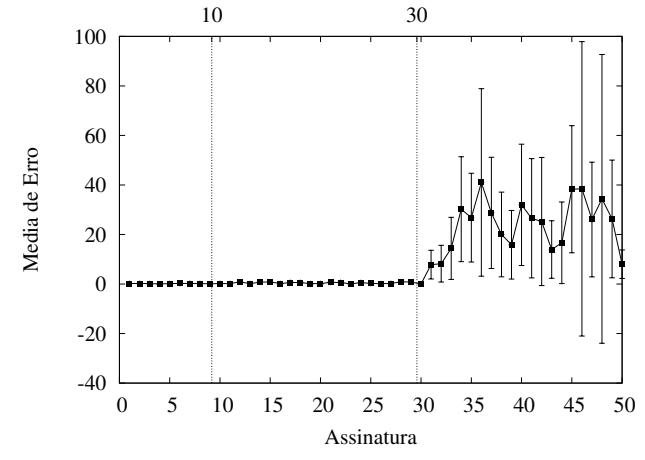

(b) DD1 - diferença entre as coordenadas da amostragem

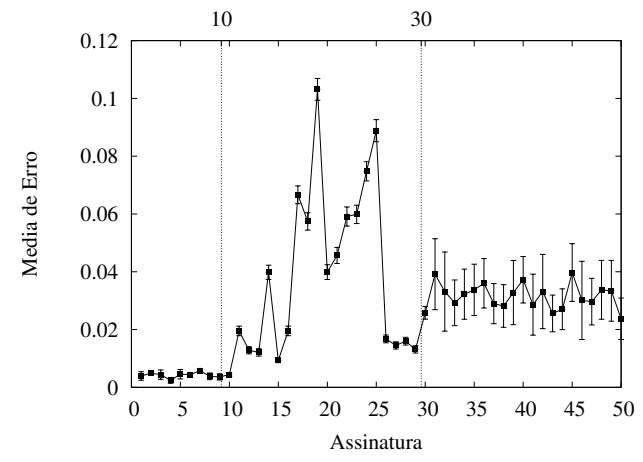

(d) DD3 - frequência dos pontos
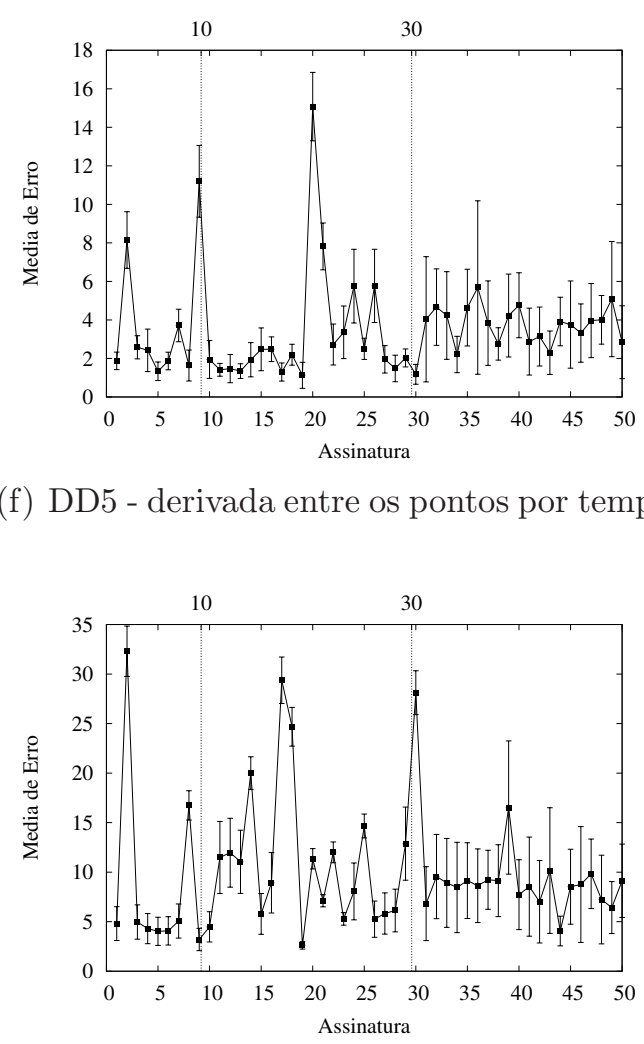

(h) DD7 - distância por tempo (velocidade)

Usuário 31 - Resultado dos experimentos utilizando a medida de similaridade DTW, onde são comparados os resultados de treinamento com 10 assinaturas verdadeiras e 40 falsas. 


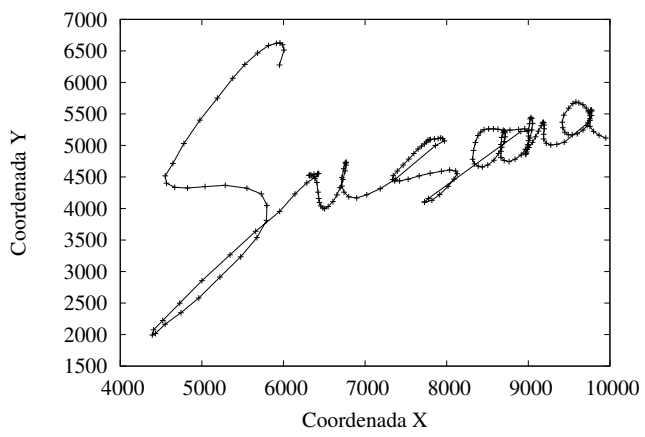

(a) Assinatura

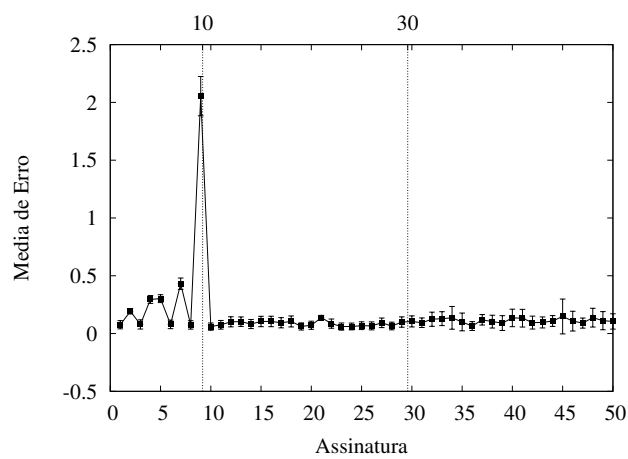

(c) DD2 - tempo por ponto

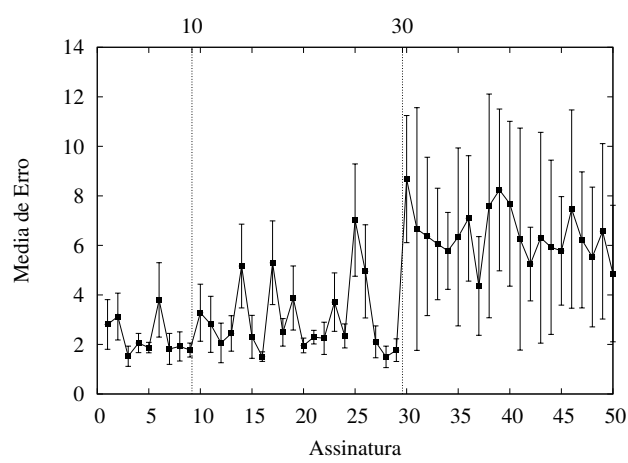

(e) DD4 - derivada entre as coordenadas da (f) DD5 - derivada entre os pontos por tempo amostragem

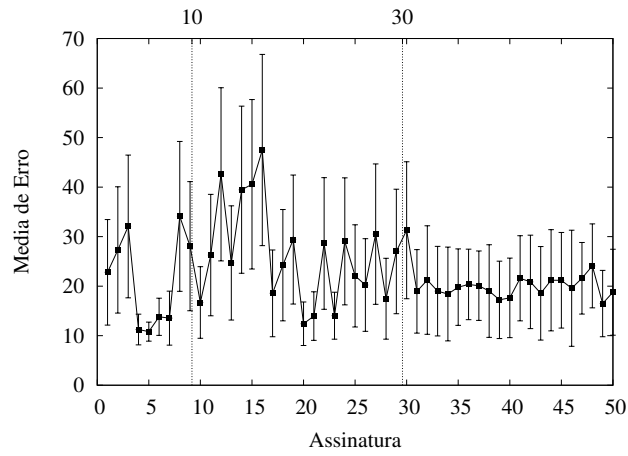

(g) DD6 - distância entre os pontos

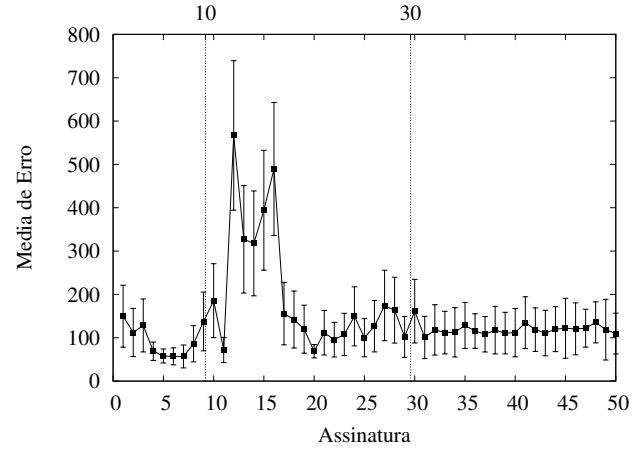

(b) DD1 - diferença entre as coordenadas da amostragem

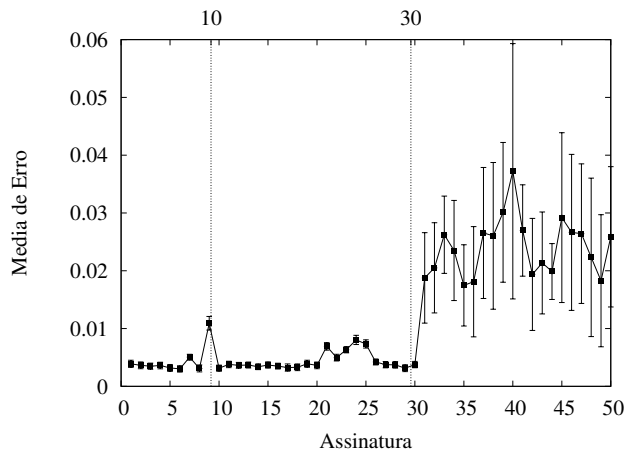

(d) DD3 - frequência dos pontos

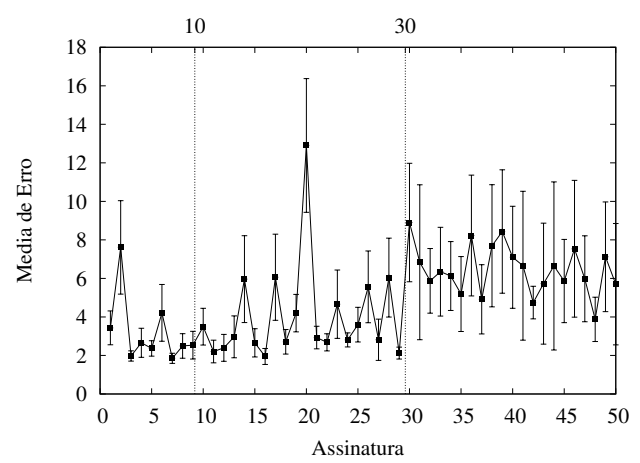

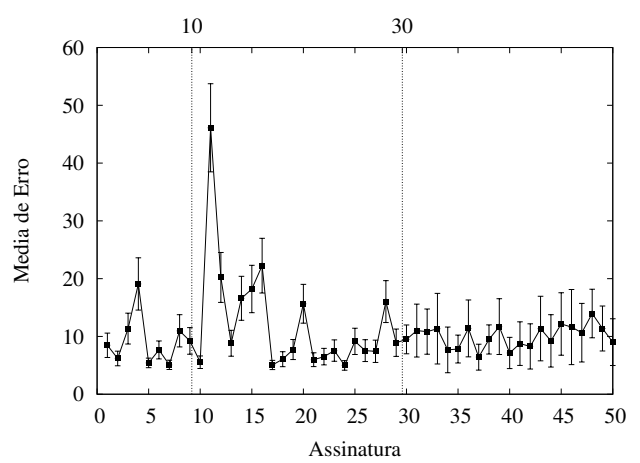

(h) DD7 - distância por tempo (velocidade)

Usuário 32 - Resultado dos experimentos utilizando a medida de similaridade DTW, onde são comparados os resultados de treinamento com 10 assinaturas verdadeiras e 40 falsas. 


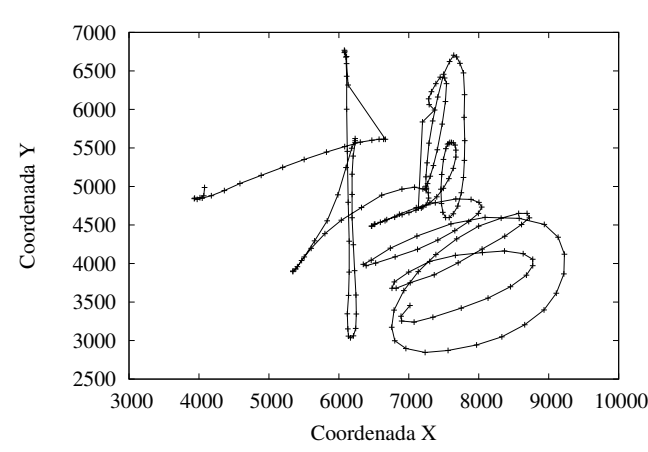

(a) Assinatura

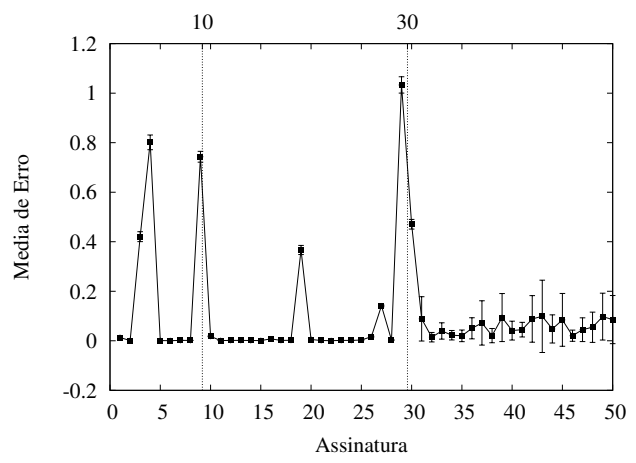

(c) DD2 - tempo por ponto

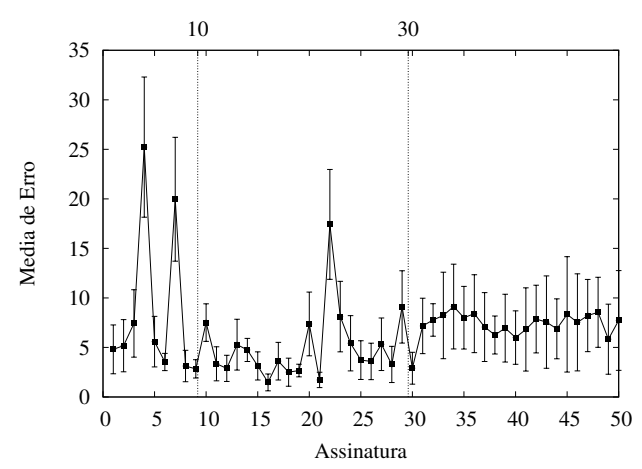

(e) DD4 - derivada entre as coordenadas da amostragem

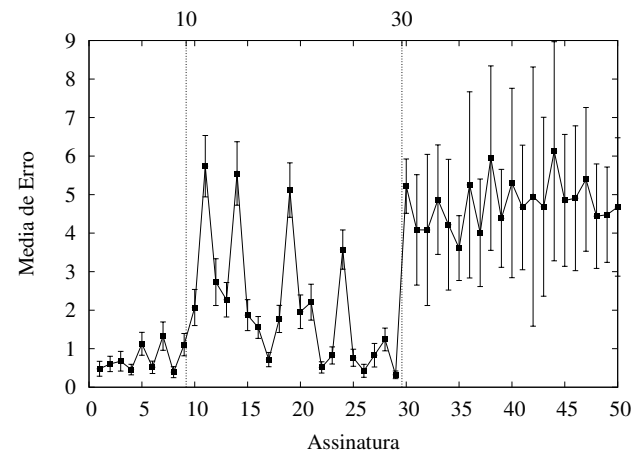

(g) DD6 - distância entre os pontos

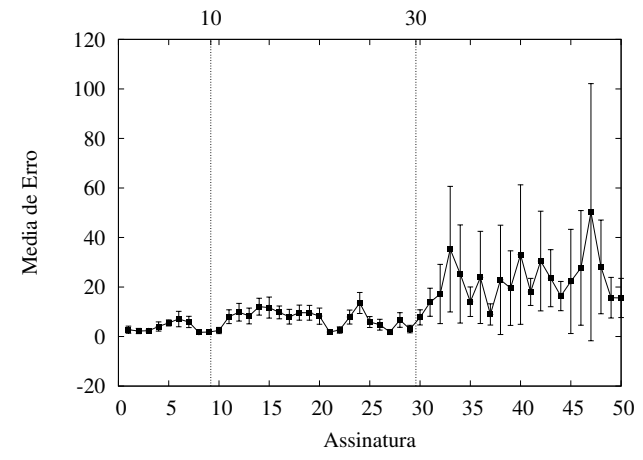

(b) DD1 - diferença entre as coordenadas da amostragem

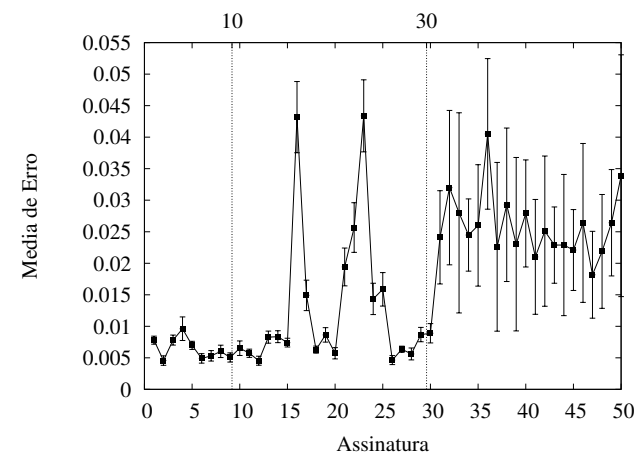

(d) DD3 - frequência dos pontos

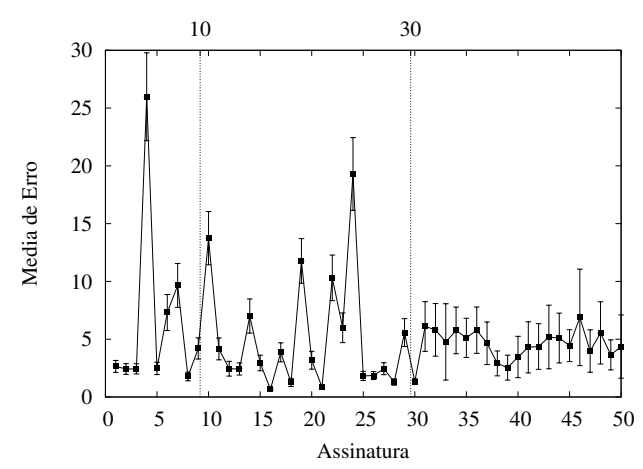

(f) DD5 - derivada entre os pontos por tempo

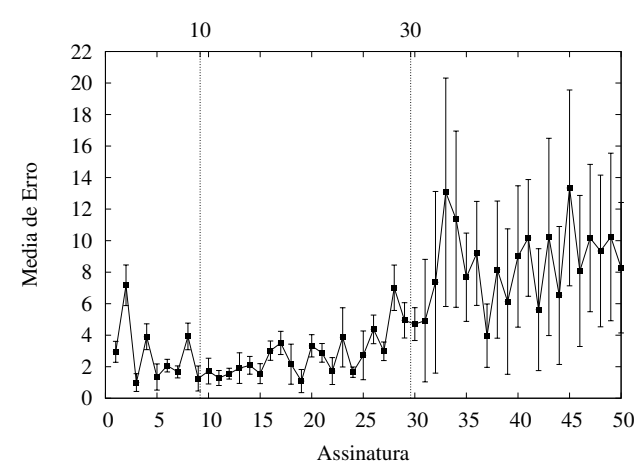

(h) DD7 - distância por tempo (velocidade)

Usuário 33 - Resultado dos experimentos utilizando a medida de similaridade DTW, onde são comparados os resultados de treinamento com 10 assinaturas verdadeiras e 40 falsas. 


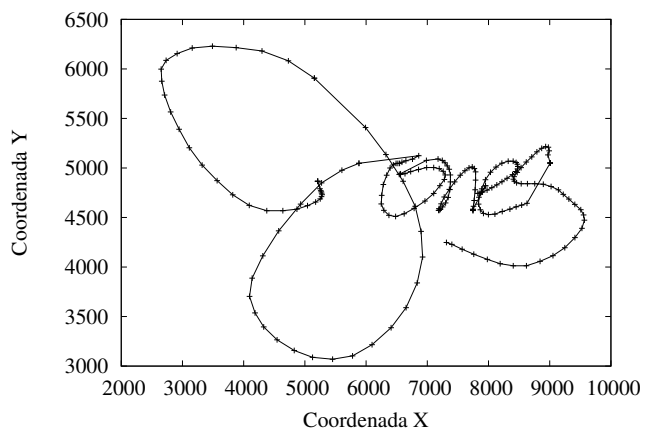

(a) Assinatura

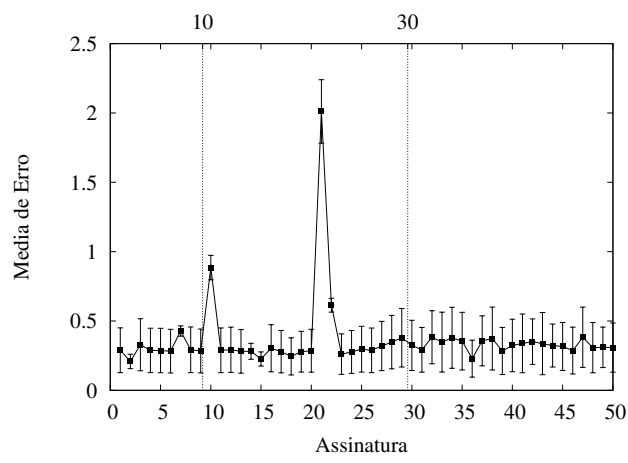

(c) DD2 - tempo por ponto

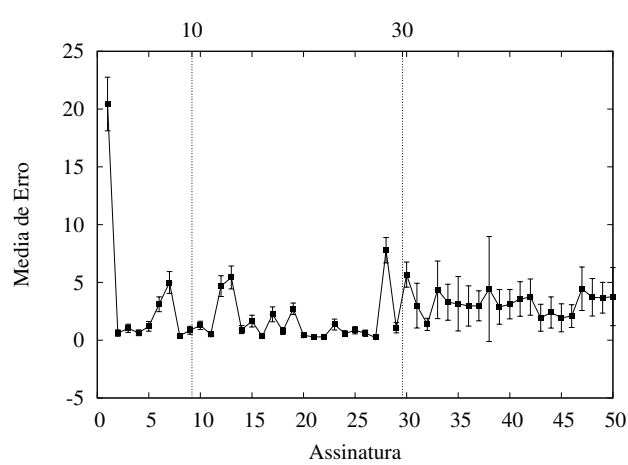

(e) DD4 - derivada entre as coordenadas da (f) DD5 - derivada entre os pontos por tempo amostragem

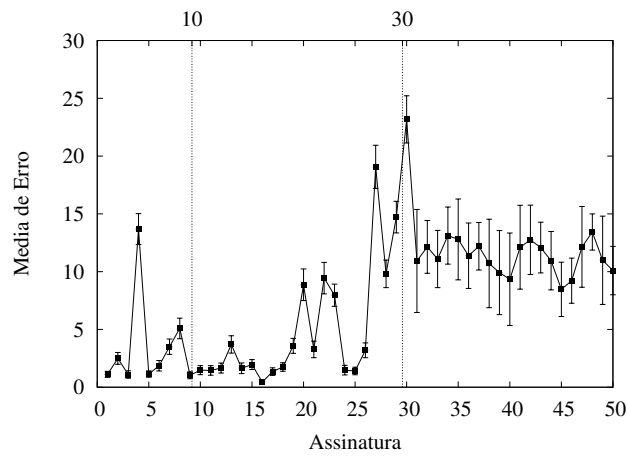

(g) DD6 - distância entre os pontos

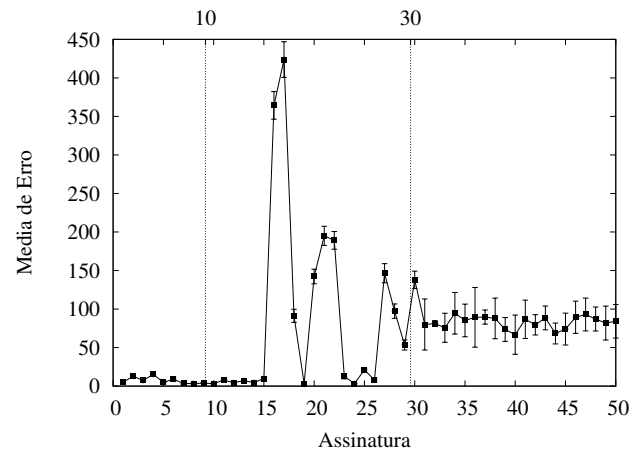

(b) DD1 - diferença entre as coordenadas da amostragem

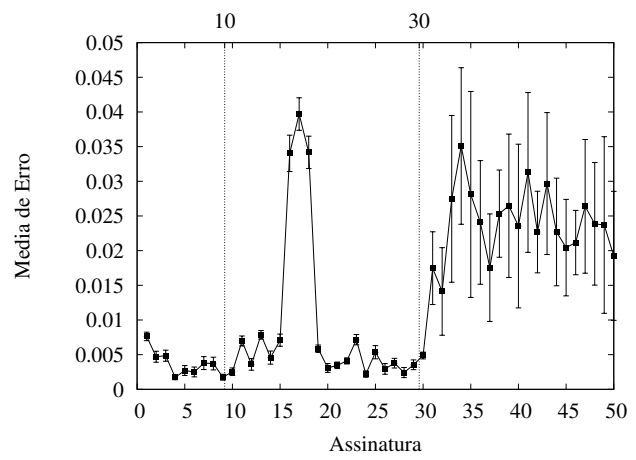

(d) DD3 - frequência dos pontos

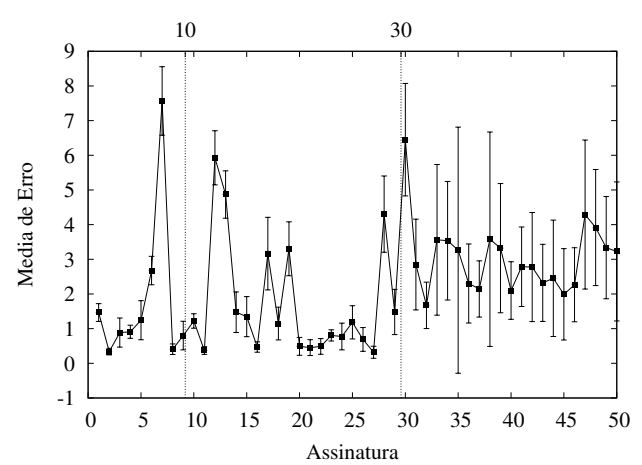

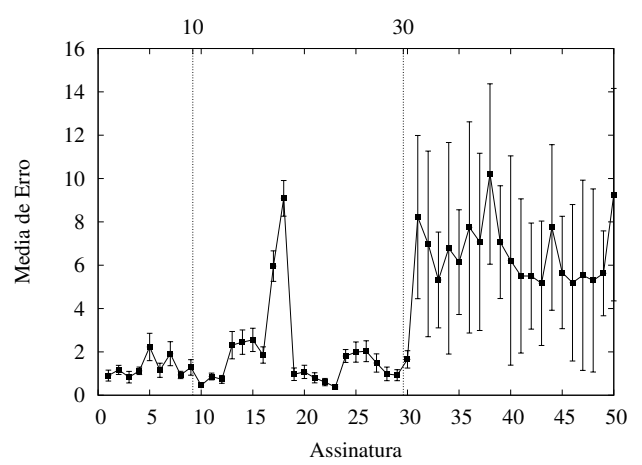

(h) DD7 - distância por tempo (velocidade)

Usuário 34 - Resultado dos experimentos utilizando a medida de similaridade DTW, onde são comparados os resultados de treinamento com 10 assinaturas verdadeiras e 40 falsas. 


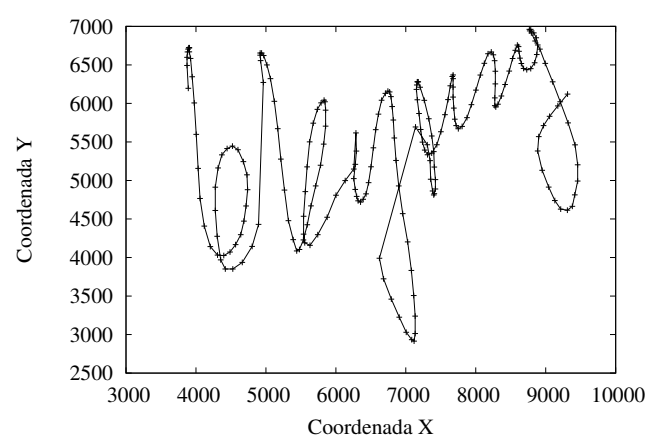

(a) Assinatura

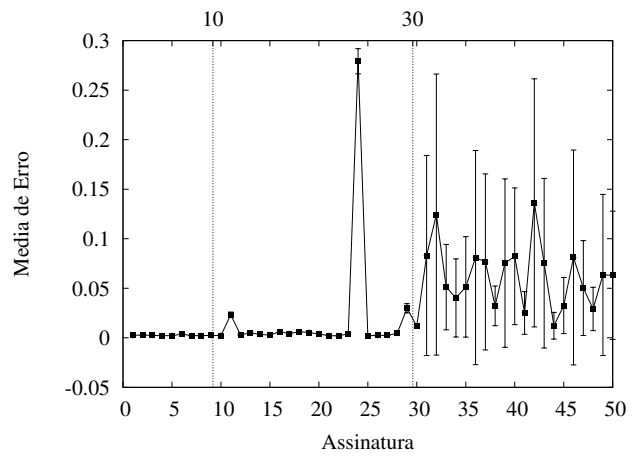

(c) DD2 - tempo por ponto

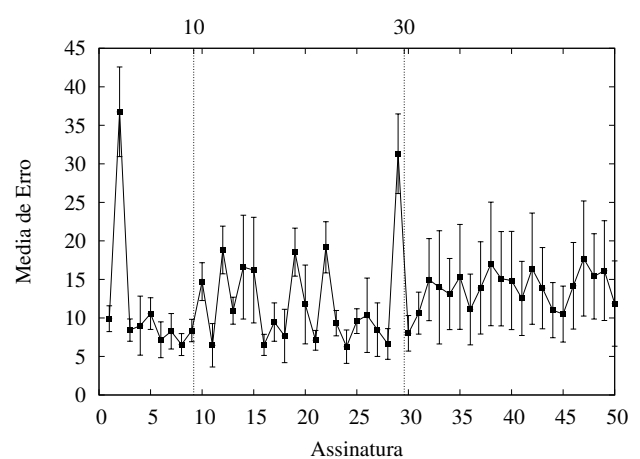

(e) DD4 - derivada entre as coordenadas da amostragem

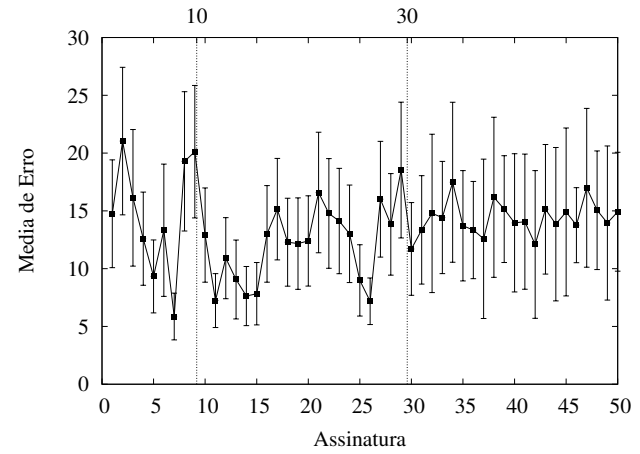

(g) DD6 - distância entre os pontos

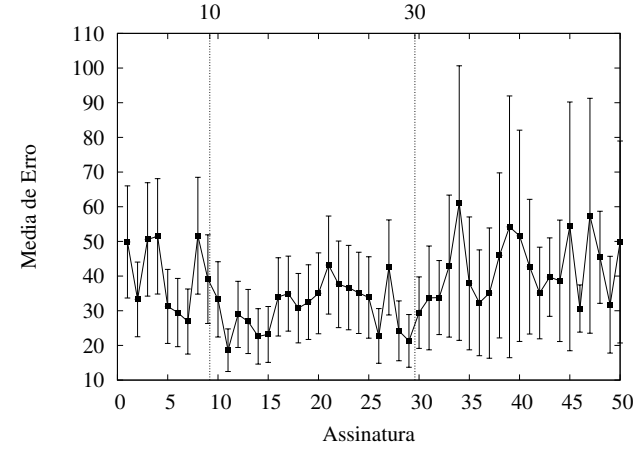

(b) DD1 - diferença entre as coordenadas da amostragem

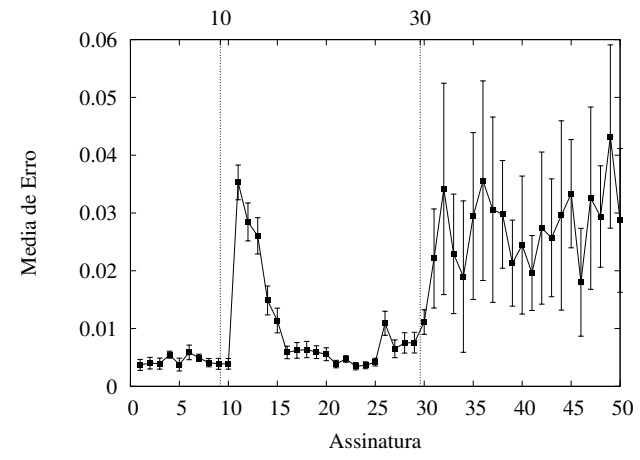

(d) DD3 - frequência dos pontos

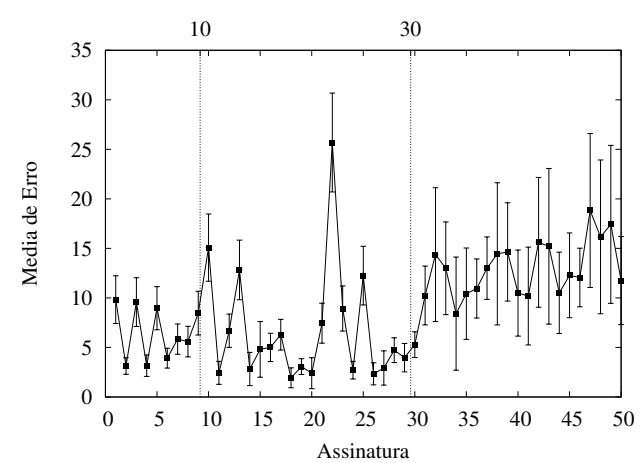

(f) DD5 - derivada entre os pontos por tempo

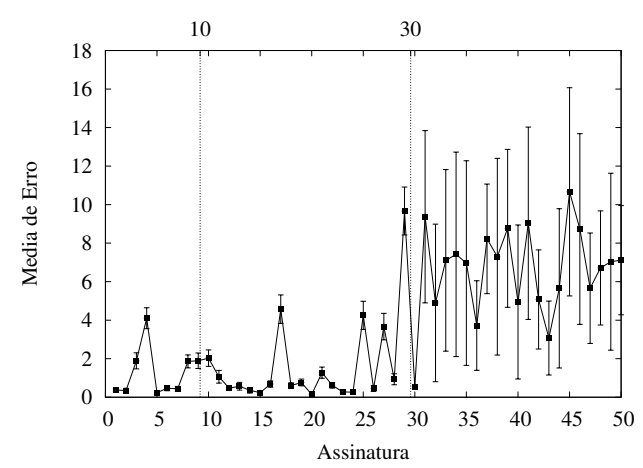

(h) DD7 - distância por tempo (velocidade)

Usuário 35 - Resultado dos experimentos utilizando a medida de similaridade DTW, onde são comparados os resultados de treinamento com 10 assinaturas verdadeiras e 40 falsas. 


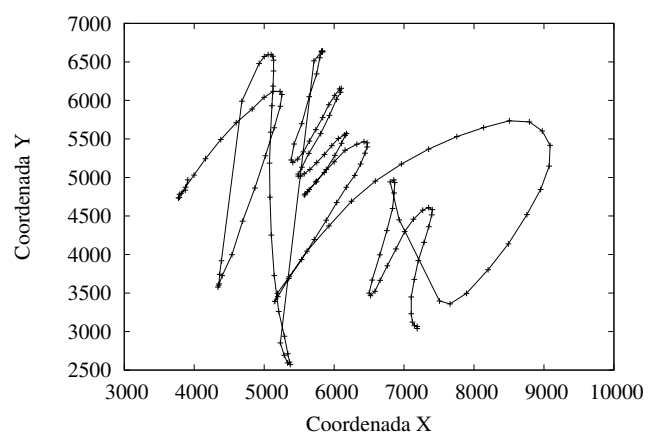

(a) Assinatura

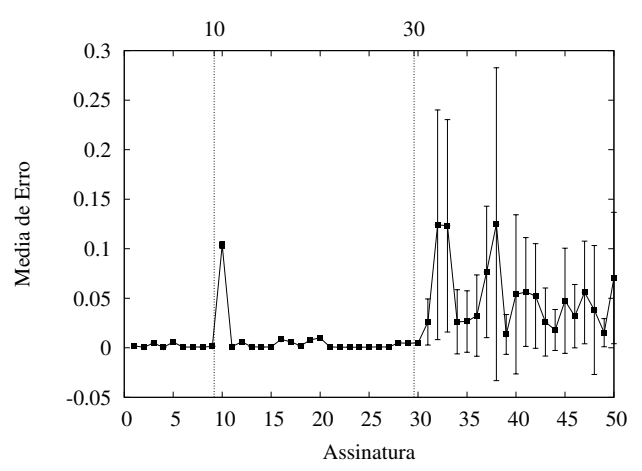

(c) DD2 - tempo por ponto

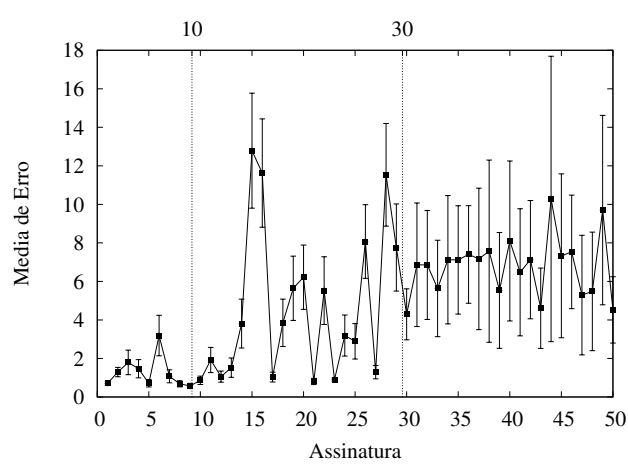

(e) DD4 - derivada entre as coordenadas da (f) DD5 - derivada entre os pontos por tempo amostragem

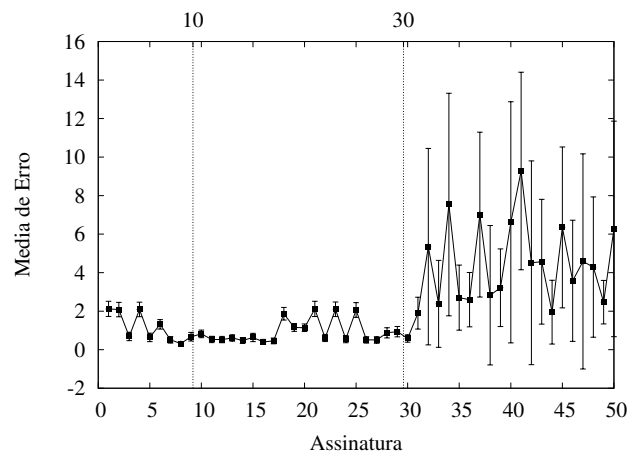

(g) DD6 - distância entre os pontos

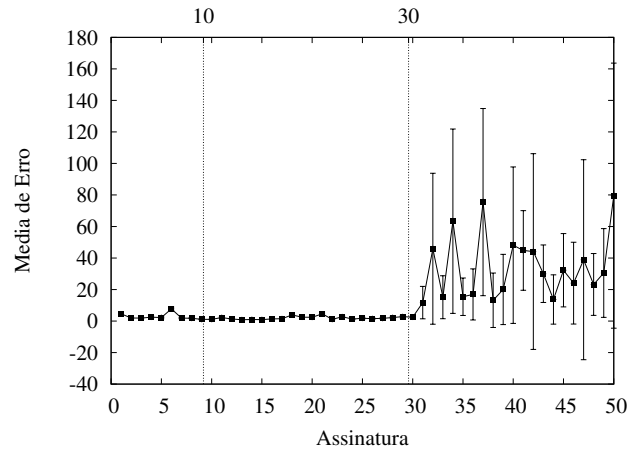

(b) DD1 - diferença entre as coordenadas da amostragem

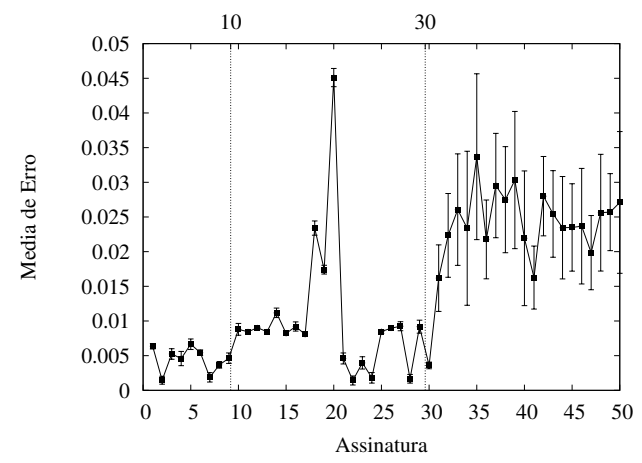

(d) DD3 - frequência dos pontos

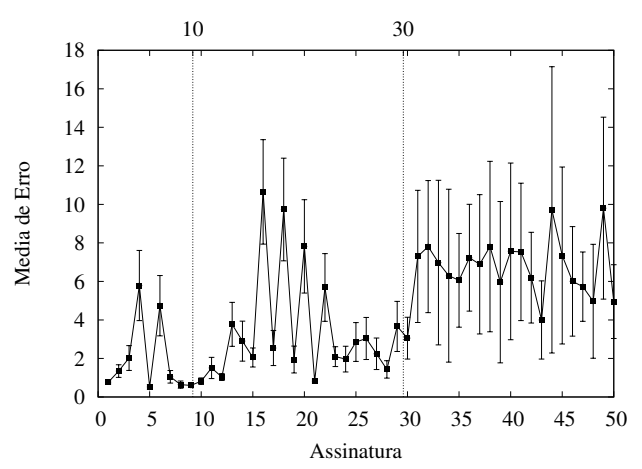

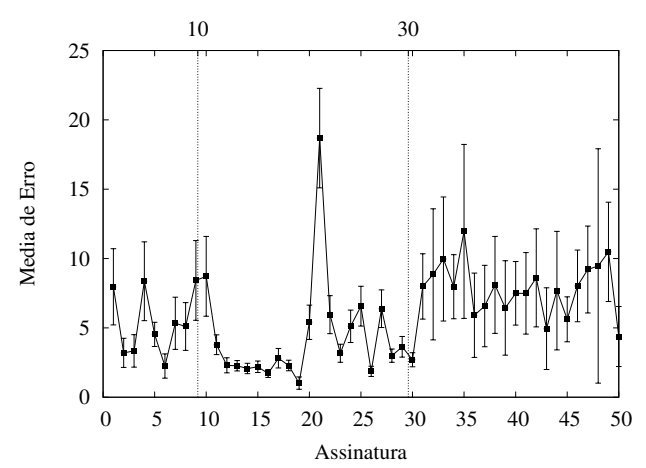

(h) DD7 - distância por tempo (velocidade)

Usuário 36 - Resultado dos experimentos utilizando a medida de similaridade DTW, onde são comparados os resultados de treinamento com 10 assinaturas verdadeiras e 40 falsas. 


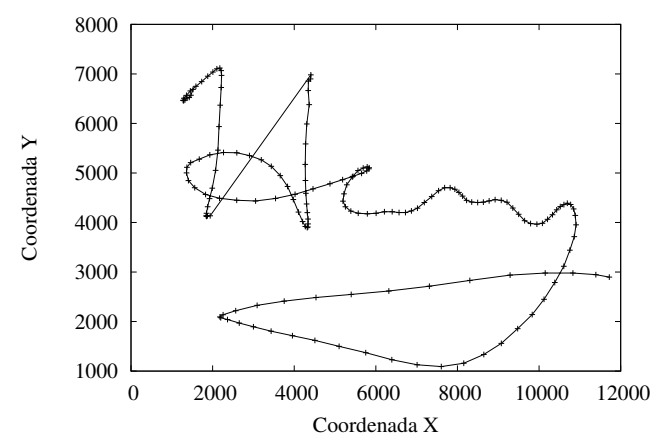

(a) Assinatura

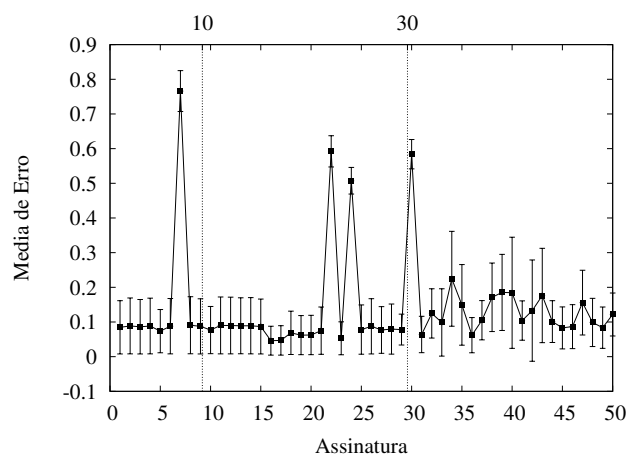

(c) DD2 - tempo por ponto

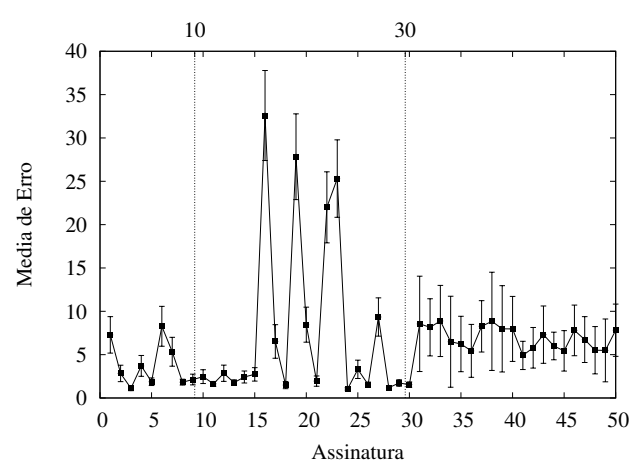

(e) DD4 - derivada entre as coordenadas da amostragem

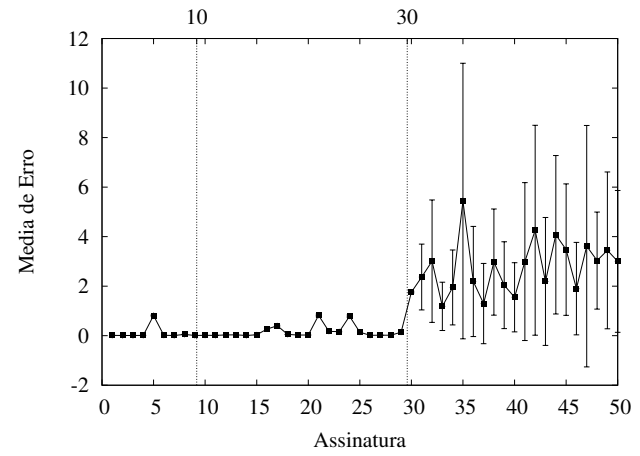

(g) DD6 - distância entre os pontos

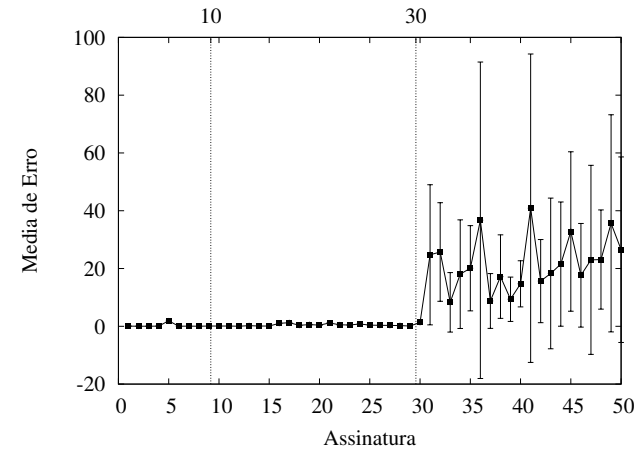

(b) DD1 - diferença entre as coordenadas da amostragem

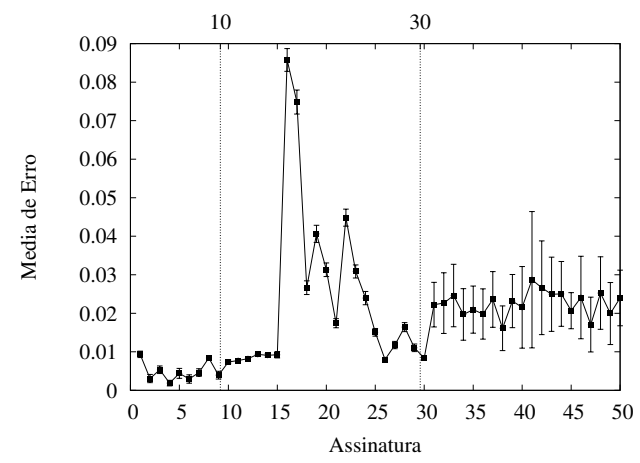

(d) DD3 - frequência dos pontos

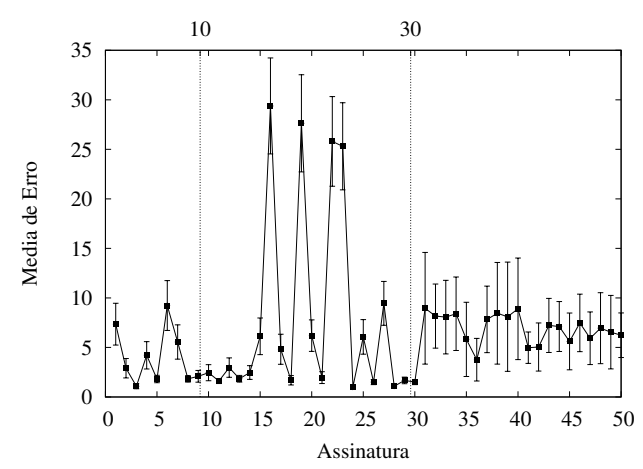

(f) DD5 - derivada entre os pontos por tempo

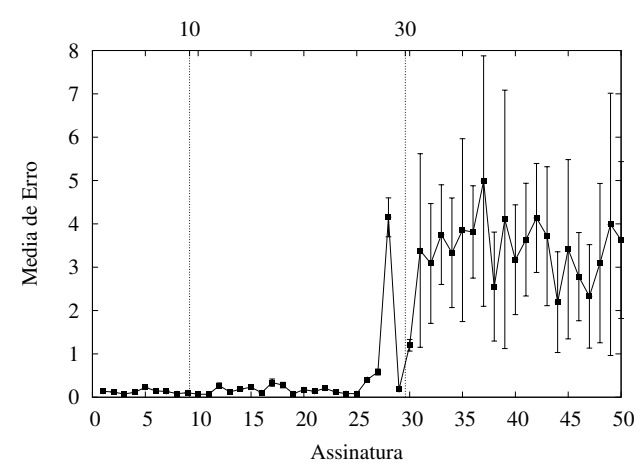

(h) DD7 - distância por tempo (velocidade)

Usuário 37 - Resultado dos experimentos utilizando a medida de similaridade DTW, onde são comparados os resultados de treinamento com 10 assinaturas verdadeiras e 40 falsas. 


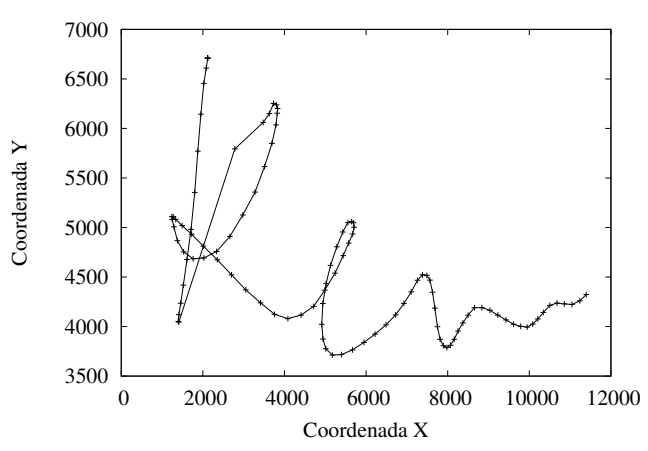

(a) Assinatura

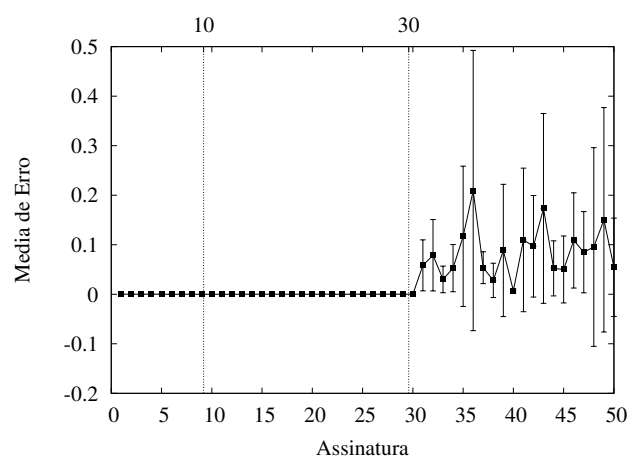

(c) DD2 - tempo por ponto

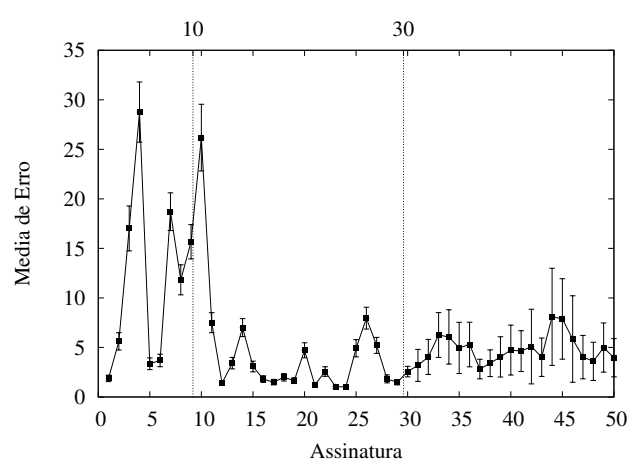

(e) DD4 - derivada entre as coordenadas da (f) DD5 - derivada entre os pontos por tempo amostragem

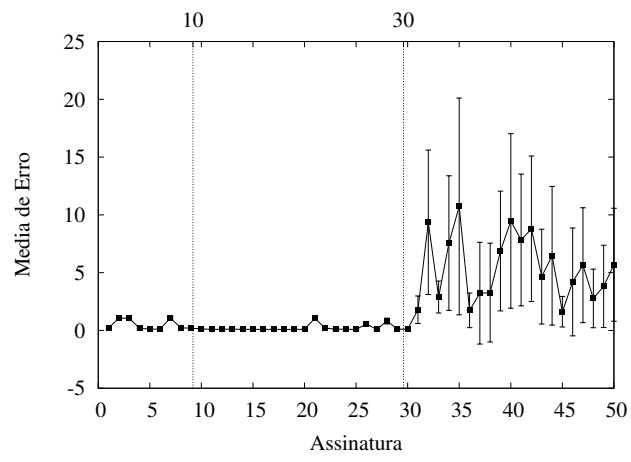

(g) DD6 - distância entre os pontos

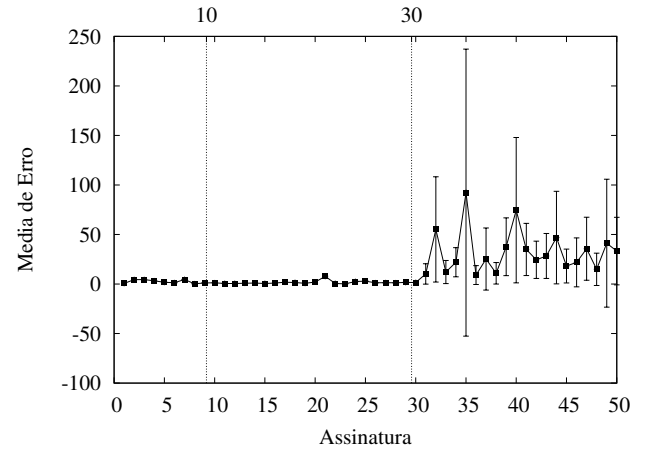

(b) DD1 - diferença entre as coordenadas da amostragem

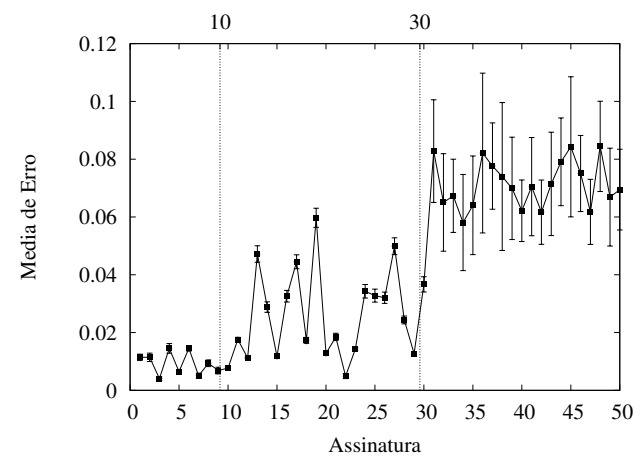

(d) DD3 - frequência dos pontos

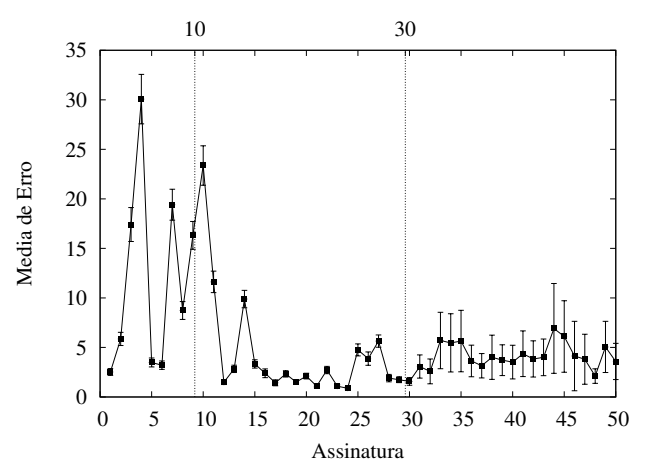

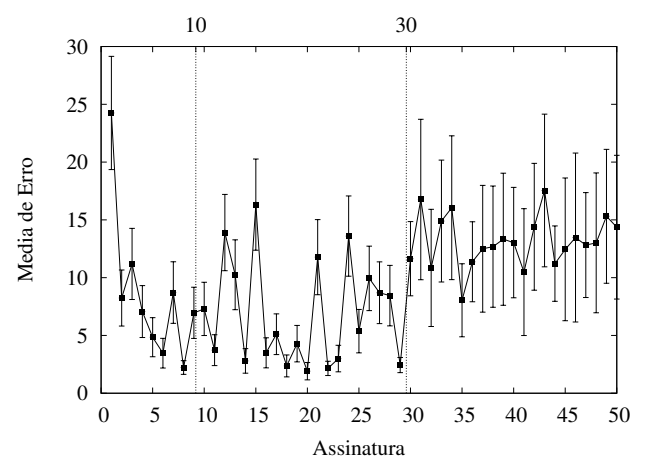

(h) DD7 - distância por tempo (velocidade)

Usuário 38 - Resultado dos experimentos utilizando a medida de similaridade DTW, onde são comparados os resultados de treinamento com 10 assinaturas verdadeiras e 40 falsas. 


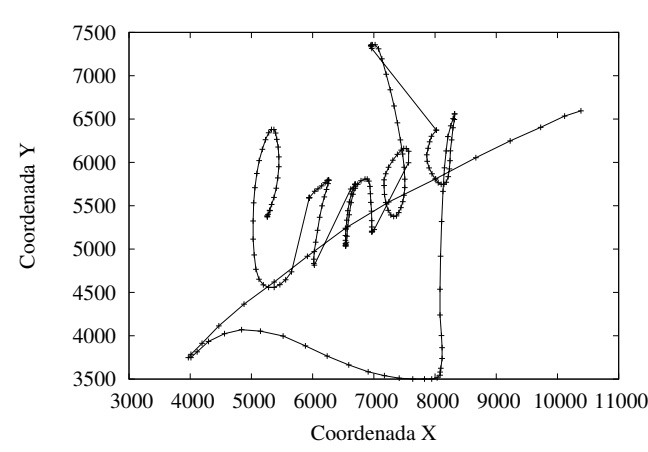

(a) Assinatura

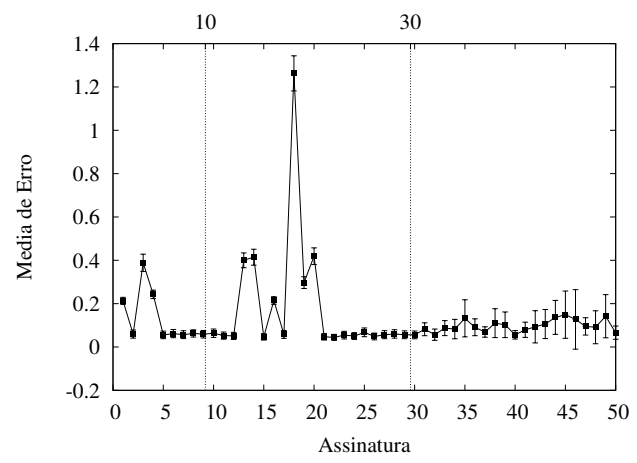

(c) DD2 - tempo por ponto

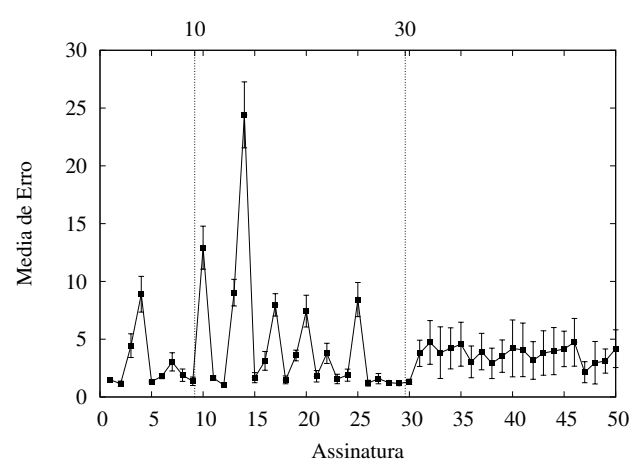

(e) DD4 - derivada entre as coordenadas da amostragem

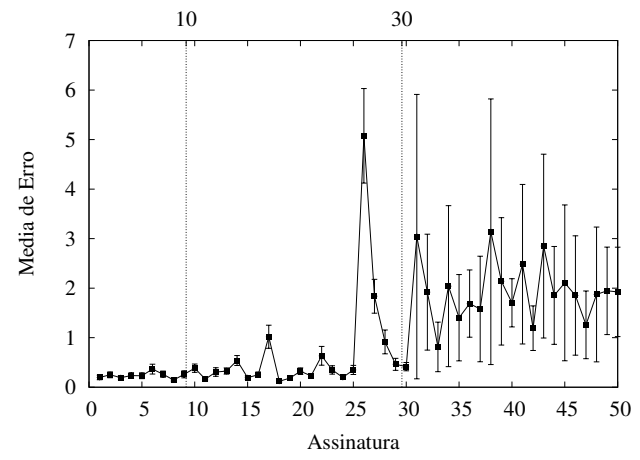

(g) DD6 - distância entre os pontos

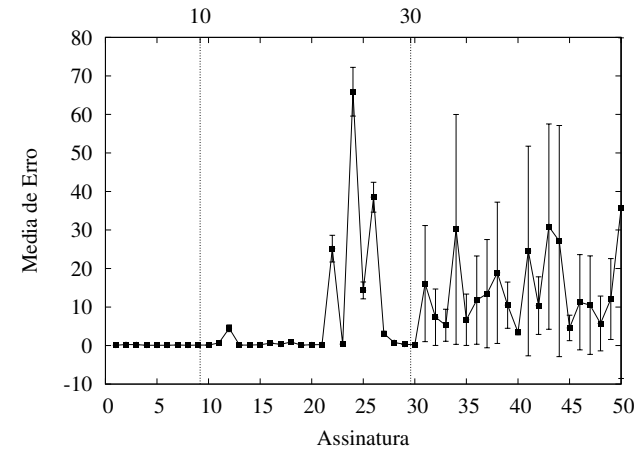

(b) DD1 - diferença entre as coordenadas da amostragem

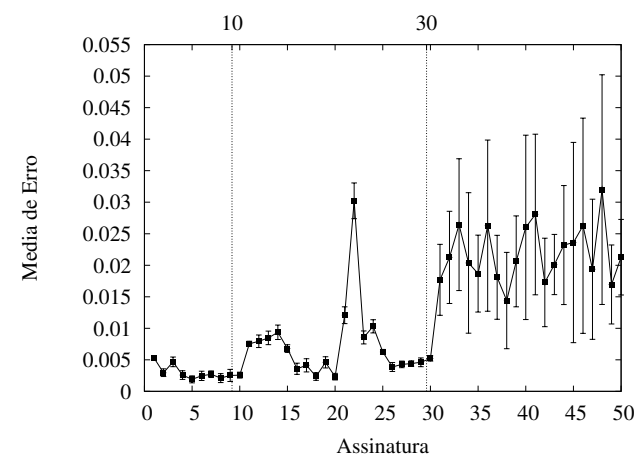

(d) DD3 - frequência dos pontos

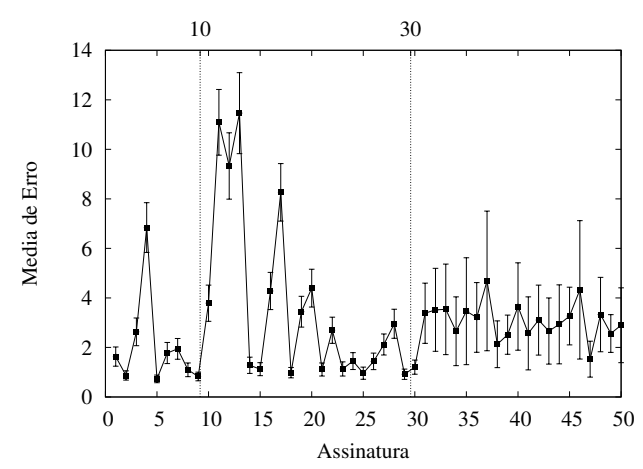

(f) DD5 - derivada entre os pontos por tempo

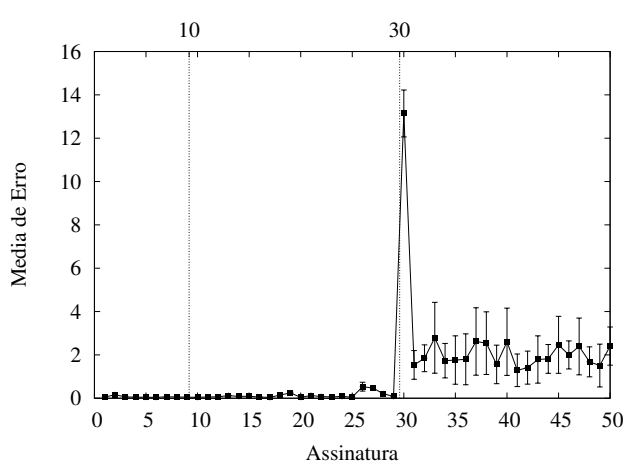

(h) DD7 - distância por tempo (velocidade)

Usuário 39 - Resultado dos experimentos utilizando a medida de similaridade DTW, onde são comparados os resultados de treinamento com 10 assinaturas verdadeiras e 40 falsas. 


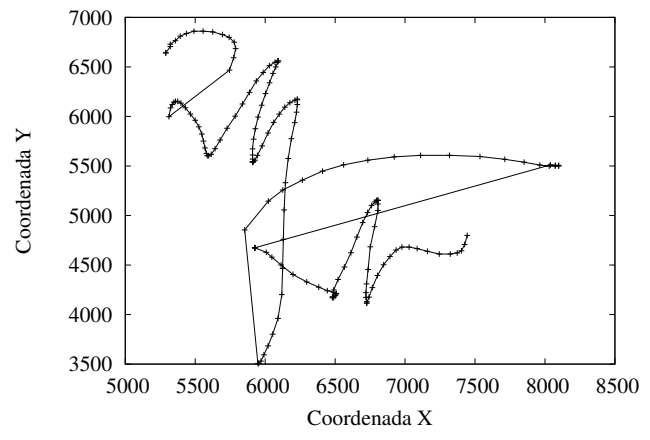

(a) Assinatura

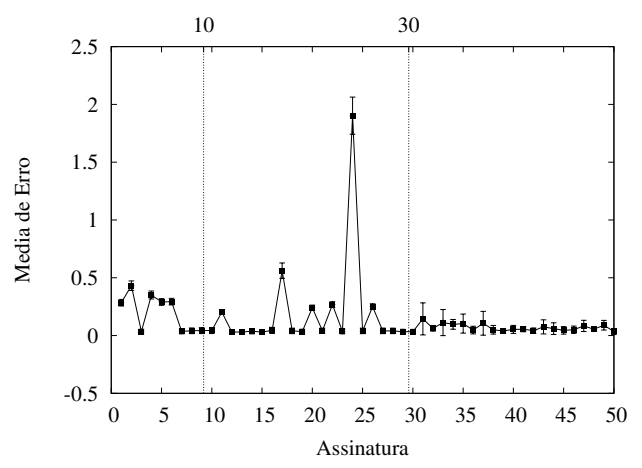

(c) DD2 - tempo por ponto

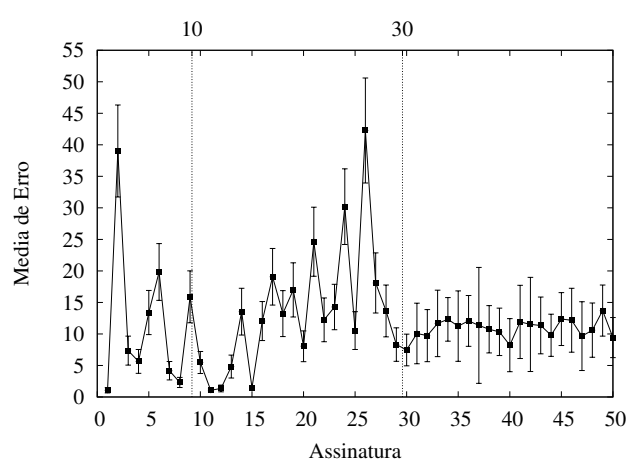

(e) DD4 - derivada entre as coordenadas da (f) DD5 - derivada entre os pontos por tempo amostragem

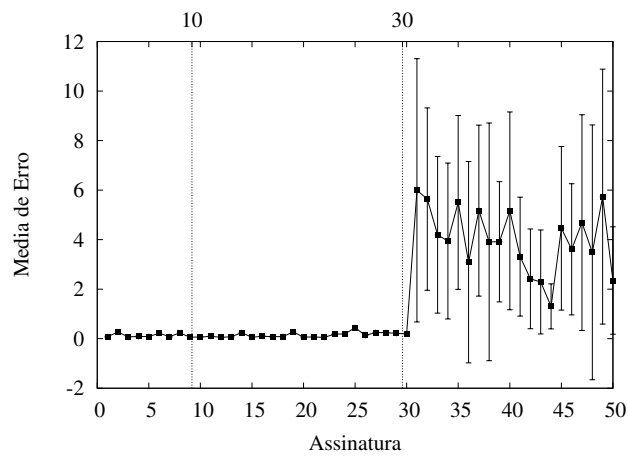

(g) DD6 - distância entre os pontos

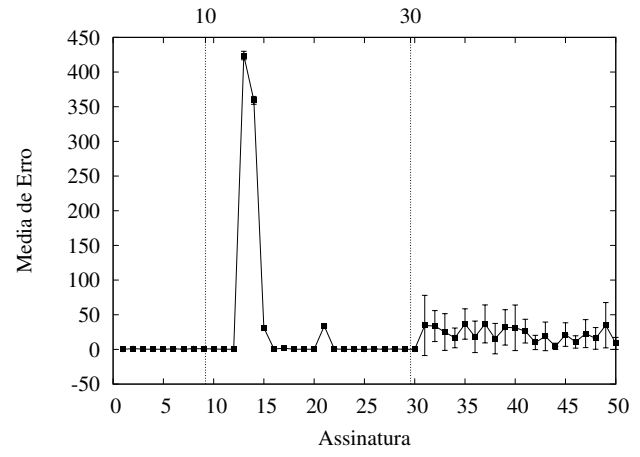

(b) DD1 - diferença entre as coordenadas da amostragem

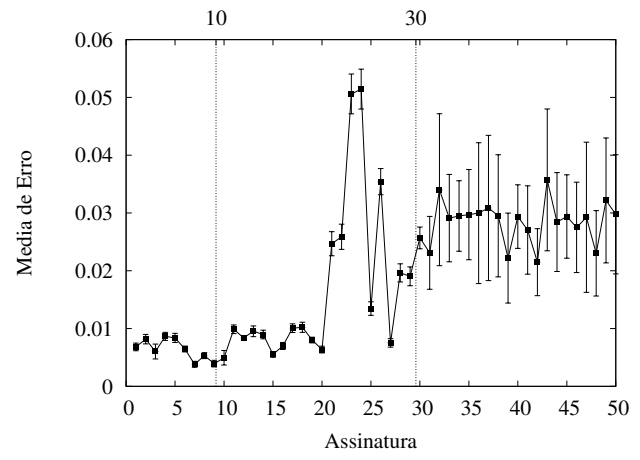

(d) DD3 - frequência dos pontos

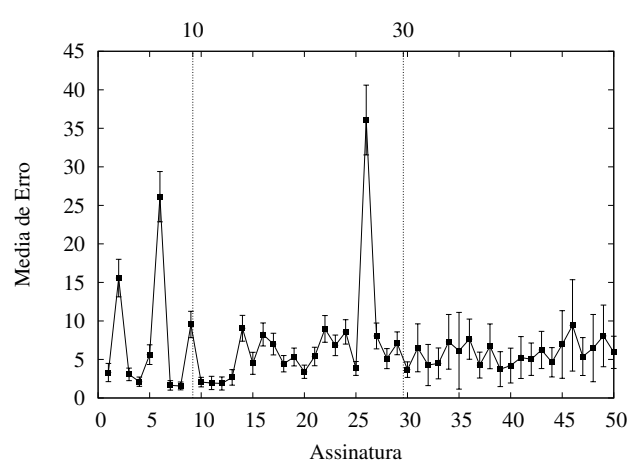

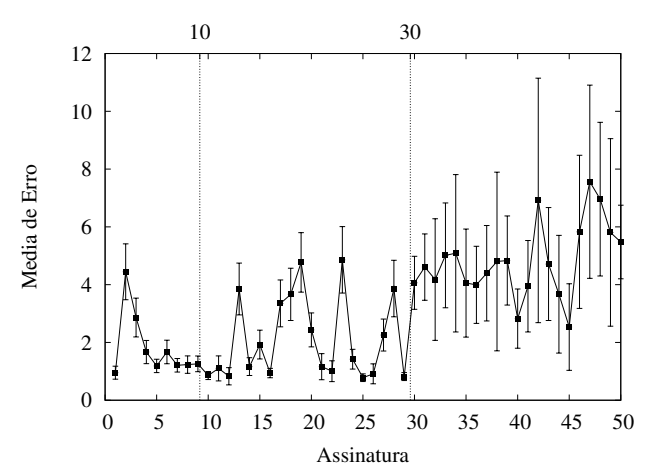

(h) DD7 - distância por tempo (velocidade)

Usuário 40 - Resultado dos experimentos utilizando a medida de similaridade DTW, onde são comparados os resultados de treinamento com 10 assinaturas verdadeiras e 40 falsas. 


\section{B - Resultados de experimentos (CDM)}

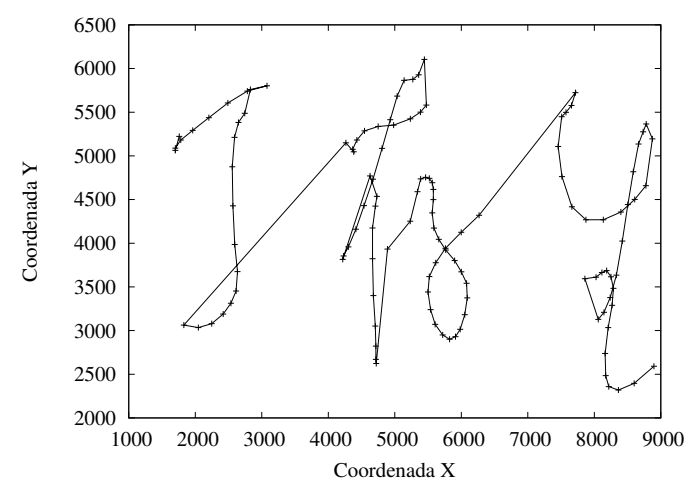

(a) Assinatura

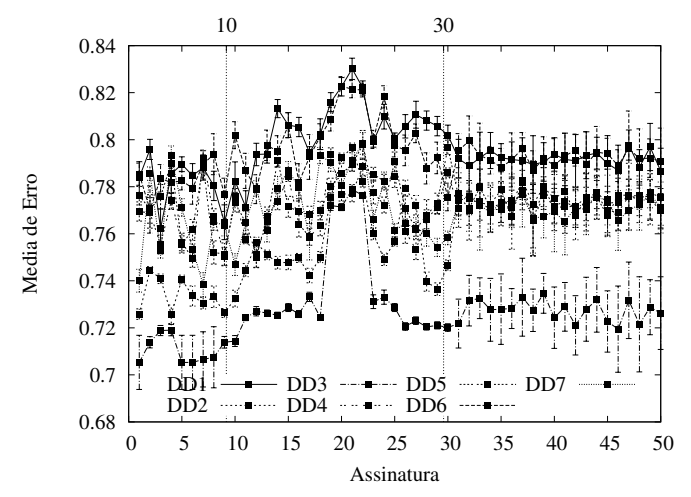

(b) Representação das 7 distribuições de dados.

Usuário 1 - Resultado dos experimentos utilizando a medida de similaridade CDM, onde são comparados os resultados de treinamento com 10 assinaturas verdadeiras e 40 falsas.

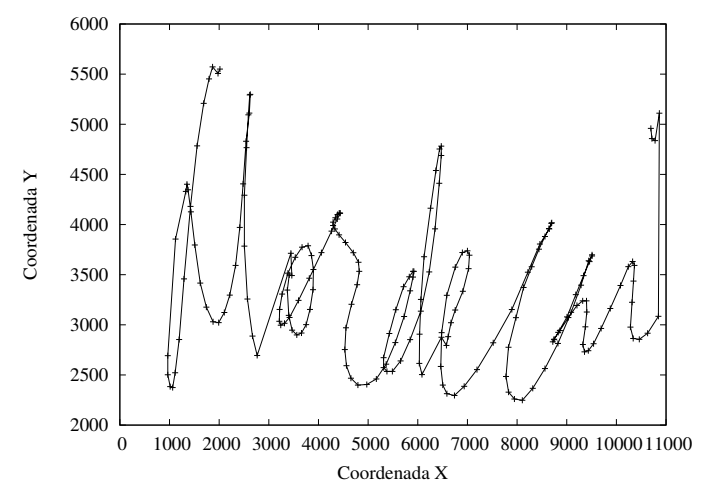

(a) Assinatura

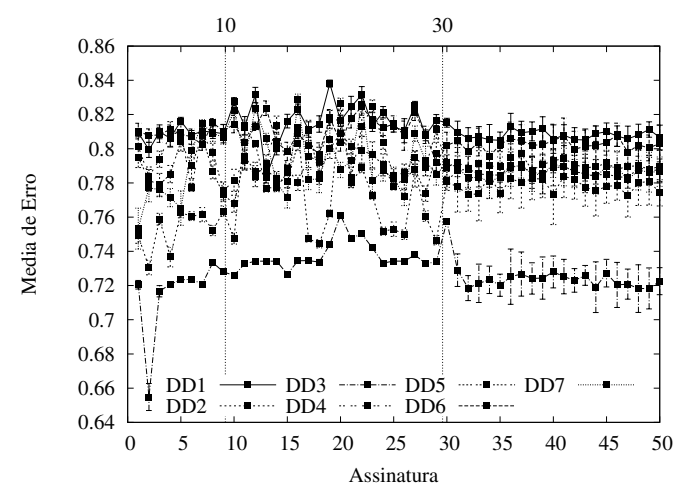

(b) Representação das 7 distribuições de dados.

Usuário 2 - Resultado dos experimentos utilizando a medida de similaridade CDM, onde são comparados os resultados de treinamento com 10 assinaturas verdadeiras e 40 falsas.

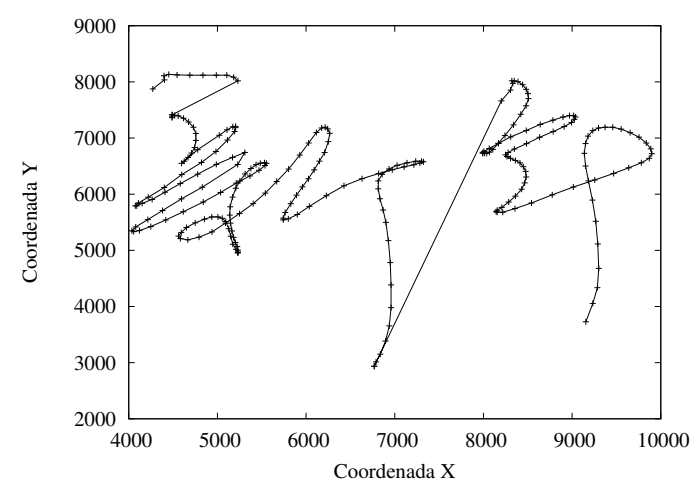

(a) Assinatura

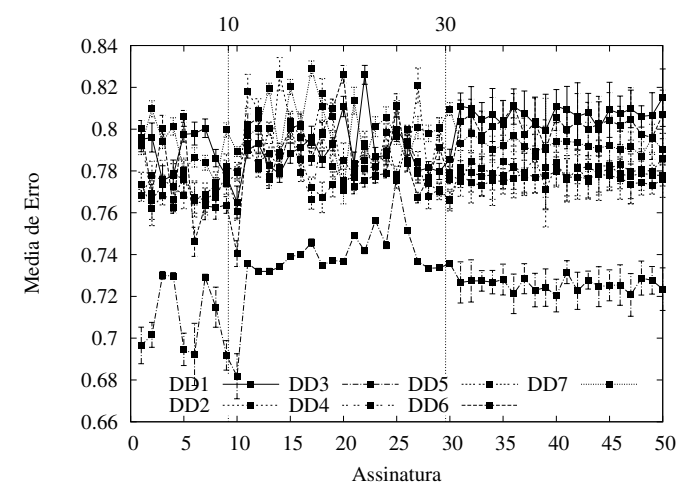

(b) Representação das 7 distribuições de dados.

Usuário 3 - Resultado dos experimentos utilizando a medida de similaridade CDM, onde são comparados os resultados de treinamento com 10 assinaturas verdadeiras e 40 falsas. 


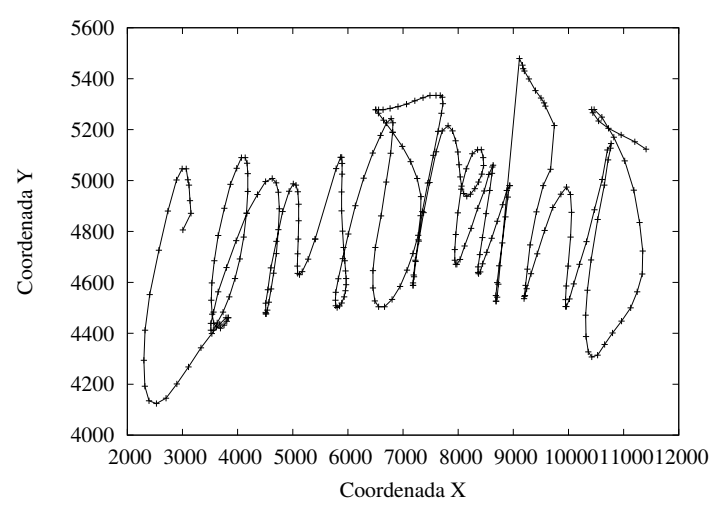

(a) Assinatura

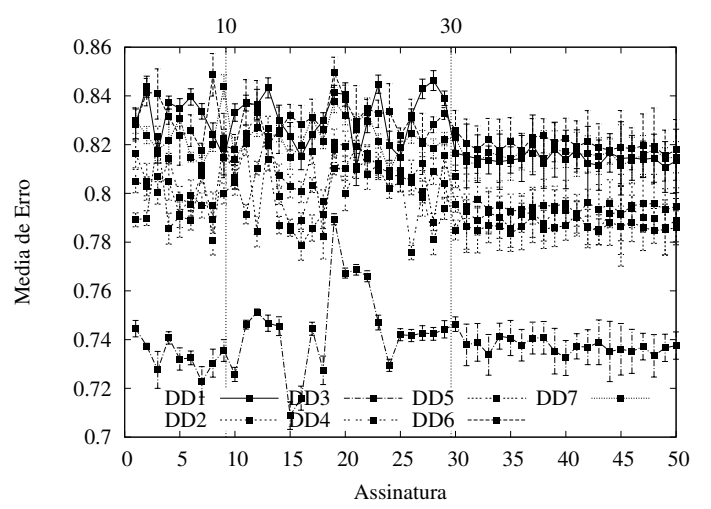

(b) Representação das 7 distribuições de dados.

Usuário 4 - Resultado dos experimentos utilizando a medida de similaridade CDM, onde são comparados os resultados de treinamento com 10 assinaturas verdadeiras e 40 falsas.

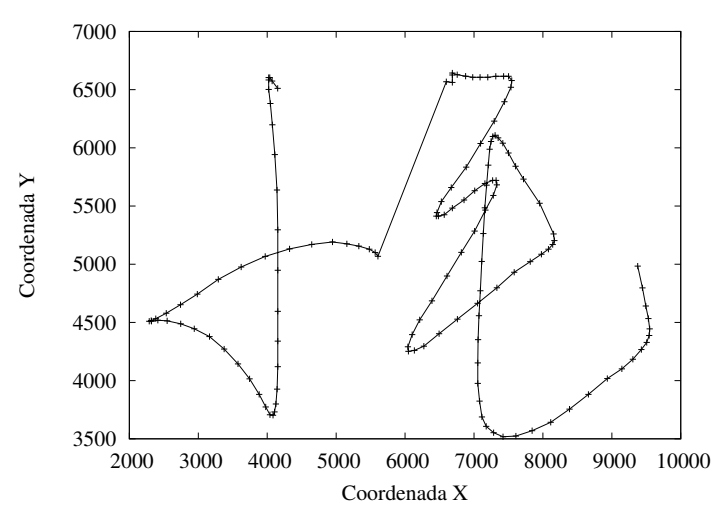

(a) Assinatura

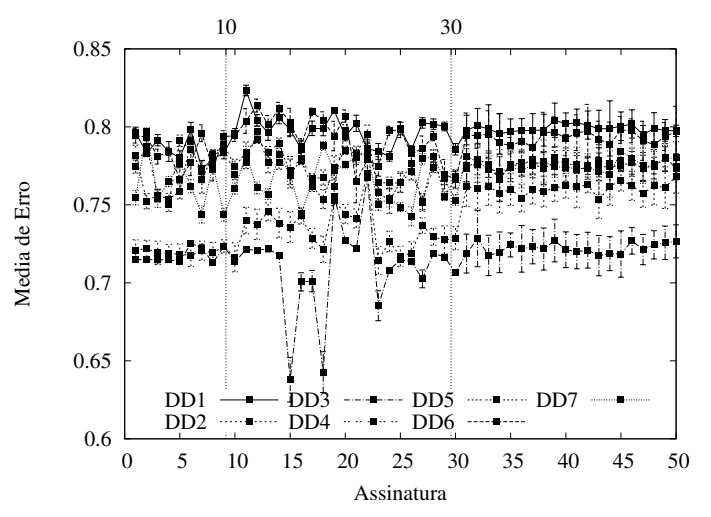

(b) Representação das 7 distribuições de dados.

Usuário 5 - Resultado dos experimentos utilizando a medida de similaridade CDM, onde são comparados os resultados de treinamento com 10 assinaturas verdadeiras e 40 falsas.

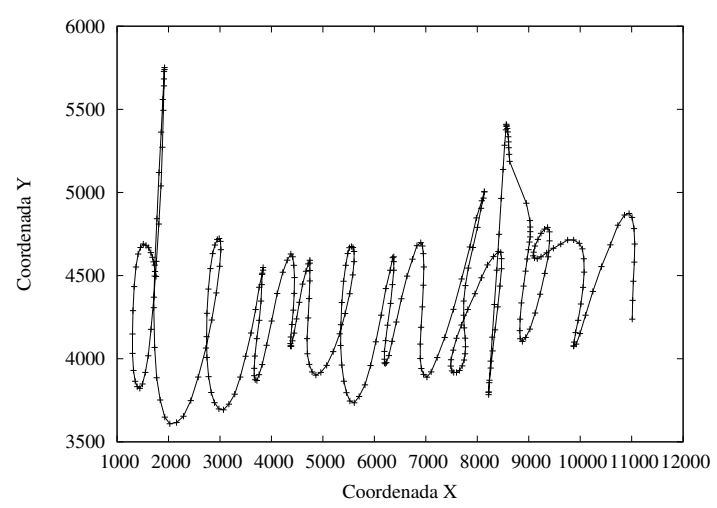

(a) Assinatura

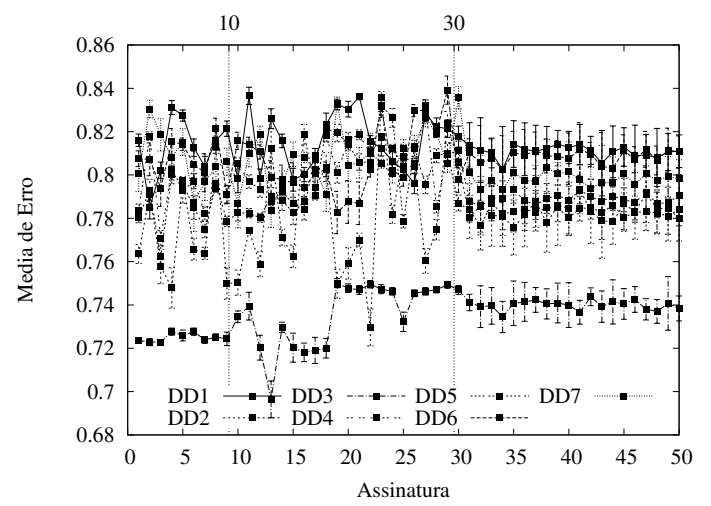

(b) Representação das 7 distribuições de dados.

Usuário 6 - Resultado dos experimentos utilizando a medida de similaridade CDM, onde são comparados os resultados de treinamento com 10 assinaturas verdadeiras e 40 falsas. 


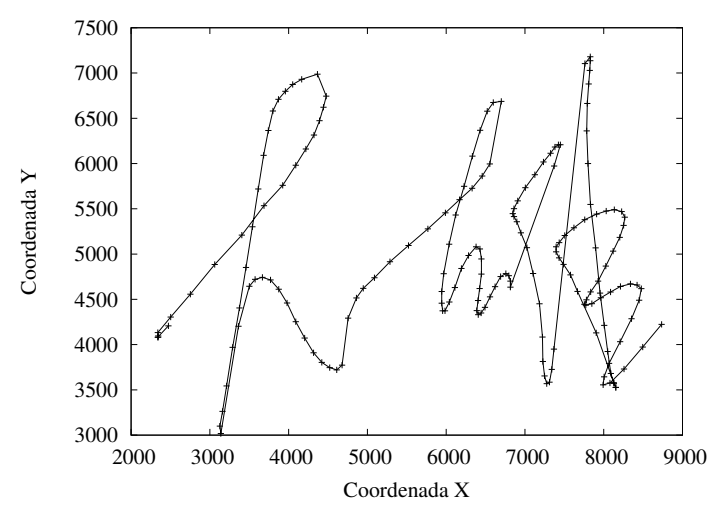

(a) Assinatura

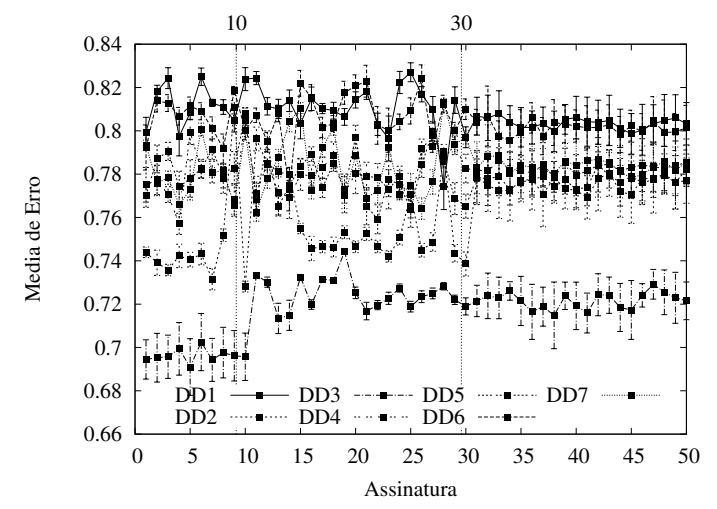

(b) Representação das 7 distribuições de dados.

Usuário 7 - Resultado dos experimentos utilizando a medida de similaridade CDM, onde são comparados os resultados de treinamento com 10 assinaturas verdadeiras e 40 falsas.

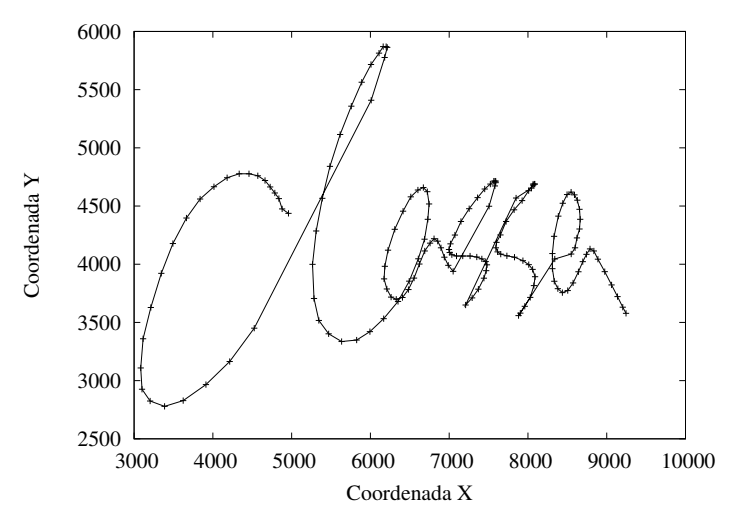

(a) Assinatura

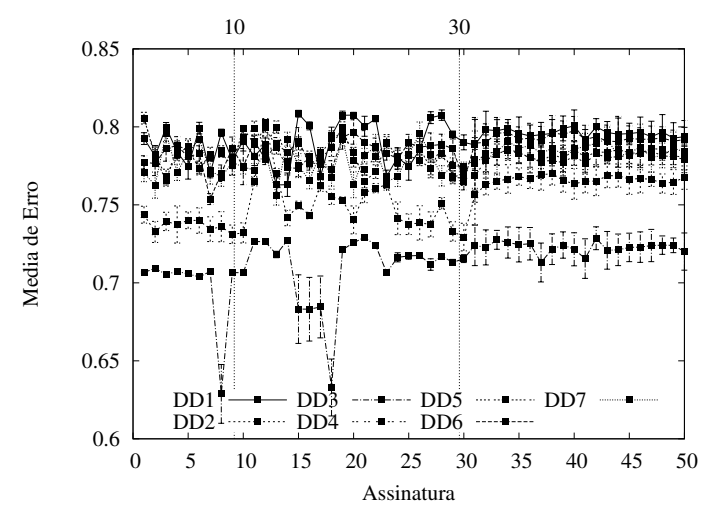

(b) Representação das 7 distribuições de dados.

Usuário 8 - Resultado dos experimentos utilizando a medida de similaridade CDM, onde são comparados os resultados de treinamento com 10 assinaturas verdadeiras e 40 falsas.

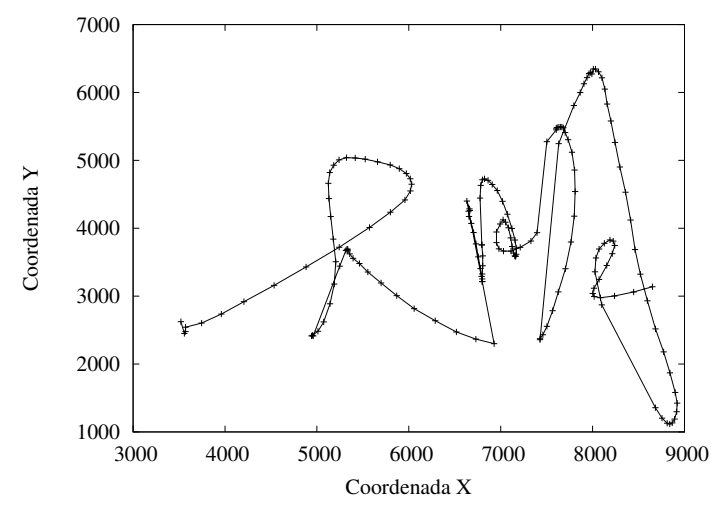

(a) Assinatura

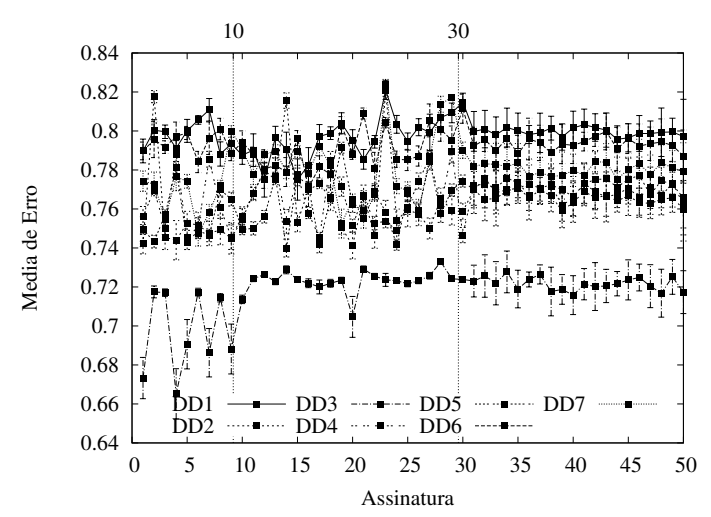

(b) Representação das 7 distribuições de dados.

Usuário 9 - Resultado dos experimentos utilizando a medida de similaridade CDM, onde são comparados os resultados de treinamento com 10 assinaturas verdadeiras e 40 falsas. 


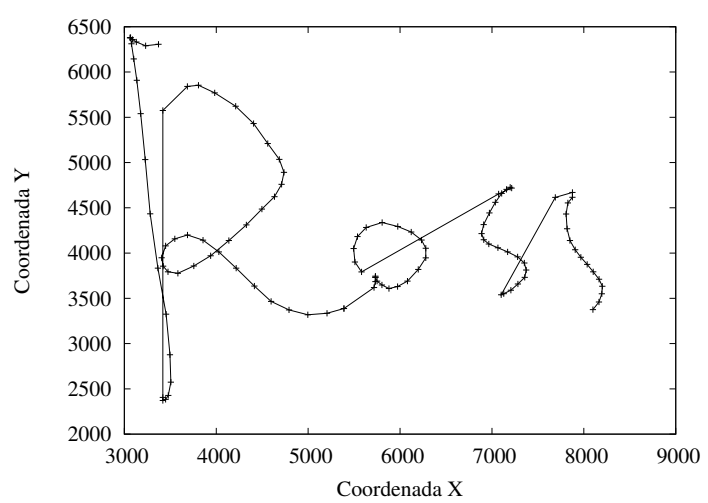

(a) Assinatura

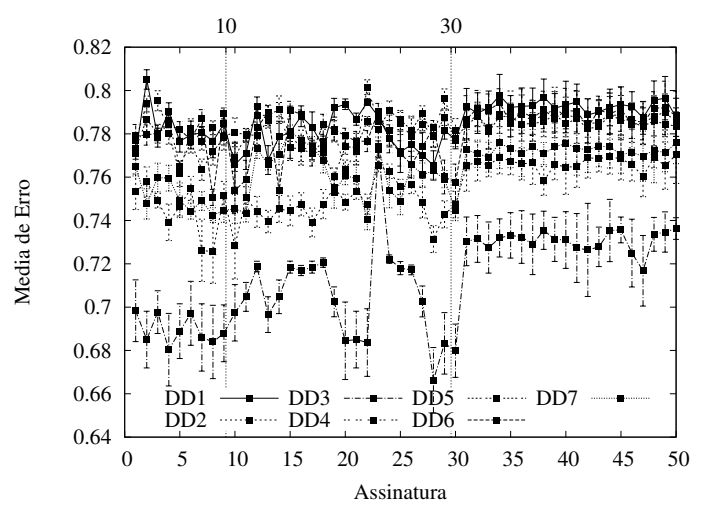

(b) Representação das 7 distribuições de dados.

Usuário 10 - Resultado dos experimentos utilizando a medida de similaridade CDM, onde são comparados os resultados de treinamento com 10 assinaturas verdadeiras e 40 falsas.

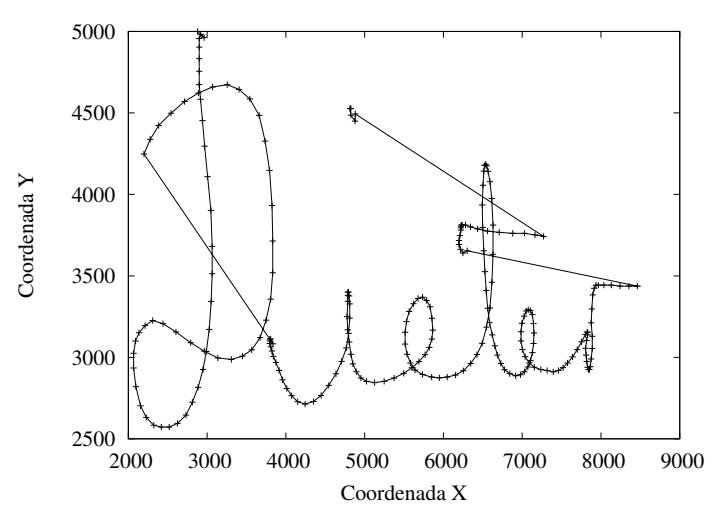

(a) Assinatura

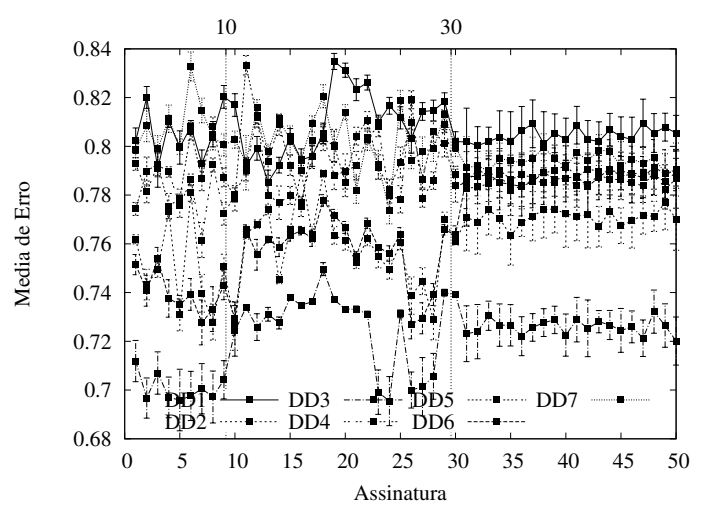

(b) Representação das 7 distribuições de dados.

Usuário 11 - Resultado dos experimentos utilizando a medida de similaridade CDM, onde são comparados os resultados de treinamento com 10 assinaturas verdadeiras e 40 falsas.

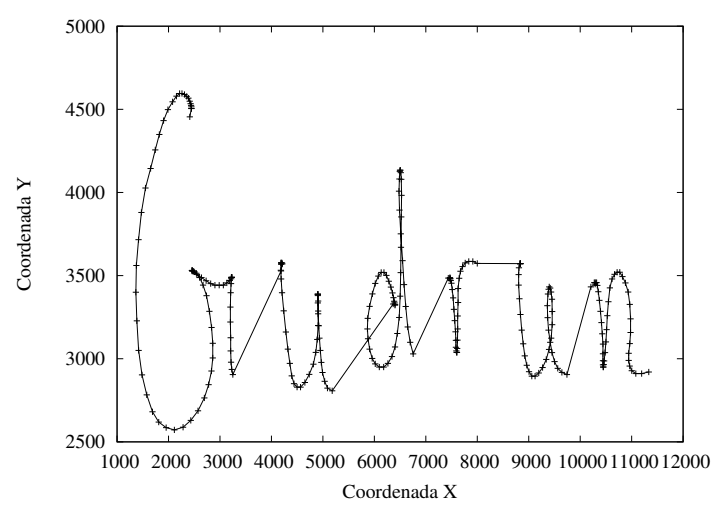

(a) Assinatura

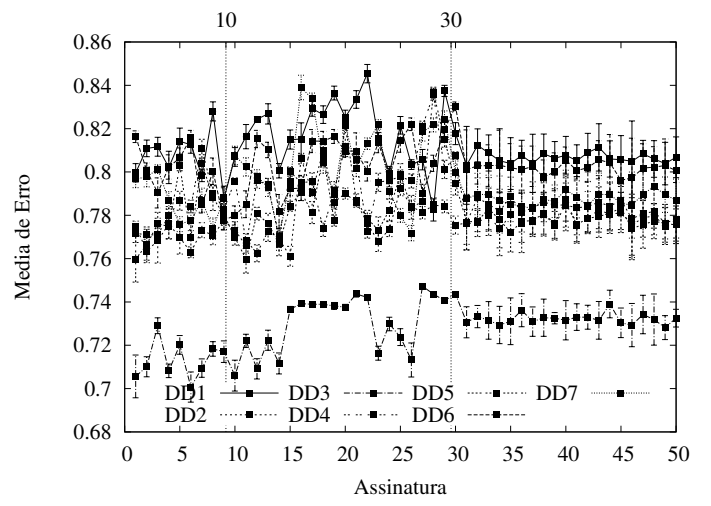

(b) Representação das 7 distribuições de dados.

Usuário 12 - Resultado dos experimentos utilizando a medida de similaridade CDM, onde são comparados os resultados de treinamento com 10 assinaturas verdadeiras e 40 falsas. 


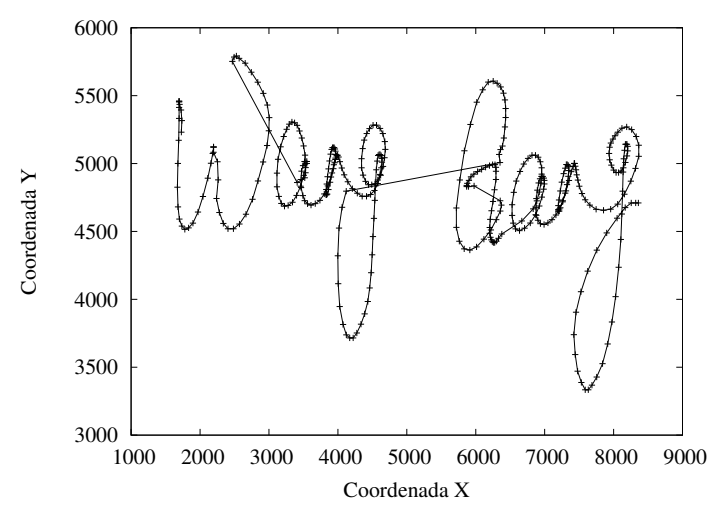

(a) Assinatura

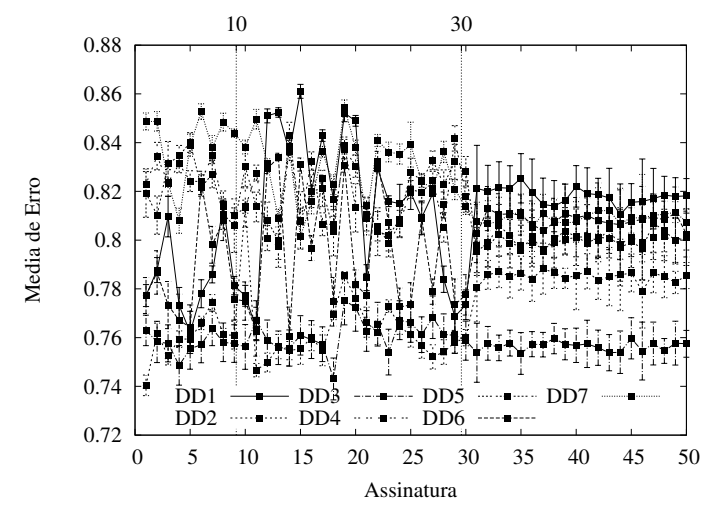

(b) Representação das 7 distribuições de dados.

Usuário 13 - Resultado dos experimentos utilizando a medida de similaridade CDM, onde são comparados os resultados de treinamento com 10 assinaturas verdadeiras e 40 falsas.

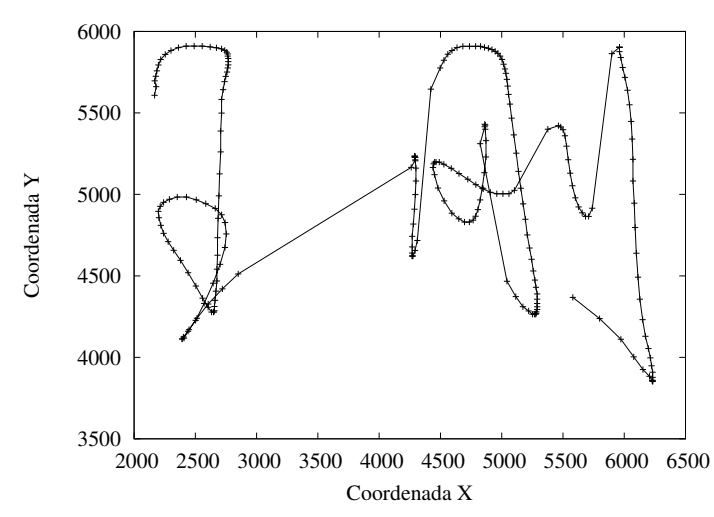

(a) Assinatura

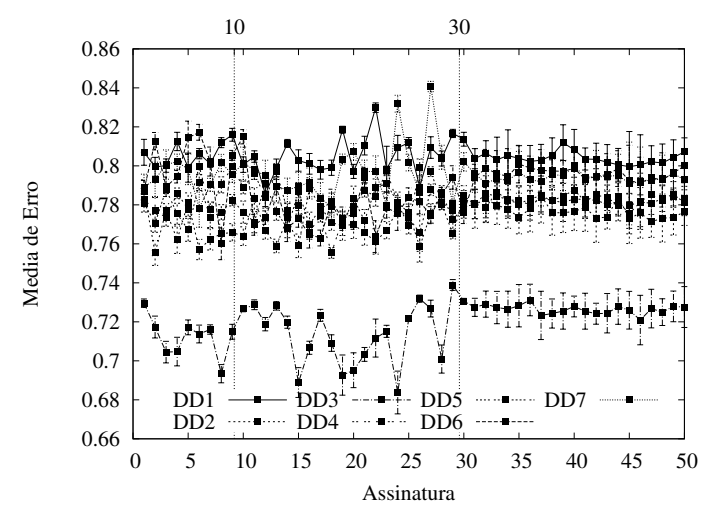

(b) Representação das 7 distribuições de dados.

Usuário 14 - Resultado dos experimentos utilizando a medida de similaridade CDM, onde são comparados os resultados de treinamento com 10 assinaturas verdadeiras e 40 falsas.

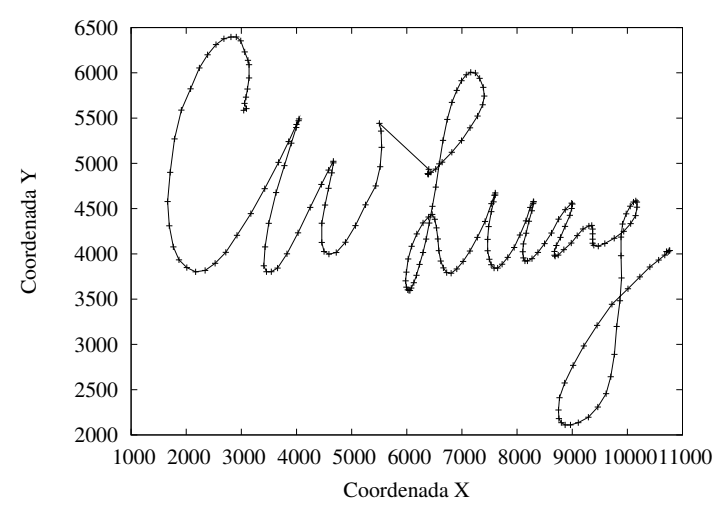

(a) Assinatura

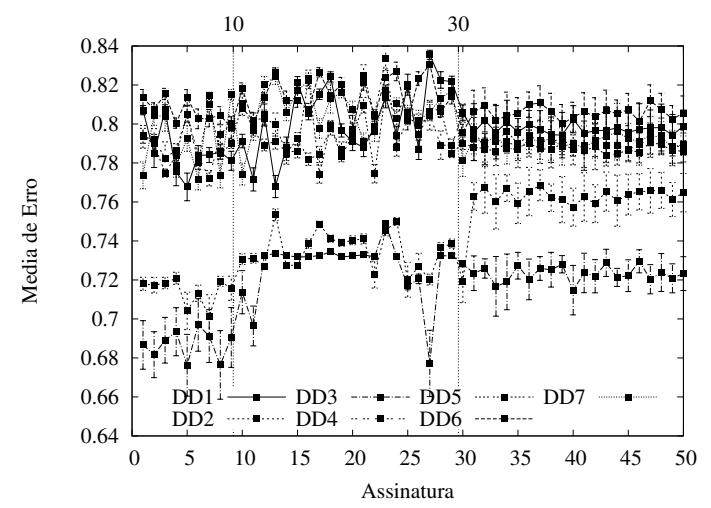

(b) Representação das 7 distribuições de dados.

Usuário 15 - Resultado dos experimentos utilizando a medida de similaridade CDM, onde são comparados os resultados de treinamento com 10 assinaturas verdadeiras e 40 falsas. 


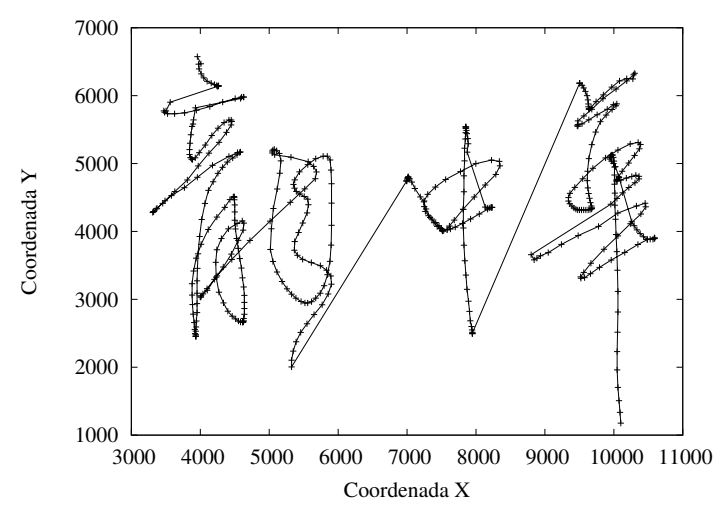

(a) Assinatura

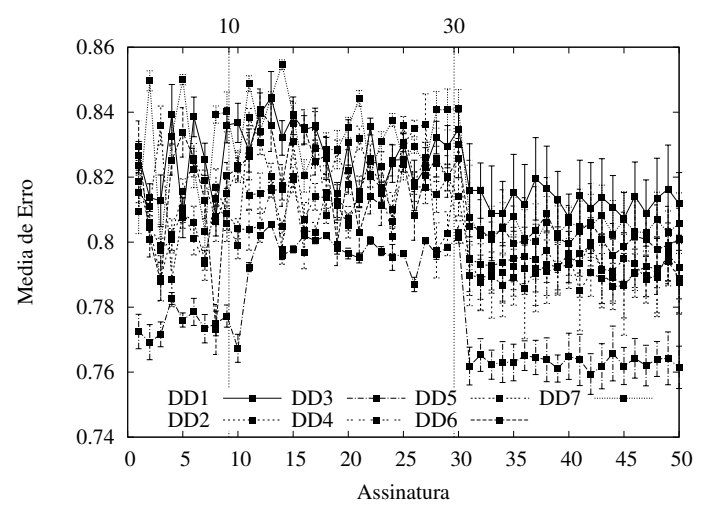

(b) Representação das 7 distribuições de dados.

Usuário 16 - Resultado dos experimentos utilizando a medida de similaridade CDM, onde são comparados os resultados de treinamento com 10 assinaturas verdadeiras e 40 falsas.

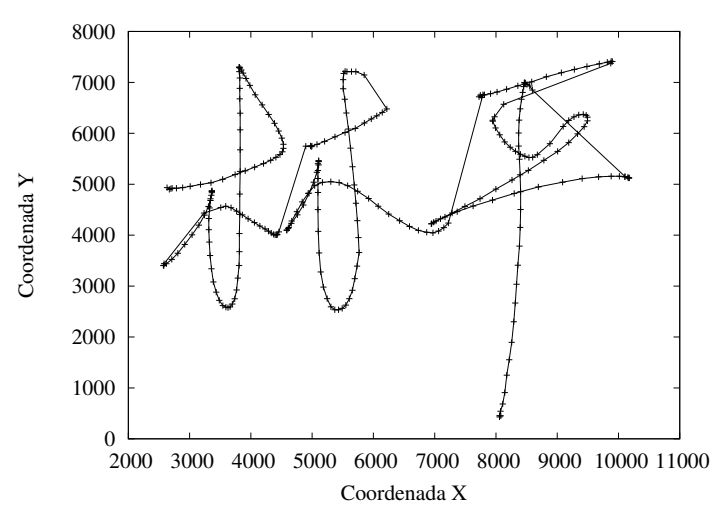

(a) Assinatura

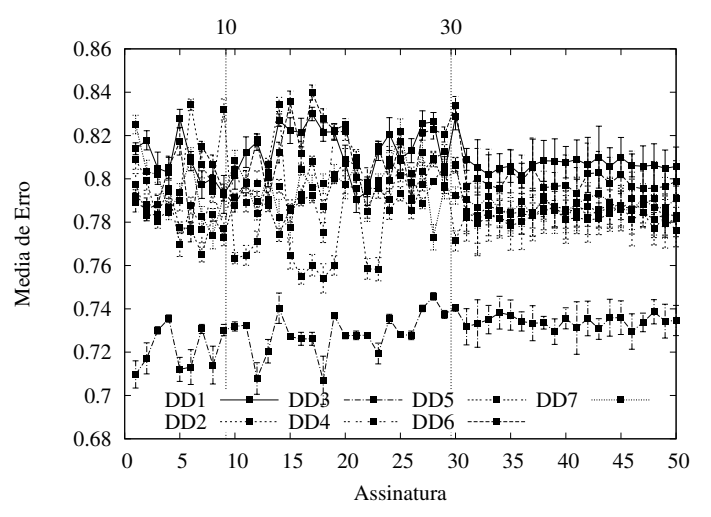

(b) Representação das 7 distribuições de dados.

Usuário 17 - Resultado dos experimentos utilizando a medida de similaridade CDM, onde são comparados os resultados de treinamento com 10 assinaturas verdadeiras e 40 falsas.

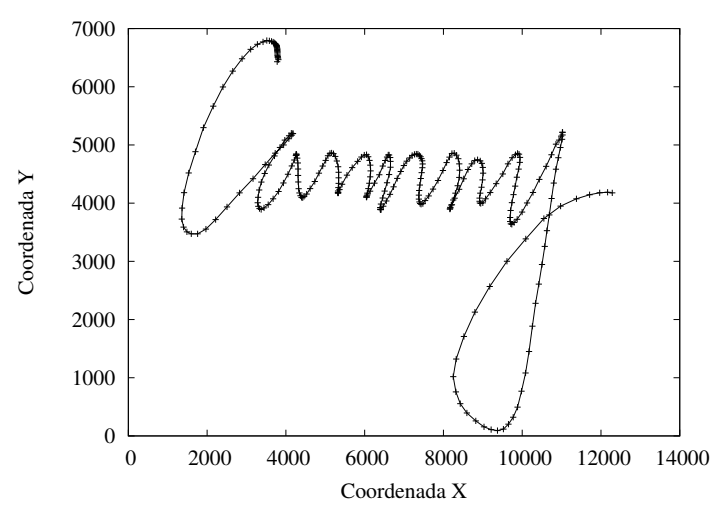

(a) Assinatura

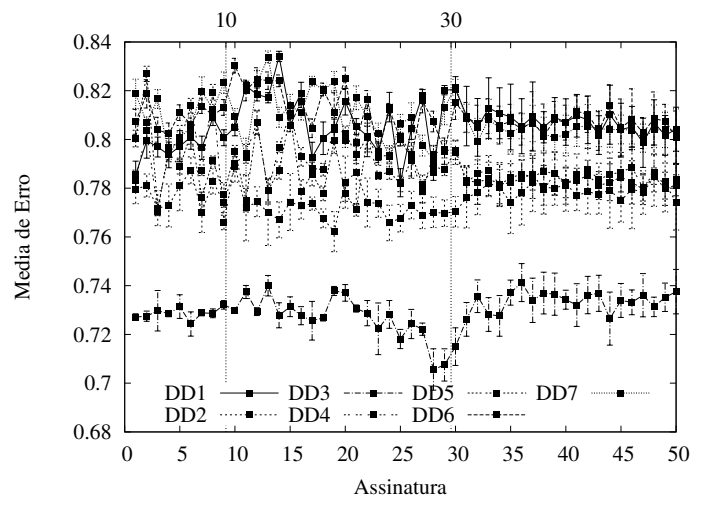

(b) Representação das 7 distribuições de dados.

Usuário 18 - Resultado dos experimentos utilizando a medida de similaridade CDM, onde são comparados os resultados de treinamento com 10 assinaturas verdadeiras e 40 falsas. 


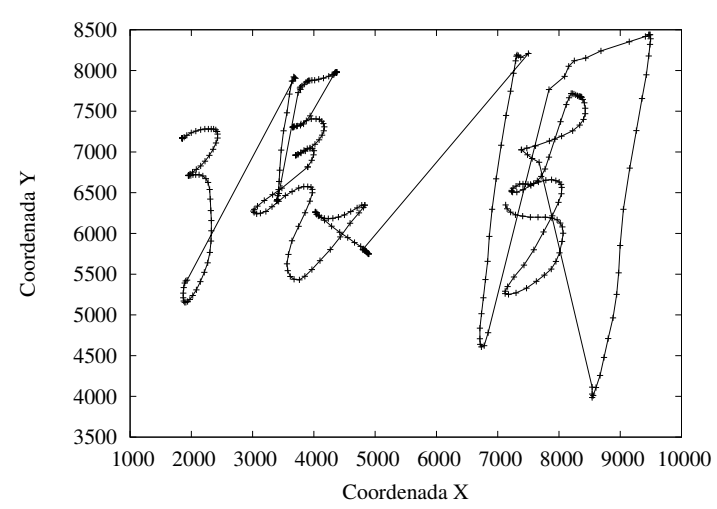

(a) Assinatura

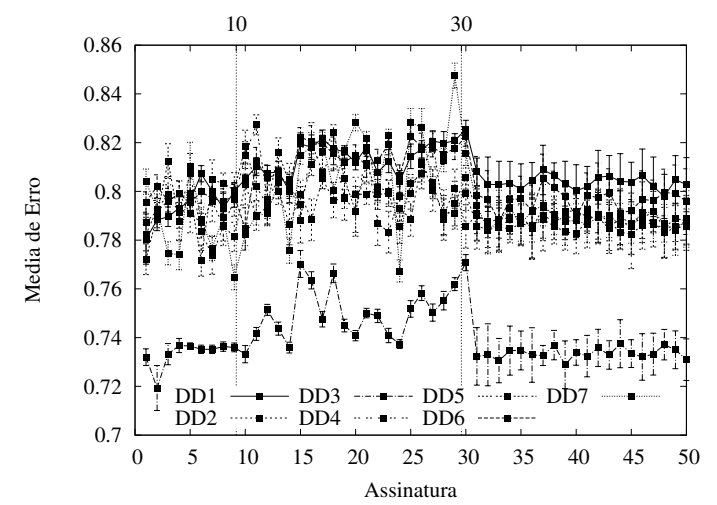

(b) Representação das 7 distribuições de dados.

Usuário 19 - Resultado dos experimentos utilizando a medida de similaridade CDM, onde são comparados os resultados de treinamento com 10 assinaturas verdadeiras e 40 falsas.

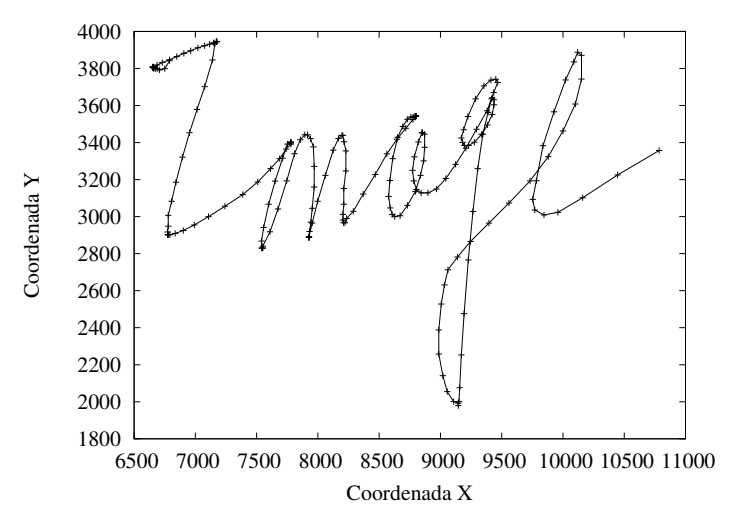

(a) Assinatura

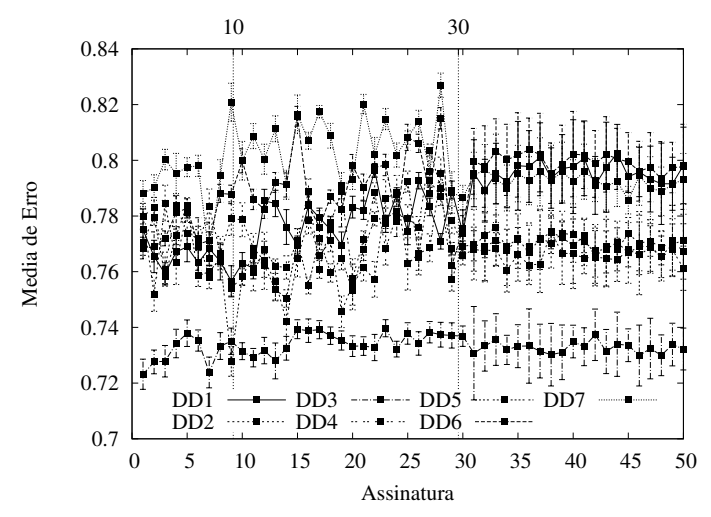

(b) Representação das 7 distribuições de dados.

Usuário 20 - Resultado dos experimentos utilizando a medida de similaridade CDM, onde são comparados os resultados de treinamento com 10 assinaturas verdadeiras e 40 falsas.

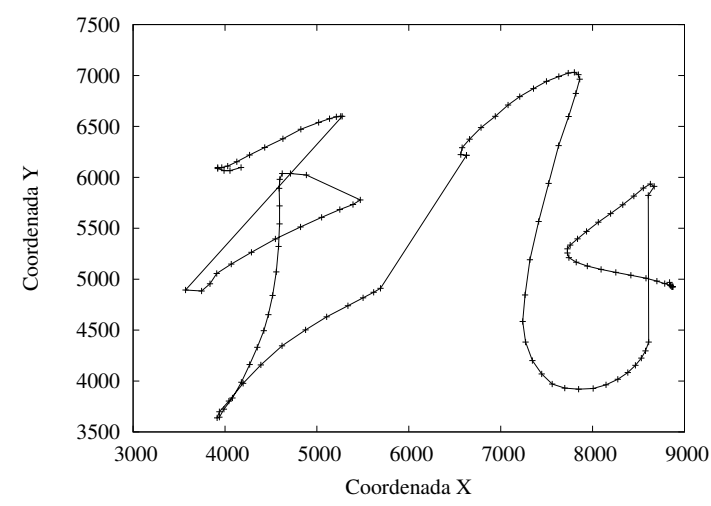

(a) Assinatura

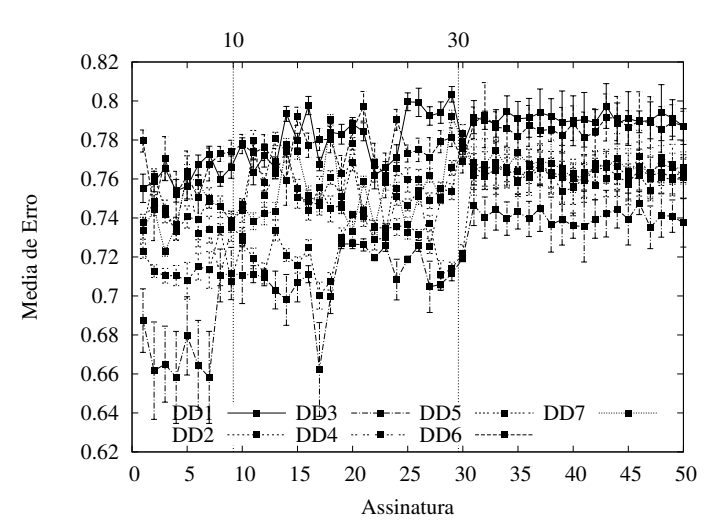

(b) Representação das 7 distribuições de dados.

Usuário 21 - Resultado dos experimentos utilizando a medida de similaridade CDM, onde são comparados os resultados de treinamento com 10 assinaturas verdadeiras e 40 falsas. 


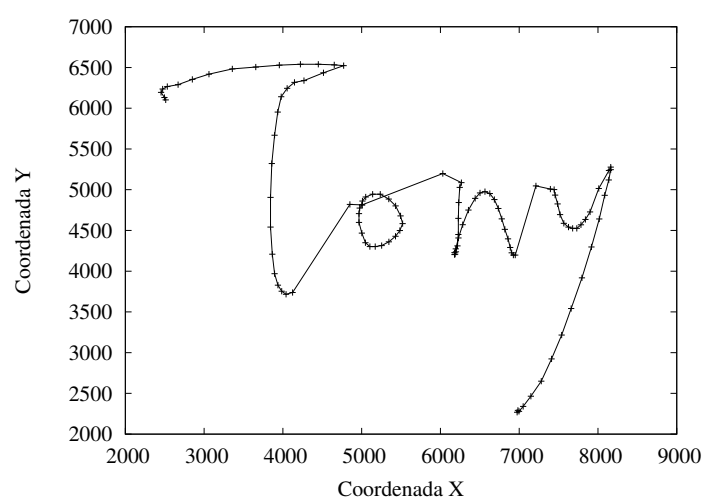

(a) Assinatura

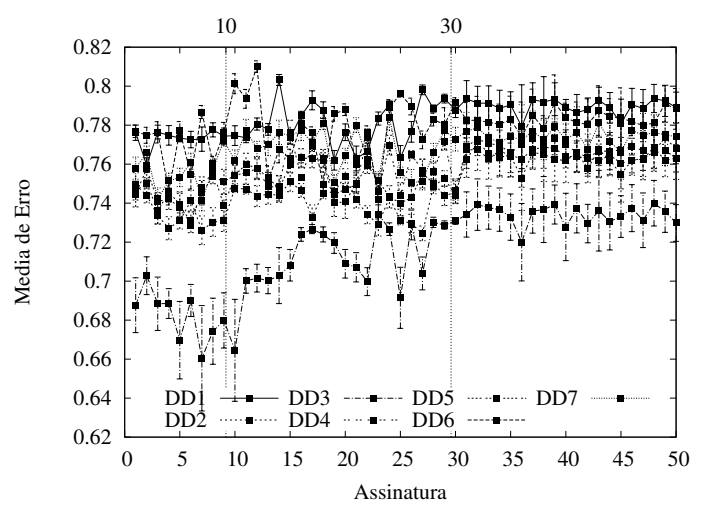

(b) Representação das 7 distribuições de dados.

Usuário 22 - Resultado dos experimentos utilizando a medida de similaridade CDM, onde são comparados os resultados de treinamento com 10 assinaturas verdadeiras e 40 falsas.

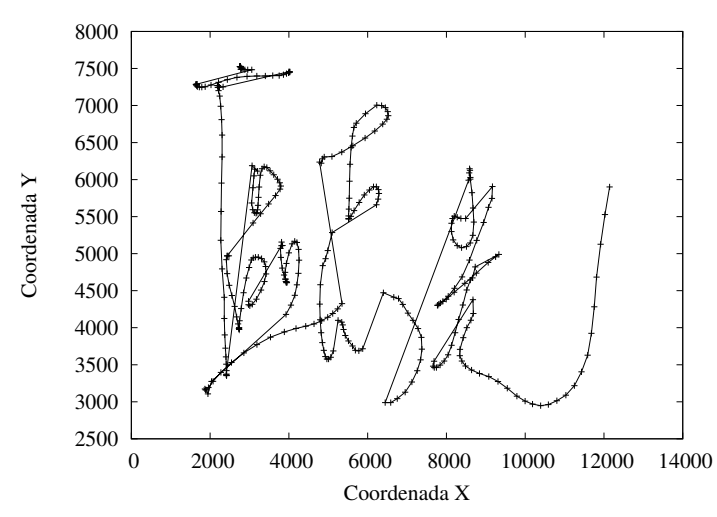

(a) Assinatura

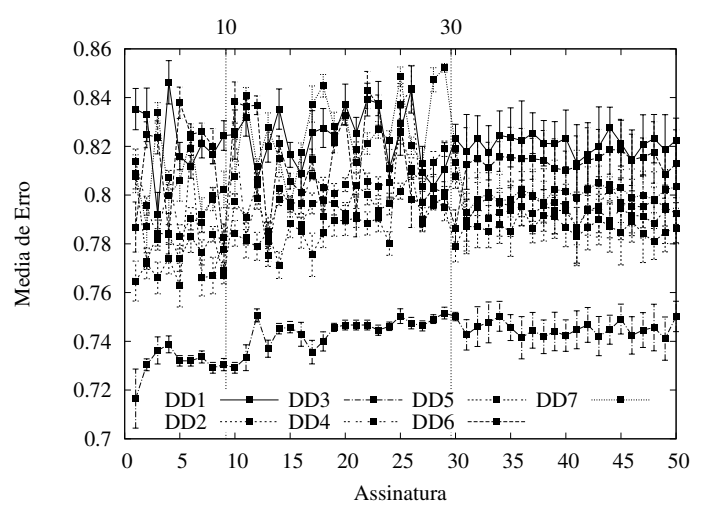

(b) Representação das 7 distribuições de dados.

Usuário 23 - Resultado dos experimentos utilizando a medida de similaridade CDM, onde são comparados os resultados de treinamento com 10 assinaturas verdadeiras e 40 falsas.

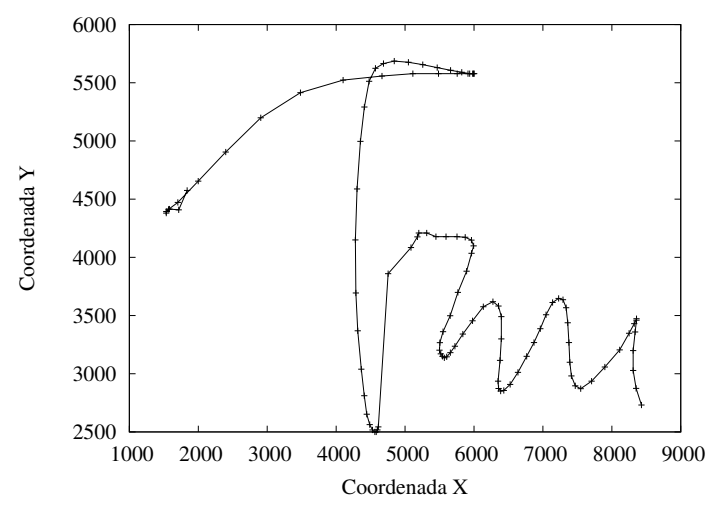

(a) Assinatura

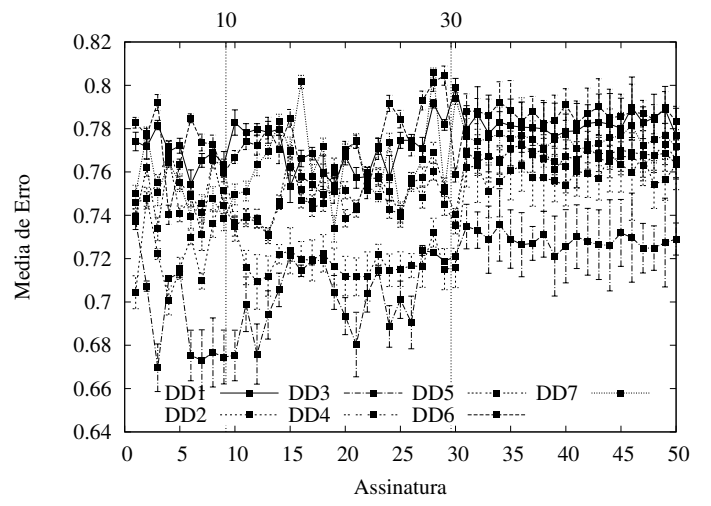

(b) Representação das 7 distribuições de dados.

Usuário 24 - Resultado dos experimentos utilizando a medida de similaridade CDM, onde são comparados os resultados de treinamento com 10 assinaturas verdadeiras e 40 falsas. 


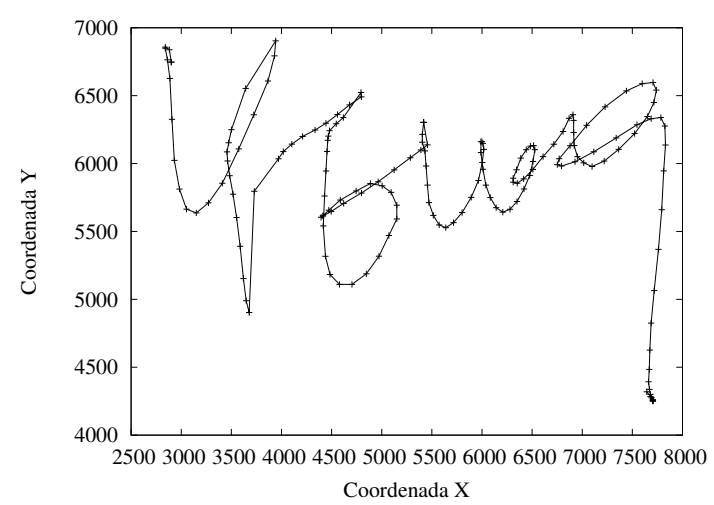

(a) Assinatura

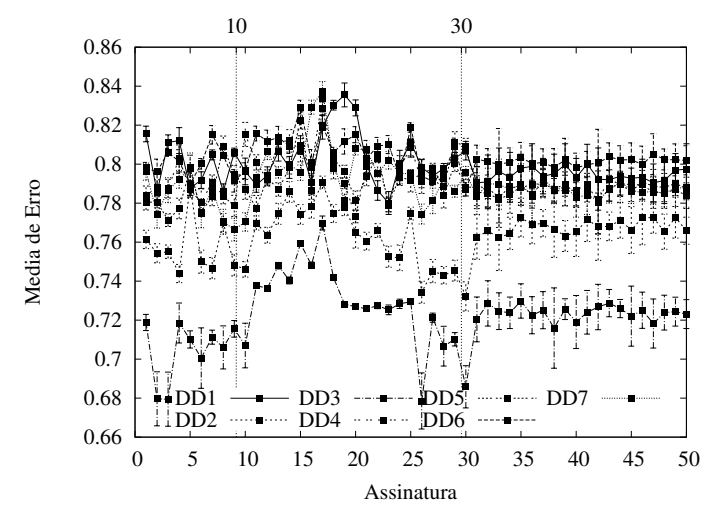

(b) Representação das 7 distribuições de dados.

Usuário 25 - Resultado dos experimentos utilizando a medida de similaridade CDM, onde são comparados os resultados de treinamento com 10 assinaturas verdadeiras e 40 falsas.

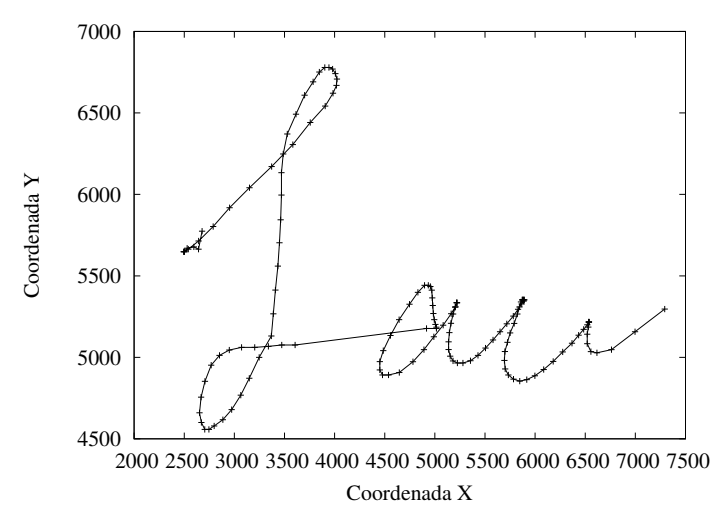

(a) Assinatura

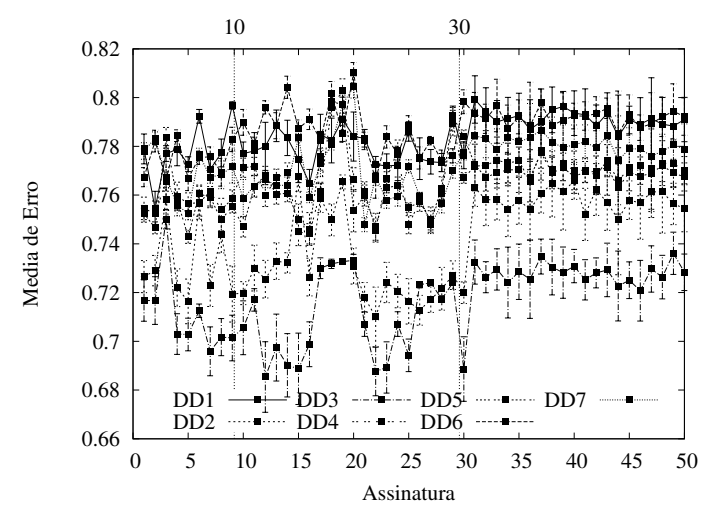

(b) Representação das 7 distribuições de dados.

Usuário 26 - Resultado dos experimentos utilizando a medida de similaridade CDM, onde são comparados os resultados de treinamento com 10 assinaturas verdadeiras e 40 falsas.

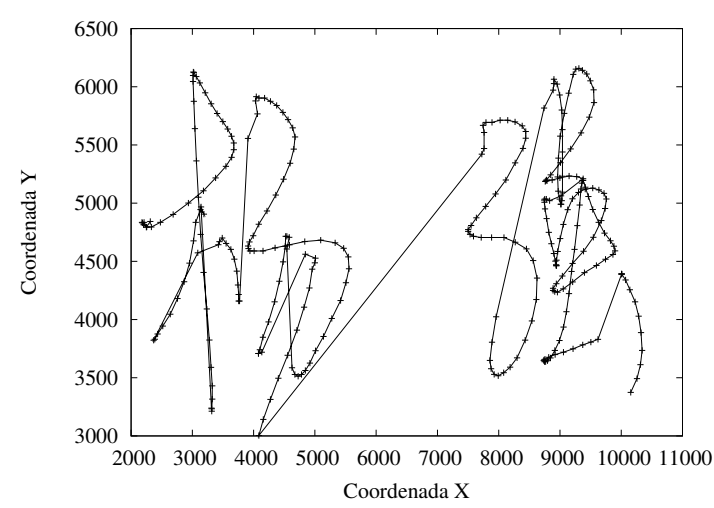

(a) Assinatura

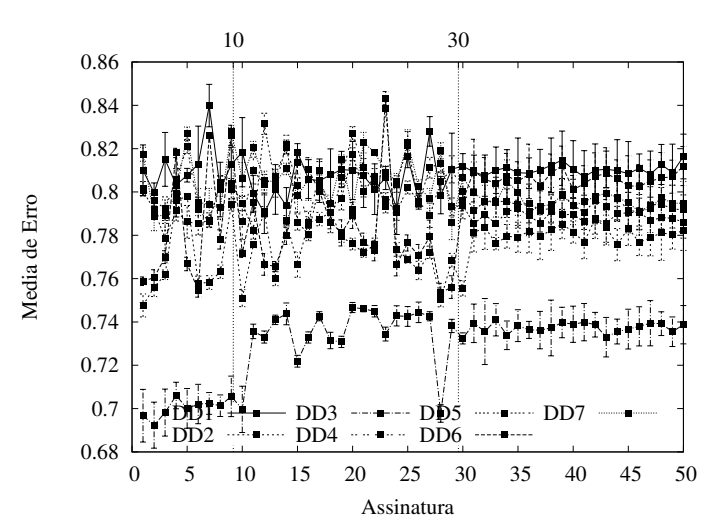

(b) Representação das 7 distribuições de dados.

Usuário 27 - Resultado dos experimentos utilizando a medida de similaridade CDM, onde são comparados os resultados de treinamento com 10 assinaturas verdadeiras e 40 falsas. 


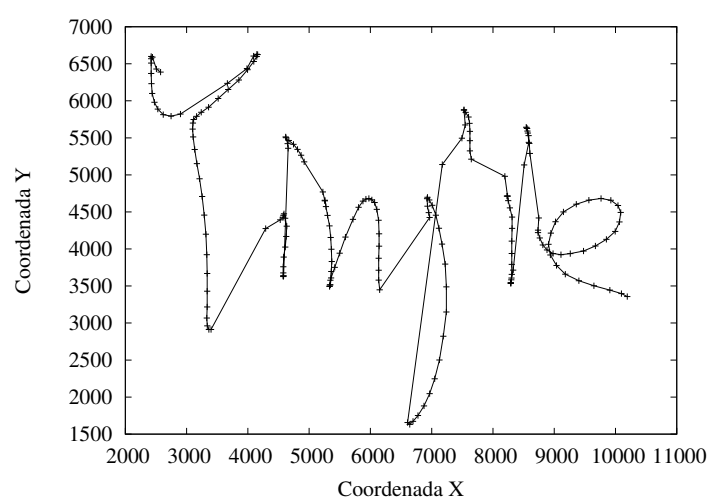

(a) Assinatura

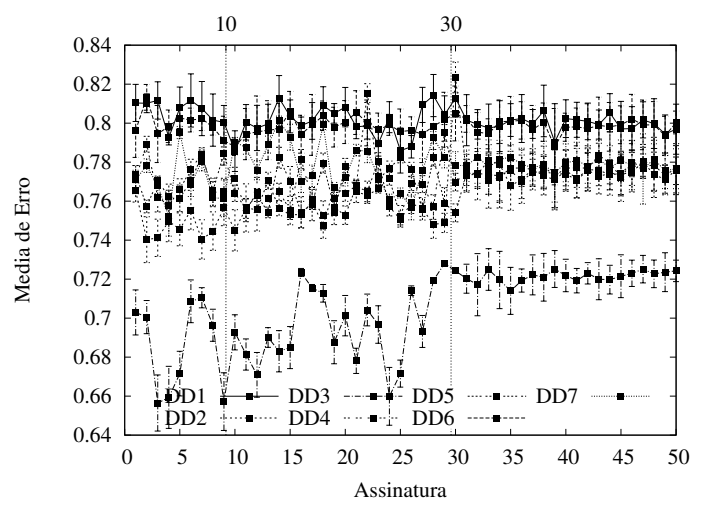

(b) Representação das 7 distribuições de dados.

Usuário 28 - Resultado dos experimentos utilizando a medida de similaridade CDM, onde são comparados os resultados de treinamento com 10 assinaturas verdadeiras e 40 falsas.

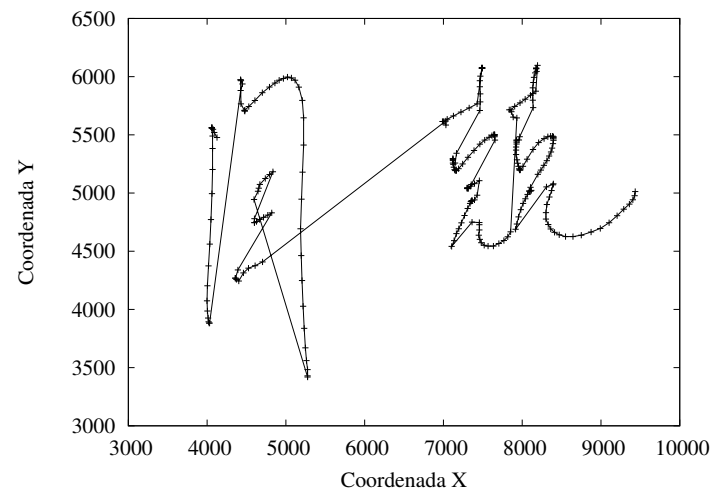

(a) Assinatura

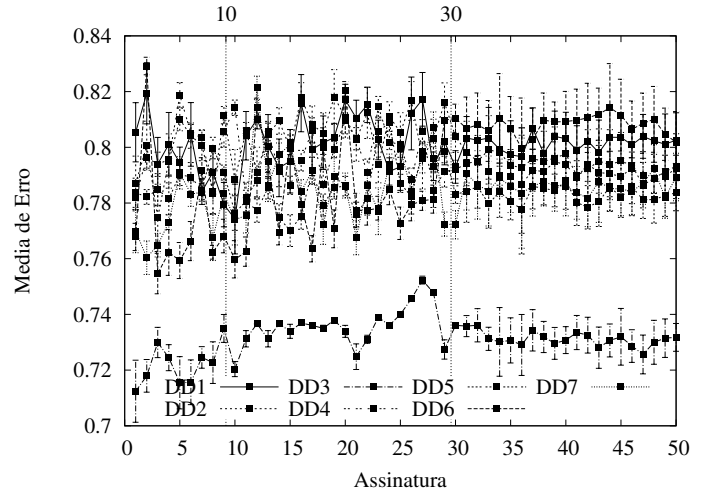

(b) Representação das 7 distribuições de dados.

Usuário 29 - Resultado dos experimentos utilizando a medida de similaridade CDM, onde são comparados os resultados de treinamento com 10 assinaturas verdadeiras e 40 falsas.

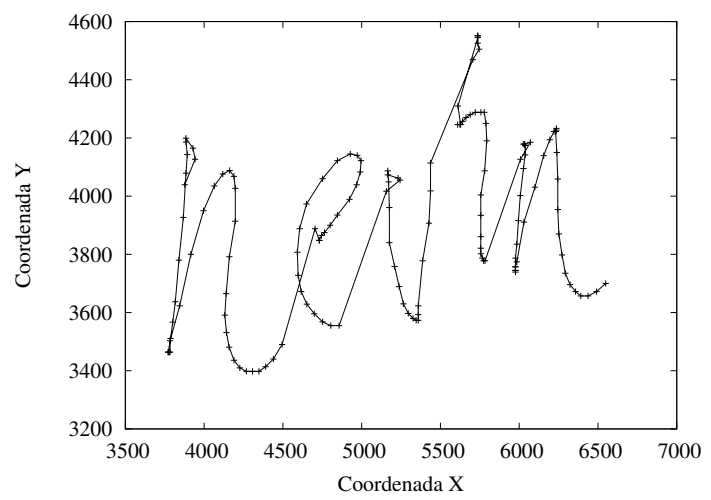

(a) Assinatura

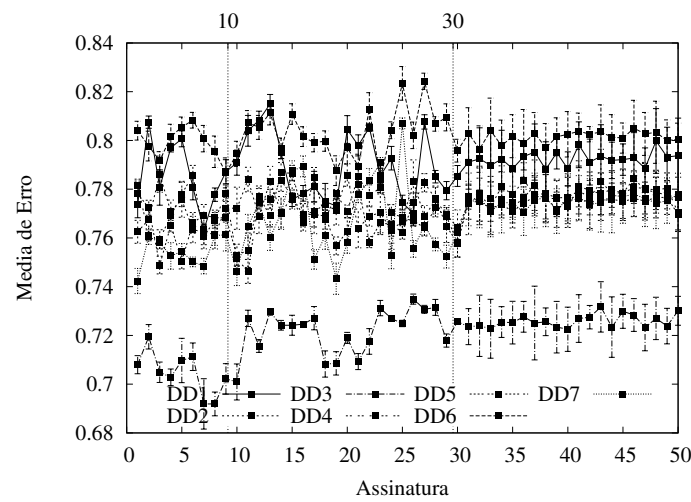

(b) Representação das 7 distribuições de dados.

Usuário 30 - Resultado dos experimentos utilizando a medida de similaridade CDM, onde são comparados os resultados de treinamento com 10 assinaturas verdadeiras e 40 falsas. 


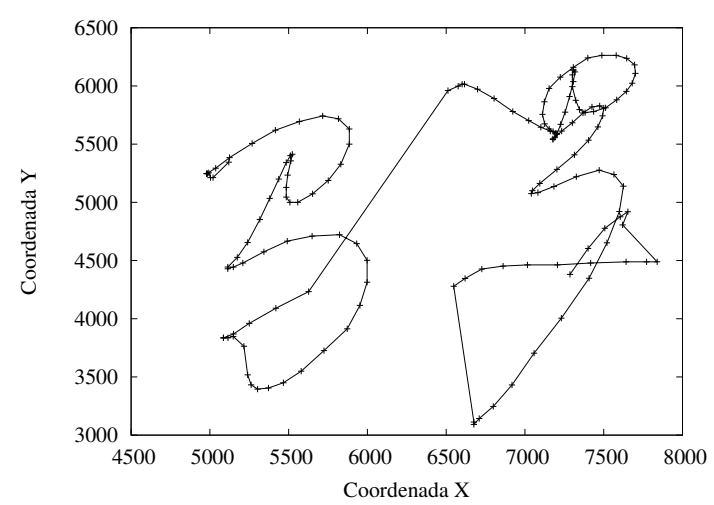

(a) Assinatura

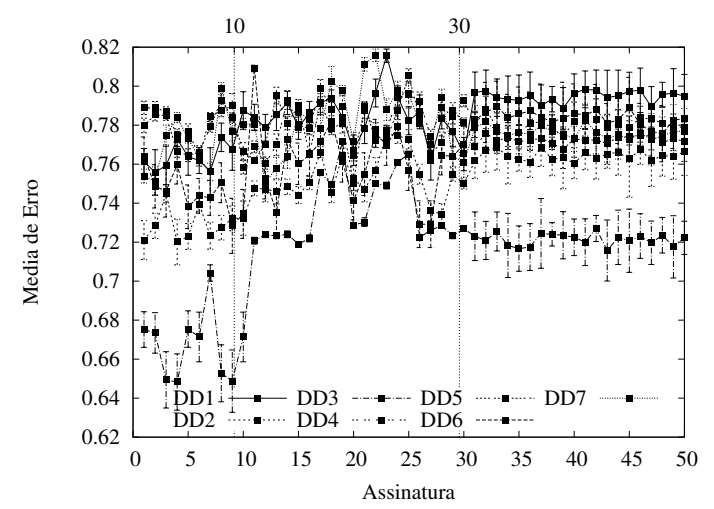

(b) Representação das 7 distribuições de dados.

Usuário 31 - Resultado dos experimentos utilizando a medida de similaridade CDM, onde são comparados os resultados de treinamento com 10 assinaturas verdadeiras e 40 falsas.

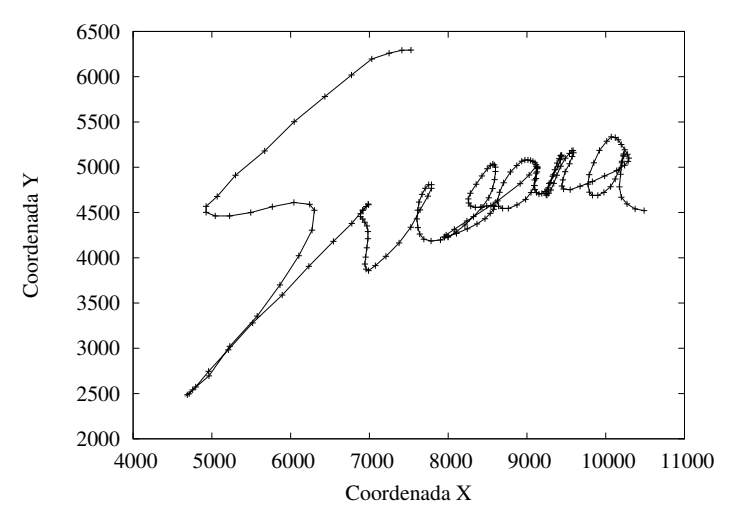

(a) Assinatura

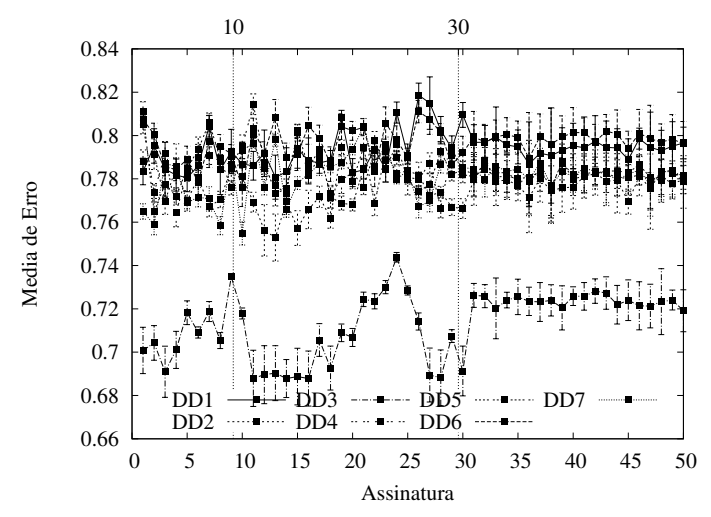

(b) Representação das 7 distribuições de dados.

Usuário 32 - Resultado dos experimentos utilizando a medida de similaridade CDM, onde são comparados os resultados de treinamento com 10 assinaturas verdadeiras e 40 falsas.

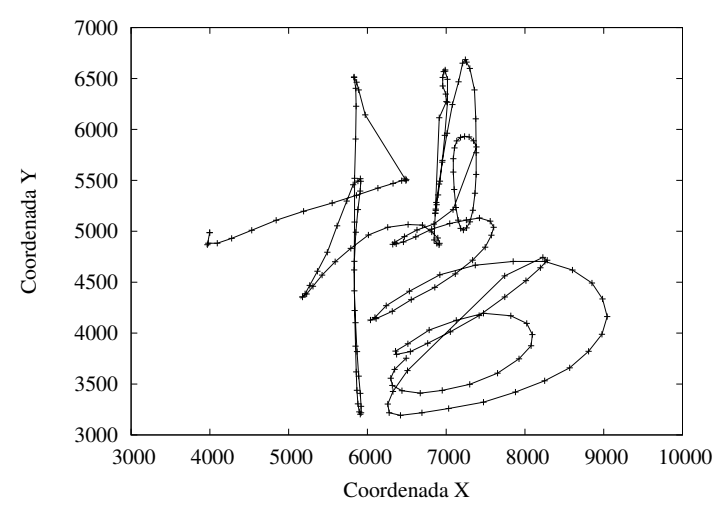

(a) Assinatura

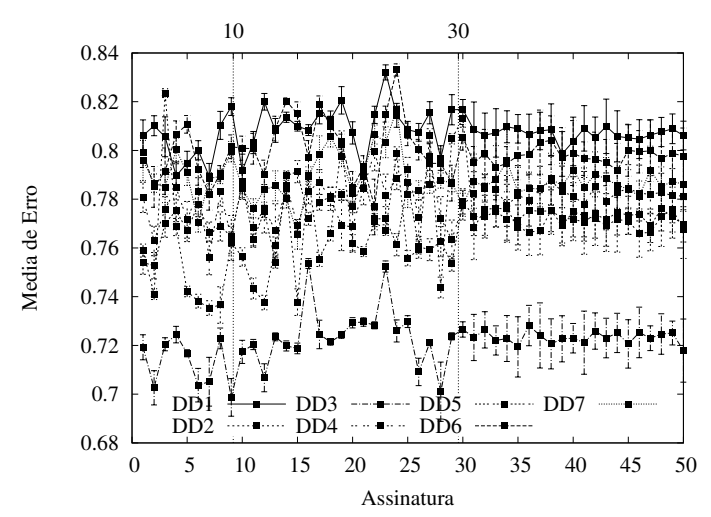

(b) Representação das 7 distribuições de dados.

Usuário 33 - Resultado dos experimentos utilizando a medida de similaridade CDM, onde são comparados os resultados de treinamento com 10 assinaturas verdadeiras e 40 falsas. 


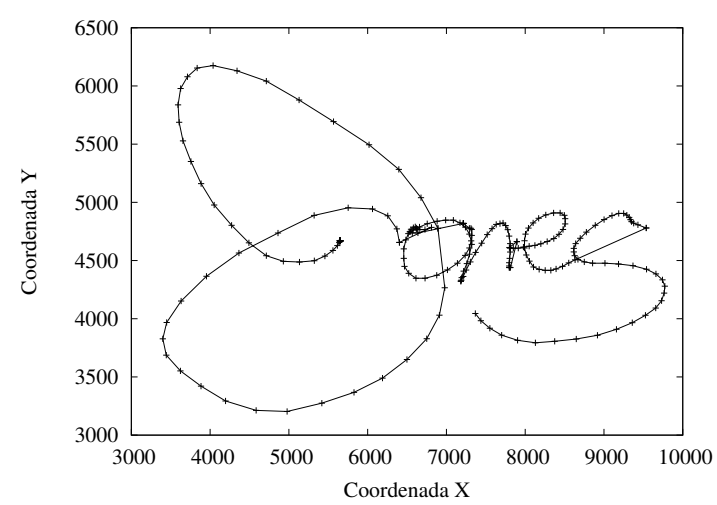

(a) Assinatura

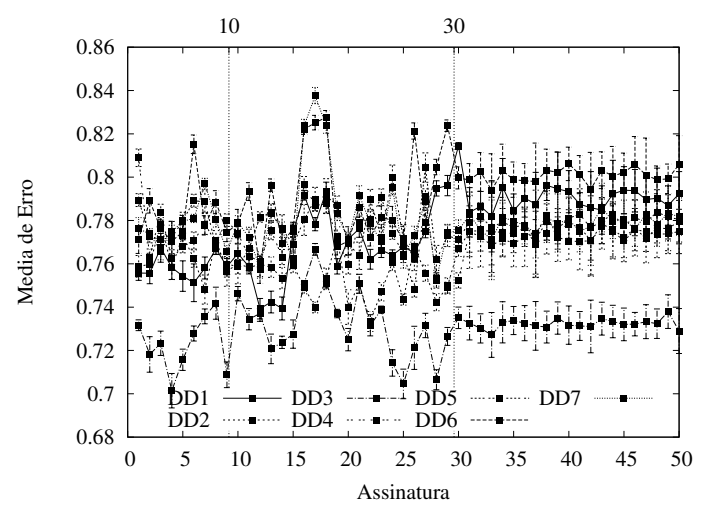

(b) Representação das 7 distribuições de dados.

Usuário 34 - Resultado dos experimentos utilizando a medida de similaridade CDM, onde são comparados os resultados de treinamento com 10 assinaturas verdadeiras e 40 falsas.

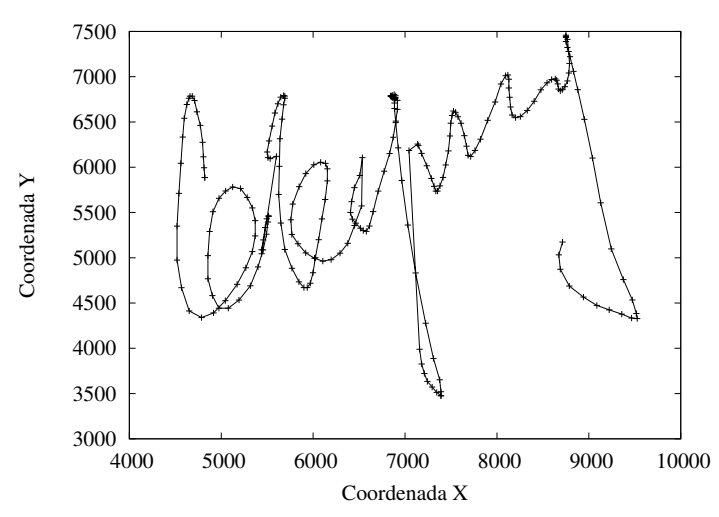

(a) Assinatura

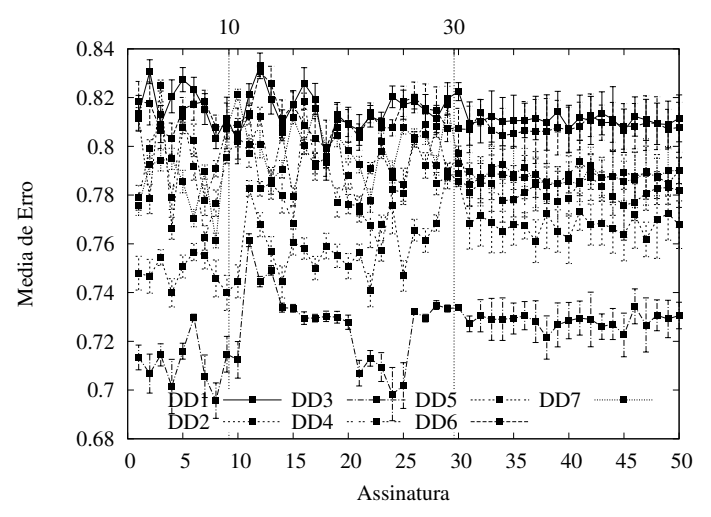

(b) Representação das 7 distribuições de dados.

Usuário 35 - Resultado dos experimentos utilizando a medida de similaridade CDM, onde são comparados os resultados de treinamento com 10 assinaturas verdadeiras e 40 falsas.

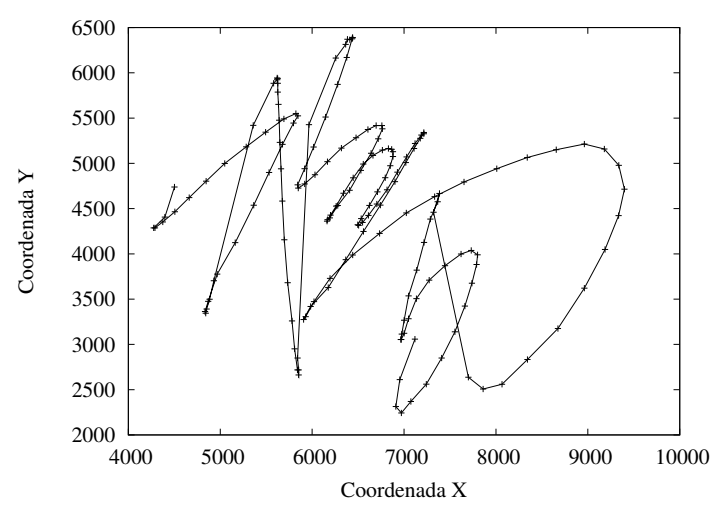

(a) Assinatura

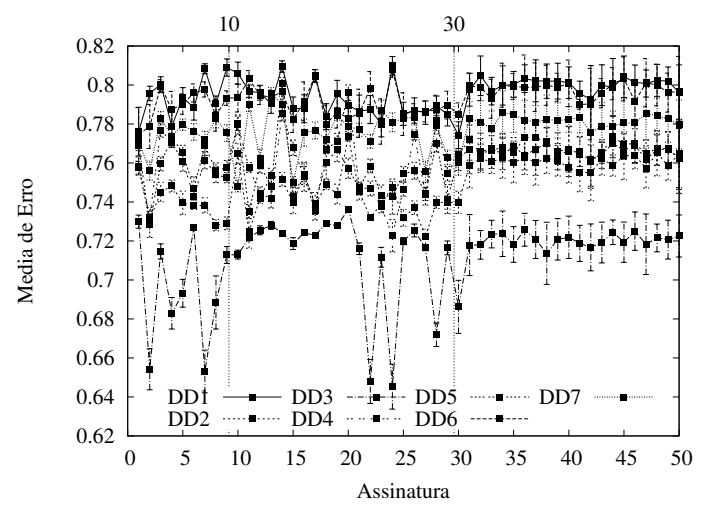

(b) Representação das 7 distribuições de dados.

Usuário 36 - Resultado dos experimentos utilizando a medida de similaridade CDM, onde são comparados os resultados de treinamento com 10 assinaturas verdadeiras e 40 falsas. 


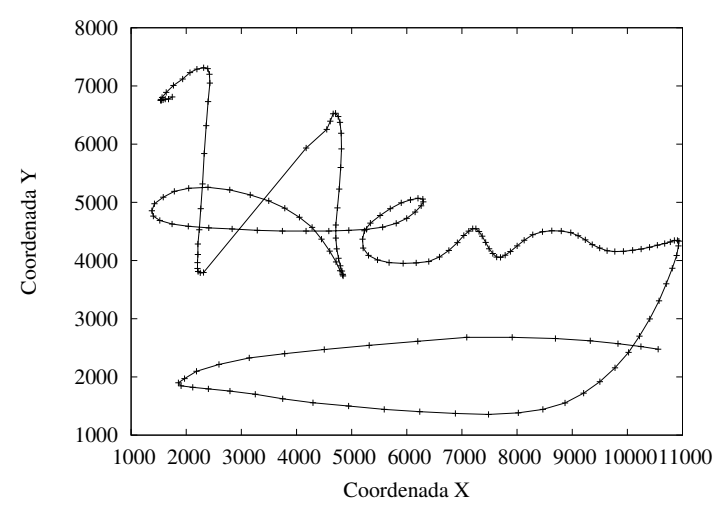

(a) Assinatura

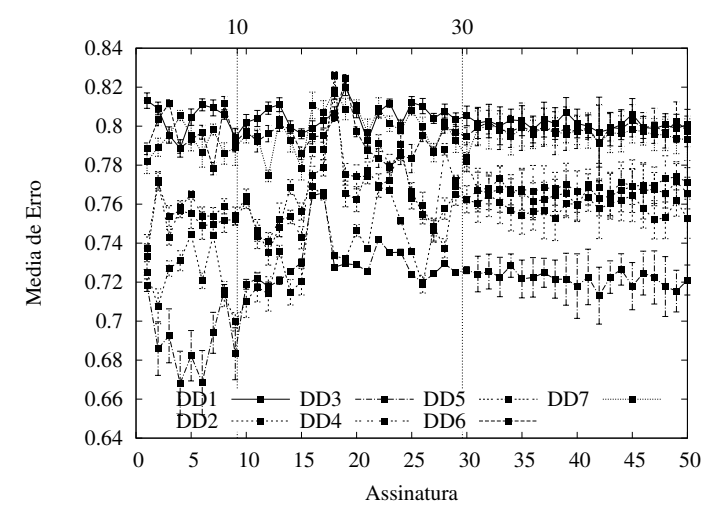

(b) Representação das 7 distribuições de dados.

Usuário 37 - Resultado dos experimentos utilizando a medida de similaridade CDM, onde são comparados os resultados de treinamento com 10 assinaturas verdadeiras e 40 falsas.

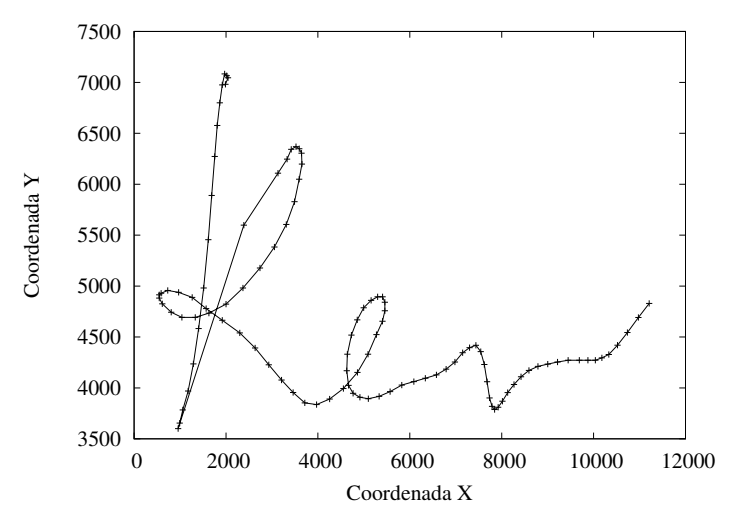

(a) Assinatura

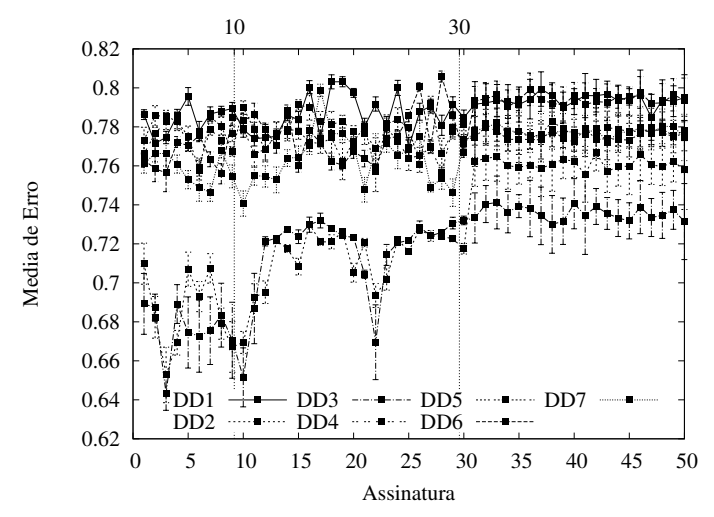

(b) Representação das 7 distribuições de dados.

Usuário 38 - Resultado dos experimentos utilizando a medida de similaridade CDM, onde são comparados os resultados de treinamento com 10 assinaturas verdadeiras e 40 falsas.

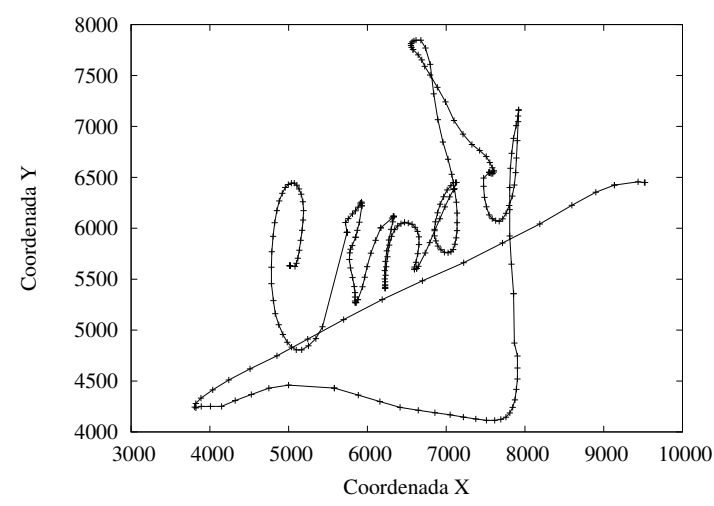

(a) Assinatura

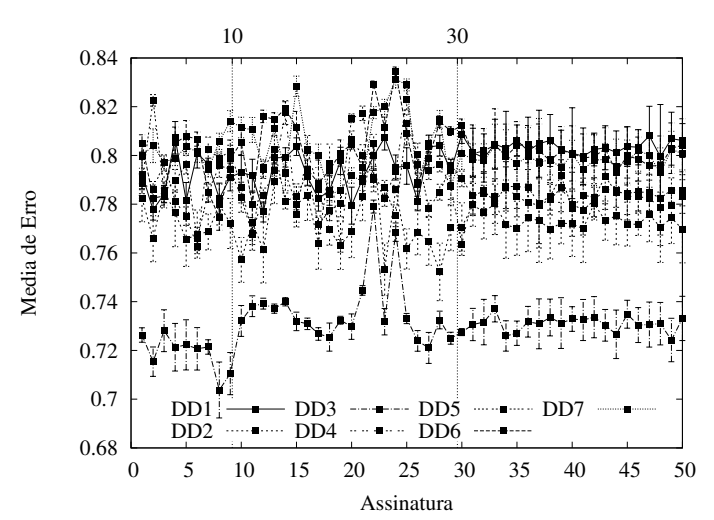

(b) Representação das 7 distribuições de dados.

Usuário 39 - Resultado dos experimentos utilizando a medida de similaridade CDM, onde são comparados os resultados de treinamento com 10 assinaturas verdadeiras e 40 falsas. 


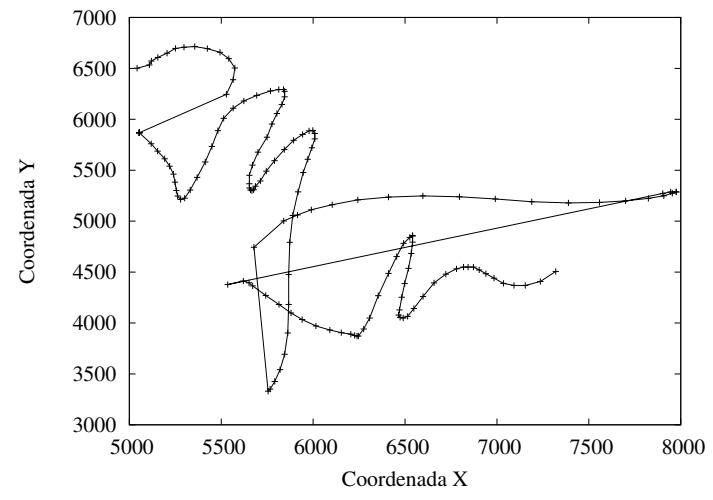

(a) Assinatura

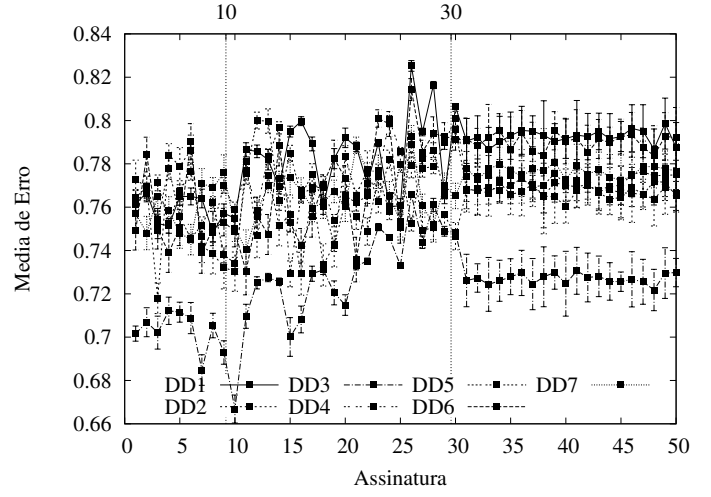

(b) Representação das 7 distribuições de dados.

Usuário 40 - Resultado dos experimentos utilizando a medida de similaridade CDM, onde são comparados os resultados de treinamento com 10 assinaturas verdadeiras e 40 falsas. 